\title{
WestVirginiaUniversity
}

THE RESEARCH REPOSITORY @ WVU

Graduate Theses, Dissertations, and Problem Reports

2001

\section{Real world heavy-duty vehicle emissions modeling}

\author{
Paul Andrei \\ West Virginia University
}

Follow this and additional works at: https://researchrepository.wvu.edu/etd

\section{Recommended Citation}

Andrei, Paul, "Real world heavy-duty vehicle emissions modeling" (2001). Graduate Theses, Dissertations, and Problem Reports. 1149.

https://researchrepository.wvu.edu/etd/1149

This Thesis is protected by copyright and/or related rights. It has been brought to you by the The Research Repository @ WVU with permission from the rights-holder(s). You are free to use this Thesis in any way that is permitted by the copyright and related rights legislation that applies to your use. For other uses you must obtain permission from the rights-holder(s) directly, unless additional rights are indicated by a Creative Commons license in the record and/ or on the work itself. This Thesis has been accepted for inclusion in WVU Graduate Theses, Dissertations, and Problem Reports collection by an authorized administrator of The Research Repository @ WVU. For more information, please contact researchrepository@mail.wvu.edu. 


\title{
Real World Heavy-Duty Vehicle Emissions Modeling
}

\author{
Paul Andrei
}

\author{
A THESIS \\ Submitted to \\ The College of Engineering and Mineral Resources \\ at \\ West Virginia University \\ in partial fulfillment of the requirements \\ for the degree of \\ Masters of Science \\ in \\ Mechanical Engineering
}

Nigel N. Clark, Ph. D., Chair

Donald W. Lyons, Ph. D.

Gregory Thomson, Ph. D.

Department of Mechanical and Aerospace Engineering

West Virginia University

2001

Keywords: Emissions, SCF, Heavy-Duty Diesel, Engine Cycles 


\section{ABSTRACT \\ Real World Heavy-Duty Vehicle Emissions Modeling}

\section{Paul Andrei}

Heavy-duty vehicle emissions represent a significant portion of the mobile source emissions inventory. Accurate estimation of their contribution is essential as on-highway and non-road heavy-duty diesel emissions account for at least one third of the oxides of nitrogen $\left(\mathrm{NO}_{\mathrm{x}}\right)$ in the inventory. West Virginia University (WVU) has developed an extensive database of continuous transient gaseous emissions levels from a wide variety of heavy-duty vehicles in field operation. The database was built using WVU Transportable Heavy-Duty Vehicle Emissions Testing Laboratories (THDVETL). Several different transient cycles were utilized for testing including the Central Business District (CBD) schedule.

Present day vehicle tailpipe emissions inventory approaches fail to consider directly the influence of terrain and road grade on the inventory. The behavior of a heavyduty class 8 tractor truck, a medium-duty class 6 box truck and a heavy-duty class 8 transit bus over roads with varying grades were simulated in order to predict $\mathrm{NO}_{\mathrm{x}}, \mathrm{CO}_{2}$, $\mathrm{CO}$ and PM emissions. As expected, road grade has a modest but significant effect on $\mathrm{NO}_{\mathrm{x}}$ and $\mathrm{CO}_{2}$ emissions (especially when the road is very steep), but a more substantial effect on $\mathrm{CO}$ and PM emissions. These results were obtained based on the simulation of the considered vehicles over roads with different grades ( $0 \%$ (flat land), $-2 \%,+2 \%,-5 \%$ and $+5 \%$ ) and over sinusoidal roads with a maximum grade between $0 \%$ and $7 \%$. The road grade has a modest but significant effect on $\mathrm{NO}_{\mathrm{x}}$ and $\mathrm{CO}_{2}$ emissions, especially when the road is very steep (road grade greater than $2 \%$ ), but a substantial effect on $\mathrm{CO}$ emissions. Like CO, PM emissions are very much influenced by the road grade especially if the road is very steep because these emissions increase substantially near full engine load.

As it is well known vehicles emissions in $\mathrm{g} / \mathrm{bhp}-\mathrm{hr}$ are infinite at idle. Also known is that vehicles emissions are often high due to high load $\left(1 / 2 \rho_{\mathrm{a}} \mathrm{C}_{\mathrm{D}} \mathrm{A} \underline{\mathrm{V}}^{3}\right)$ at high speeds. All these show the necessity of the development of speed correction factors to be used in inventory purposes. Several speed correction factors were developed for the three vehicles considered in this analysis. These correction factors can be used to account the variations in the vehicle condition, class and variations in the testing environment. 


\section{Acknowledgements}

Many people deserve a lot of thanks and credits for helping me complete this research and thesis. First, I express my sincere gratitude to Dr. Nigel N. Clark for providing me with an opportunity to work with him and for guiding me to prepare myself for a professional career. Next, I thank the rest of my committee, Dr. Donald Lyons and Dr. Gregory Thompson for their help and the time they've devoted to this.

I would like to thank Sorin Petreanu, Ronald Jarrett, Justin Kern, Csaba TothNagy, Baskaran Ganesan and many more I've failed to mention for their valuable help during the help of the research. The moral support that they provided cannot be compensated.

My family has provided support in many ways and for that, thank you very much, Mom, Dad and my wife Ioana especially. 


\section{Table of Contents}

Acknowledgements ......................................................................................................ii

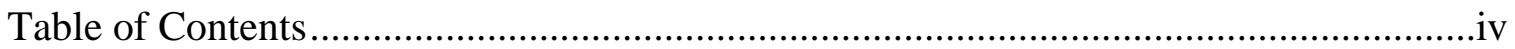

List of Tables................................................................................................................. vi

List of Figures ....................................................................................................

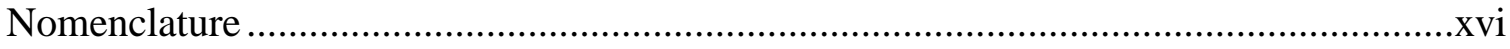

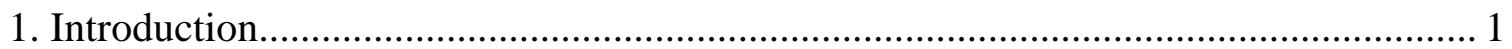

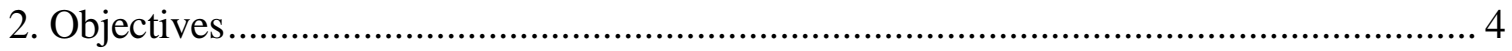

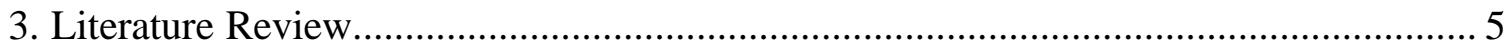

3.1 Previous Prediction Methods …………………….................................. 5

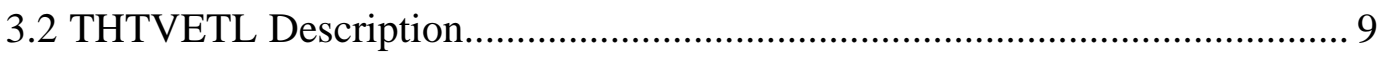

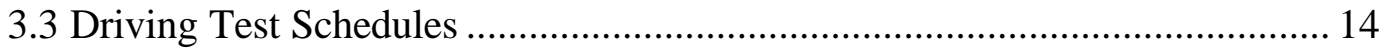

3.3.1 Rewiew of Driving Schedules.......................................................... 14

3.3.2 Synthesized Chassis Schedules ....................................................... 15

3.3.3 Realistic Chassis Cycles.............................................................. 19

3.3.4 Engine Cycles.................................................................................. 23

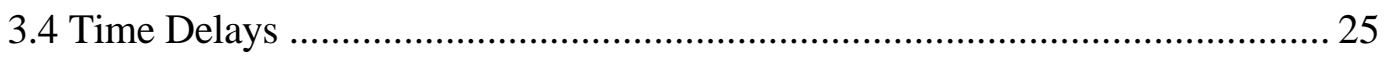

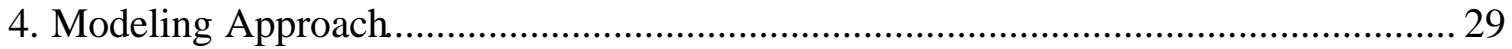

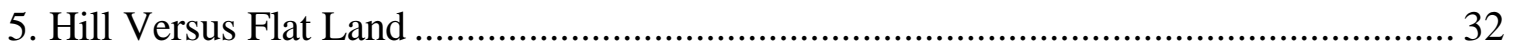

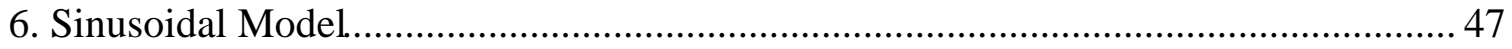

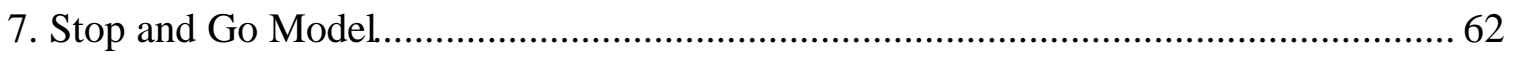

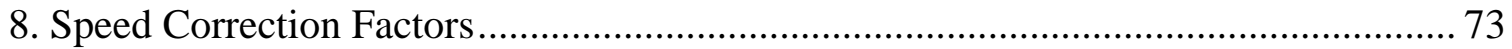




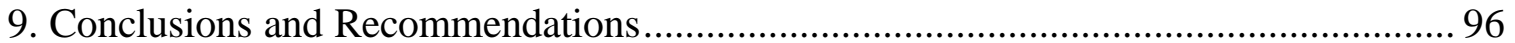

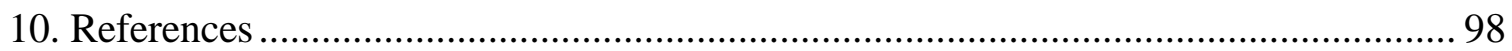




\section{List of Tables}

Table 3.1 American Automotive Manufacturers Association (AAMA) Vehicle Classifications

Table 3.2 Federal Heavy-Duty Engine Emission standards............................................... 8

Table 3.3 EPA Emission Standards for Model Year 2004 and Later Heavy-Duty Diesel Engines.

Table 3.4 The Manufacturers and Model Numbers of the Specific Analyzers Used by the Transportable Laboratories 13

Table 3.5 Calculated Parameters of the Synthesized Cycles and Routes 18

Table 3.6 Calculated Parameters of the Realistic Cycles 22

Table 4.1 Constants Used for Terrain Modeling....... 30

Table 4.2 Details of the Considered Vehicles and Engines 31

Table 5.1 $\mathrm{NO}_{\mathrm{x}}$ Emissions for the Considered Heavy-Duty Class 8 Tractor Truck Described in Table 4.2 in Grams per Second.

Table 5.2 $\mathrm{CO}_{2}$ Emissions for the Considered Heavy-Duty Class 8 Tractor Truck Described in Table 4.2 in Grams per Second

Table 5.3 CO Emissions for the Considered Heavy-Duty Class 8 Tractor Truck Described in Table 4.2 in Grams per Second.

Table 5.4 PM Emissions for the Considered Heavy-Duty Class 8 Tractor Truck Described in Table 4.2 in Milligrams per Second.....

Table 5.5 $\mathrm{NO}_{\mathrm{x}}$ Emissions for the Considered Medium-Duty Class 6 Box Truck Described in Table 4.2 in Grams per Second

Table 5.6 $\mathrm{CO}_{2}$ Emissions for the Considered Medium-Duty Class 6 Box Truck Described in Table 4.2 in Grams per Second

Table 5.7 CO Emissions for the Considered Medium-Duty Class 6 Box Truck Described in Table 4.2 in Grams per Second

Table 5.8 PM Emissions for the Considered Medium-Duty Class 6 Box Truck Described in Table 4.2 in Milligrams per Second. 
Table 5.9 $\mathrm{NO}_{\mathrm{x}}$ Emissions for the Considered Class 8 Transit Bus Described in Table 4.2 in Grams per Second

Table 5.10 $\mathrm{CO}_{2}$ Emissions for the Considered Class 8 Transit Bus Described in Table 4.2 in Grams per Second

Table 5.11 CO Emissions for the Considered Class 8 Transit Bus Described in Table 4.2 in Grams per Second

Table 5.12 PM Emissions for the Considered Class 8 Transit Bus Described in Table 4.2 in Milligrams per Second

Table 7.1 Additional Emissions for Each Extra Minute of Engine Running at Idle Speed for the Considered Heavy-Duty Class 8 Tractor Truck

Table 7.2 Additional Emissions for Each Extra Minute of Engine Running at Idle Speed for the Considered Medium-Duty Class 6 Box Truck

Table 7.3 Additional Emissions for Each Extra Minute of Engine Running at Idle Speed for the Considered Class 8 Transit Bus 


\section{List of Figures}

Figure 3.1 Transportable Heavy-Duty Vehicle Emissions Testing Laboratory THDVETL) \#1 .

Figure 3.2 Speed Versus Time Plot for the Central Business District (CBD) Cycle....... 15

Figure 3.3 Speed Versus Time Plot for the WVU 5-Peak Cycle ...................................... 16

Figure 3.4 Speed Versus Time Plot for the New York Garbage Truck Cycle

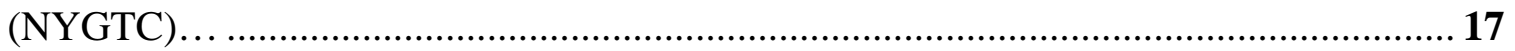

Figure 3.5 Speed Versus Time Plot for the New York Bus Cycle (NYBC).................... 19

Figure 3.6 Speed Versus Time Plot for the EPA Urban Dynamometer Driving Schedule for Heavy-Duty Vehicles (Test-D).

Figure 3.7 Speed Versus Time Plot for the Considered Class 8 Heavy-Duty Tractor Truck Described in Table 4.2 Following CSHVR

Figure 3.8 Percent Speed Versus Time for the Federal Test Procedure Engine Cycle.... 23

Figure 3.9 Percent Torque Versus Time for the Federal Test Procedure Engine Cycle .. 24

Figure 5.1 Model Developed for $\mathrm{NO}_{\mathrm{x}}$ Emissions Prediction of a Class 8 Heavy-Duty Tractor Truck. The Data Points Were Obtained from an Emissions Test of the HeavyDuty Tractor Truck Described in Table 4.2 Exercised Through the Central Business District (CBD) Cycle. 33

Figure 5.2 Model Developed for $\mathrm{CO}_{2}$ Emissions Prediction of a Class 8 Heavy-Duty Tractor Truck. The Data Points Were Obtained from an Emissions Test of the HeavyDuty Tractor Truck Described in Table 4.2 Exercised Through the Central Business District (CBD) Cycle. 34

Figure 5.3 Model Developed for CO Emissions Prediction of a Class 8 Heavy-Duty Tractor Truck. The Data Points Were Obtained from an Emissions Test of the HeavyDuty Tractor Truck Described in Table 4.2 Exercised Through the Central Business District (CBD) Cycle. 34

Figure 5.4 Model Developed for PM Emissions Prediction of a Class 8 Heavy-Duty Tractor Truck. The Data Points Were Obtained from an Emissions Test of the HeavyDuty Tractor Truck Described in Table 4.2 Exercised Through the Central Business District (CBD) Cycle. 35 
Figure 5.5 Model Developed for $\mathrm{NO}_{\mathrm{x}}$ Emissions Prediction of a Class 6 Medium-Duty Box Truck. The Data Points Were Obtained from an Emissions Test of the Medium-Duty Box Truck Described in Table 4.2 Exercised Through the Central Business District (CBD) Cycle.

Figure 5.6 Model Developed for $\mathrm{CO}_{2}$ Emissions Prediction of a Class 6 Medium-Duty Box Truck. The Data Points Were Obtained from an Emissions Test of the Medium-Duty Box Truck Described in Table 4.2 Exercised Through the Central Business District (CBD) Cycle.

Figure 5.7 Model Developed for CO Emissions Prediction of a Class 6 Medium-Duty Box Truck. The Data Points Were Obtained from an Emissions Test of the Medium-Duty Box Truck Described in Table 4.2 Exercised Through the Central Business District (CBD) Cycle.

Figure 5.8 Model Developed for PM Emissions Prediction of a Class 6 Medium-Duty Box Truck. The Data Points Were Obtained from an Emissions Test of the Medium-Duty Box Truck Described in Table 4.2 Exercised Through the Central Business District (CBD) Cycle.

Figure 5.9 Model Developed for $\mathrm{NO}_{\mathrm{x}}$ Emissions Prediction of a Class 8 Transit Bus. The Data Points Were Obtained from an Emissions Test of the Transit Bus Described in Table 4.2 Exercised Through the Central Business District (CBD) Cycle.....

Figure 5.10 Model Developed for $\mathrm{CO}_{2}$ Emissions Prediction of a Class 8 Transit Bus. The Data Points Were Obtained from an Emissions Test of the Transit Bus Described in Table 4.2 Exercised Through the Central Business District (CBD) Cycle 38

Figure 5.11 Model Developed for CO Emissions Prediction of a Class 8 Transit Bus. The Data Points Were Obtained from an Emissions Test of the Transit Bus Described in Table 4.2 Exercised Through the Central Business District (CBD) Cycle......

Figure 5.12 Model Developed for PM Emissions Prediction of a Class 8 Transit Bus. The Data Points Were Obtained from an Emissions Test of the Transit Bus Described in Table 4.2 Exercised Through the Central Business District (CBD) Cycle 39

Figure 6.1 Shapes of a Flat Road and the Considered Sinusoidal Road Model with a Maximum Road Grade of $+4 \%$.

Figure 6.2 $\mathrm{NO}_{\mathrm{x}}$ Emissions in $\mathrm{g} / \mathrm{s}$ for the Considered Class 8 Heavy-Duty Tractor Truck over a Sinusoid Road with a Maximum Road Grade of $+4 \%$. The Model Uses the Emissions Equation Shown in Figure 5.1 48

Figure 6.3 $\mathrm{CO}_{2}$ Emissions in $\mathrm{g} / \mathrm{s}$ for the Considered Class 8 Heavy-Duty Tractor Truck over a Sinusoid Road with a Maximum Road Grade of $+4 \%$. The Model Uses the Emissions Equation Shown in Figure 5.2 .... 
Figure 6.4 CO Emissions in $\mathrm{g} / \mathrm{s}$ for the Considered Class 8 Heavy-Duty Tractor Truck over a Sinusoid Road with a Maximum Road Grade of $+4 \%$. The Model Uses the Emissions Equation Shown in Figure 5.3

Figure 6.5 PM Emissions in $\mathrm{g} / \mathrm{s}$ for the Considered Class 8 Heavy-Duty Tractor Truck over a Sinusoid Road with a Maximum Road Grade of $+4 \%$. The Model Uses the Emissions Equation Shown in Figure 5.4

Figure 6.6 $\mathrm{NO}_{\mathrm{x}}$ Emissions in g/s for the Considered Class 6 Medium-Duty Box Truck over a Sinusoid Road with a Maximum Road Grade of $+4 \%$. The Model Uses the Emissions Equation Shown in Figure 5.5

Figure 6.7 $\mathrm{CO}_{2}$ Emissions in g/s for the Considered Class 6 Medium-Duty Box Truck over a Sinusoid Road with a Maximum Road Grade of $+4 \%$. The Model Uses the Emissions Equation Shown in Figure 5.6

Figure 6.8 CO Emissions in $\mathrm{g} / \mathrm{s}$ for the Considered Class 6 Medium-Duty Box Truck over a Sinusoid Road with a Maximum Road Grade of $+4 \%$. The Model Uses the Emissions Equation Shown in Figure 5.7

Figure 6.9 PM Emissions in $\mathrm{g} / \mathrm{s}$ for the Considered Class 6 Medium-Duty Box Truck over a Sinusoid Road with a Maximum Road Grade of $+4 \%$. The Model Uses the Emissions Equation Shown in Figure 5.8

Figure 6.10 $\mathrm{NO}_{\mathrm{x}}$ Emissions in $\mathrm{g} / \mathrm{s}$ for the Considered Class 8 Heavy-Duty Tractor Truck over a Sinusoid Road with a Maximum Road Grade of $+4 \%$. The Model Uses the Emissions Equation Shown in Figure 5.9

Figure 6.11 $\mathrm{CO}_{2}$ Emissions in $\mathrm{g} / \mathrm{s}$ for the Considered Class 8 Transit Bus over a Sinusoid Road with a Maximum Road Grade of $+4 \%$. The Model Uses the Emissions Equation Shown in Figure 5.10

Figure 6.12 CO Emissions in g/s for the Considered Class 8 Transit Bus over a Sinusoid Road with a Maximum Road Grade of $+4 \%$. The Model Uses the Emissions Equation Shown in Figure 5.11 53

Figure 6.13 PM Emissions in $\mathrm{g} / \mathrm{s}$ for the Considered Class 8 Transit Bus over a Sinusoid Road with a Maximum Road Grade of $+4 \%$. The Model Uses the Emissions Equation Shown in Figure 5.12

Figure 6.14 Grade Influence on $\mathrm{NO}_{\mathrm{x}}$ Emissions in $\mathrm{g} / \mathrm{mile}$ of the Considered Class 8 Heavy-Duty Tractor Truck. The Model Uses the Emissions Equation Shown in Figure 5.1 
Figure 6.15 Grade Influence on $\mathrm{CO}_{2}$ Emissions in $\mathrm{g} /$ mile of the Considered Class 8 Heavy-Duty Tractor Truck. The Model Uses the Emissions Equation Shown in Figure 5.2 . 56

Figure 6.16 Grade Influence on $\mathrm{CO}$ Emissions in g/mile of the Considered Class 8 Heavy-Duty Tractor Truck. The Model Uses the Emissions Equation Shown in Figure 5.3 .

Figure 6.17 Grade Influence on PM Emissions in g/mile of the Considered Class 8 Heavy-Duty Tractor Truck. The Model Uses the Emissions Equation Shown in Figure 5.4 .

Figure 6.18 Grade Influence on $\mathrm{NO}_{\mathrm{x}}$ Emissions in $\mathrm{g} / \mathrm{mile}$ of the Considered Class 6 Medium-Duty Box Truck. The Model Uses the Emissions Equation Shown in Figure 5.5.

Figure 6.19 Grade Influence on $\mathrm{CO}_{2}$ Emissions in $\mathrm{g} / \mathrm{mile}$ of the Considered Class 6 Medium-Duty Box Truck. The Model Uses the Emissions Equation Shown in Figure 5.6.

Figure 6.20 Grade Influence on $\mathrm{CO}$ Emissions in $\mathrm{g} / \mathrm{mile}$ of the Considered Class 6 Medium-Duty Box Truck. The Model Uses the Emissions Equation Shown in Figure 5.7.

Figure 6.21 Grade Influence on PM Emissions in g/mile of the Considered Class 6 Medium-Duty Box Truck. The Model Uses the Emissions Equation Shown in Figure 5.8.

Figure 6.22 Grade Influence on $\mathrm{NO}_{\mathrm{x}}$ Emissions in $\mathrm{g} / \mathrm{mile}$ of the Considered Class 8 Transit Bus. The Model Uses the Emissions Equation Shown in Figure 5.9

Figure 6.23 Grade Influence on $\mathrm{CO}_{2}$ Emissions in $\mathrm{g} / \mathrm{mile}$ of the Considered Class 8 Transit Bus. The Model Uses the Emissions Equation Shown in Figure 5.10

Figure 6.24 Grade Influence on $\mathrm{CO}$ Emissions in g/mile of the Considered Class 8 Transit Bus. The Model Uses the Emissions Equation Shown in Figure 5.11

Figure 6.25 Grade Influence on PM Emissions in g/mile of the Considered Class 8 Transit Bus. The Model Uses the Emissions Equation Shown in Figure 5.12

Figure 7.1 Distance Versus Time Plot for the Considered Heavy-Duty Class 8 Tractor Truck Traveling Over a Distance of 5000 meters, With and Without Stop. 63

Figure 7.2 Speed Versus Time Plot for the Considered Heavy-Duty Class 8 Tractor Truck Traveling Over a Distance of 5000 meters, With and Without Stop. 63 
Figure 7.3 $\mathrm{NO}_{\mathrm{x}}$ Emissions Versus Time Plot for the Considered Heavy-Duty Class 8 Tractor Truck Traveling Over a Distance of 5000 meters, With and Without Stop. 64

Figure 7.4 $\mathrm{CO}_{2}$ Emissions Versus Time Plot for the Considered Heavy-Duty Class 8 Tractor Truck Traveling Over a Distance of 5000 meters, With and Without Stop.....

Figure 7.5 CO Emissions Versus Time Plot for the Considered Heavy-Duty Class 8 Tractor Truck Traveling Over a Distance of 5000 meters, With and Without Stop. 65

Figure 7.6 PM Emissions Versus Time Plot for the Considered Heavy-Duty Class 8 Tractor Truck Traveling Over a Distance of 5000 meters, With and Without Stop 65

Figure 7.7 Distance Versus Time Plot for the Considered Medium-Duty Class 6 Box Truck Traveling Over a Distance of 5000 meters, With and Without Stop. 66

Figure 7.8 Speed Versus Time Plot for the Considered Medium-Duty Class 6 Box Truck Traveling Over a Distance of 5000 meters, With and Without Stop 66

Figure 7.9 $\mathrm{NO}_{\mathrm{x}}$ Emissions Versus Time Plot for the Considered Medium-Duty Class 6 Box Truck Traveling Over a Distance of 5000 meters, With and Without Stop.... 67

Figure 7.10 $\mathrm{CO}_{2}$ Emissions Versus Time Plot for the Considered Medium-Duty Class 6 Box Truck Traveling Over a Distance of 5000 meters, With and Without Stop.... 67

Figure 7.11 CO Emissions Versus Time Plot for the Considered Medium-Duty Class 6 Box Truck Traveling Over a Distance of 5000 meters, With and Without Stop.... 68

Figure 7.12 PM Emissions Versus Time Plot for the Considered Medium-Duty Class 6 Box Truck Traveling Over a Distance of 5000 meters, With and Without Stop.... 68

Figure 7.13 Distance Versus Time Plot for the Considered Class 8 Transit Bus Traveling Over a Distance of 5000 meters, With and Without Stop.

Figure 7.14 Speed Versus Time Plot for the Considered Class 8 Transit Bus Traveling Over a Distance of 5000 meters, With and Without Stop.....

Figure 7.15 $\mathrm{NO}_{\mathrm{x}}$ Emissions Versus Time Plot for the Considered Class 8 Transit Bus Traveling Over a Distance of 5000 meters, With and Without Stop 70

Figure 7.16 $\mathrm{CO}_{2}$ Emissions Versus Time Plot for the Considered Class 8 Transit Bus Traveling Over a Distance of 5000 meters, With and Without Stop 70

Figure 7.17 CO Emissions Versus Time Plot for the Considered Class 8 Transit Bus Traveling Over a Distance of 5000 meters, With and Without Stop 71

Figure 7.18 PM Emissions Versus Time Plot for the Considered Class 8 Transit Bus Traveling Over a Distance of 5000 meters, With and Without Stop 71 
Figure 8.1 $\mathrm{NO}_{\mathrm{x}}$ Emissions in g/mile Versus Average Speed for Several Cycles and Microcycles of these Cycles for the Considered Class 8 Heavy-Duty Tractor Truck Described in Table 4.2

Figure 8.2 $\mathrm{CO}_{2}$ Emissions in $\mathrm{g} / \mathrm{mile}$ Versus Average Speed for Several Cycles and Microcycles of these Cycles for the Considered Class 8 Heavy-Duty Tractor Truck Described in Table 4.2

Figure 8.3 CO Emissions in g/mile Versus Average Speed for Several Cycles and Microcycles of these Cycles for the Considered Class 8 Heavy-Duty Tractor Truck Described in Table 4.2

Figure 8.4 PM Emissions in g/mile Versus Average Speed for Several Cycles and Microcycles of these Cycles for the Considered Class 8 Heavy-Duty Tractor Truck Described in Table 4.2 77

Figure 8.5 $\mathrm{NO}_{\mathrm{x}} \mathrm{SCF}$ Versus Average Speed for Several Cycles and Microcycles of these Cycles for the Class 8 Heavy-Duty Tractor Truck Described in Table 4.2. The SCF Uses Emissions Equations Shown in Figure 8.2. 78

Figure 8.6 $\mathrm{CO}_{2} \mathrm{SCF}$ Versus Average Speed for Several Cycles and Microcycles of these Cycles for the Class 8 Heavy-Duty Tractor Truck Described in Table 4.2. The SCF Uses Emissions Equations Shown in Figure 8.3.

Figure 8.7 CO SCF Versus Average Speed for Several Cycles and Microcycles of these Cycles for the Class 8 Heavy-Duty Tractor Truck Described in Table 4.2. The SCF Uses Emissions Equations Shown in Figure 8.4..... 79

Figure 8.8 PM SCF Versus Average Speed for Several Cycles and Microcycles of these Cycles for the Class 8 Heavy-Duty Tractor Truck Described in Table 4.2. The SCF Uses Emissions Equations Shown in Figure 8.5.

Figure 8.9 $\mathrm{NO}_{\mathrm{x}}$ Emissions in $\mathrm{g} / \mathrm{mile}$ Versus Average Speed for Several Cycles and Microcycles of these Cycles for the Considered Class 6 Medium-Duty Box Truck Described in Table 4.2 80

Figure 8.10 $\mathrm{CO}_{2}$ Emissions in $\mathrm{g} / \mathrm{mile}$ Versus Average Speed for Several Cycles and Microcycles of these Cycles for the Considered Class 6 Medium-Duty Box Truck Described in Table 4.2 .....

Figure 8.11 CO Emissions in g/mile Versus Average Speed for Several Cycles and Microcycles of these Cycles for the Considered Class 6 Medium-Duty Box Truck Described in Table 4.2 81

Figure 8.12 PM Emissions in g/mile Versus Average Speed for Several Cycles and Microcycles of these Cycles for the Considered Class 6 Medium-Duty Box Truck Described in Table 4.2 . 
Figure 8.13 $\mathrm{NO}_{\mathrm{x}} \mathrm{SCF}$ Versus Average Speed for Several Cycles and Microcycles of these Cycles for the Class 6 Medium-Duty Box Truck Described in Table 4.2. The SCF Uses Emissions Equations Shown in Figure 8.10....

Figure 8.14 $\mathrm{CO}_{2} \mathrm{SCF}$ Versus Average Speed for Several Cycles and Microcycles of these Cycles for the Class 6 Medium-Duty Box Truck Described in Table 4.2. The SCF Uses Emissions Equations Shown in Figure 8.11

Figure 8.15 CO SCF Versus Average Speed for Several Cycles and Microcycles of these Cycles for the Class 6 Medium-Duty Box Truck Described in Table 4.2. The SCF Uses Emissions Equations Shown in Figure 8.12..... 83

Figure 8.16 PM SCF Versus Average Speed for Several Cycles and Microcycles of these Cycles for the Class 6 Medium-Duty Box Truck Described in Table 4.2. The SCF Uses Emissions Equations Shown in Figure 8.13. 83

Figure 8.17 Simplified Model of a Divided Microcycle Used to Develop $\mathrm{NO}_{\mathrm{x}}, \mathrm{CO}_{2}$ and $\mathrm{CO} \mathrm{SCF}$ 84

Figure 8.18 $\mathrm{NO}_{\mathrm{x}}$ Emissions in $\mathrm{g} /$ mile Versus Average Speed for Different Zones of a Microcycle of the CSHVR for the Considered Class 8 Heavy-Duty Tractor Truck Described in Table 4.2 ....... 85

Figure 8.19 $\mathrm{CO}_{2}$ Emissions in g/mile Versus Average Speed for Different Zones of a Microcycle of the CSHVR for the Considered Class 8 Heavy-Duty Tractor Truck Described in Table 4.2 86

Figure 8.20 CO Emissions in g/mile Versus Average Speed for Different Zones of a Microcycle of the CSHVR for the Considered Class 8 Heavy-Duty Tractor Truck Described in Table 4.2 ....... 86

Figure 8.21 $\mathrm{NO}_{\mathrm{x}} \mathrm{SCF}$ Versus Average Speed Based on the Model Presented in Figure 8.19 for the Considered Class 8 Heavy-Duty Tractor Truck Described in Table 4.2 ...... 87

Figure 8.22 $\mathrm{CO}_{2} \mathrm{SCF}$ Versus Average Speed Based on the Model Presented in Figure 8.20 for the Considered Class 8 Heavy-Duty Tractor Truck Described in Table 4.2 ...... 87

Figure 8.23 CO SCF Versus Average Speed Based on the Model Presented in Figure 8.21 for the Considered Class 8 Heavy-Duty Tractor Truck Described in Table 4.2 ...... 88

Figure 8.24 $\mathrm{NO}_{\mathrm{x}}$ Emissions in g/mile Versus Average Speed for Different Zones of a Microcycle of a Highway Cycle for the Considered Class 6 Medium-Duty Box Truck Described in Table 4.2 88

Figure 8.25 $\mathrm{CO}_{2}$ Emissions in $\mathrm{g} / \mathrm{mile}$ Versus Average Speed for Different Zones of a Microcycle of a Highway Cycle for the Considered Class 6 Medium-Duty Box Truck Described in Table 4.2 
Figure 8.26 CO Emissions in g/mile Versus Average Speed for Different Zones of a Microcycle of a Highway Cycle for the Considered Class 6 Medium-Duty Box Truck Described in Table 4.2

Figure 8.27 $\mathrm{NO}_{\mathrm{x}} \mathrm{SCF}$ Versus Average Speed Based on the Model Presented in Figure 8.25 for the Considered Class 6 Medium-Duty Box Truck Described in Table 4.2 ........ 90

Figure 8.28 $\mathrm{CO}_{2} \mathrm{SCF}$ Versus Average Speed Based on the Model Presented in Figure 8.26 for the Considered Class 6 Medium-Duty Box Truck Described in Table 4.2........90

Figure 8.29 CO SCF Versus Average Speed Based on the Model Presented in Figure 8.27 for the Considered Class 6 Medium-Duty Box Truck Described in Table 4.2 ........ 91

Figure 8.30 $\mathrm{NO}_{\mathrm{x}}$ Emissions in g/mile Versus Average Speed for Different Zones of a Microcycle of the CBD Cycle for the Considered Class 8 Transit Bus Described in Table 4.2 .

Figure 8.31 $\mathrm{CO}_{2}$ Emissions in $\mathrm{g} / \mathrm{mile}$ Versus Average Speed for Different Zones of a Microcycle of the CBD Cycle for the Considered Class 8 Transit Bus Described in Table 4.2 .

Figure 8.32 CO Emissions in g/mile Versus Average Speed for Different Zones of a Microcycle of the CBD Cycle for the Considered Class 8 Transit Bus Described in Table 4.2 .

Figure 8.33 $\mathrm{NO}_{\mathrm{x}} \mathrm{SCF}$ Versus Average Speed Based on the Model Presented in Figure 8.31 for the Considered Class 8 Transit Bus Described in Table 4.2

Figure 8.34 $\mathrm{CO}_{2} \mathrm{SCF}$ Versus Average Speed Based on the Model Presented in Figure 8.32 for the Considered Class 8 Transit Bus Described in Table 4.2

Figure 8.35 CO SCF Versus Average Speed Based on the Model Presented in Figure 8.33 for the Considered Class 8 Transit Bus Described in Table 4.2

Figure 8.36 Comparison Between EPA NO $\mathrm{NCF}_{\mathrm{x}} \mathrm{SCF}$ and the Three $\mathrm{NO}_{\mathrm{x}} \mathrm{SCF}$ Developed in This Paper for the Considered Class 8 Heavy-Duty Tractor Truck Described in Table 4.2

Figure 8.37 Comparison Between EPA CO SCF and the Three CO SCF Developed in This Paper for the Considered Class 8 Heavy-Duty Tractor Truck Described in Table 4.2 


\section{Nomenclature}

\begin{tabular}{|c|c|}
\hline AAMA & American Automotive Manufacturers Association \\
\hline ahp & axle horsepower \\
\hline$\theta$ & angle of inclination of the road grade $(\theta=0$ being horizontal) \\
\hline$\rho_{\mathrm{a}}$ & air density \\
\hline BSFC & Brake Specific Fuel Consumption \\
\hline CARB & California Air Resources Board \\
\hline CBD & Central Business District \\
\hline $\mathrm{C}_{\mathrm{D}}$ & Drag Coefficient \\
\hline CFR & Code of Federal Regulations \\
\hline $\mathrm{CH}_{4}$ & Methane \\
\hline $\mathrm{CO}$ & Carbon monoxide \\
\hline $\mathrm{CO}_{2}$ & Carbon dioxide \\
\hline CSHVR & City Suburban Heavy Vehicle Route \\
\hline$\Pi$ & Correlation Coefficient \\
\hline $\mathrm{dV} / \mathrm{dt}$ & vehicle acceleration \\
\hline EMFAC & CARB's emissions factor program \\
\hline EPA & Environmental Protection Agency \\
\hline $\mathrm{FE}$ & Fuel Economy \\
\hline FTP & Federal Test Procedure \\
\hline$\rho_{\mathrm{f}}$ & fuel density \\
\hline g & acceleration due to gravity \\
\hline g/bhp-hr & grams per brake horsepower hour \\
\hline
\end{tabular}




\begin{tabular}{|c|c|}
\hline $\mathrm{g} / \mathrm{mile}$ & grams per mile \\
\hline $\mathrm{g} / \mathrm{s}$ & grams per second \\
\hline gal & gallon \\
\hline GVW & Gross Vehicle Weight \\
\hline $\mathrm{HC}$ & Hydrocarbons \\
\hline hp & horsepower \\
\hline $\mathrm{kg}$ & kilograms \\
\hline $\mathrm{km}$ & kilometers \\
\hline $\mathrm{kW}$ & kilowatts \\
\hline lbs & pounds \\
\hline $\mathrm{m} / \mathrm{s}$ & meters per second \\
\hline $\mathrm{m} / \mathrm{s}^{2}$ & meters per second squared \\
\hline MOBILE6 & EPA's emissions factor program \\
\hline $\mathrm{mph}$ & miles per hour \\
\hline N/A & Not available \\
\hline $\mathrm{NO}_{\mathrm{x}}$ & Oxides of Nitrogen \\
\hline NYGTC & New York Garbage Truck Cycle \\
\hline $\mathrm{O}_{3}$ & Ozone \\
\hline $\mathrm{P}(\mathrm{t})$ & Power \\
\hline PART5 & EPA's PM emissions factor program \\
\hline PM & Particulate Matter \\
\hline ppm & parts per million \\
\hline $\mathrm{R}^{2}$ & coefficient of Regression \\
\hline
\end{tabular}


SAE Society of Automotive Engineers

SCF Speed Correction Factor

scfm standard cubic feet per minute

TEST-D Urban Dynamometer Driving Schedule defined by 40 CFR 86

THDVETL Transportable Heavy-Duty Vehicle Emissions Testing Laboratory

$\Delta \mathrm{t} \quad$ time interval

$\mu \quad$ tire rolling resistance

V vehicle speed

VMT vehicle miles traveled

WVU West Virginia University 


\section{Introduction}

Diesel engines are the most efficient internal combustion engines available today and are currently the main power source for heavy-duty on-road and off-road vehicles. Recent concerns about personal and environmental health have brought the subject of exhaust emissions of these vehicles to public awareness. The US Environmental Protection Agency (EPA) has set regulations limiting the production of certain chemical species that emit from diesel engines. The California Air Resources Board estimates the oxides of nitrogen $\left(\mathrm{NO}_{\mathrm{x}}\right)$ emissions of heavy-duty diesel vehicles at $30 \%$ of total on-road vehicle emissions of $\mathrm{NO}_{\mathrm{x}}$ and particulate matter (PM) emissions for the same heavy-duty vehicles at $65 \%$ of total PM, even if these vehicles comprise only $2 \%$ of the total on-road vehicles. The US EPA estimated in 1998 that heavy-duty vehicles powered by diesel engines produce about $27 \%$ of the total on-road $\mathrm{NO}_{\mathrm{x}}$ emissions and more than $60 \%$ of the total on-road PM emissions in the USA (1). A study from 1999 estimates that about 50\% of the total on-road emissions of $\mathrm{NO}_{\mathrm{x}}$ and more than $75 \%$ of the total exhaust emissions of PM are caused by heavy-duty diesel vehicles. All of these estimates rely on emissions inventory tools that have not yet reached a high level of sophistication.

Across the country, the majority of the heavy-duty vehicles are powered by diesel fueled internal combustion engines that produce undesirable exhaust gas emissions. Since 1985 the U.S. government has limited the emissions of certain exhaust gas components. An emissions inventory is necessary to determine the contribution of heavy-duty vehicles to overall atmospheric pollutant load. The emissions factors are generated by incorporating changes in calendar year, ambient temperature and driving situation, which are then used to determine emissions inventories in various localities (2). 
Many studies argue that $\mathrm{NO}_{\mathrm{x}}$ and $\mathrm{PM}$ mass are mainly contributed by diesel engines while carbon monoxide (CO) and hydrocarbons ( $\mathrm{HC})$ are mainly contributed by gasoline engines. $\mathrm{NO}_{\mathrm{x}}$ and gas phase $\mathrm{HC}$ are the main precursors of urban/regional ozone $\left(\mathrm{O}_{3}\right)$. The increase of $\mathrm{O}_{3}$ at the ground level is undesirable, as $\mathrm{O}_{3}$ is a poisonous gas (3).

The effects of global warming on urban smog formation represent another concern of these days. The smog formation is affected by topography, demography, meteorology, and the level and rate of industrialization and socioeconomic development. Some major sources of pollution which lead directly to urban smog are the combustion of fossil fuels for domestic heating, power generation, motor vehicle emissions, industrial processes, and disposal of solid wastes by incineration. The main pollutants these processes emit in urban environments are $\mathrm{SO}_{2}, \mathrm{NO}_{\mathrm{x}}, \mathrm{CO}, \mathrm{PM}$, and lead. $\mathrm{NO}_{\mathrm{x}}$ contributes to particulate matter formation and acid deposition, but most importantly is the catalyst for $\mathrm{O}_{3}$ formation. Ozone is the main constituent of photochemical smog.

The two emissions of primary interest for a heavy-duty compression ignition vehicle, because of their high contribution are $\mathrm{NO}_{\mathrm{x}}$ and $\mathrm{PM} . \mathrm{NO}_{\mathrm{x}}$ contributes to the production of smog in urban areas and PM has been targeted as a carcinogen. Heavy-duty diesel engines are the largest source of diesel PM in the US. The second group of emissions in the case of a heavy-duty vehicle consists of $\mathrm{CO}, \mathrm{CO}_{2}$, and $\mathrm{HC}$.

One of the most important factors in pollutant formation in diesel engines is the fuel injection process. During diesel engine operation, the fuel is injected at high velocity into the cylinder. The fuel atomizes into small droplets, which then vaporize and mix with the in cylinder air, that is under high pressure, and burn. The distribution of fuel is nonuniform, and the generation of unwanted emissions in diesel engines increases along 
with this nonuniformity. $\mathrm{NO}_{\mathrm{x}}$ emissions can decrease if one retards the injection timing, relative to the optimum injection time for the best fuel economy (4). As a general rule, it can be assumed that the greater is the efficiency of the combustion, the greater the $\mathrm{NO}_{\mathrm{x}}$ formation that will occur if other factors are constant. Incomplete combustion, which is mainly determined by lower combustion temperature or poor mixing, induce raised levels of $\mathrm{HC}, \mathrm{CO}$ and $\mathrm{PM}$ emissions. The main problem regarding diesel engines emissions minimization is the inverse correlation that exists between $\mathrm{NO}_{\mathrm{x}}$ and $\mathrm{PM}$ emissions (5).

In present day emissions models, effect of engine load due to road grade is largely neglected. For light-duty vehicles, the emissions measurements are provided using speedtime traces that assume that the vehicle is traveling on flat land with inertia, tire rolling resistance and wind resistance considered. In the heavy-duty case, the certification (FTP) procedure examines the engine emissions out of the vehicle and employs values of torque and speed that imply the terrain used in the original vehicle and engine activity measurement program (the CAPE-21 program). For heavy-duty vehicles fuel consumption is used to translate the emissions from units of $\mathrm{g} / \mathrm{bhp}-\mathrm{hr}$ into units of $\mathrm{g} / \mathrm{mile}$, but this consumption is simply a national estimate. However, heavy-duty vehicle power demand is highly grade sensitive. For example, a light-duty vehicle $\left(3,000 \mathrm{lb}\right.$. mass, $2 \mathrm{~m}^{2}$ frontal area, 0.4 drag coefficient and 0.006 rolling resistance coefficient) traveling on flat land requires $19 \mathrm{hp}$ at the rear wheels at $65 \mathrm{mph}$ and $29 \mathrm{hp}$ up a $2 \%$ grade. A heavy-duty vehicle $\left(60,000 \mathrm{lb}\right.$. mass, $7 \mathrm{~m}^{2}$ frontal area, 0.7 drag coefficient and 0.01 rolling resistance coefficient) would require $200 \mathrm{hp}$ at the rear wheels on flat land and $407 \mathrm{hp}$ up a $2 \%$ grade. 


\section{Objectives}

The primary objectives of this analysis were to focus attention on the problem of the influence of road grade and stop and go behavior on $\mathrm{NO}_{\mathrm{x}}, \mathrm{PM}, \mathrm{CO}$ and $\mathrm{CO}_{2}$ emissions, a problem that has not been considered previously. Because $\mathrm{HC}$ emissions are highly dependent on engine transient behavior, a different approach has to be performed and that is way this analyses fail to predict the behavior of $\mathrm{HC}$ emissions. For the accomplishment of these goals there have been developed several models for emissions of $\mathrm{NO}_{\mathrm{x}}, \mathrm{CO}, \mathrm{CO}_{2}$ and $\mathrm{PM}$ for a heavy-duty class 8 tractor truck, a medium-duty class 6 box truck and a heavy-duty class 8 transit bus. Based on these models data comparisons, analytical modeling and simulations were used in order to determine the effect of these factors on vehicles exhaust emissions. One of these simulations can be used in the future for emissions prediction.

Another objective of this analysis was to develop speed correction factors for the considered vehicles based on the available data. These correction factors can be used to account the variation in the vehicle condition, class and variation in the testing environment.

This multidimensional study used information that was gathered from the previous effort to identify the factors that influenced the measured exhaust emissions. The incorporation of representative activity data enabled the prediction methods to produce emissions factors in grams per mile and grams per second suitable for future inventory use. 


\section{Literature Review}

\subsection{Previous Prediction Methods}

There are many heavy vehicles used across the country to haul goods (such as tractor trucks), and render services (such as refuse trucks and buses). The majority of these vehicles are powered by diesel fueled internal combustion engines that produce undesirable exhaust gas emissions. Since 1985 there have been restrictions imposed on these engines by the US government to limit the emissions of designated exhaust gas components and limit emissions of particulate matter. To determine the contribution of heavy vehicles to overall loss of atmosphere quality, an emission inventory is employed. For a complete and accurate inventory of mobile source emissions, each vehicle should be tested for emissions using a driving cycle that reproduces its real world use, and have its total vehicle miles traveled (VMT) recorded. This is obviously impractical, so a simplified inventory model is used.

The inventory models currently used by the United States EPA and the Air Resources Board of the California EPA (CARB) are titled MOBILE6, PART5 and EMFAC. These computer models for heavy-duty vehicles use engine emissions certification data (although California is now favoring chassis based emissions data) and information about vehicle activity to produce an emission factor for a set of vehicles, usually expressed in grams of emissions per mile (g/mile). The emissions factor is generated by incorporating changes in calendar year, ambient temperature and driving situation, which are then used to determine emissions inventories in various localities. Since heavy-duty engine testing provides emissions data in terms of grams per brake 
horsepower-hour (g/bhp-hr), conversion factors of brake horsepower-hour per mile (bhp$\mathrm{hr} / \mathrm{mile}$ ) are needed to convert the brake-specific emissions levels into units of $\mathrm{g} / \mathrm{mile}$. This is shown in the following equation.

$$
\mathrm{g} / \mathrm{mile}=\mathrm{g} / \mathrm{bhp}-\mathrm{hr} * \text { bhp-hr/mile }
$$

The bhp-hr/mile conversion factors are calculated from tabulated brake-specific fuel consumption (BSFC), fuel density ( $\rho$ ), and fuel economy (FE), because it is difficult to measure bhp-hr/mile directly. These measurable parameters were implemented in the following equation to calculate the conversion factor (CF).

$$
\mathrm{CF}(\mathrm{bhp}-\mathrm{hr} / \mathrm{mile})=\rho(\mathrm{lb} / \mathrm{gal}) / \mathrm{BSFC}(\mathrm{lb} / \mathrm{bhp}-\mathrm{hr}) / \mathrm{FE}(\mathrm{mile} / \mathrm{gal})
$$

Speed correction factors for $\mathrm{NO}_{\mathrm{x}}$ alone also exist, but their origin and efficacy remain obscure. These factors indicate that for some certain speed, there is a minimum emissions rate and higher or lower speed operation increases the emissions.

To provide a better understanding of the factors affecting heavy vehicle emissions, the parameters that may be used to calculate future inventories need to be evaluated. These parameters include vehicle class, driving test cycle, vehicle vocations, fuel type, engine exhaust aftertreatment, vehicle age, and terrain traveled. Driving cycles are employed to evaluate vehicle emissions using chassis dynamometer based testing. Since driving cycles are usually proposed with vehicle class, driving activity and vehicle vocation in mind, the categories mentioned above are not independent of one another (2). 
Recently, the newest version of EMFAC, CARB's emissions factor software, has been released. The previous method used by this program was very similar to EPA's MOBILE software. This newest version now incorporates chassis measured emissions factors.

Light-duty emissions regulations are placed on the vehicle itself rather than the engine, like heavy-duty vehicles. This creates a large database of emissions factors that, combined with in-use vehicle activity data, can produce a complete and accurate inventory. The problems that are addressed in this research for converting measured emissions to an inventory for heavy-duty vehicles are not present in light-duty inventory modeling.

The American Automotive Manufacturers Association (AAMA), classifies trucks in 8 different classes, from class 1 (light-duty trucks) to class 8 (heavy-duty trucks). A complete listing of vehicle classification can be seen in Table 3.1 (4). For heavy-duty vehicles, emissions regulations are imposed on the engine regardless of the size of the specific use of the vehicle in which the engine may be installed. The transient test used to establish certification to emissions standards is based upon maximum power, unlike in light-duty applications where the test uses a chassis dynamometer and is affected by road-load power and vehicle weight. Some class 1 and 2 trucks may be emissions certified using the light-duty automotive approach. Table 3.2 shows the emission standards for heavy-duty engines from 1985 to 1998. Table 3.3 shows the emission standards for model year 2004 and later heavy-duty diesel engines. Either option of combined non-methane hydrocarbons (NMHC) and $\mathrm{NO}_{\mathrm{x}}$ can be used. The standards for 
CO and PM in 2004 have not been changed from previous years. Following an investigation, selected heavy-duty diesel engine manufacturers engaged in a consent decree with the EPA requiring the 2004 emissions standards to be met in 2002. The manufacturers also engaged in other emissions reduction activities as part of this ruling.

Table 3.1 American Automotive Manufacturers Association (AAMA) Vehicle Classifications.

\begin{tabular}{|c|c|c|}
\hline Class & Truck Description & Gross Vehicle Weight (lbs.) \\
\hline $\mathbf{1}$ & Light-Duty & 6,000 and less \\
\hline $\mathbf{2}$ & Light-Duty & $6,001-10,000$ \\
\hline $\mathbf{3}$ & Light-Duty & $10,001-14,000$ \\
\hline $\mathbf{4}$ & Medium-Duty & $14,001-16,000$ \\
\hline $\mathbf{5}$ & Medium-Duty & $16,001-19,500$ \\
\hline $\mathbf{6}$ & Medium-Duty & $19,501-26,000$ \\
\hline $\mathbf{7}$ & Heavy-Duty & $26,001-33,000$ \\
\hline $\mathbf{8}$ & Heavy-Duty & 33,001 and over \\
\hline
\end{tabular}

Table 3.2 Federal Heavy-Duty Engine Emission standards.

\begin{tabular}{|c|c|c|c|c|c|}
\hline $\begin{array}{c}\text { Model } \\
\text { Year }\end{array}$ & $\begin{array}{c}\text { HC } \\
\text { (g/bhp-hr) }\end{array}$ & $\begin{array}{c}\text { CO } \\
\text { (g/bhp-hr) }\end{array}$ & $\begin{array}{c}\text { NO } \\
\text { (g/bhp-hr) }\end{array}$ & $\begin{array}{c}\text { PM (trucks) } \\
\text { (g/bhp-hr) }\end{array}$ & $\begin{array}{c}\text { PM (buses) } \\
\text { (g/bhp-hr) }\end{array}$ \\
\hline $\mathbf{1 9 8 5 - 1 9 8 7}$ & 1.3 & 15.5 & 10.7 & No standard & No standard \\
\hline $\mathbf{1 9 8 8 - 1 9 8 9}$ & 1.3 & 15.5 & 10.7 & 0.6 & 0.6 \\
\hline $\mathbf{1 9 9 0}$ & 1.3 & 15.5 & 6.0 & 0.6 & 0.6 \\
\hline $\mathbf{1 9 9 1 - 1 9 9 2}$ & 1.3 & 15.5 & 5.0 & 0.25 & 0.25 \\
\hline $\mathbf{1 9 9 3}$ & 1.3 & 15.5 & 5.0 & 0.25 & 0.1 \\
\hline $\mathbf{1 9 9 4 - 1 9 9 5}$ & 1.3 & 15.5 & 5.0 & 0.1 & 0.07 \\
\hline $\mathbf{1 9 9 6 - 1 9 9 7}$ & 1.3 & 15.5 & 5.0 & 0.1 & 0.05 \\
\hline $\mathbf{1 9 9 8}$ & 1.3 & 15.5 & 4.0 & 0.1 & 0.05 \\
\hline
\end{tabular}

Table 3.3 EPA Emission Standards for Model Year 2004 and Later Heavy-Duty Diesel Engines.

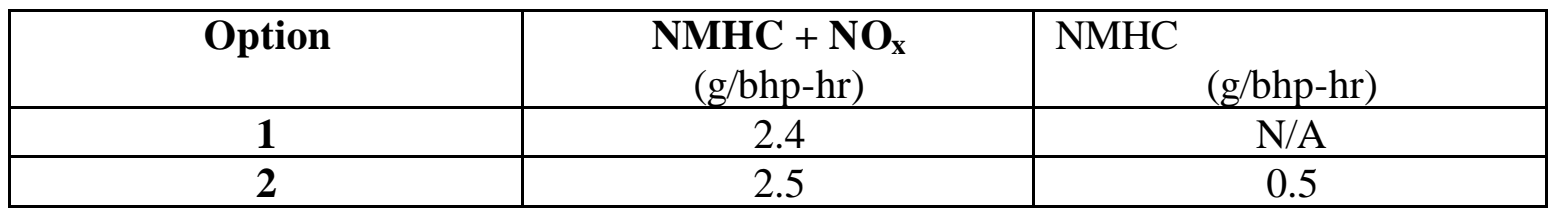




\subsection{Transportable Heavy-Duty Vehicle Emissions Testing Laboratory (THDVETL) Description}

West Virginia University (WVU) currently possesses facilities capable of running transient and steady state testing on either heavy-duty vehicles or engines: two transportable heavy-duty vehicle emissions laboratories and one stationary engine emissions laboratory $(6,7)$. The chassis dynamometer laboratories collect emissions from vehicles while simulating road conditions, without removing the engine from the chassis of the vehicle. The engine dynamometer gathers the emissions produced from an engine independent of the vehicle.

West Virginia University Transportable Heavy-Duty Vehicle Emissions Testing Laboratories \#1 and \#2 are capable of performing transient and steady state tests on vehicles for emissions at any location depending only on the weather conditions. These laboratories were constructed with funding from the US Department of Energy, Office of Transportation Technologies and emissions data gathered by the laboratories are added to a database maintained by the National Renewable Energy Laboratory (NREL), in Golden, Colorado. The transportable laboratories consist of three vehicle combinations when moved from site to site. A tractor-trailer with the dynamometer section, an emissions trailer with the gas analyzer and a straight truck commute from one site to another. The major components of the laboratory consist of the following: chassis dynamometer test bed, load simulating devices, exhaust gas analyzers, a dilution tunnel, a blower with critical flow venturi, a generator and an extensive data acquisition system. The transportable laboratories are capable of testing the vehicle over steady state and transient cycles. 


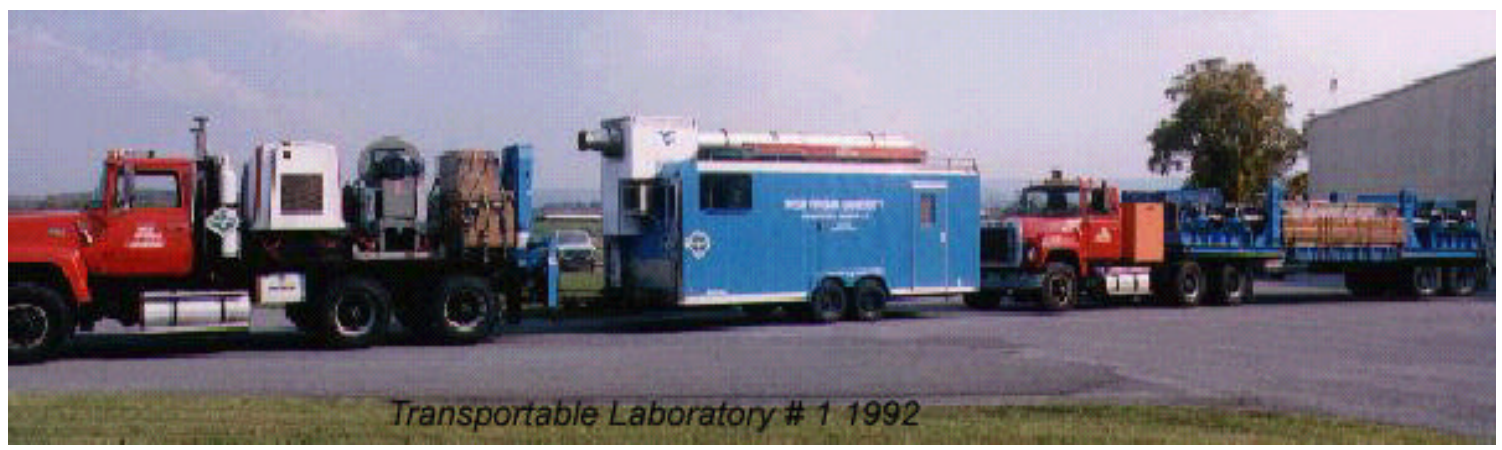

\section{Figure 3.1 Transportable Heavy-Duty Vehicle Emissions Testing Laboratory} (THDVETL) \#1.

The dynamometer test bed is a flat bed trailer, specially designed and built so that heavy-duty trucks and buses can be driven on it to simulate real-world driving. Vehicles are tested with the drive wheels running on $32 \mathrm{~cm}$ diameter twin rollers, but power is extracted from the vehicle hubs (wheel lug nuts) rather than through rollers as slippage between the tires and rollers can render tests inaccurate and generate heat. The rollers served only to cause the left and right drive wheels to maintain the same linear speed. The load simulating devices mounted on the test bed consists of two sets of power absorbers, one side for each side of the vehicle, to simulate the on road driving conditions and flywheels to simulate the inertial load of the vehicle.

The power absorbers simulate the aerodynamic drag and friction losses on the vehicle as if it were driven on the road. The Mustang $300 \mathrm{hp}$ power absorbers are air cooled, eddy current dynamometers controlled by the main computer with feedback from a load cell to measure the torque at the power absorbers. The torque produced by the vehicle is translated to the sensors and load simulating devices via shafts and gearboxes. Lebow manufactured strain gage shaft torque sensors and speed transducers were installed in the dynamometer drive train to measure the vehicle torque and speed at rear 
axle continuously during a test cycle. The readings obtained from the torque sensor on each side are summed together to obtain the axle torque or the vehicle.

The flywheels simulate the inertial load of the vehicle from 15,000 to 60,000 pounds in gross vehicle weight. Individual flywheels are engaged to or disengaged from driven discs to mimic inertia in 250 pounds increments, depending on tire size.

To monitor the emissions from the vehicle, the exhaust gas from the exhaust system of the vehicle is channeled to a dilution tunnel through a 5 inch $(12.5 \mathrm{~cm})$ diameter insulated transfer tube. The exhaust gas is mixed with fresh air in an 18 inch (45 $\mathrm{cm}$ ) primary dilution tunnel. The flow rate in the tunnel is maintained by a critical flow venturi. There are three available venturi settings namely 1000, 1500 and 2000 standard cubic feet per minute $(\mathrm{scfm})\left(0.47,0.71\right.$ and $\left.0.94 \mathrm{~m}^{3} / \mathrm{sec}\right)$. The venturi is designated to have the exhaust gas concentration within the available ranges of the analyzers. A Tedlar bag is installed to obtain a sample of the outside air that is used to dilute the exhaust stream. This is the background data that is subtracted from the diluted exhaust data in order to know the net tailpipe emissions of the vehicle. A blower situated at the far end of the tunnel draws the flow through the tunnel and the venturi.

Near the end of the primary dilution tunnel, a sample is drawn at 2 to $5 \mathrm{scfm}$ into the secondary dilution tunnel. The sample flow rate is proportional to the flow rate in the primary dilution tunnel within $5 \%$ through out all the tests. Flow rate in the secondary dilution tunnel is maintained in proportion to the primary tunnel through a mass flow controller. The secondary stream used for particulate matter analysis may again be diluted with the outside air to bring the temperature at the filter face to less than $125^{\circ} \mathrm{F}$. The particulate matter is sampled on a $70 \mathrm{~mm}$ fluorocarbon coated fiber glass filters that 
have been preconditioned in an environmental chamber to $70{ }^{\circ} \mathrm{F}$ and $50 \%$ relative humidity and weighed using a microbalance before testing. The filters are weighed again with a microbalance after the test in the environmental chamber to determine the amount of particulate matter in the diluted exhaust (8). The microbalance used for weighing the particulate matter has a sensitivity of 0.1 micrograms.

The exhaust gas analyzers, calibration gases, dilution tunnel, environmental chamber and data acquisition and control system are transported in a box trailer when moving from one test site to another. A full calibration is completed prior to the start of the test and any incongruities are corrected before the commencement of the test

The gas analysis equipment in the trailer measures the emissions in the exhaust sample. The sample probes at the far end of the tunnel sample a portion of the diluted exhaust for analysis. Heated sample lines transport the exhaust gas to the analyzers. The gas analyzers detect the concentration of each emission gas in parts per million and relay a signal to a computer that records the data on a continuous basis at a frequency of $10 \mathrm{~Hz}$. The laboratories are capable of testing the following emission gases: carbon dioxide $\left(\mathrm{CO}_{2}\right)$, carbon monoxide $(\mathrm{CO})$, hydrocarbons $(\mathrm{HC})$ and oxides of nitrogen $\left(\mathrm{NO}_{\mathrm{x}}\right)$ as well as other exhaust gases such as formaldehyde $(\mathrm{HCHO})$, methane $\left(\mathrm{CH}_{4}\right)$ and methanol $\left(\mathrm{CH}_{3} \mathrm{OH}\right)$. $\mathrm{HC}$ concentrations are measured with a heated flame ionization detector. $\mathrm{NO}_{\mathrm{x}}$ concentrations are measured using a chemiluminescent detector. $\mathrm{CO}$ and $\mathrm{CO}_{2}$ concentrations are found using non- dispersive infrared analyzers (3). 
Table 3.4 The Manufacturers and Model Numbers of the Specific Analyzers Used by the Transportable Laboratories.

\begin{tabular}{|c|c|c|}
\hline Gas & Analyzer & Method of Detection \\
\hline $\mathbf{H C}$ & Rosemount Analytical Model & Heated Flame Ionization \\
& 402 High-Temperature & Detector \\
\hline $\mathbf{C O}$ & $\begin{array}{c}\text { Rosemount Industrial Model } \\
\text { 880A and 868 }\end{array}$ & $\begin{array}{c}\text { Non-dispersive Infrared } \\
\text { Detector }\end{array}$ \\
\hline $\mathbf{C O}_{2}$ & $\begin{array}{c}\text { Rosemount Industrial Model } \\
\text { 880A }\end{array}$ & $\begin{array}{c}\text { Non-dispersive Infrared } \\
\text { Detector }\end{array}$ \\
\hline $\mathbf{N O}_{\mathbf{x}}$ & Rosemount Analytical Model & Chemiluminescent Detector \\
& 955 NO/NO & \\
\hline
\end{tabular}

The data acquisition and control system that makes all of this testing possible has six major components:

- Control System Computer;

- Driver's Interface Computer;

- Data Acquisition Boards and Signal Conditioners;

- Dynamometer Controllers;

- Sensors, Cabling and Interconnections;

- Calibration and Test Software.

These six components together acquire, process and store data. The data acquisition and control assembly is also where instrument errors are introduced and accounted for in the system. 


\subsection{Driving Test Schedules}

\subsubsection{Review of Driving Schedules}

Driving test schedules are used in the measurement of vehicle emissions with a chassis dynamometer. The traffic conditions and the routes traveled by each vehicle affect driving operation. In a similar way, test schedules vary widely in that they attempt to mimic specific driving behavior. Consequently, measured vehicle emissions are largely affected by the driving schedule. For comparison, existing test schedules have been divided into two groups for description below, namely synthesized and actual test schedules. Synthesized schedules are geometric in nature and usually consist of constant acceleration and constant speed phases.

The actual or realistic driving schedules are derived or created from data collected as a vehicle performs its tasks. Most chassis test schedules are defined by a speed versus time trace with load implied by a road load equation with no gradient assumed. Emissions testing are conducted on engines for EPA certification and so chassis driving schedules do not play a direct role in current emissions regulation. The test schedules for engine testing are commonly defined by speed and torque traces over a period of time (9). The actual speeds and torques are derived using the maximum torque curve and rated and idle speeds of the engine.

Relevant schedules, presented and discussed below, include four synthesized for chassis testing, two from the engine certification test, three cycles developed from actual truck data and three engine test cycles. Speed versus time plots of every test cycle and route discussed are included for visual comparison. 


\subsubsection{Synthesized Chassis Schedules}

\section{Central Business District}

The Central Business District (CBD) cycle is a synthesized driving cycle originally created for performance verification and fuel economy measurement of transit buses. This cycle is a portion of the Transit Coach Operating Duty Cycle, which also includes arterial and commuter phases. These are not addressed here, as they are not often used for heavy vehicle emissions testing. A modified CBD cycle (which is referred to as the Truck-CBD Cycle) has lower acceleration rates to suit heavy trucks with manual transmissions, but is no longer in regular use by any chassis dynamometer laboratory. Figure 3.2 shows a speed versus time plot of the entire CBD cycle (2).

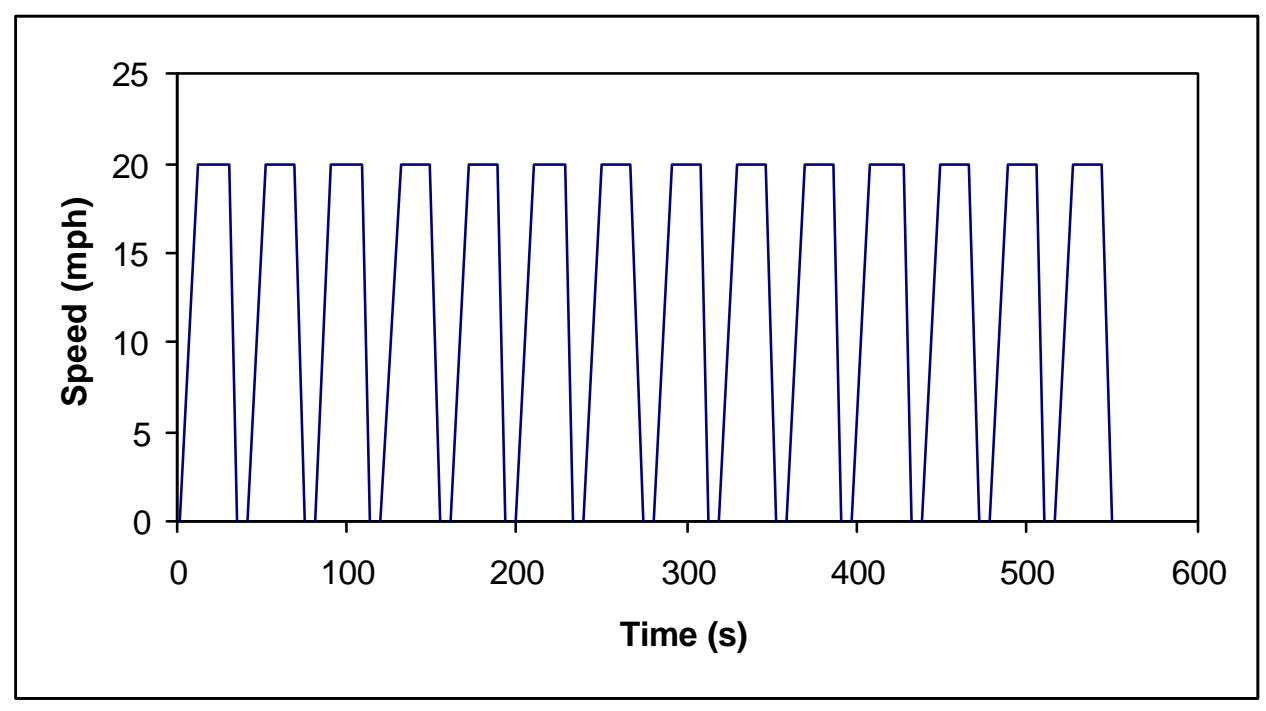

Figure 3.2 Speed Versus Time Plot for the Central Business District (CBD) Cycle.

\section{WVU 5-Peak Cycle}

The WVU 5-Peak Cycle is also called the WVU Truck Cycle. This cycle was developed by the research group at the Transportable Heavy-Duty Vehicle Emissions 
Testing Laboratory in West Virginia University in 1994 (9). The WVU 5-Peak Cycle is designed for general truck chassis testing for comparison of diesel and alternate fuels. Figure 3.3 shows a speed versus time plot for this cycle. The cycle consists of five segments, each with acceleration to a peak speed followed by a brief steady-state operation and then a deceleration back to idle. The five peak speeds are 20, 25, 30, 35 and $40 \mathrm{mph}$ and the cycle covers a five mile distance.

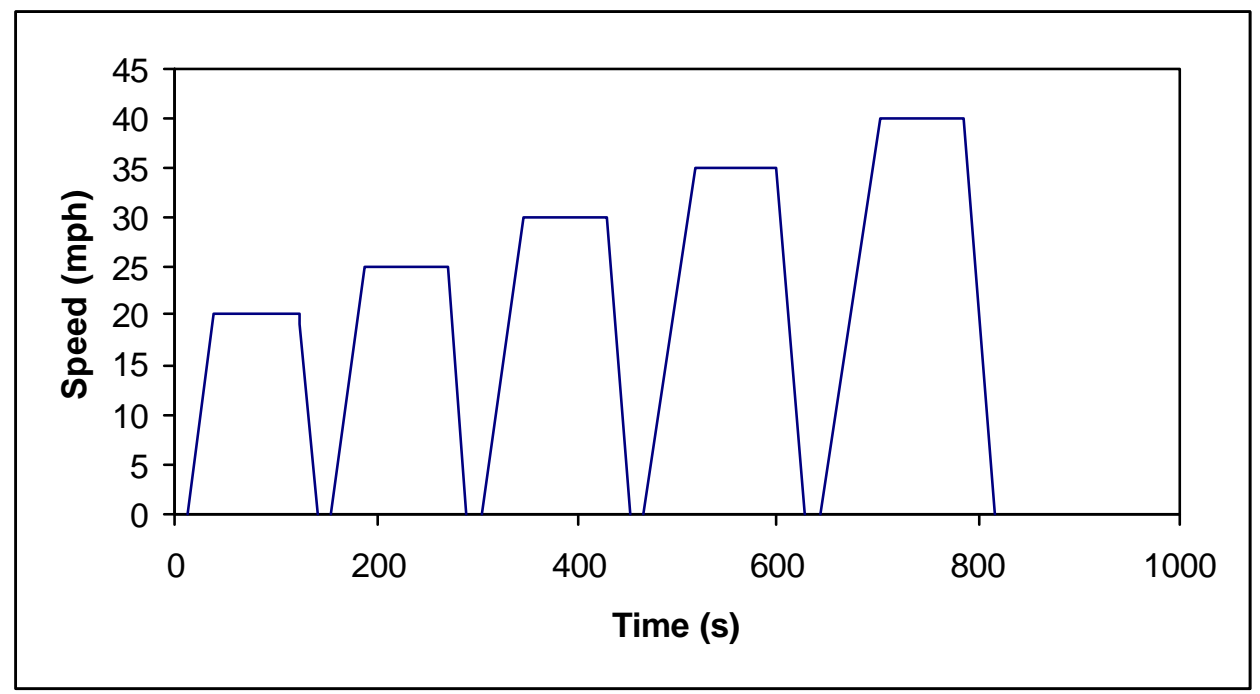

Figure 3.3 Speed Versus Time Plot for the WVU 5-Peak Cycle.

\section{WVU 5-Mile Route}

The WVU 5-Mile Route is also called the Modified WVU Truck Cycle although it is a route, by definition. A route, as opposed to a cycle, utilizes the vehicle's maximum acceleration to the peak speed followed by a steady-state operation before deceleration to an idle. The total distance is controlled always to equal five miles, regardless of the acceleration the vehicle can attain. This causes the speed versus time schedule to vary from one vehicle to another and a more powerful vehicle will be able to complete the 
driving portion in less time. The target cycle cannot be illustrated on a speed versus time plot for the WVU 5-Mile Route, but can be illustrated on a speed versus distance plot.

New York Garbage Truck Cycle

WVU researchers developed the New York Garbage Truck Cycle (NYGTC) by following refuse trucks and recording the characteristics of their typical operation (10). Although not statistically derived, this cycle mimics real refuse truck use better than the CBD cycle. This cycle incorporates three compactions while the truck is not moving. The acceleration ramps in this cycle are at a fixed rate rather than at the maximum acceleration the vehicle can attain. A speed versus time plot of the NYGTC, with compactions noted, is shown in Figure 3.4.

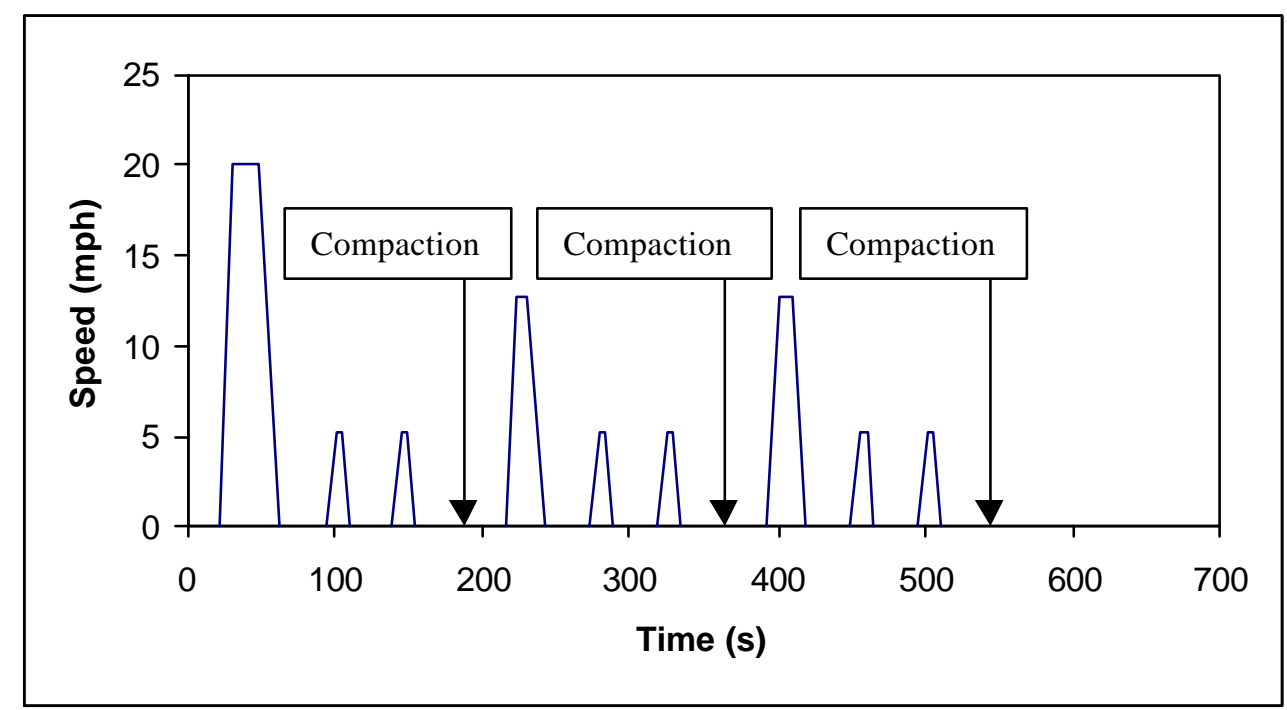

\section{Figure 3.4 Speed Versus Time Plot for the New York Garbage Truck Cycle (NYGTC).}

From the plots of each cycle, it can be seen that the CBD cycle favors the one speed of $20 \mathrm{mph}$, while the WVU 5-Peak Cycle incorporates a variety of speeds, with the 
maximum being $40 \mathrm{mph}$. Favoring a single speed through a cycle can bias emissions measurement through gear selection. The WVU 5-Peak Cycle has the highest average speed of $21.2 \mathrm{mph}$ shown in Table 3.5. The CBD, WVU 5-Peak and NYGT cycle statistics have been calculated from the target cycle.

Table 3.5 Calculated Parameters of the Synthesized Cycles and Routes.

\begin{tabular}{|c|c|c|c|}
\hline Cycle or Route & CBD & WVU 5-Peak & NYGT \\
\hline Total Duration (s) & 574 & 900 & 600 \\
\hline Idle (\%) & 17.8 & 17.3 & 68.5 \\
\hline Acceleration (\%) & 26.6 & 23.4 & 9.7 \\
\hline Cruise (\%) & 43.5 & 46.3 & 12.0 \\
\hline Deceleration (\%) & 12.1 & 12.9 & 9.8 \\
\hline Maximum Accel. (mph/s) & 1.93 & 0.80 & 1.30 \\
\hline Average Accel. (mph/s) & 1.93 & 0.72 & 1.31 \\
\hline Maximum Decel. (mph/s) & -3.73 & -1.33 & -1.40 \\
\hline Average Decel. (mph/s) & -3.73 & -1.33 & -1.29 \\
\hline Maximum Speed (mph) & 20 & 40 & 20 \\
\hline Average Speed (mph) & 12.6 & 21.2 & 2.3 \\
\hline Total Distance (miles) & 2.0 & 5.0 & 0.38 \\
\hline
\end{tabular}




\subsubsection{Realistic Chassis Cycles}

New York Bus Cycle

This cycle was derived from in-use vehicle data from the CAPE-21 survey (11). The CAPE-21 project also yielded the data used to formulated the present heavy-duty engine certification test schedule, as presented in the Code of Federal Regulation, Title 40, Part 86, Subpart N. This survey collected data from buses, trucks and tractor trailers in New York and Los Angeles. This cycle is intended to simulate very low average speed operation in dense city traffic. Figure 3.5 shows a speed versus time plot for the NYBC.

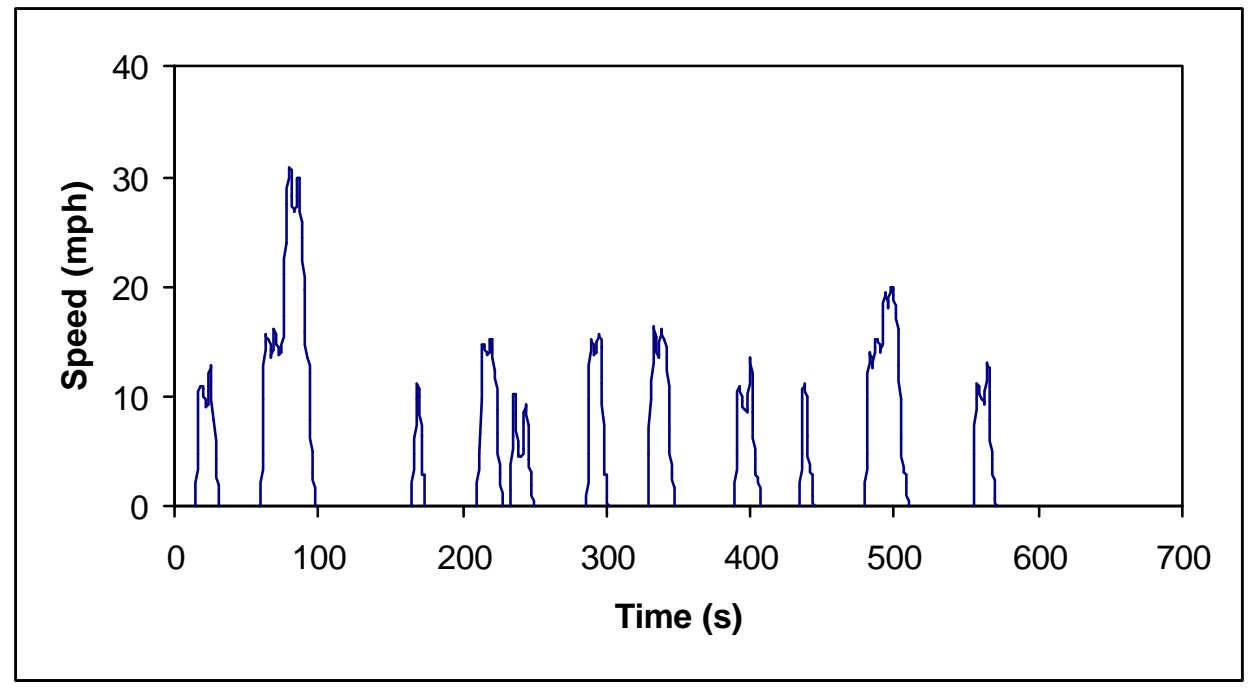

Figure 3.5 Speed Versus Time Plot for the New York Bus Cycle (NYBC).

EPA Urban Dynamometer Driving Schedule for Heavy-Duty Vehicles (Test-D)

The EPA Urban Dynamometer Driving Schedule for Heavy-Duty Vehicles is also referred to as "Test-D". It is another cycle developed from the CAPE-21 database and presented in the Code of Federal Regulation, Title 40, Part 86, Subpart N, as a conditioning cycle for heavy-duty vehicle evaporative emissions testing. This cycle was 
developed from the freeway and non-freeway data collected in the survey and it is meant to represent heavy-duty driving in all US urban areas. This speed-time cycle is arduous to follow with a heavy truck having a low power-to-weight ratio and an unsynchronized transmissions. Although it is intended to reflect the same operation as the present day engine certification test, Dietzmann and Warner-Selph found poor emissions correlation between the two (12). This cycle has been employed occasionally as a "best attempt" basis to simulate vehicle activity and emissions by most heavy-duty chassis emissions laboratories in North America. Test-D has now been adopted by CARB to aquire emissions inventory data for heavy-duty vehicles. Figure 3.6 shows the scheduled speed versus time plot for Test-D.

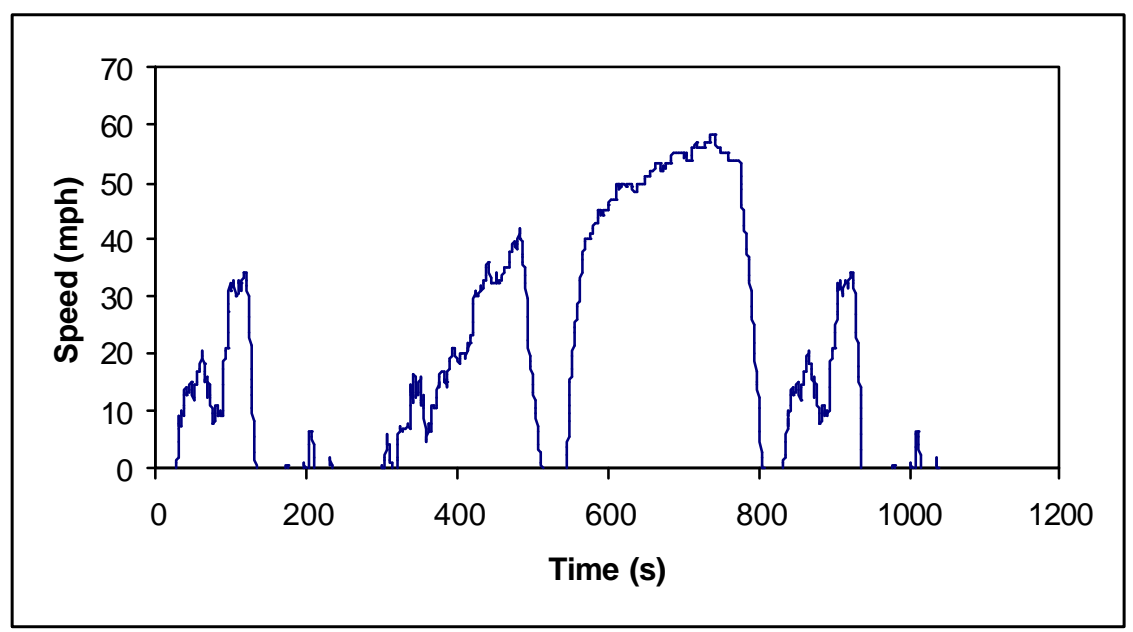

Figure 3.6 Speed Versus Time Plot for the EPA Urban Dynamometer Driving Schedule for Heavy-Duty Vehicles (Test-D).

\section{City Suburban Heavy Vehicle Route (CSHVR)}

The City Suburban Heavy Vehicle Route was developed by WVU by concatenating microtrips (defined as one delivery stop to the next) from data collected in the field from trucks operating in Richmond, Virginia and Akron, Ohio (13). The target 
cycle cannot be illustrated on a speed versus time plot for the CSHVR, but a speed versus time plot of the considered class 8 heavy-duty tractor truck described in Table 4.2 following CSHVR is shown in Figure 3.7.

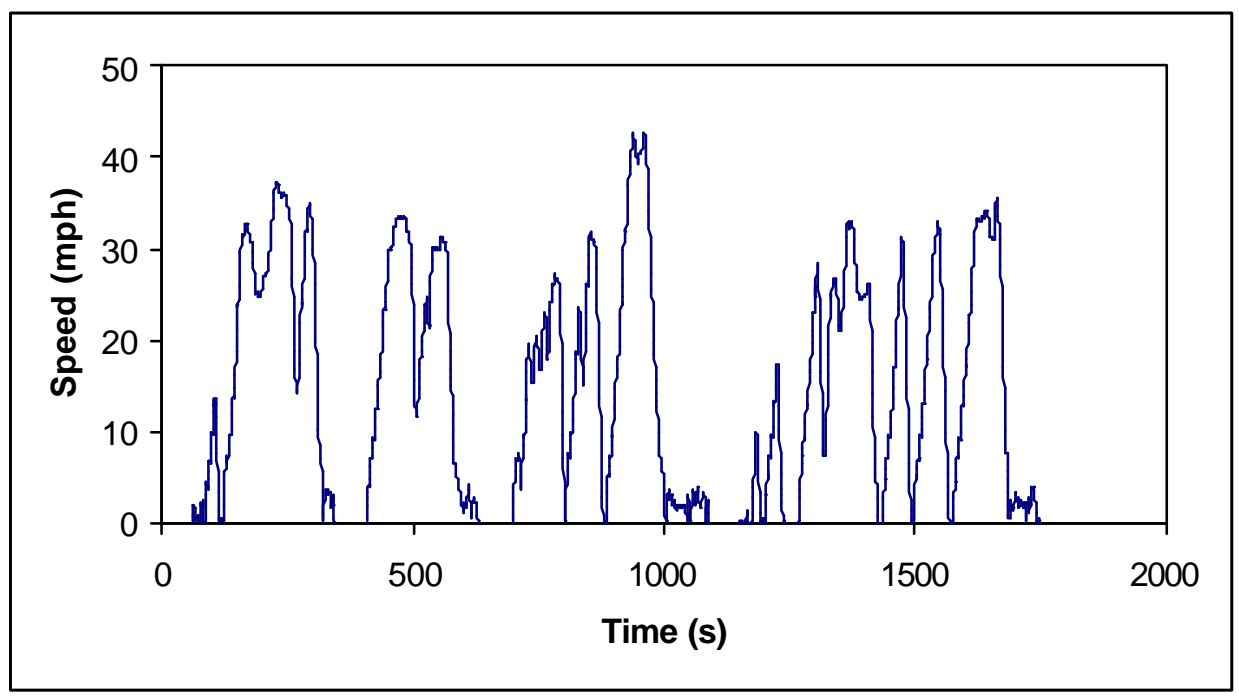

Figure 3.7 Speed Versus Time Plot for the Considered Class 8 Heavy-Duty Tractor Truck Described in Table 4.2 Following CSHVR.

The Table 3.6 shows the demographics of the actual cycles. The statistics for NYBC and Test-D have been obtained from target speed-time data. The NYBC has a long percentage of idle time $(58 \%)$ and a relatively large maximum acceleration (4.43 $\mathrm{mph} / \mathrm{s})$. The low average speed (3.69 $\mathrm{mph}$ ) and maximum speed (31 mph) along with the short travel distance are representative of bus traffic with many short trips between stops. Even though difficult to follow, Test-D is more suited for testing trucks due to its lower maximum acceleration $(2.80 \mathrm{mph} / \mathrm{s})$ and longer cruise time $(\sim 25 \%)$. 
Table 3.6 Calculated Parameters of the Realistic Cycles.

\begin{tabular}{|c|c|c|}
\hline Cycle & NYB & Test-D \\
\hline Total Duration (s) & 600 & 1062 \\
\hline Idle (\%) & 58.0 & 27.4 \\
\hline Acceleration (\%) & 15.3 & 29.3 \\
\hline Cruise (\%) & 8.2 & 24.6 \\
\hline Deceleration (\%) & 18.5 & 18.8 \\
\hline Maximum Accel. $(\mathbf{m p h} / \mathbf{s})$ & 4.43 & 2.80 \\
\hline Average Accel. $(\mathbf{m p h} / \mathbf{s})$ & 1.79 & 0.75 \\
\hline Maximum Decel. $(\mathbf{m p h} / \mathbf{s})$ & -3.35 & -3.19 \\
\hline Average Decel. $(\mathbf{m p h} / \mathbf{s})$ & -1.51 & -1.17 \\
\hline Maximum Speed $(\mathbf{m p h})$ & 31 & 58 \\
\hline Average Speed $(\mathbf{m p h})$ & 3.69 & 18.8 \\
\hline Total Distance (miles) & 0.615 & 5.55 \\
\hline
\end{tabular}




\subsubsection{Engine Cycles}

Federal Test Procedure (FTP)

Heavy-duty engine test cycles are defined by a speed and torque (load) schedule over a period of time. Generally, the specified speed and torque are defined as percent of maximum rated speed, and percent of maximum rated torque. The certification cycle for engine testing is also referred to as the Federal Test Procedure (FTP) cycle. Figure 3.8 shows the scheduled speed versus time for the FTP cycle and Figure 3.9 shows the scheduled torque versus time (2).

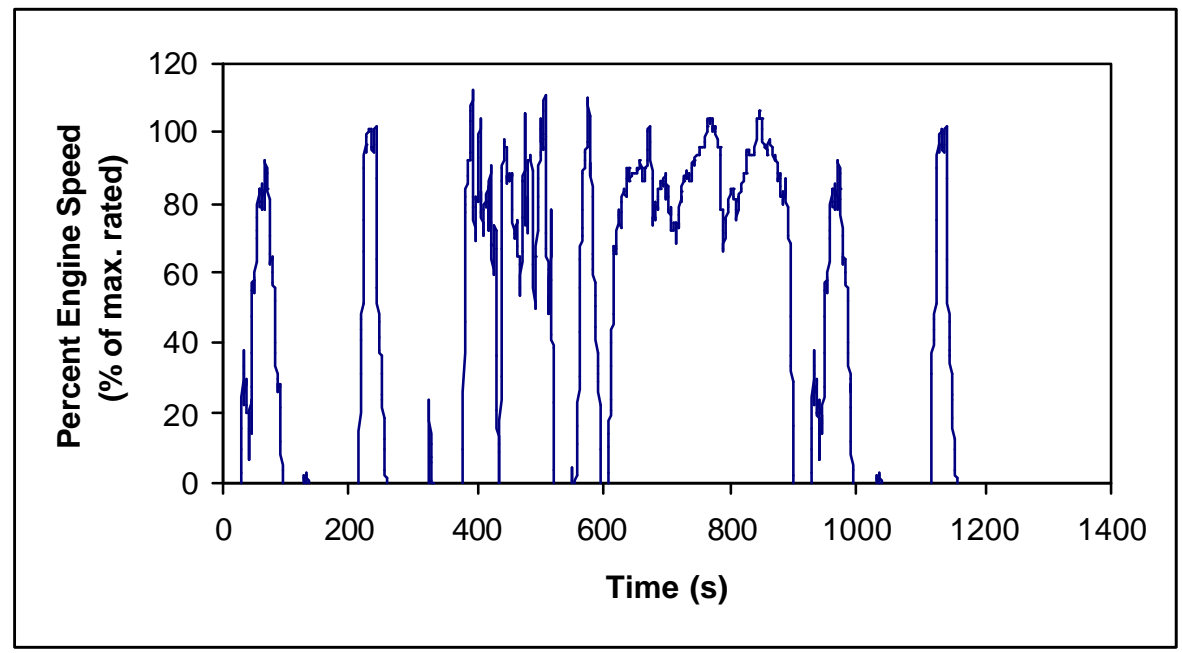

Figure 3.8 Percent Speed Versus Time for the Federal Test Procedure Engine Cycle. 


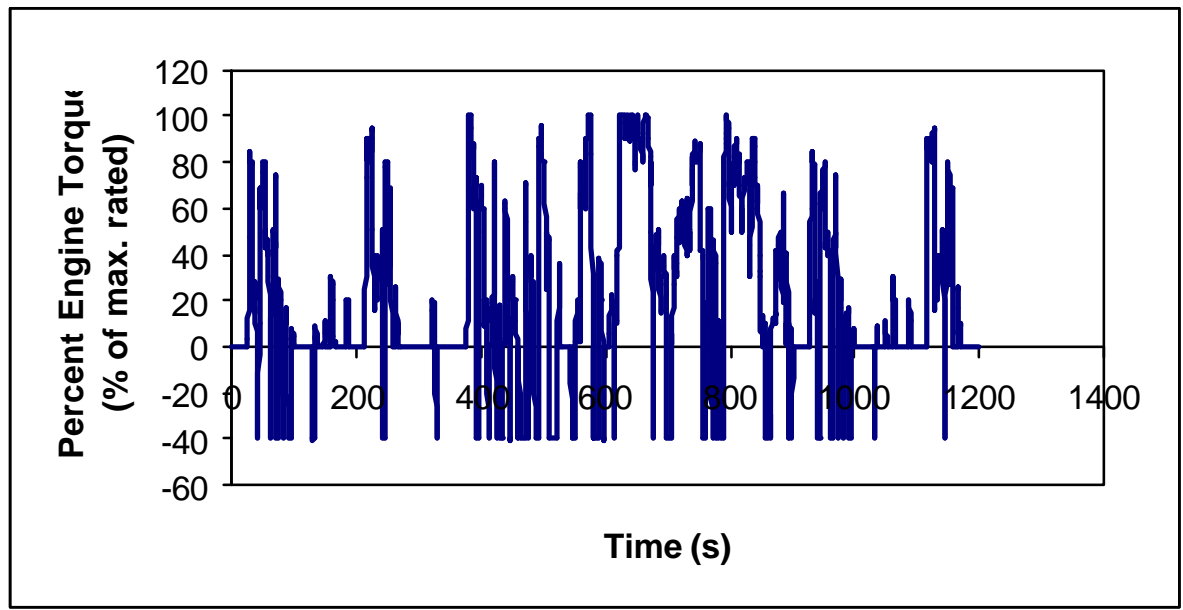

Figure 3.9 Percent Torque Versus Time for the Federal Test Procedure Engine Cycle. 


\subsection{Time Delays}

The measurement delay time caused by the exhaust collection network will vary due to the type of the vehicle being tested and the design of its exhaust network. On similar lines, the response time of the analyzer is not identical. The response of the analyzer is a combination of physical response due to the changes in sample gas concentration and a variable electronic response that can be set by the operator (14).

The measurement delay associated with the tailpipe exhaust from the exhaust collection network depends on the velocity of flow down the connecting lengths of the pipe. The flow rate of the exhaust depends on the engine speed, turbocharger boost (if equipped), fuel flow and ambient air conditions. Measurement delay depends on the vehicle exhaust configuration because identical engines tested on different vehicles produce different vehicle exhaust flow velocities. The combination of one or more of these factors produces different delay times. However the delay caused by the analyzer transport time and analyzer response are larger than the delay due to the other factor.

A theoretical measurement delay associated with gas transfer within gas sampling and measurement system may be calculated by modeling the exhaust collection system using basic fluid flow and heat transfer equations. The overall measurement delay time for each pollutant is a combination of response time of the analyzer and the time taken by the gases to travel through the tunnel and the sampling lines.

Cross-correlation is comparing two sets of data against a common variable and calculating the best time shift, if any, that best matches the two sets of data assuming that there exists a correlation between them. Cross-correlation is done in order to calculate the measurement time delays involved in the gas sampling lines and due to the analyzer 
response times by comparing the power and emissions data. For the process of crosscorrelation it is assumed that the emissions would lag behind power. Correlation coefficients for each of the time shift are calculated through a basic program and the highest correlation coefficient corresponds to the lag of one signal to the other. Results that show little change between correlation coefficients indicates that two sets of data do not have similar trends.

Correlation coefficients involving two sets of data can be calculated using the following correlation equation:

$$
\prod_{\Delta t}=\frac{\sum_{\Delta t=-t_{\max }}^{t_{\max }-\Delta t}\left[P(t) * C\left(t+\Delta t_{\text {average }}\right)\right]}{\sum_{\Delta t=-t_{\max }}^{t_{\max }-\Delta t}[P(t) * C(t)]},
$$

where $\Pi_{\Delta t}$ is the correlation coefficient, $\mathrm{P}(\mathrm{t})$ is the power, $\mathrm{C}(\mathrm{t})$ is the emission rate of the gas and $\Delta \mathrm{t}_{\text {average }}$ is the time shift between signals.

It is necessary that the emissions increase with power so that the cross-correlation method to be successful. Evidently $\mathrm{CO}_{2}$ emissions increases along with the consumed power because $\mathrm{CO}_{2}$ represents the fuel consumed during the engine operation. Most of the time, $\mathrm{NO}_{\mathrm{x}}$ also increase with power, even if there can be cases when a high speed, low load request may produce more $\mathrm{NO}_{\mathrm{x}}$ than a low speed, high power request for the same engine power rating. Emissions of $\mathrm{NO}_{\mathrm{x}}$ also depend on the manufacturer's timing maps (14).

Cross-correlating emissions data to power yields the time shift $\left(\Delta \mathrm{t}_{\text {average }}\right)$, which is the average response time for the exhaust collection system to detect a change in 
emission gas levels. The time shift depends on the power output from the engine. An increase in the power output from the engine results in an increase in exhaust flow rate and exhaust temperature, which decreases the exhaust transport time of the exhaust collection system. Thus $\Delta \mathrm{t}_{\text {average }}$ should lie between the extremes of idle power and maximum power exhibited during any testing cycle.

This window of delay time is thus a function of the power level output from the engine that can be represented as:

$$
\Delta \mathrm{t}_{\mathrm{average}}=\Delta \mathrm{t}_{\max }-\mathrm{A} * \mathrm{P}
$$

where the delay time decreases with an increase of power, P. From the previous discussion, the value for $\Delta \mathrm{t}_{\text {max }}$ must be larger than $\Delta \mathrm{t}_{\text {average }}$ by some additional duration:

$$
\Delta \mathrm{t}_{\max }=\Delta \mathrm{t}_{\text {average }}+\mathrm{M}
$$

and correlation coefficients will take on the form:

$$
\prod_{\Delta t}=\frac{\sum_{\Delta t=-t_{\max }}^{t_{\max }-\Delta t}\left[P(t) * C\left(t+\left(\Delta t_{\max }-A * P(t)\right)\right)\right]}{\sum_{\Delta t=-t_{\max }}^{t_{\max }-\Delta t}[P(t) * C(t)]}
$$

The task becomes finding combination of values for $\mathrm{A}$ and $\Delta \mathrm{t}_{\max }$ that maximizes the last equation. 
Before building simple correlation models it is necessary to align $\mathrm{NO}_{\mathrm{x}}$ or $\mathrm{CO}$ and power data with respect to time. Cross-correlation of instantaneous $\mathrm{NO}_{\mathrm{x}}$ or $\mathrm{CO}$ and axle power data with respect to power (3). 


\section{Modeling Approach}

In this paper, the instantaneous emissions of $\mathrm{NO}_{\mathrm{x}}, \mathrm{CO}_{2}, \mathrm{CO}$ and $\mathrm{PM}$ in grams per second (g/s), were related solely to the power output at the wheels of the vehicle, in units of axle horsepower (ahp). A simulation of driving road load and inertia yielded the axle power needed at any moment in time and the power was directly translated into instantaneous $\mathrm{NO}_{\mathrm{x}}, \mathrm{CO}_{2}, \mathrm{CO}$ and $\mathrm{PM}$ emissions. This method does not directly provide for the influence of transients (such as gear changes or gear selection) on $\mathrm{NO}_{\mathrm{x}}$, but $\mathrm{NO}_{\mathrm{x}}$ is known to be influenced only slightly by transients, except where transients may precipitate engine controller decisions to employ "off-cycle" emissions (15). A steady state approach of this kind could not be employed with as much confidence for heavyduty PM modeling because PM emissions increase substantially during transient operation and are highly cycle dependent (16). The correlation model of emissions components such as $\mathrm{NO}_{\mathrm{x}}, \mathrm{CO}_{2}, \mathrm{CO}$ and $\mathrm{PM}$ with the axle power was developed using a simple road load relation, considering aerodynamic drag, tire rolling resistance and grade:

$$
P=1 / 2 \rho_{a} C_{D} A V^{3}+\mu M g V+M g V \sin \theta+M(d V / d t) V
$$

where $\mathrm{P}$ is the axle power required for a steady speed, $\rho_{a}$ is the density of air, $C_{D}$ is the drag coefficient, $\mathrm{A}$ is the frontal area of the vehicle, $\mathrm{V}$ is the speed at which the vehicle is traveling, $\mu$ is the tire rolling resistance coefficient, $\mathrm{M}$ is the mass of the vehicle, $\mathrm{g}$ is the acceleration due to gravity, $\theta$ is the angle of inclination of the road grade and $(\mathrm{dV} / \mathrm{dt})$ is acceleration of the vehicle. From the equation it can be seen that the four main factors 
that govern power demand are speed, acceleration, weight and road grade (2). The values of each constant used in the analysis are listed in Table 4.1:

Table 4.1 Constants Used for Terrain Modeling.

\begin{tabular}{|c|c|c|}
\hline Constant & Value & Vehicle Type \\
\hline \multirow{3}{*}{$\boldsymbol{\rho}_{\mathbf{a}}$} & $1.2 \mathrm{~kg} / \mathrm{m}^{3}$ & All \\
\hline \multirow{3}{*}{$\mathbf{C}_{\mathbf{D}}$} & 0.6 & Tractor truck \\
\cline { 2 - 3 } & 0.5 & Box truck \\
\cline { 2 - 3 } & 0.6 & Transit bus \\
\hline \multirow{3}{*}{$\mathbf{A}$} & $7 \mathrm{~m}^{2}$ & Tractor truck \\
\cline { 2 - 3 } & $4 \mathrm{~m}^{2}$ & Box truck \\
\cline { 2 - 3 } & $7 \mathrm{~m}^{2}$ & Transit bus \\
\hline \multirow{3}{*}{$\boldsymbol{\mu}$} & 0.01 & Tractor truck \\
\cline { 2 - 3 } & 0.008 & Box truck \\
\cline { 2 - 3 } & 0.00938 & Transit bus \\
\hline \multirow{3}{*}{$\mathbf{M}$} & $42,000 \mathrm{lb} .(19,100 \mathrm{~kg})$ & Tractor truck \\
\cline { 2 - 3 } & $22,000 \mathrm{lb} .(10,000 \mathrm{~kg})$ & Box truck \\
\cline { 2 - 3 } & $32,800 \mathrm{lb} .(14,900 \mathrm{~kg})$ & Transit bus \\
\hline \multirow{2}{*}{$\mathbf{g}$} & $9.807 \mathrm{~m} / \mathrm{s}^{2}$ & All \\
\hline
\end{tabular}

A detailed description of the three vehicles (a heavy-duty class 8 tractor truck, a medium-duty class 6 box truck and a class 8 transit bus) that has been used for the simulations from this thesis, are presented in Table 4.2: 
Table 4.2 Details of the Considered Vehicles and Engines.

\begin{tabular}{|c|c|c|c|}
\hline Vehicle Type & Tractor Truck & Box Truck & Transit Bus \\
\hline Engine Type & $\begin{array}{c}\text { Detroit Diesel } \\
\text { series 60 }\end{array}$ & Caterpillar 3116 & $\begin{array}{c}\text { Detroit Diesel } \\
\text { series } 50\end{array}$ \\
\hline Model Year & 1998 & 1995 & 1996 \\
\hline $\begin{array}{c}\text { Gross Vehicle } \\
\text { Weight }\end{array}$ & $80,000 \mathrm{lb}$. & $22,000 \mathrm{lb}$. & $38,000 \mathrm{lb}$. \\
$(36,300 \mathrm{~kg})$ & $(10,000 \mathrm{~kg})$ & $(17,200 \mathrm{~kg})$ \\
\hline $\begin{array}{c}\text { Vehicle Tested } \\
\text { Weight }\end{array}$ & $42,000 \mathrm{lb}$. & $22,000 \mathrm{lb}$. & $32,800 \mathrm{lb}$. \\
$(19,100 \mathrm{~kg})$ & $(10,000 \mathrm{~kg})$ & $(14,900 \mathrm{~kg})$ \\
\hline Vehicle Class & 8 & 6 & 8 \\
\hline Engine Power & $470 \mathrm{hp}(350 \mathrm{~kW})$ & $170 \mathrm{hp}(127 \mathrm{~kW})$ & $275 \mathrm{hp}(205 \mathrm{~kW})$ \\
\hline Engine & 12.7 liters & 6.6 liters & 8.5 liters \\
Displacement & & 6 & 4 \\
\hline No. of Cylinders & 6 & Automatic & Automatic \\
\hline Vehicle \\
Transmission \\
and
\end{tabular}




\section{Hill versus Flat Land}

The models developed for prediction of $\mathrm{NO}_{\mathrm{x}}, \mathrm{CO}_{2}$ and $\mathrm{CO}$ emissions of the considered vehicles (described in Table 4.2) versus terrain are based on data gathered with one of the two West Virginia University Transportable Heavy Duty Vehicle Emissions Testing Laboratories (THDVETL) and are presented in Figures 5.1, 5.2, 5.3, 5.5, 5.6, 5.7, 5.9, 5.10 and 5.11. The data points used in this paper were obtained from an emission test of the considered heavy-duty tractor truck described in Table 4.2 exercised through the CSHVR and two other tests for the considered box truck and transit bus exercised through the CBD Cycle. Data obtained with the heavy-duty chassis dynamometer system-based WVU THDVETL have been entered in emissions versus axle power plots and then a curve was fitted for each vehicle for each emissions species. In producing a relationship between continuous emissions and instantaneous axle load, data processing must account for delays that are inherent in the response of the emissions measurement system.

PM cannot be measured continuously, so that a model for PM emissions cannot be directly developed from data collected with the WVU THDVETL. However, there is one paper that argues that continuous $\mathrm{CO}$ may serve as a tool for apportioning total PM over a cycle to predict instantaneous PM, and this approach was used for PM prediction (17). A relationship of the following form may be sufficiently accurate for the proportioning of total integrated PM throughout a test cycle in which, 


$$
P M_{\text {continuous }}=\frac{P M_{\text {total }} * f\left(C O_{\text {continuous }}\right)}{\int_{0}^{t} f\left(C O_{\text {continuous }}\right) d t}
$$

where $P M_{\text {continuous }}$ is the estimated particulate mass at any given moment of a cycle, $P M_{\text {total }}$ is the total gravimetrical particulate matter obtained for the whole cycle, $f\left(\mathrm{CO}_{\text {continuous }}\right)$ is the instantaneous function of $\mathrm{CO}$ at any given moment within the cycle, $\int_{0}^{t} f\left(C O_{\text {continuous }}\right) d t$ is the function of CO integrated over the test cycle.

Based on this relationship between $\mathrm{CO}$ and PM emissions there were developed three models of continuous PM emissions in $\mathrm{g} / \mathrm{s}$ versus axle power, one for each of the considered vehicles. The models are presented in Figures 5.4, 5.8 and 5.12.

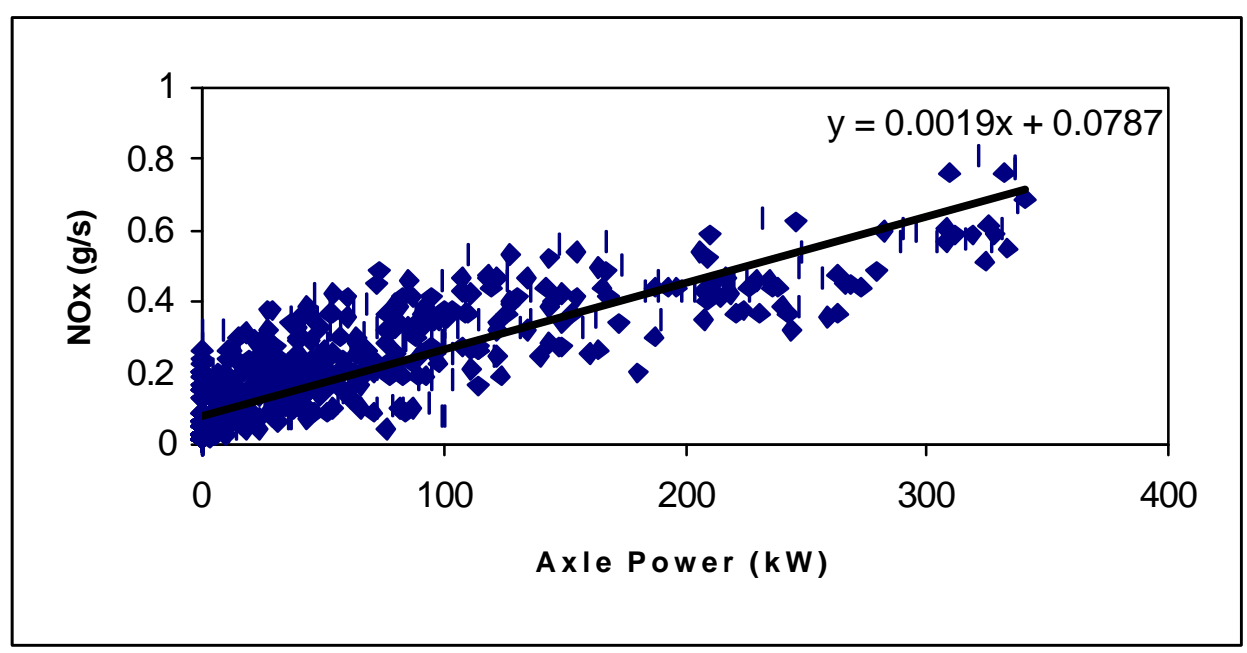

Figure 5.1 Model Developed for $\mathrm{NO}_{\mathrm{x}}$ Emissions Prediction of a Class 8 Heavy-Duty Tractor Truck. The Data Points Were Obtained from an Emissions Test of the Heavy-Duty Tractor Truck Described in Table 4.2 Exercised Through the CSHVR. 


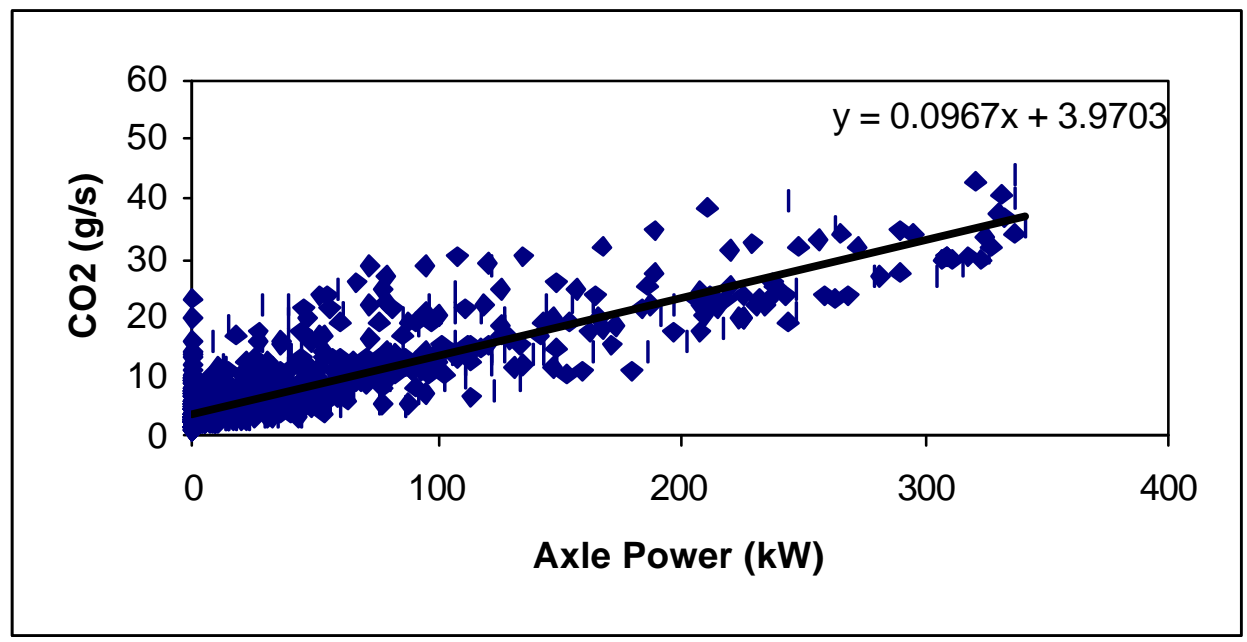

Figure 5.2 Model Developed for $\mathrm{CO}_{2}$ Emissions Prediction of a Class 8 Heavy-Duty Tractor Truck. The Data Points Were Obtained from an Emissions Test of the Heavy-Duty Tractor Truck Described in Table 4.2 Exercised Through the CSHVR.

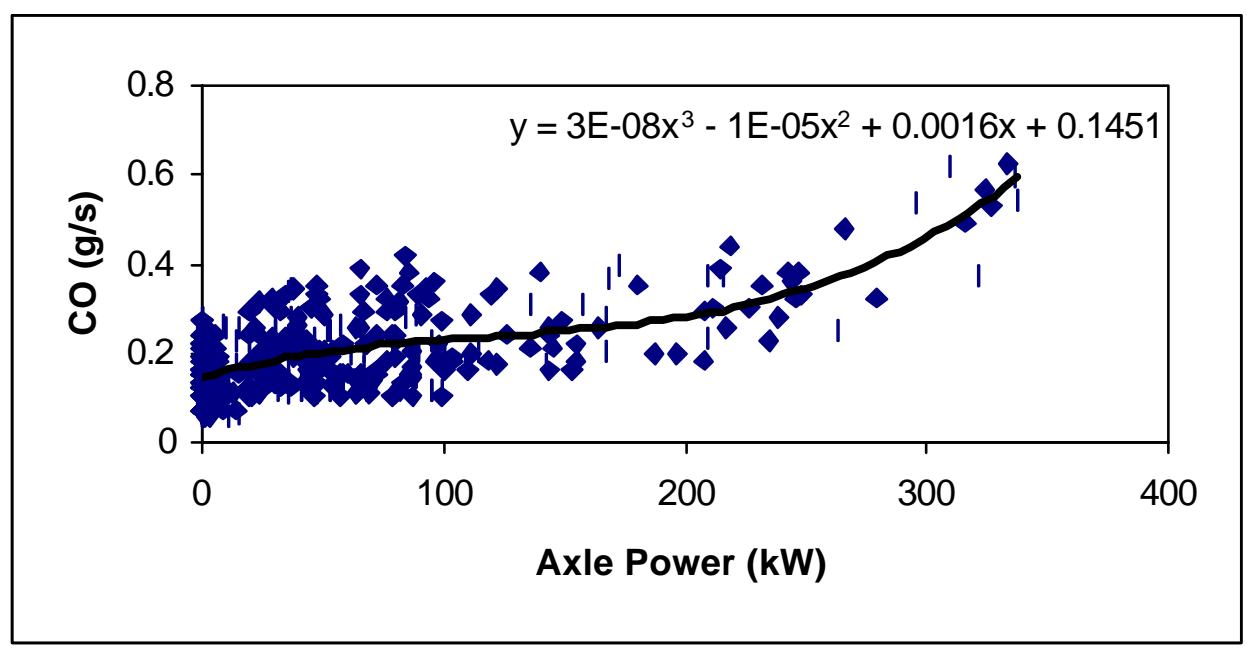

Figure 5.3 Model Developed for CO Emissions Prediction of a Class 8 Heavy-Duty Tractor Truck. The Data Points Were Obtained from an Emissions Test of the Heavy-Duty Tractor Truck Described in Table 4.2 Exercised Through the CSHVR. 


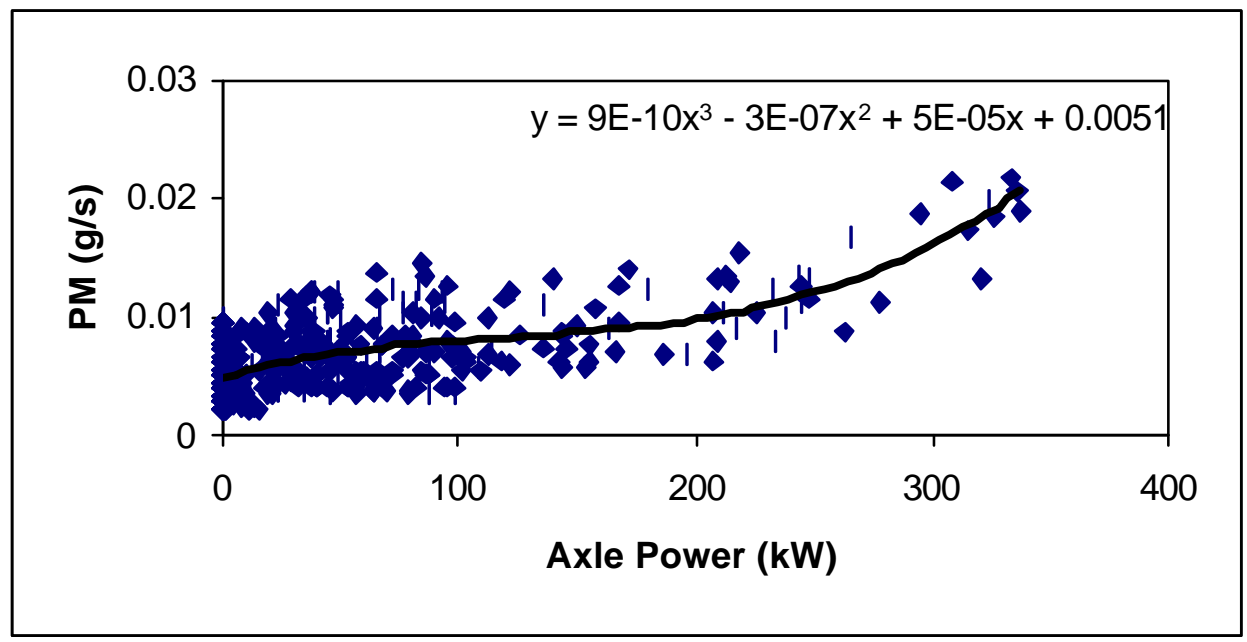

Figure 5.4 Model Developed for PM Emissions Prediction of a Class 8 Heavy-Duty Tractor Truck. The Data Points Were Obtained from an Emissions Test of the Heavy-Duty Tractor Truck Described in Table 4.2 Exercised Through the CSHVR.

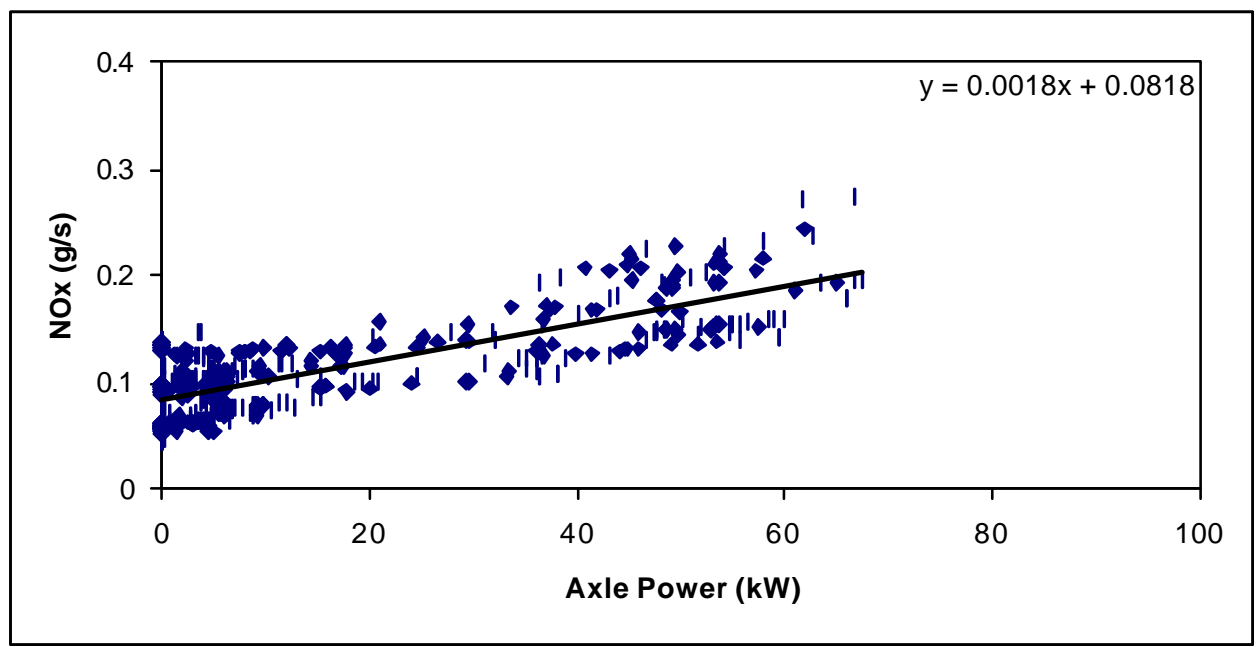

Figure 5.5 Model Developed for $\mathrm{NO}_{\mathrm{x}}$ Emissions Prediction of a Class 6 MediumDuty Box Truck. The Data Points Were Obtained from an Emissions Test of the Medium-Duty Box Truck Described in Table 4.2 Exercised Through the Central Business District (CBD) Cycle. 


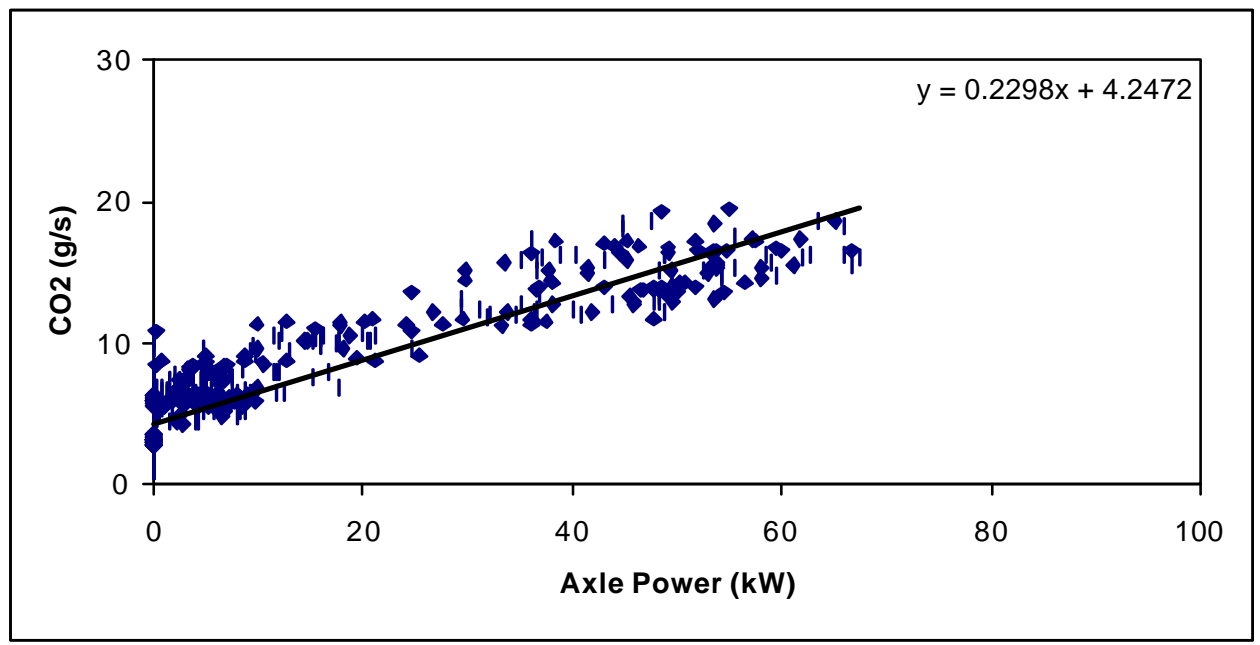

Figure 5.6 Model Developed for $\mathrm{CO}_{2}$ Emissions Prediction of a Class 6 MediumDuty Box Truck. The Data Points Were Obtained from an Emissions Test of the Medium-Duty Box Truck Described in Table 4.2 Exercised Through the Central Business District (CBD) Cycle.

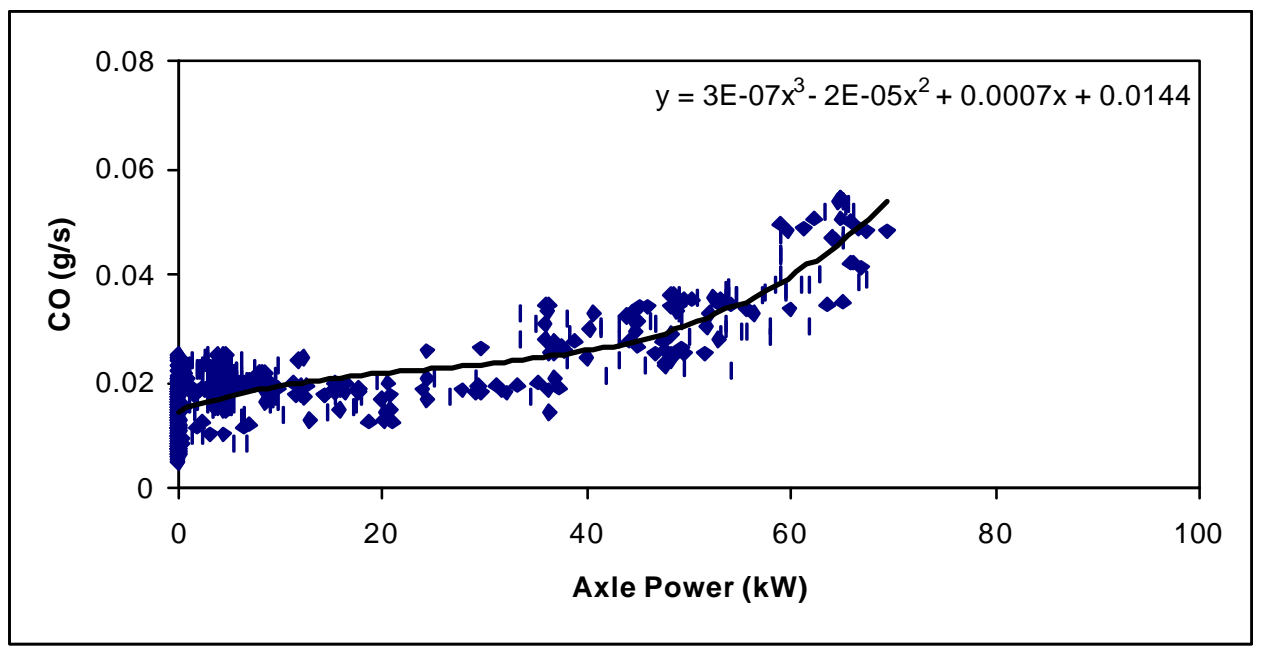

Figure 5.7 Model Developed for CO Emissions Prediction of a Class 6 Medium-Duty Box Truck. The Data Points Were Obtained from an Emissions Test of the MediumDuty Box Truck Described in Table 4.2 Exercised Through the Central Business District (CBD) Cycle. 


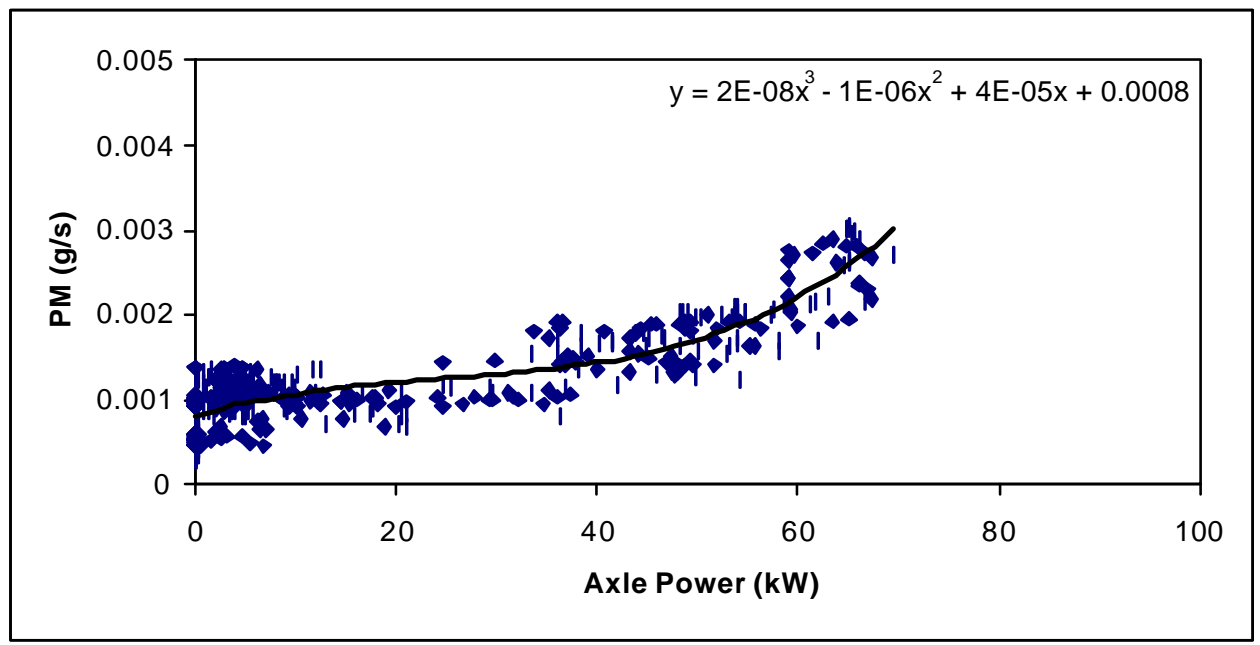

Figure 5.8 Model Developed for PM Emissions Prediction of a Class 6 Medium-Duty Box Truck. The Data Points Were Obtained from an Emissions Test of the MediumDuty Box Truck Described in Table 4.2 Exercised Through the Central Business District (CBD) Cycle.

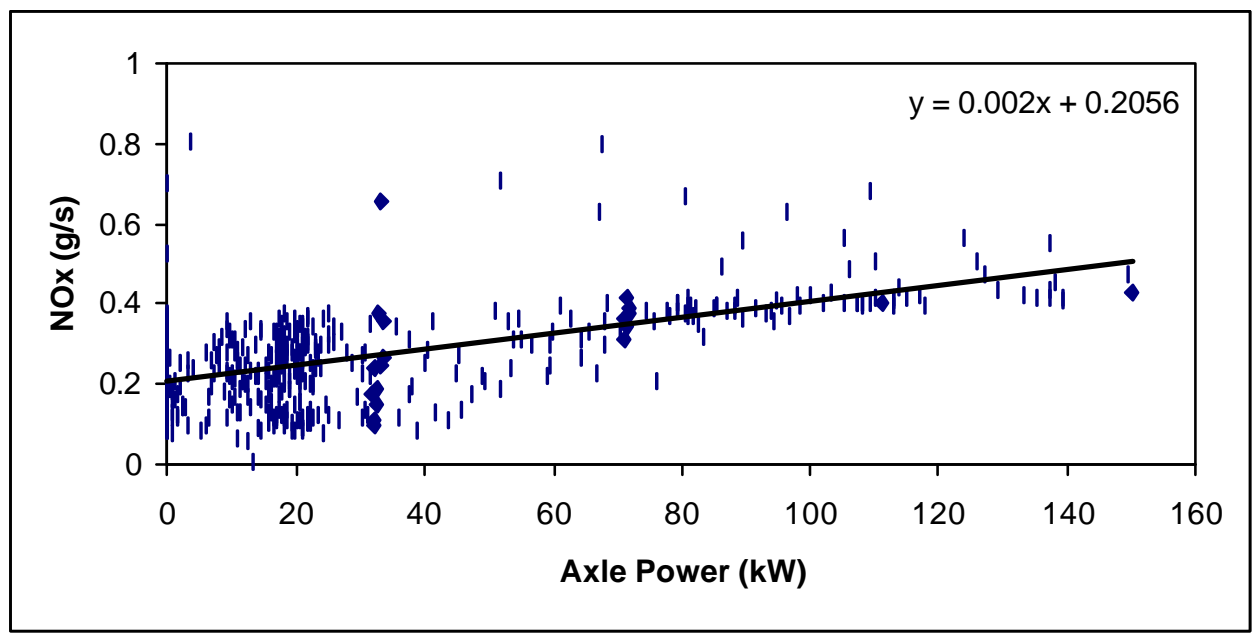

Figure 5.9 Model Developed for $\mathrm{NO}_{\mathrm{x}}$ Emissions Prediction of a Class 8 Transit Bus. The Data Points Were Obtained from an Emissions Test of the Transit Bus Described in Table 4.2 Exercised Through the Central Business District (CBD) Cycle. 


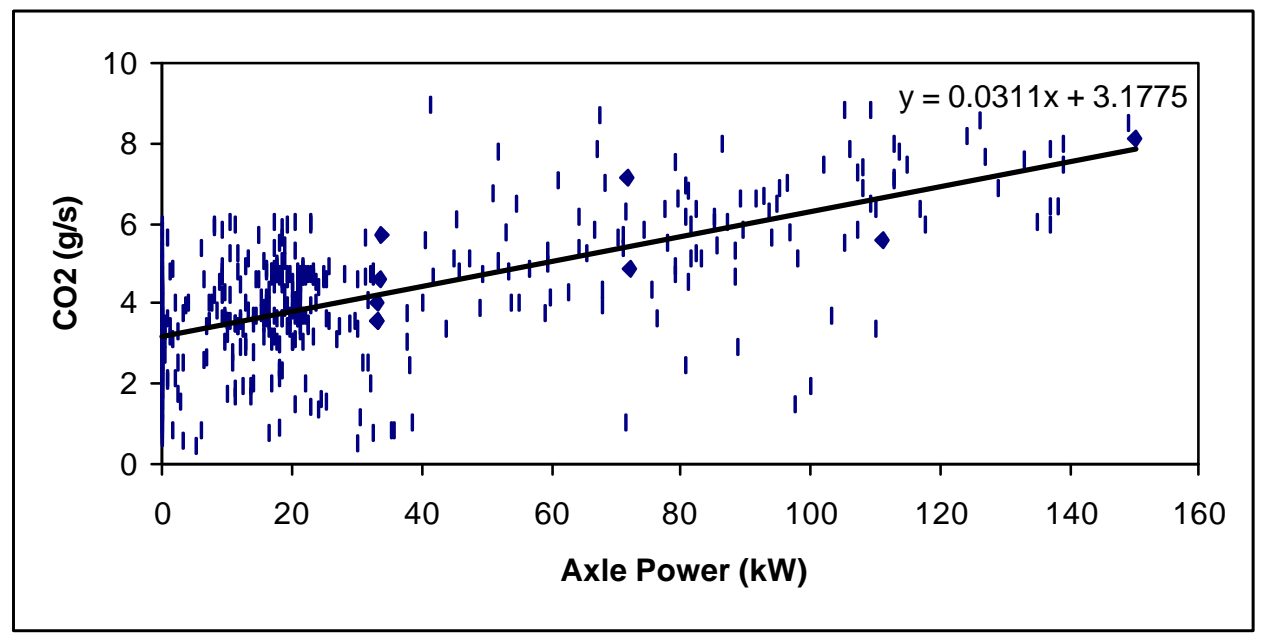

Figure 5.10 Model Developed for $\mathrm{CO}_{2}$ Emissions Prediction of a Class 8 Transit Bus. The Data Points Were Obtained from an Emissions Test of the Transit Bus Described in Table 4.2 Exercised Through the Central Business District (CBD) Cycle.

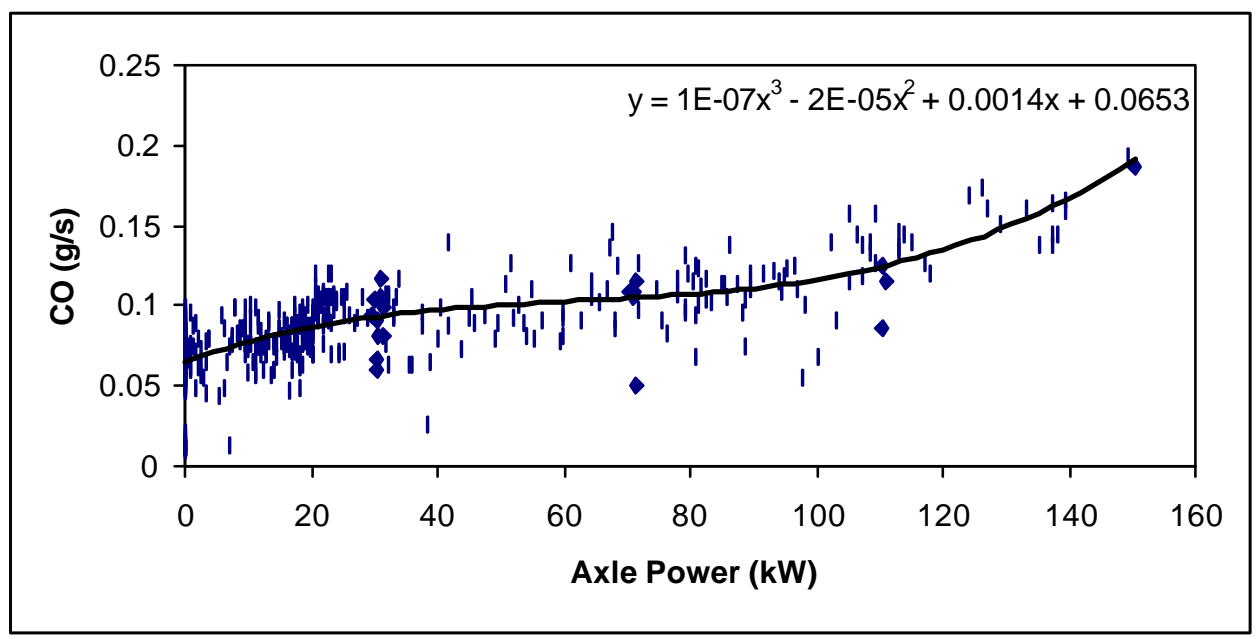

Figure 5.11 Model Developed for $\mathrm{NO}_{\mathrm{x}}$ Emissions Prediction of a Class 8 Transit Bus. The Data Points Were Obtained from an Emissions Test of the Transit Bus Described in Table 4.2 Exercised Through the Central Business District (CBD) Cycle. 


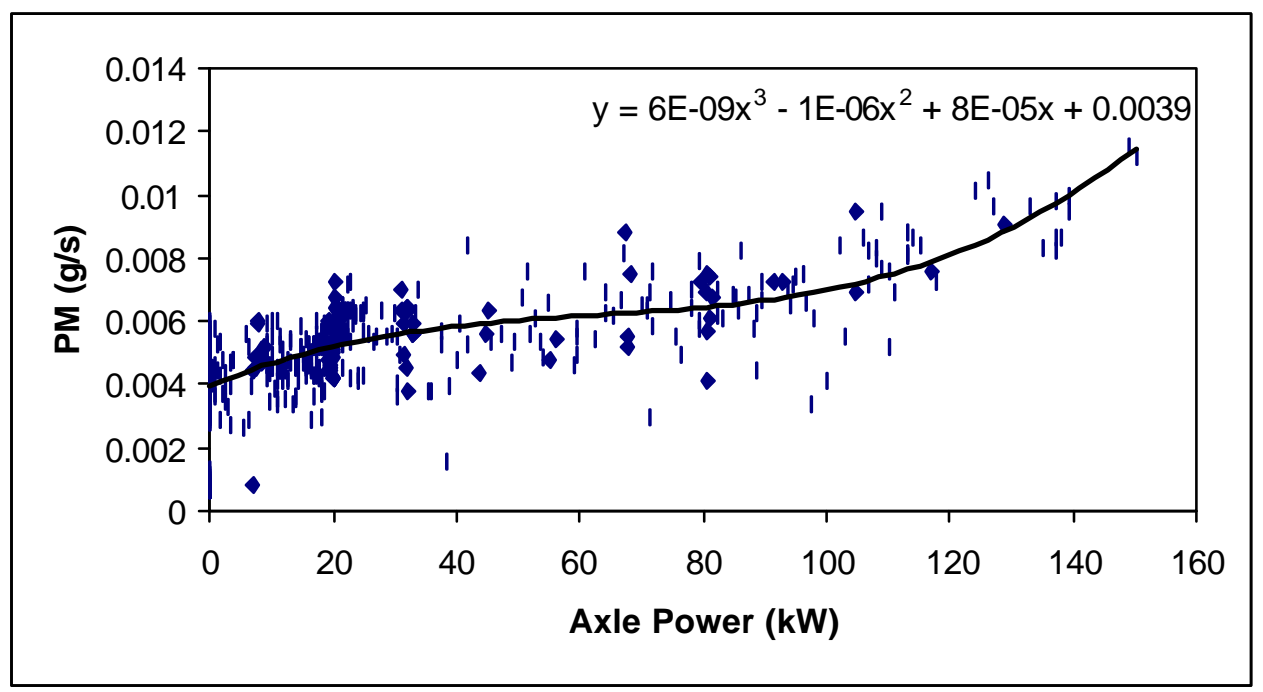

Figure 5.12 Model Developed for $\mathrm{NO}_{\mathrm{x}}$ Emissions Prediction of a Class 8 Transit Bus. The Data Points Were Obtained from an Emissions Test of the Transit Bus Described in Table 4.2 Exercised Through the Central Business District (CBD) Cycle.

These models yielded twelve Tables (5.1 to 5.12), four for each of the considered vehicles (a heavy-duty class 8 tractor truck, a medium-duty class 6 box truck and a class 8 transit bus). The mentioned tables present $\mathrm{NO}_{\mathrm{x}}, \mathrm{CO}_{2}, \mathrm{CO}$ and $\mathrm{PM}$ emissions in units of $\mathrm{g} / \mathrm{s}$ for various road grades ( $0 \%$ (flat land), $-2 \%,+2 \%,-5 \%$ and $+5 \%)$ and various steady state speeds $(5,10,15,20,25,30,35,40,45,50,55,60,65$ and $70 \mathrm{mph})$. 
Table 5.1 $\mathrm{NO}_{\mathrm{x}}$ Emissions for the Considered Heavy-Duty Class 8 Tractor Truck Described in Table 4.2 in Grams per Second.

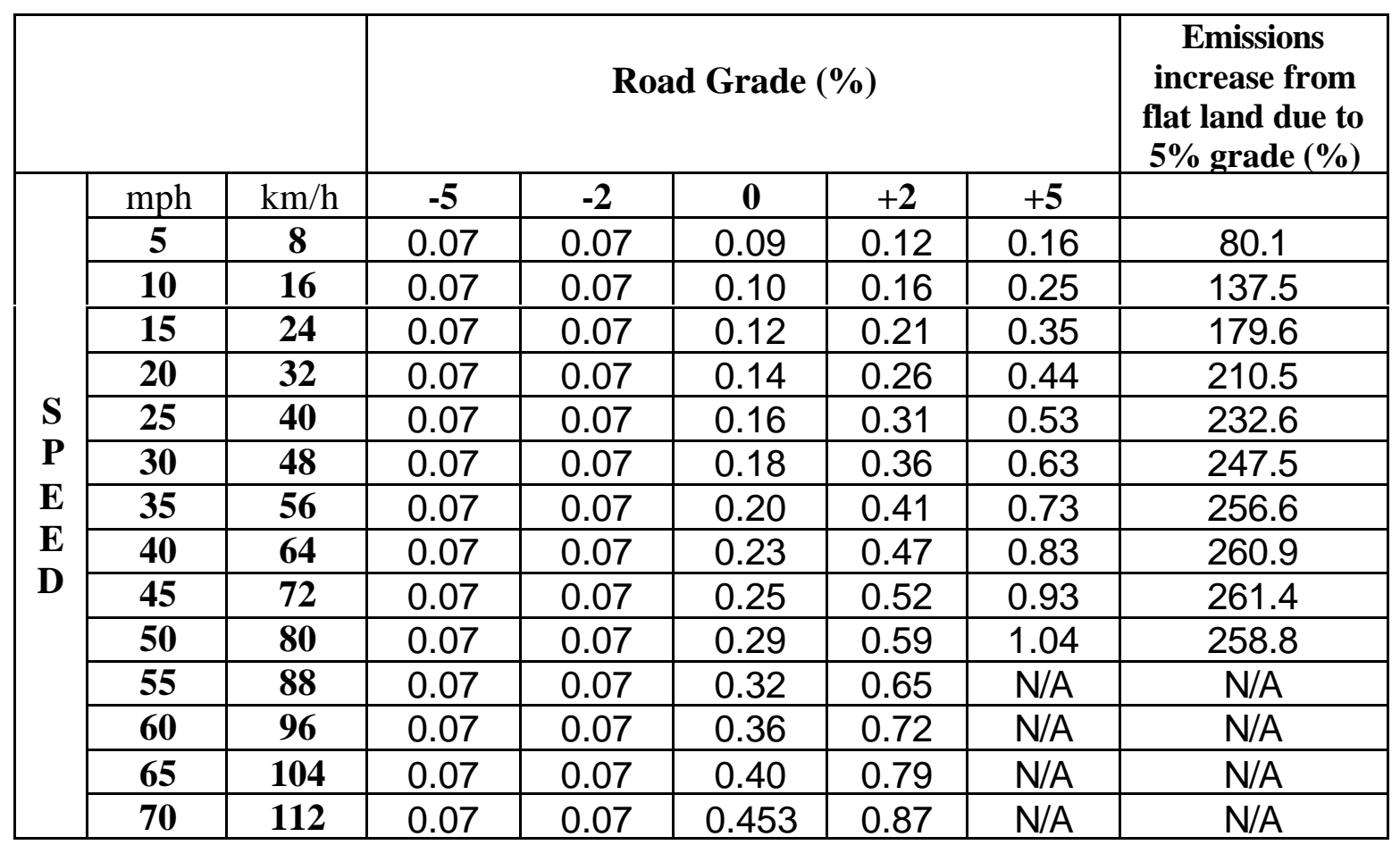

Table 5.2 $\mathrm{CO}_{2}$ Emissions for the Considered Heavy-Duty Class 8 Tractor Truck Described in Table 4.2 in Grams per Second.

\begin{tabular}{|c|c|c|c|c|c|c|c|c|}
\hline & \multicolumn{5}{|c|}{ Road Grade (\%) } & \multirow{2}{*}{$\begin{array}{c}\text { Emissions } \\
\text { increase from } \\
\text { flat land due to } \\
5 \% \text { grade }(\%)\end{array}$} \\
\hline \multirow{15}{*}{$\begin{array}{l}\text { S } \\
\mathbf{P} \\
\mathbf{E} \\
\mathbf{E} \\
\mathbf{D}\end{array}$} & $\mathrm{mph}$ & $\mathrm{km} / \mathrm{h}$ & -5 & -2 & 0 & +2 & +5 & \\
\hline & 5 & 8 & 3.97 & 3.97 & 4.73 & 6.26 & 8.56 & 80.6 \\
\hline & 10 & 16 & 3.97 & 3.97 & 5.52 & 8.58 & 13.17 & 138.4 \\
\hline & 15 & 24 & 3.97 & 3.97 & 6.34 & 10.93 & 17.81 & 180.6 \\
\hline & 20 & 32 & 3.97 & 3.97 & 7.22 & 13.34 & 22.52 & 211.5 \\
\hline & 25 & 40 & 3.97 & 3.97 & 8.18 & 15.83 & 27.30 & 233.6 \\
\hline & 30 & 48 & 3.97 & 3.97 & 9.23 & 18.40 & 32.17 & 248.4 \\
\hline & 35 & 56 & 3.97 & 3.97 & 10.39 & 21.09 & 37.15 & 257.5 \\
\hline & 40 & 64 & 3.97 & 3.97 & 11.68 & 23.92 & 42.27 & 261.7 \\
\hline & 45 & 72 & 3.97 & 3.97 & 13.12 & 26.89 & 47.53 & 262.1 \\
\hline & 50 & 80 & 3.97 & 3.97 & 14.73 & 30.03 & 52.97 & 259.4 \\
\hline & 55 & 88 & 3.97 & 3.97 & 16.53 & 33.35 & $\mathrm{~N} / \mathrm{A}$ & $\mathrm{N} / \mathrm{A}$ \\
\hline & 60 & 96 & 3.97 & 3.97 & 18.53 & 36.89 & $\mathrm{~N} / \mathrm{A}$ & $\mathrm{N} / \mathrm{A}$ \\
\hline & 65 & 104 & 3.97 & 3.97 & 20.76 & 40.64 & $\mathrm{~N} / \mathrm{A}$ & $\mathrm{N} / \mathrm{A}$ \\
\hline & 70 & 112 & 3.97 & 3.97 & 23.23 & 44.64 & $\mathrm{~N} / \mathrm{A}$ & $\mathrm{N} / \mathrm{A}$ \\
\hline
\end{tabular}


Table 5.3 CO Emissions for the Considered Heavy-Duty Class 8 Tractor Truck Described in Table 4.2 in Grams per Second.

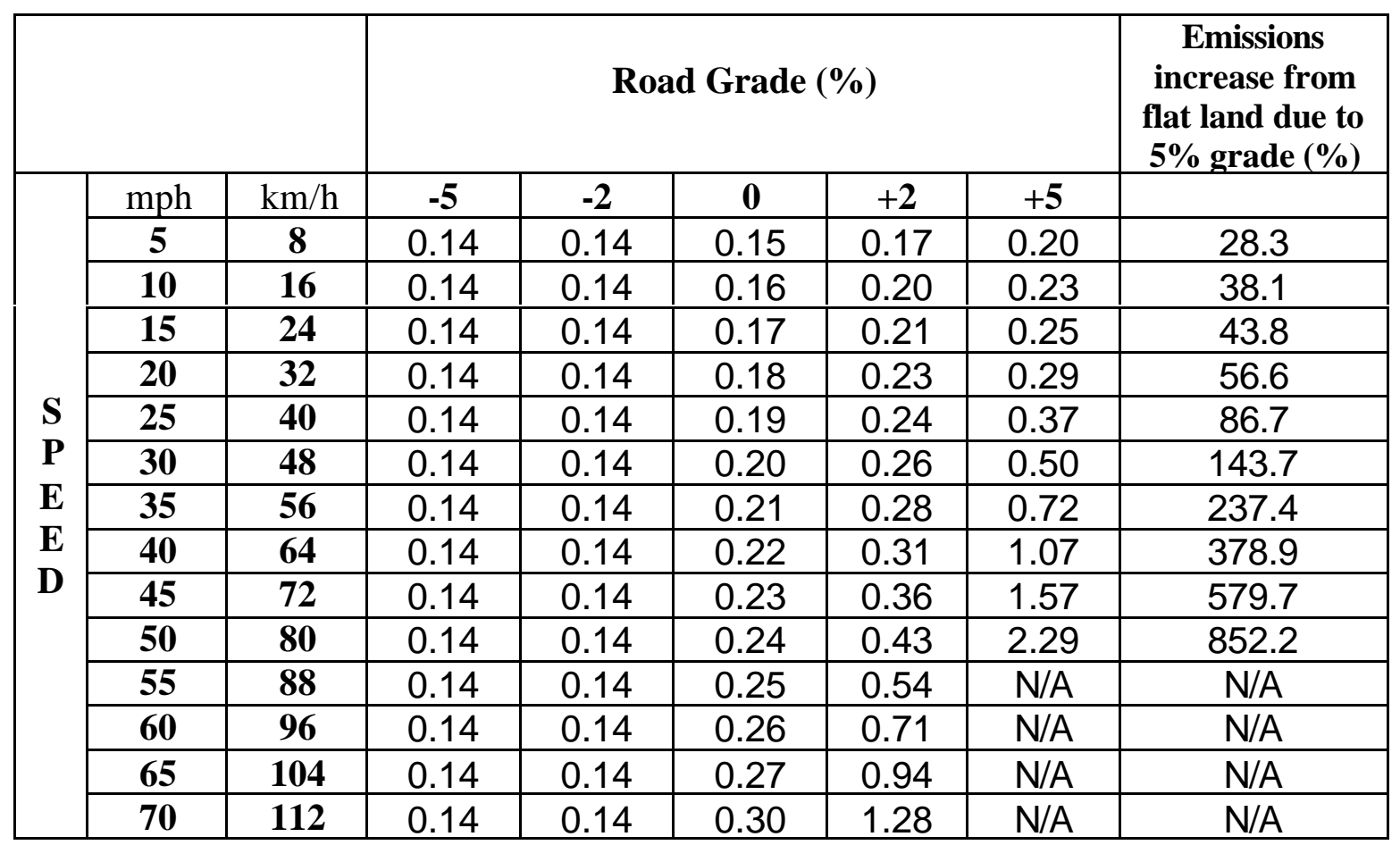

Table 5.4 PM Emissions for the Considered Heavy-Duty Class 8 Tractor Truck Described in Table 4.2 in Milligrams per Second.

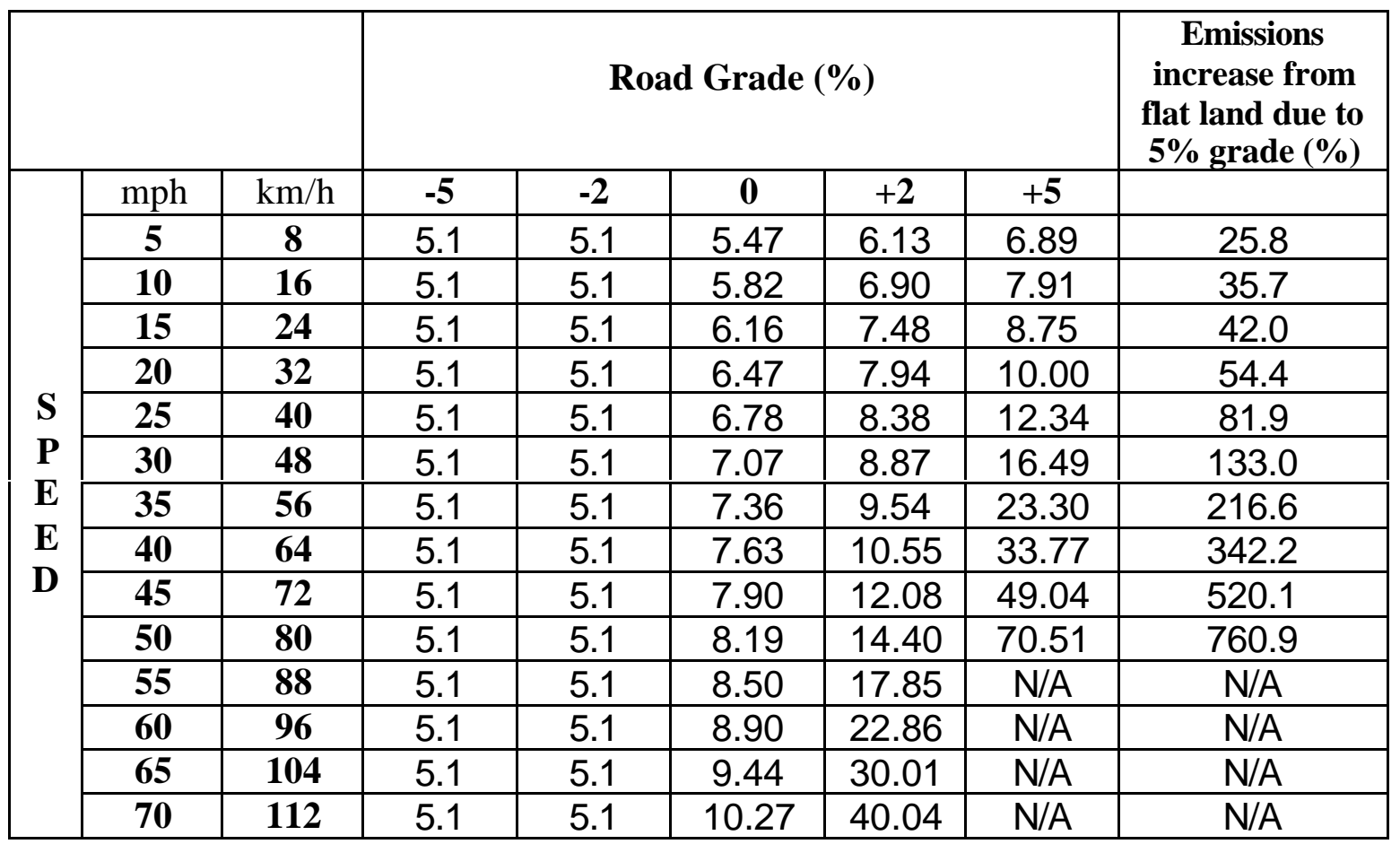


Table 5.5 $\mathrm{NO}_{\mathrm{x}}$ Emissions for the Considered Medium-Duty Class 6 Box Truck Described in Table 4.2 in Grams per Second.

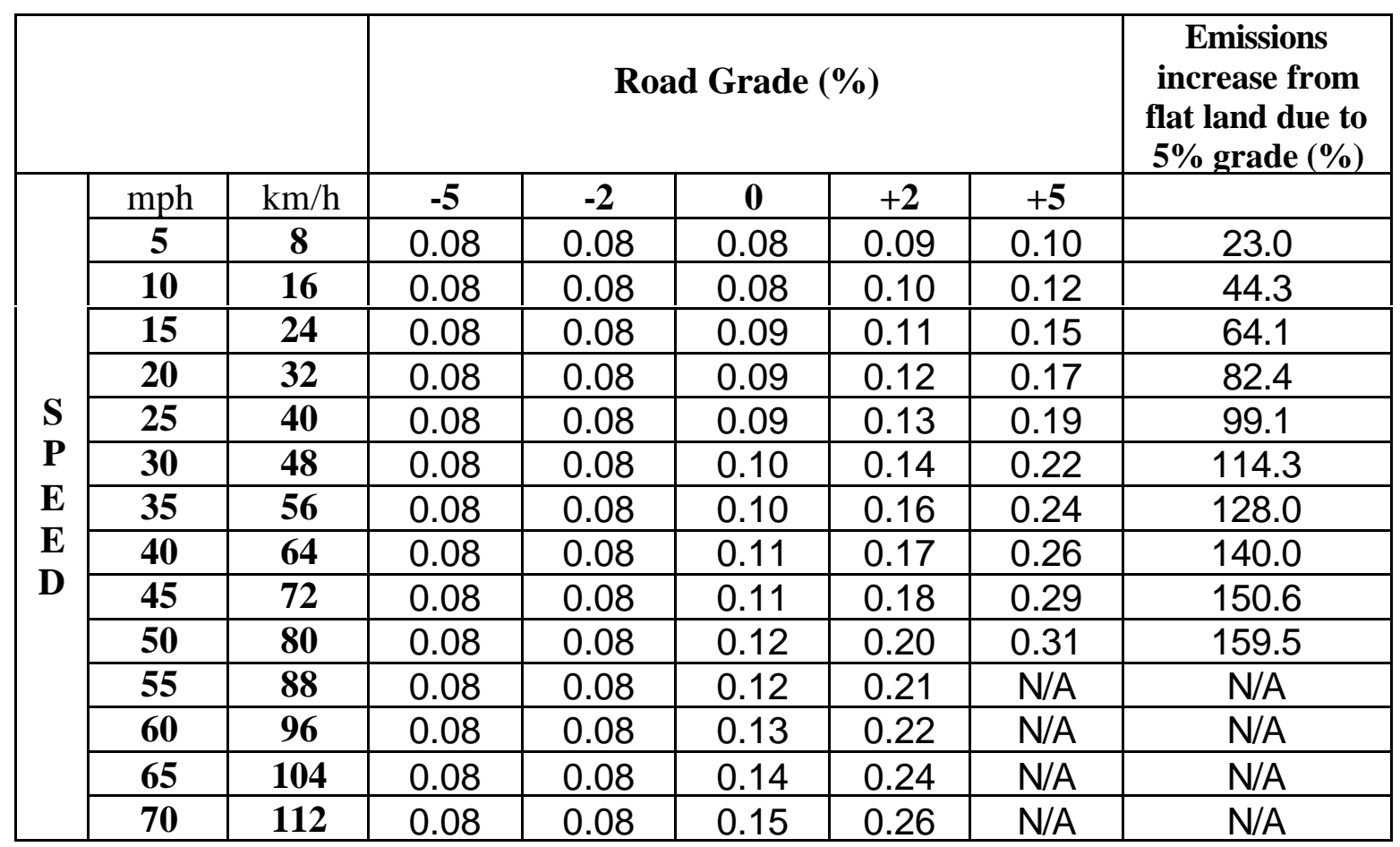

Table 5.6 $\mathrm{CO}_{2}$ Emissions for the Considered Medium-Duty Class 6 Box Truck Described in Table 4.2 in Grams per Second.

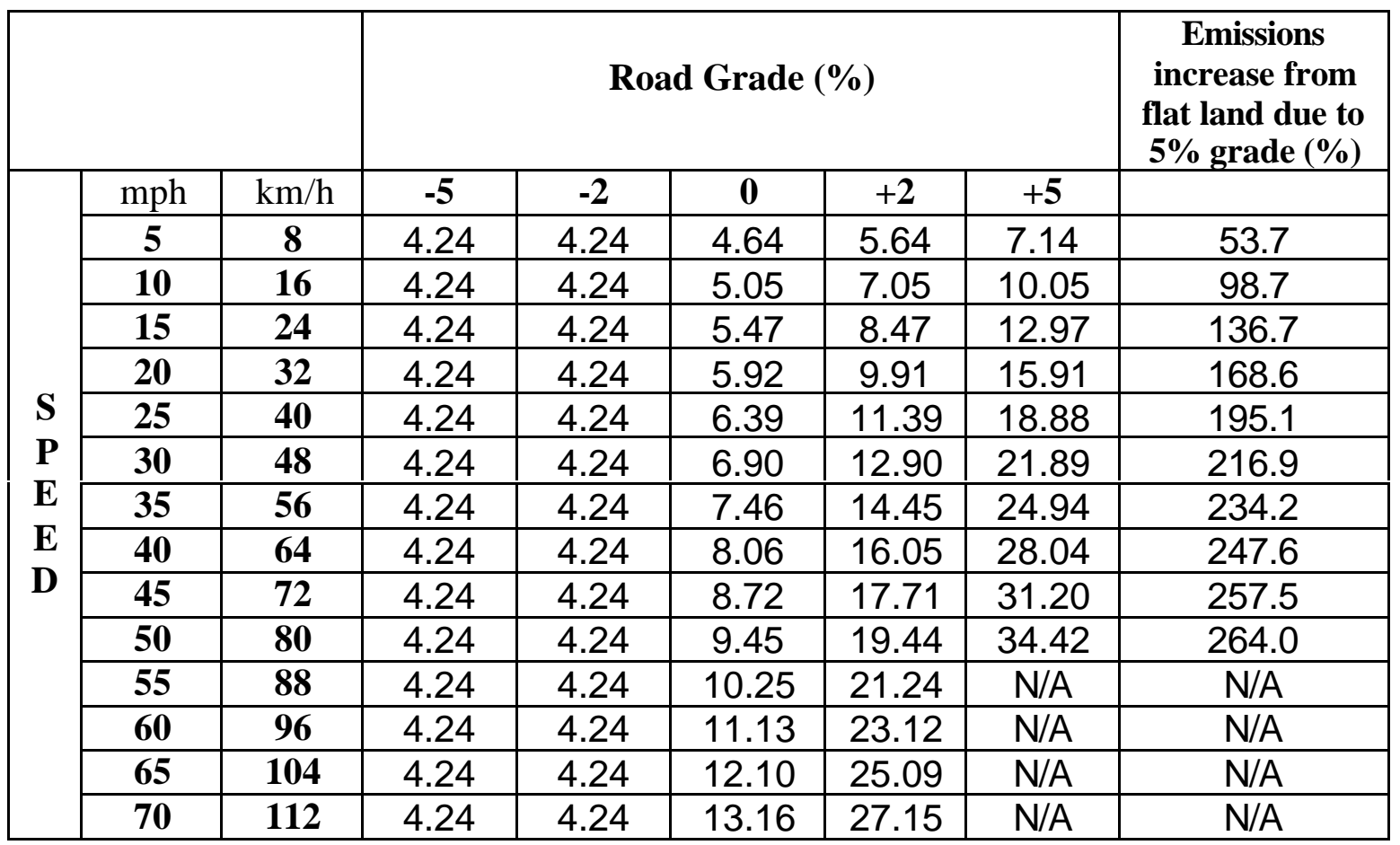


Table 5.7 CO Emissions for the Considered Medium-Duty Class 6 Box Truck Described in Table 4.2 in Grams per Second.

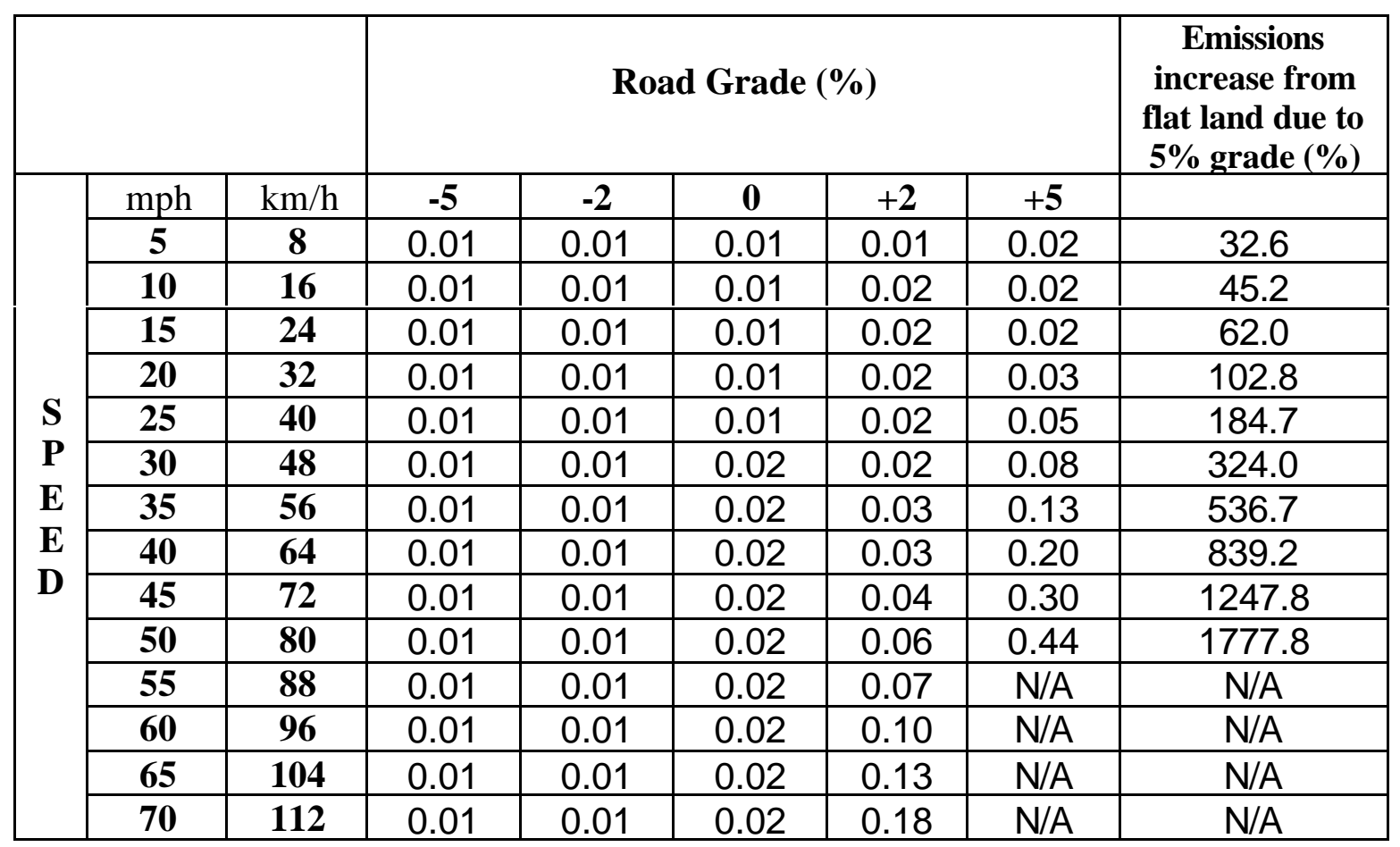

Table 5.8 PM Emissions for the Considered Medium-Duty Class 6 Box Truck Described in Table 4.2 in Milligrams per Second.

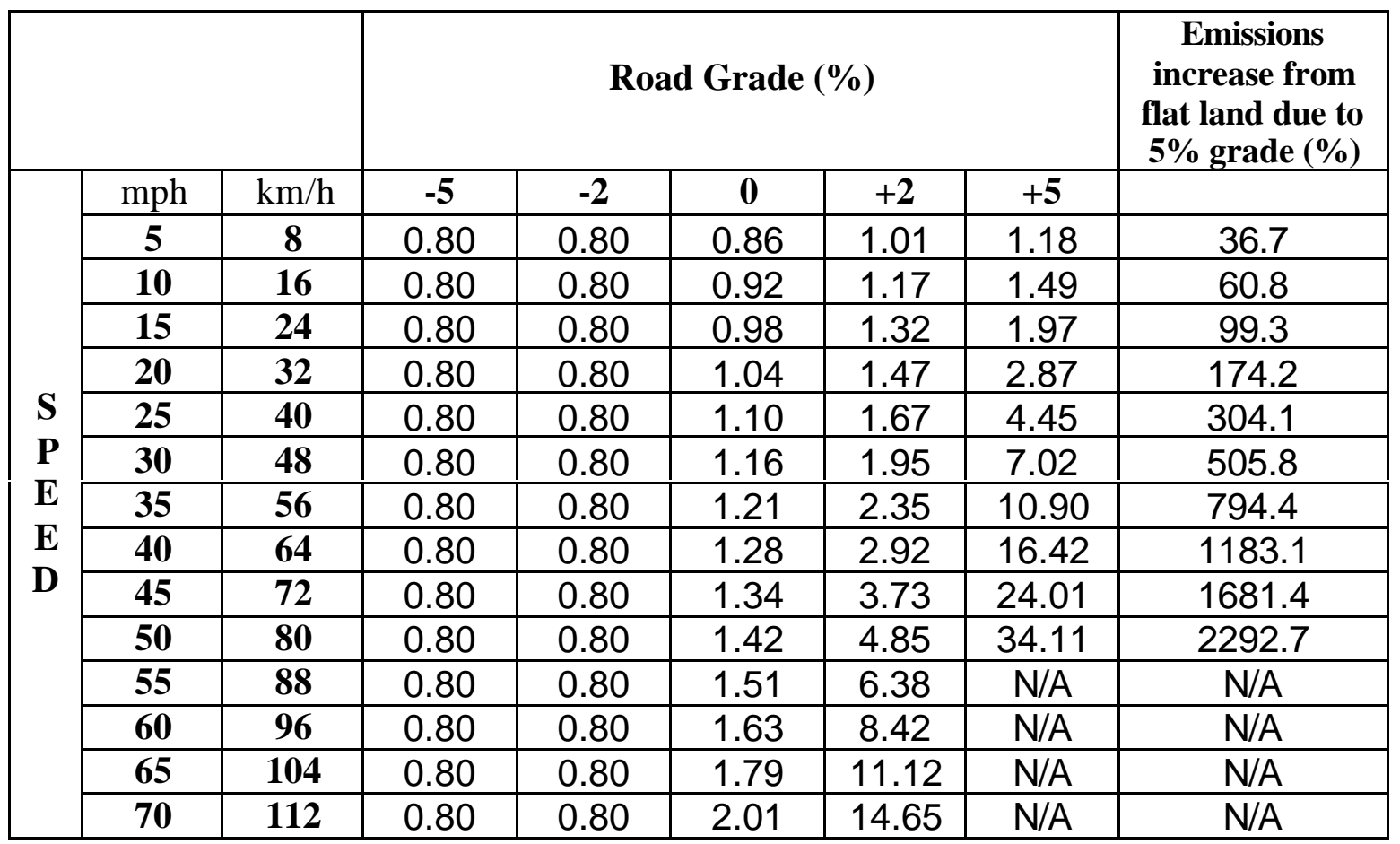


Table 5.9 $\mathrm{NO}_{\mathrm{x}}$ Emissions for the Considered Class 8 Transit Bus Described in Table 4.2 in Grams per Second.

\begin{tabular}{|c|c|c|c|c|c|c|c|c|}
\hline & \multicolumn{5}{|c|}{ Road Grade (\%) } & \multirow{2}{*}{$\begin{array}{c}\text { Emissions } \\
\text { increase from } \\
\text { flat land due to } \\
5 \% \text { grade }(\%)\end{array}$} \\
\hline \multirow{15}{*}{$\begin{array}{l}\text { S } \\
\mathbf{P} \\
\mathbf{E} \\
\mathbf{E} \\
\mathbf{D}\end{array}$} & $\mathrm{mph}$ & $\mathrm{km} / \mathrm{h}$ & -5 & -2 & $\mathbf{0}$ & +2 & +5 & \\
\hline & 5 & 8 & 0.20 & 0.20 & 0.21 & 0.22 & 0.25 & 19.0 \\
\hline & 10 & 16 & 0.20 & 0.20 & 0.22 & 0.25 & 0.29 & 31.8 \\
\hline & 15 & 24 & 0.20 & 0.20 & 0.22 & 0.27 & 0.34 & 54.5 \\
\hline & 20 & 32 & 0.20 & 0.20 & 0.23 & 0.29 & 0.38 & 65.2 \\
\hline & 25 & 40 & 0.20 & 0.20 & 0.24 & 0.32 & 0.43 & 79.1 \\
\hline & 30 & 48 & 0.20 & 0.20 & 0.26 & 0.35 & 0.48 & 84.6 \\
\hline & 35 & 56 & 0.20 & 0.20 & 0.27 & 0.38 & 0.53 & 96.3 \\
\hline & 40 & 64 & 0.20 & 0.20 & 0.29 & 0.41 & 0.59 & 103.4 \\
\hline & 45 & 72 & 0.20 & 0.20 & 0.31 & 0.45 & 0.65 & 109.6 \\
\hline & 50 & 80 & 0.20 & 0.20 & 0.34 & 0.49 & 0.71 & 108.8 \\
\hline & 55 & 88 & 0.20 & 0.20 & 0.36 & 0.53 & $\mathrm{~N} / \mathrm{A}$ & $\mathrm{N} / \mathrm{A}$ \\
\hline & 60 & 96 & 0.20 & 0.22 & 0.40 & 0.58 & $\mathrm{~N} / \mathrm{A}$ & $\mathrm{N} / \mathrm{A}$ \\
\hline & 65 & 104 & 0.20 & 0.24 & 0.43 & 0.63 & $\mathrm{~N} / \mathrm{A}$ & $\mathrm{N} / \mathrm{A}$ \\
\hline & 70 & 112 & 0.20 & 0.27 & 0.48 & 0.69 & $\mathrm{~N} / \mathrm{A}$ & $\mathrm{N} / \mathrm{A}$ \\
\hline
\end{tabular}

Table 5.10 $\mathrm{CO}_{2}$ Emissions for the Considered Class 8 Transit Bus Described in Table 4.2 in Grams per Second.

\begin{tabular}{|c|c|c|c|c|c|c|c|c|}
\hline & \multicolumn{5}{|c|}{ Road Grade (\%) } & \multirow{2}{*}{$\begin{array}{c}\text { Emissions } \\
\text { increase from } \\
\text { flat land due to } \\
5 \% \text { grade }(\%)\end{array}$} \\
\hline \multirow{15}{*}{$\begin{array}{l}\text { S } \\
\mathbf{P} \\
\mathbf{E} \\
\text { E } \\
\mathbf{D}\end{array}$} & $\mathrm{mph}$ & $\mathrm{km} / \mathrm{h}$ & -5 & -2 & $\mathbf{0}$ & +2 & +5 & \\
\hline & 5 & 8 & 3.17 & 3.28 & 3.28 & 3.52 & 3.87 & 17.9 \\
\hline & 10 & 16 & 3.17 & 3.40 & 3.40 & 3.87 & 4.56 & 34.1 \\
\hline & 15 & 24 & 3.17 & 3.53 & 3.53 & 4.23 & 5.27 & 49.2 \\
\hline & 20 & 32 & 3.17 & 3.67 & 3.67 & 4.61 & 6.00 & 63.4 \\
\hline & 25 & 40 & 3.17 & 3.84 & 3.84 & 5.01 & 6.76 & 76.0 \\
\hline & 30 & 48 & 3.17 & 4.05 & 4.05 & 5.44 & 7.54 & 86.1 \\
\hline & 35 & 56 & 3.17 & 4.28 & 4.28 & 5.91 & 8.36 & 95.3 \\
\hline & 40 & 64 & 3.17 & 4.56 & 4.56 & 6.43 & 9.22 & 102.1 \\
\hline & 45 & 72 & 3.17 & 4.89 & 4.89 & 6.99 & 10.1 & 106.5 \\
\hline & 50 & 80 & 3.17 & 5.27 & 5.27 & 7.60 & 11.0 & 108.7 \\
\hline & 55 & 88 & 3.17 & 5.71 & 5.71 & 8.28 & $\mathrm{~N} / \mathrm{A}$ & $\mathrm{N} / \mathrm{A}$ \\
\hline & 60 & 96 & 3.17 & 6.22 & 6.22 & 9.02 & $\mathrm{~N} / \mathrm{A}$ & $\mathrm{N} / \mathrm{A}$ \\
\hline & 65 & 104 & 3.17 & 6.80 & 6.80 & 9.83 & $\mathrm{~N} / \mathrm{A}$ & $\mathrm{N} / \mathrm{A}$ \\
\hline & 70 & 112 & 3.17 & 7.46 & 7.46 & 10.7 & $\mathrm{~N} / \mathrm{A}$ & $\mathrm{N} / \mathrm{A}$ \\
\hline
\end{tabular}


Table 5.11 CO Emissions for the Considered Class 8 Transit Bus Described in Table 4.2 in Grams per Second.

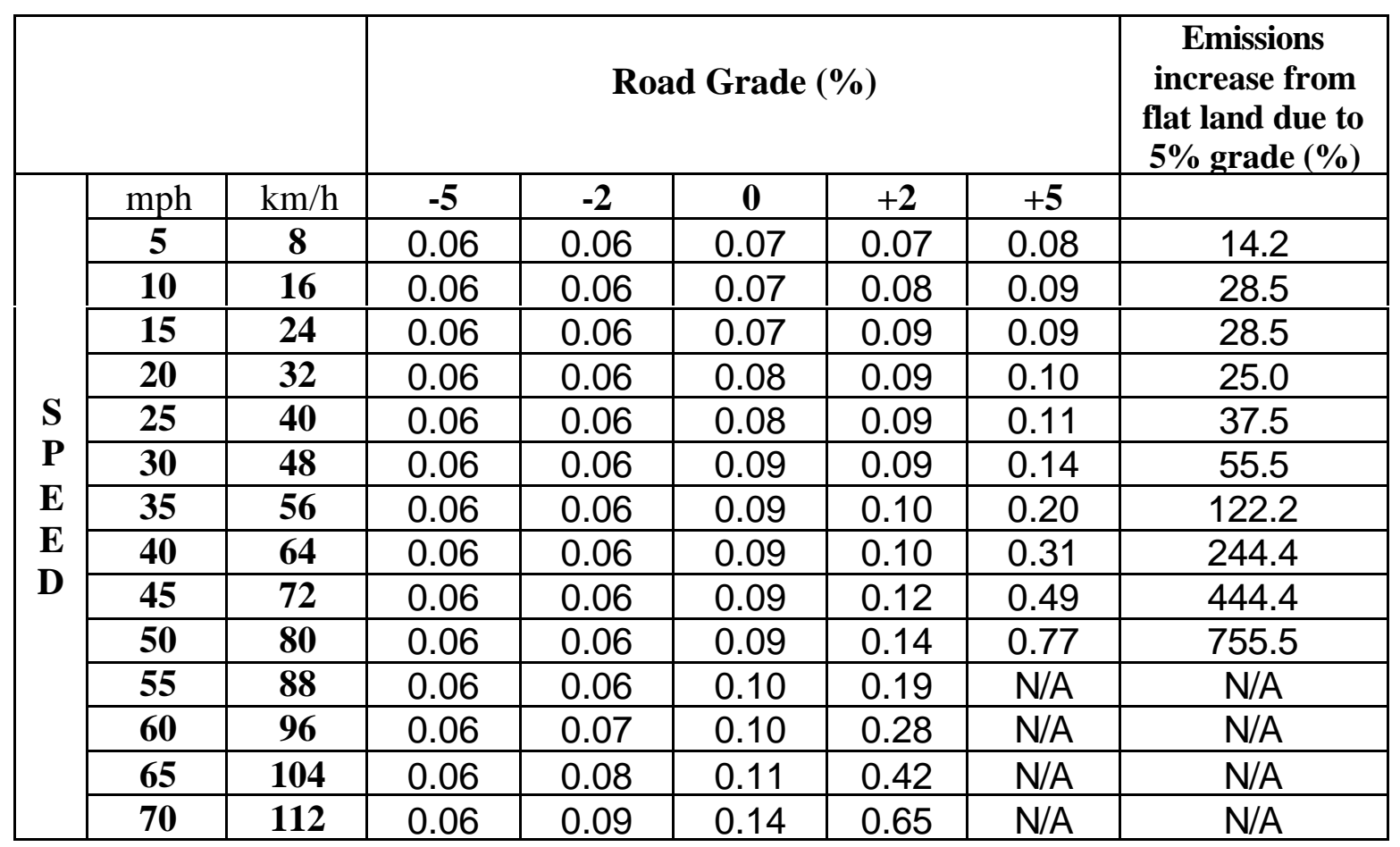

Table 5.12 PM Emissions for the Considered Class 8 Transit Bus Described in Table 4.2 in Milligrams per Second.

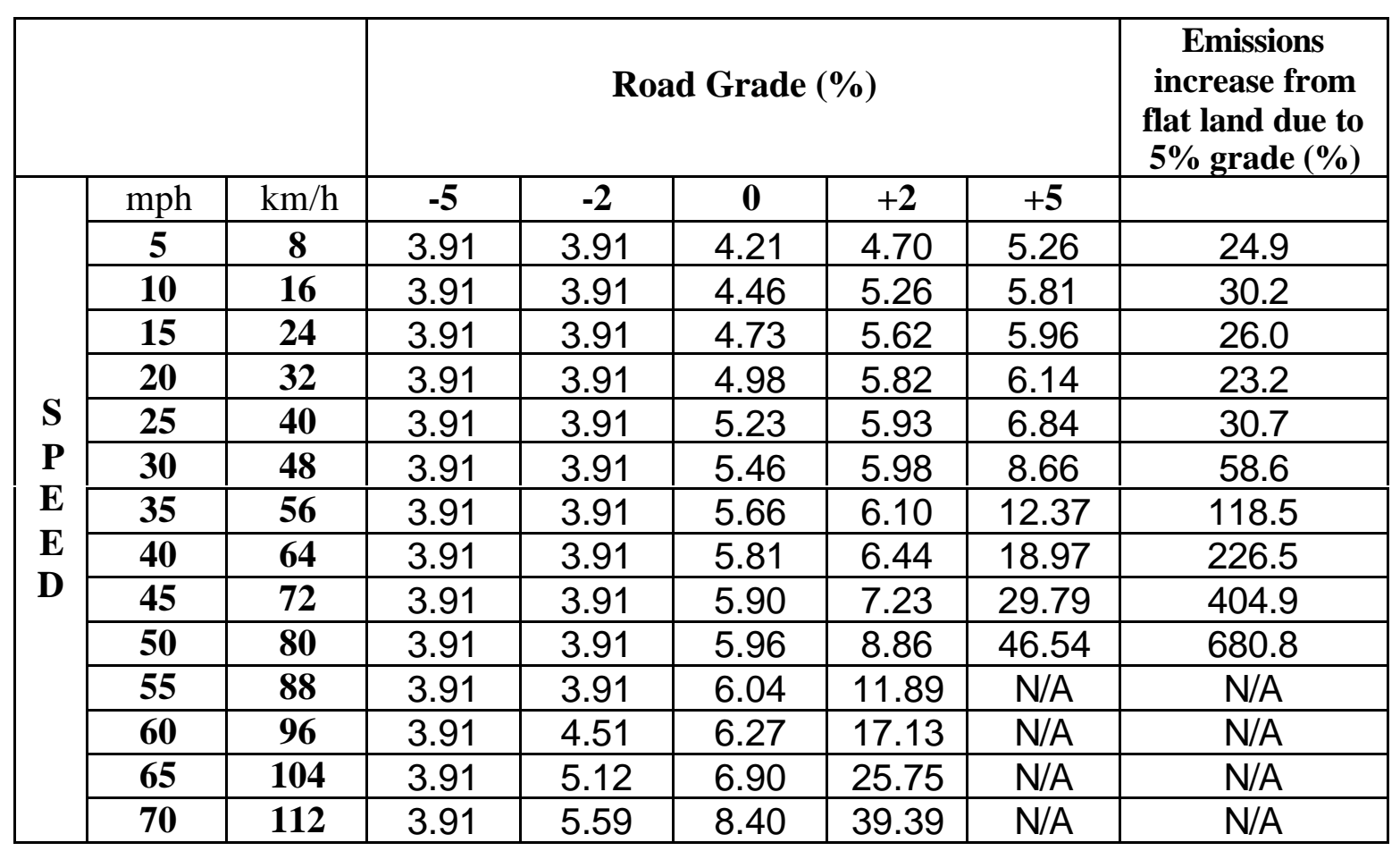


The values of $\mathrm{NO}_{\mathrm{x}}, \mathrm{CO}_{2}, \mathrm{CO}$ and $\mathrm{PM}$ emissions in $\mathrm{g} / \mathrm{sec}$ for the road with a $-5 \%$ grade for all the considered vehicles and also for the road with a $-2 \%$ grade for the tractor truck and box truck, represent the engine emissions output for the case where there is no flywheel load. These emissions arise due to auxiliary and "hotel" loads and due to engine frictional or pumping losses. In some cases, during downhill operation, the drivetrain will apply reverse (motoring) torque to the engine, and if fueling is then reduced, $\mathrm{NO}_{\mathrm{x}}$ emissions may fall in value.

The emissions prediction was made based on the power at rear wheels, which is limited to an estimated maximum $75 \%$ of the engine power due to transmission efficiency and auxiliary loads. Therefore there was no way to generate data for the vehicles traveling with $55,60,65$ or $70 \mathrm{mph}$ over a road that has a $+5 \%$ grade. For these cases "not available" (N/A) appears in Tables 5.1 to 5.12. 


\section{Sinusoidal Model}

In the real world many roads are not flat and a more accurate emissions prediction can be made by considering the roads to have a sinusoidal varying grade. Consider a hilly terrain that has a maximum grade of $+4 \%$ and a minimum of $-4 \%$.

The vehicles used for this simulation (a heavy-duty class 8 tractor truck, a medium-duty class 6 box truck and a class 8 transit bus) travel one period of a sinusoid road described in Figure 6.1. The vehicles start from one point of the road that has the maximum grade going through the highest point of the road where begin to descend to the lowest point of the road and finishes in the next point with a maximum grade. The results of this simulation are presented in Figures 6.2 to 6.13, for $\mathrm{NO}_{\mathrm{x}}, \mathrm{CO}_{2}, \mathrm{CO}$ and $\mathrm{PM}$ emissions in $\mathrm{g} / \mathrm{s}$ for the period of a sinusoidal road that measures 1.78 kilometers $(1.1$ miles). The considered vehicles have a constant speed of 20 meters per second (45 mph). As can be seen in Figures 6.2 to 6.13 the emissions do not go to zero, because of the models used (Figures 4.1 to 4.12 ). In reality on a very steep downgrade fuelling could be cut to zero and emissions may cease. 


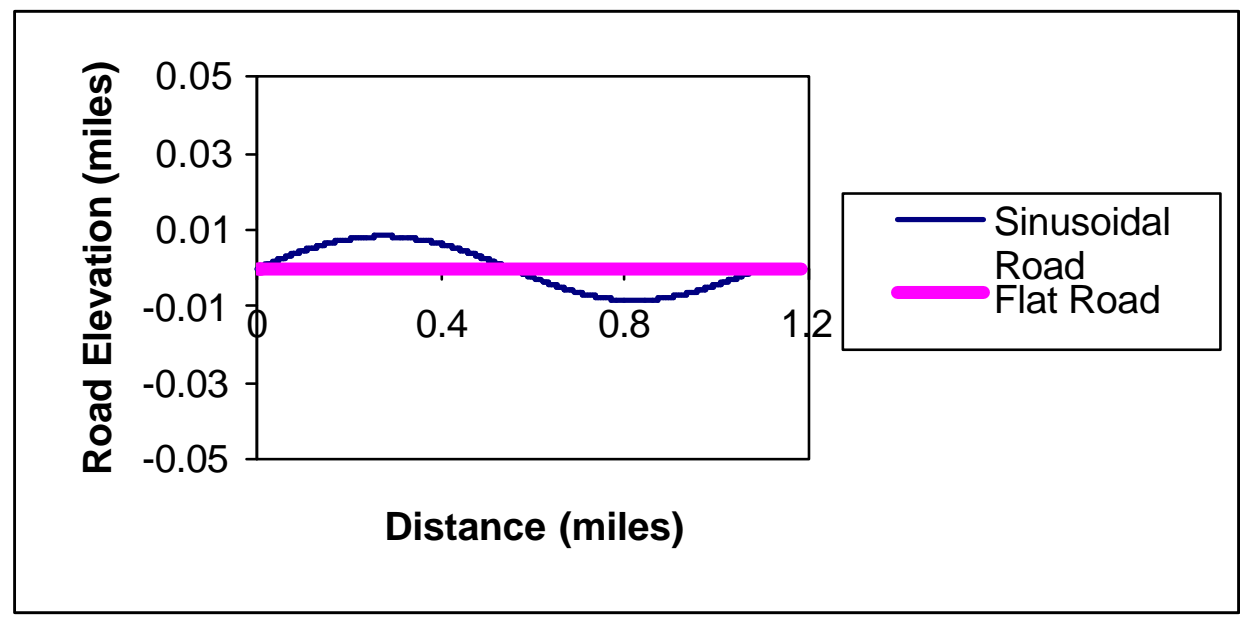

Figure 6.1 Shapes of a Flat Road and the Considered Sinusoidal Road Model with a Maximum Road Grade of $+4 \%$.

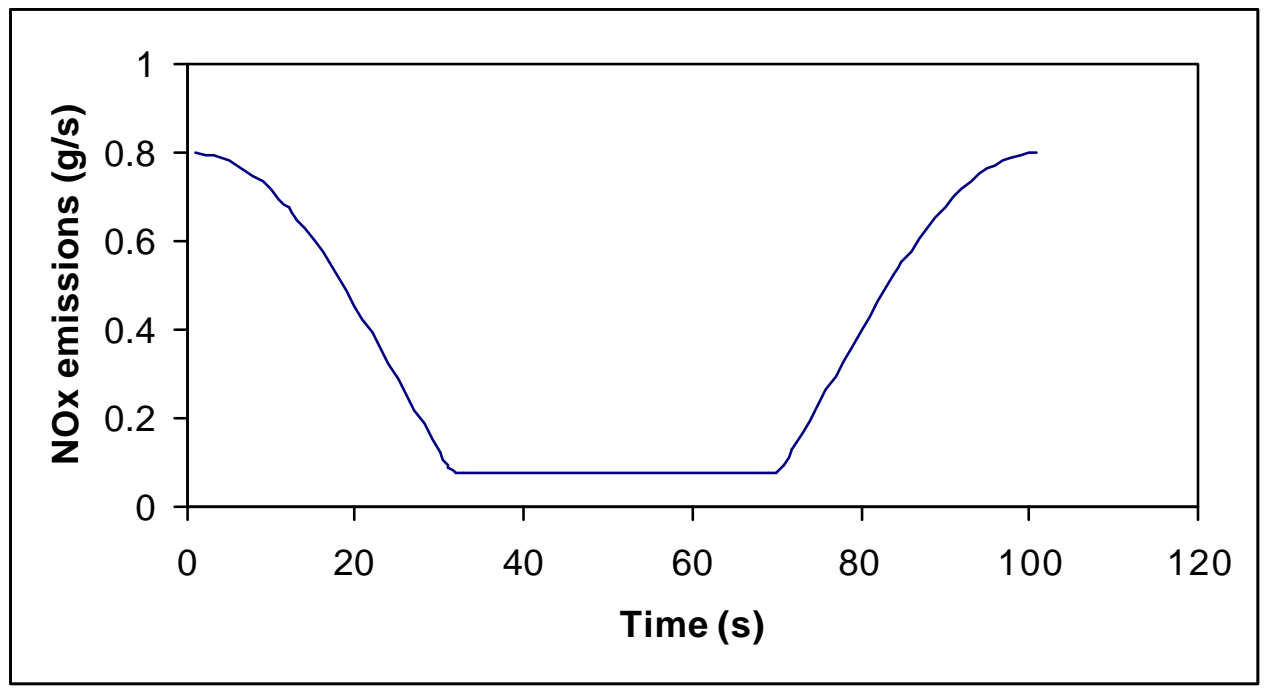

Figure 6.2 $\mathrm{NO}_{\mathrm{x}}$ Emissions for the Considered Class 8 Heavy-Duty Tractor Truck over a Sinusoid Road with a Maximum Road Grade of $+4 \%$. The Model Uses the Emissions Equation Shown in Figure 5.1. 


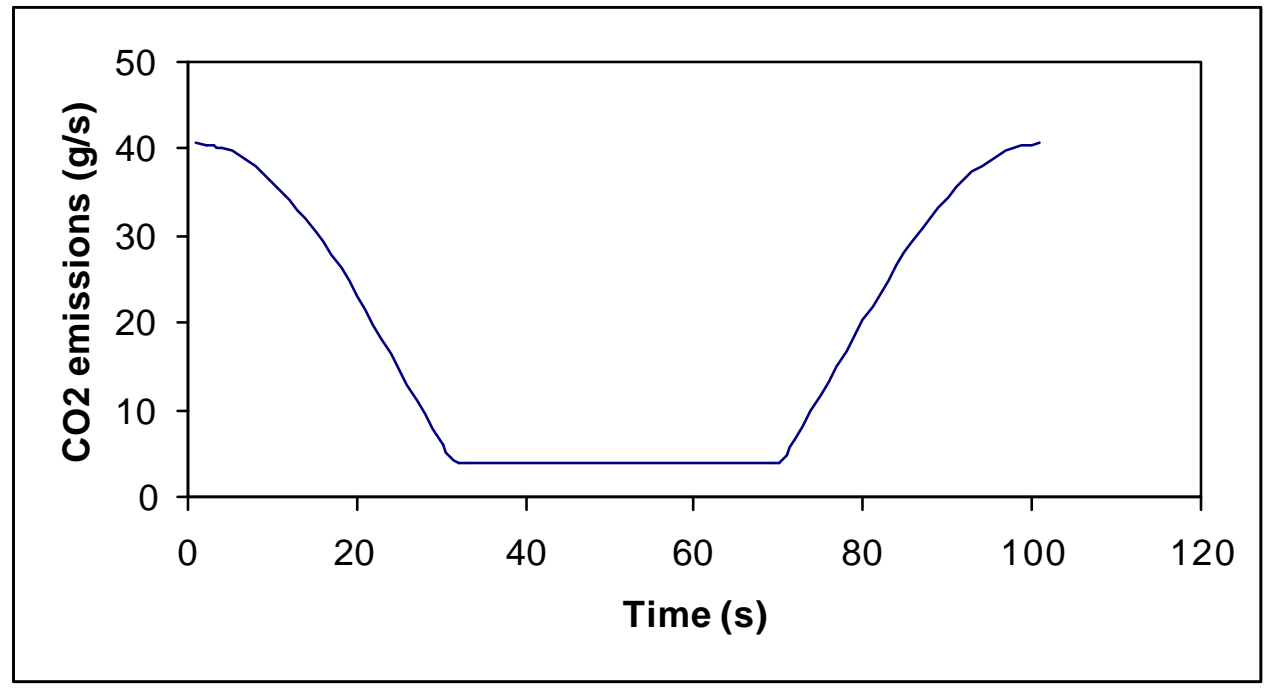

Figure 6.3 $\mathrm{CO}_{2}$ Emissions for the Considered Class 8 Heavy-Duty Tractor Truck over a Sinusoid Road with a Maximum Road Grade of $+4 \%$. The Model Uses the Emissions Equation Shown in Figure 5.2.

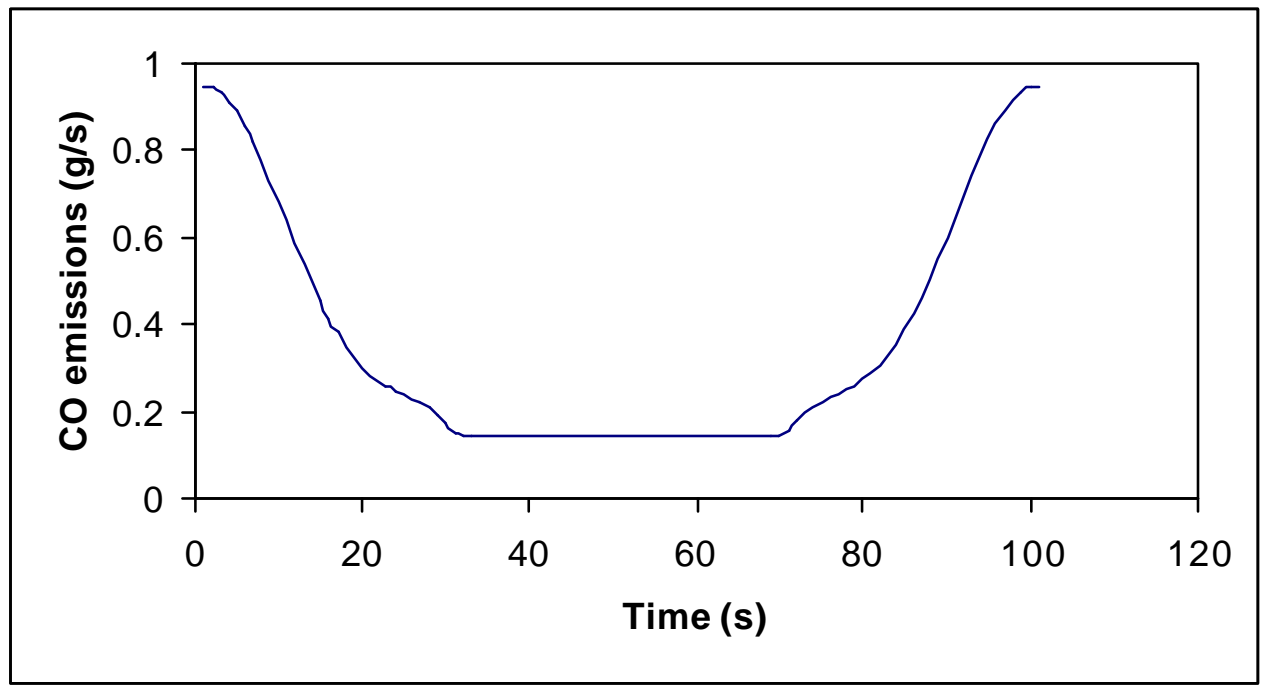

Figure 6.4 CO Emissions for the Considered Class 8 Heavy-Duty Tractor Truck over a Sinusoid Road with a Maximum Road Grade of $+4 \%$. The Model Uses the Emissions Equation Shown in Figure 5.3. 


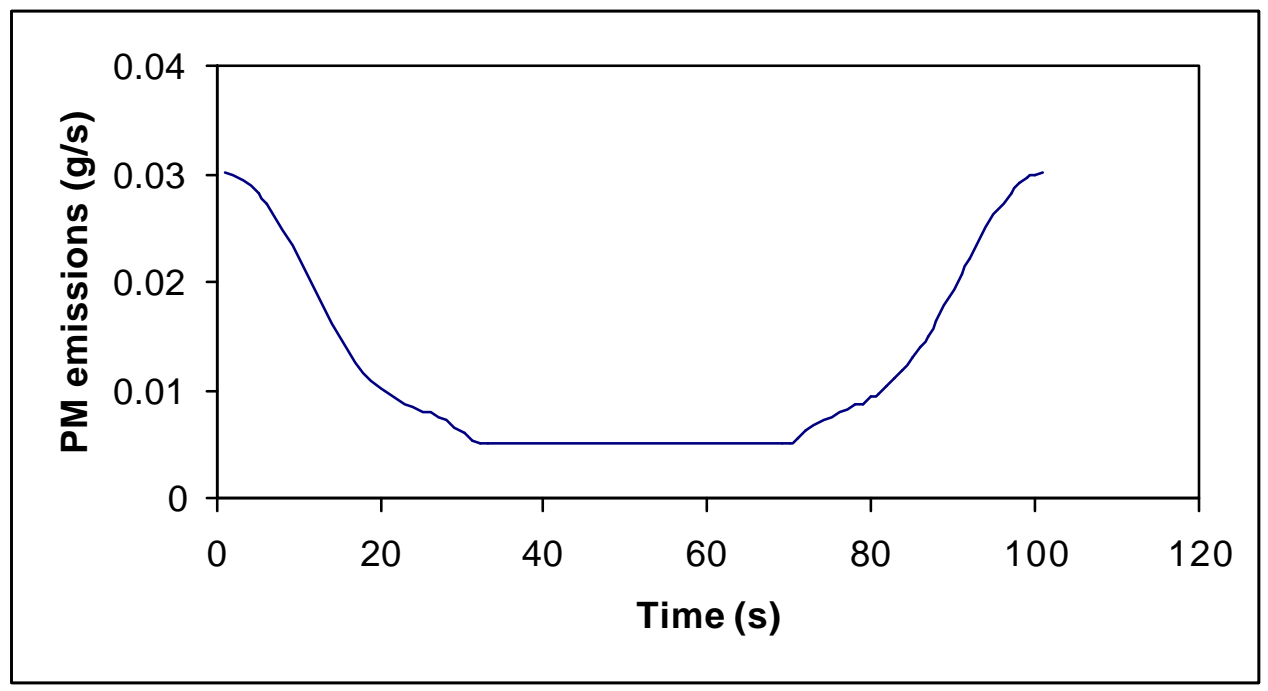

Figure 6.5 PM Emissions for the Considered Class 8 Heavy-Duty Tractor Truck over a Sinusoid Road with a Maximum Road Grade of $+4 \%$. The Model Uses the Emissions Equation Shown in Figure 5.4.

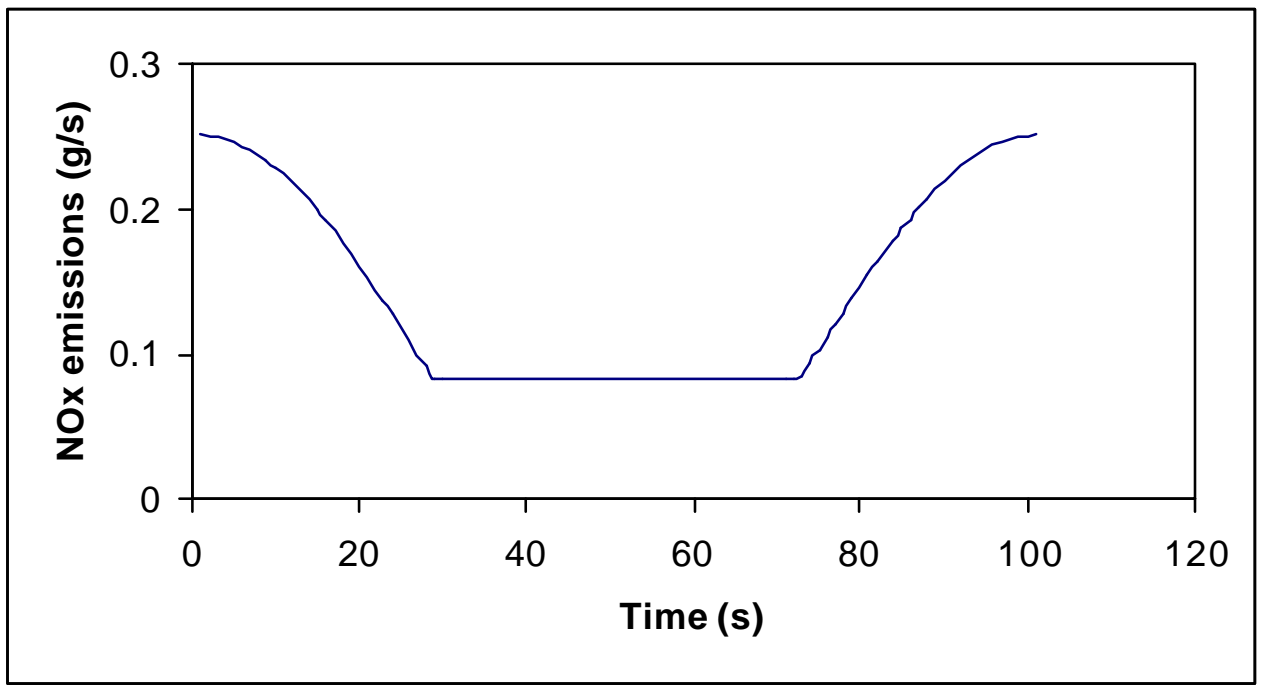

Figure 6.6 $\mathrm{NO}_{\mathrm{x}}$ Emissions for the Considered Class 6 Medium-Duty Box Truck over a Sinusoid Road with a Maximum Road Grade of $+4 \%$. The Model Uses the Emissions Equation Shown in Figure 5.5. 


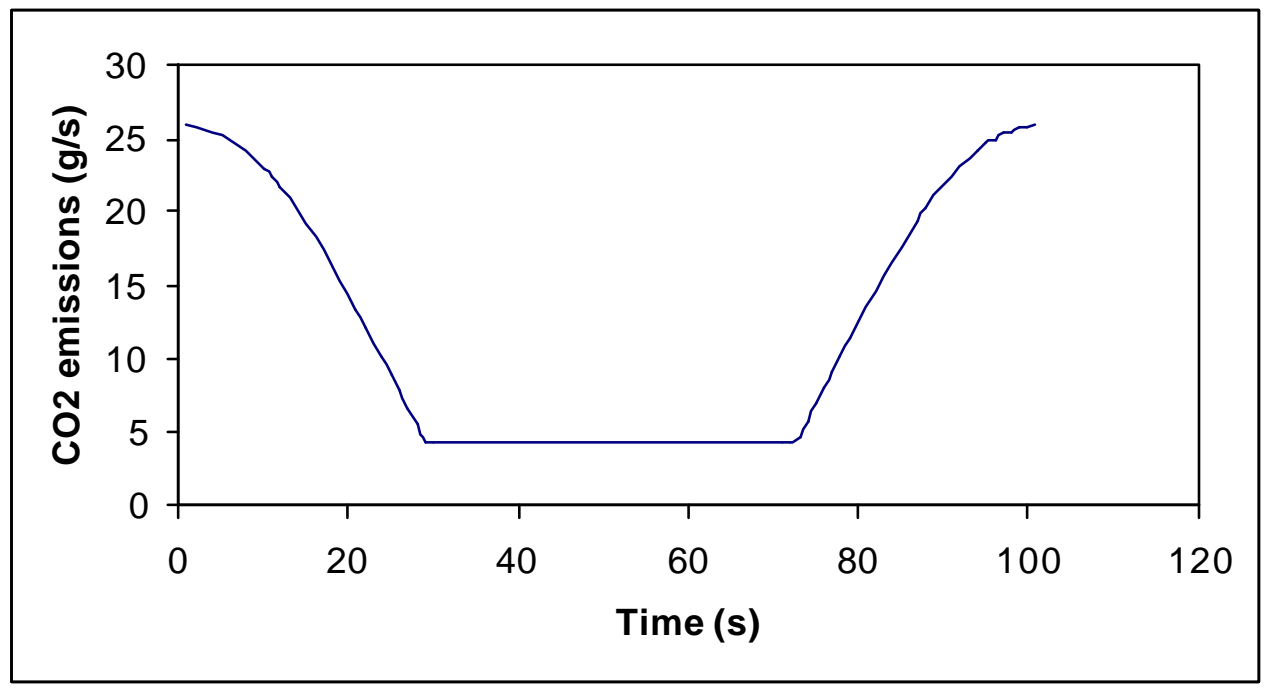

Figure 6.7 $\mathrm{CO}_{2}$ Emissions for the Considered Class 6 Medium-Duty Box Truck over a Sinusoid Road with a Maximum Road Grade of $+4 \%$. The Model Uses the Emissions Equation Shown in Figure 5.6.

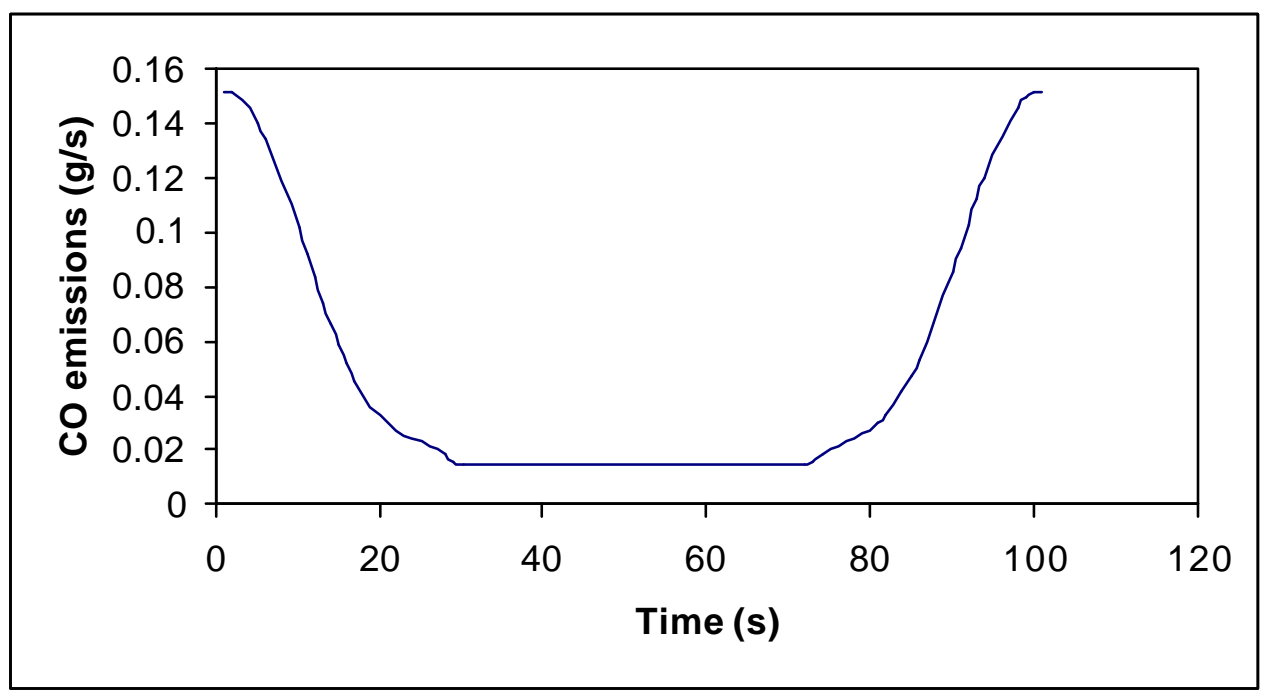

Figure 6.8 CO Emissions for the Considered Class 6 Medium-Duty Box Truck over a Sinusoid Road with a Maximum Road Grade of $+4 \%$. The Model Uses the Emissions Equation Shown in Figure 5.7. 


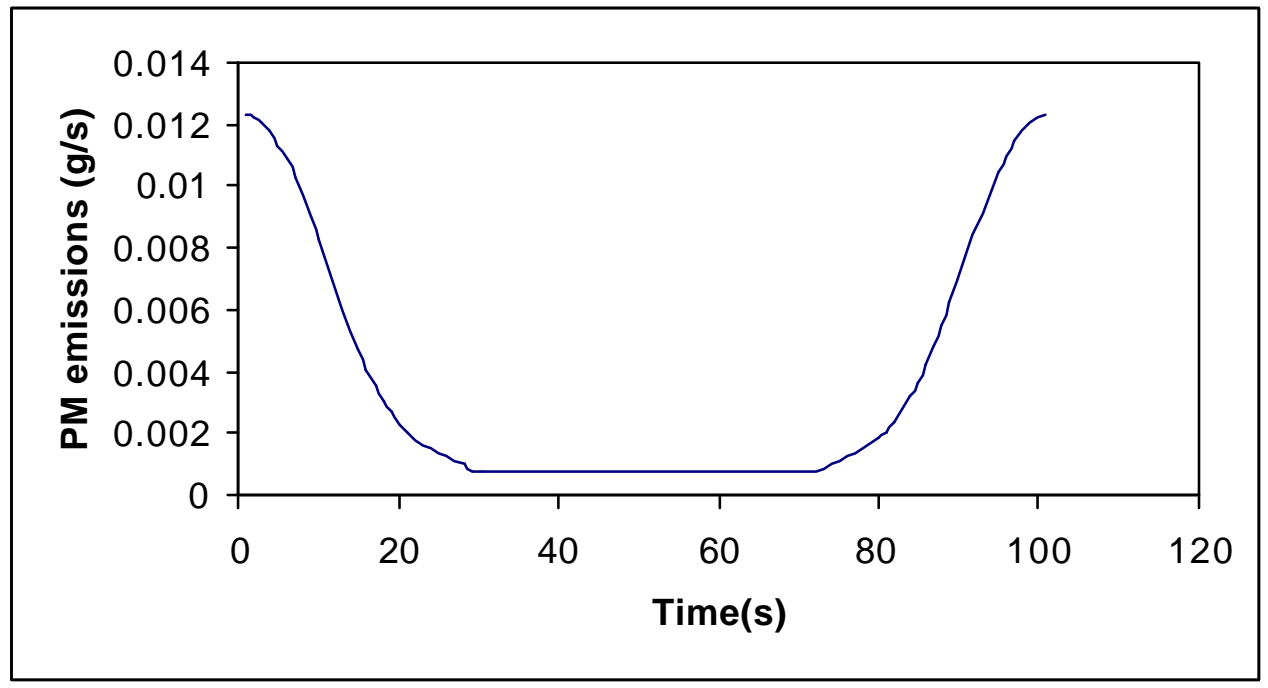

Figure 6.9 PM Emissions for the Considered Class 6 Medium-Duty Box Truck over a Sinusoid Road with a Maximum Road Grade of $+4 \%$. The Model Uses the Emissions Equation Shown in Figure 5.8.

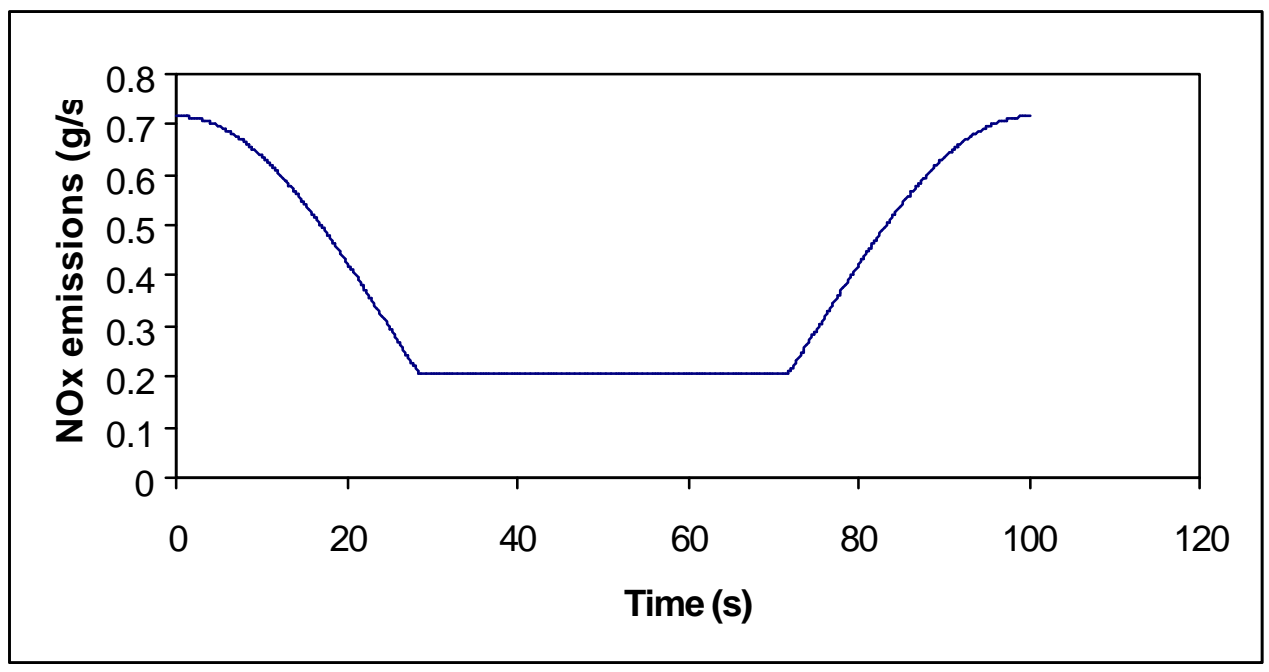

Figure 6.10 $\mathrm{NO}_{\mathrm{x}}$ Emissions for the Considered Class 8 Transit Bus over a Sinusoid Road with a Maximum Road Grade of $+4 \%$. The Model Uses the Emissions Equation Shown in Figure 5.9. 


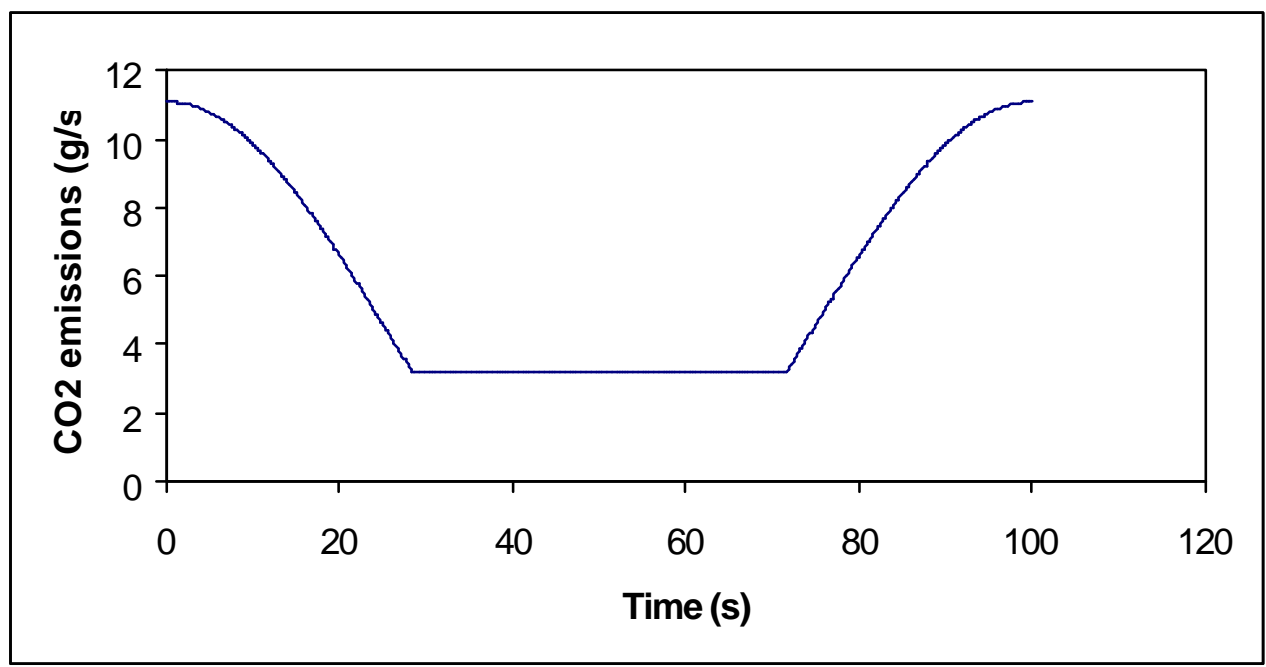

Figure 6.11 $\mathrm{CO}_{2}$ Emissions for the Considered Class 8 Transit Bus over a Sinusoid Road with a Maximum Road Grade of $+4 \%$. The Model Uses the Emissions Equation Shown in Figure 5.10.

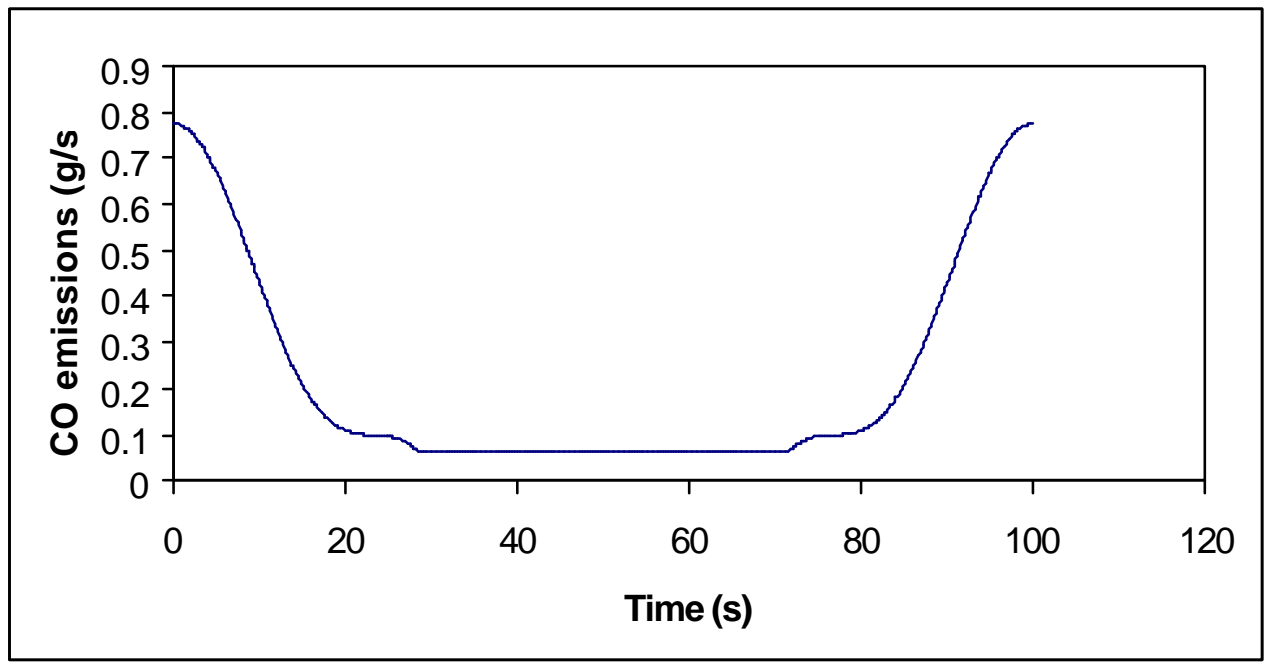

Figure 6.12 CO Emissions for the Considered Class 8 Transit Bus over a Sinusoid Road with a Maximum Road Grade of $+4 \%$. The Model Uses the Emissions Equation Shown in Figure 5.11. 


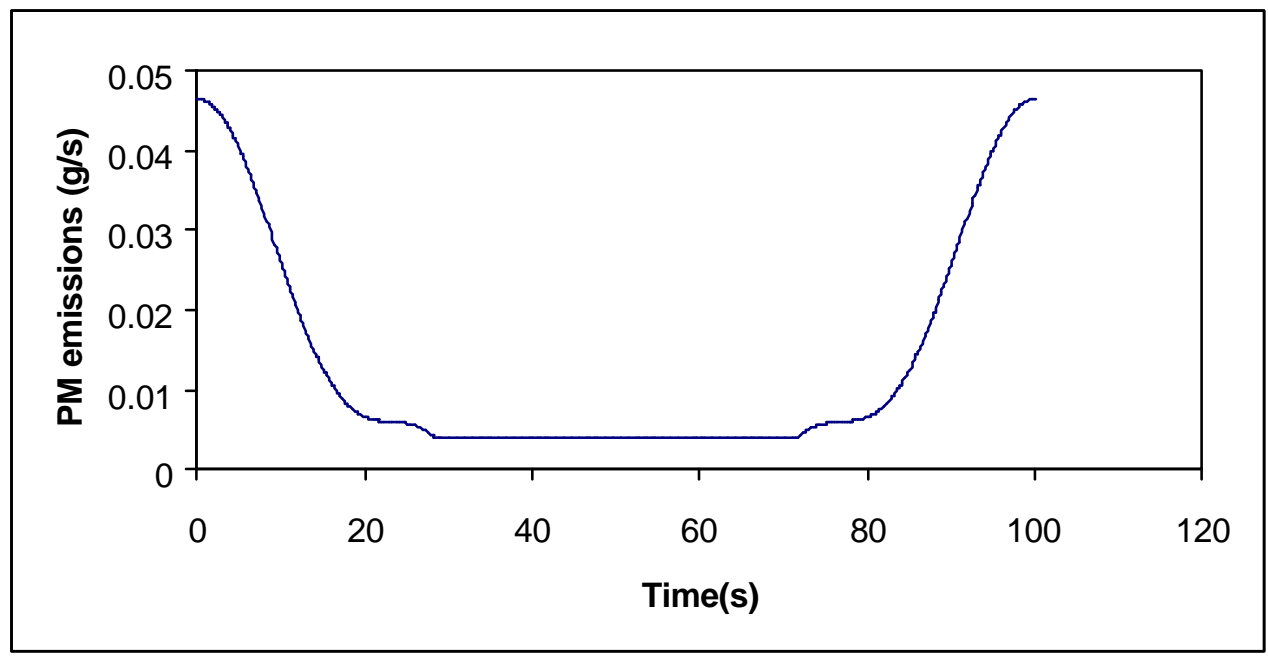

Figure 6.13 PM Emissions for the Considered Class 8 Transit Bus over a Sinusoid Road with a Maximum Road Grade of $+4 \%$. The Model Uses the Emissions Equation Shown in Figure 5.12.

For the three considered vehicles (the heavy-duty class 8 tractor truck, the medium-duty class 6 box truck and the class 8 transit bus) in the region where the sinusoidal road has a grade close to $-4 \%$, brakes must be applied in order to maintain the constant speed of $20.1 \mathrm{mph}$. In this region the $\mathrm{NO}_{\mathrm{x}}, \mathrm{CO}_{2}, \mathrm{CO}$ and $\mathrm{PM}$ emissions have the value of the case where no power is required.

For the next step of the sinusoidal model the three considered vehicles (a heavyduty class 8 tractor truck, a medium-duty class 6 box truck and a class 8 transit bus) were simulated over a period of several sinusoidal roads that have different maximum road grade.

Based on Figures 5.1, 5.2, 5.5, 5.6, 5.9 and 5.10 it can be seen that for the two considered class 8 vehicles, linear or nearly linear emissions $\mathrm{NO}_{\mathrm{x}}$ and $\left.\mathrm{CO}_{2}\right)$ for the sinusoidal case will be influenced only when the road is steep enough that brakes must be 
used, because energy is lost to braking on the downgrade and must be resupplied on the upgrade. However for nonlinear emissions ( $\mathrm{CO}$ and $\mathrm{PM})$ grade can affect the average emissions results in $\mathrm{g} / \mathrm{mile}$ even without braking. In the future hybrid vehicles will offer an alternative to friction braking on downhills.

Therefore, if one of the considered vehicles is operated half time at $50 \mathrm{~kW}$ and half time at $150 \mathrm{~kW}$ this produces more $\mathrm{CO}$ and $\mathrm{PM}$ emissions than if it is running the whole time at $100 \mathrm{~kW}$, due to the concavity of the plots in Figures 5.3, 5.4, 5.7, 5.8, 5.11 and 5.12.

Figures 6.14 to 6.25 that are based on the road models with a sinusoidal form and with a maximum grade between $0 \%$ and $5 \%$ and show exactly the way that the road grade influence emissions of $\mathrm{NO}_{\mathrm{x}}, \mathrm{CO}_{2}, \mathrm{CO}$ and $\mathrm{PM}$ in gram per mile. The models were developed for the considered vehicles (a heavy-duty class 8 tractor truck, a medium-duty class 6 box truck and a heavy-duty class 8 transit bus) traveling at a constant speed of 45 mph (20 meters per second). Also from these figures one can find the value of road grade from which these emissions start to increase significantly: about $1.5 \%$ for $\mathrm{NO}_{\mathrm{x}}$ and $\mathrm{CO}_{2}$ and about $2 \%$ for $\mathrm{CO}$ and PM in the case of the heavy-duty class 8 tractor truck; about $1 \%$ for $\mathrm{NO}_{\mathrm{x}}$ and $\mathrm{CO}_{2}$ and about $1.4 \%$ for $\mathrm{CO}$ and $\mathrm{PM}$ in the case of the medium-duty class 6 box truck and about $1.8 \%$ for $\mathrm{NO}_{\mathrm{x}}$ and $\mathrm{CO}_{2}$ and about $2 \%$ for $\mathrm{CO}$ and $\mathrm{PM}$ in the case of the class 8 transit bus. 


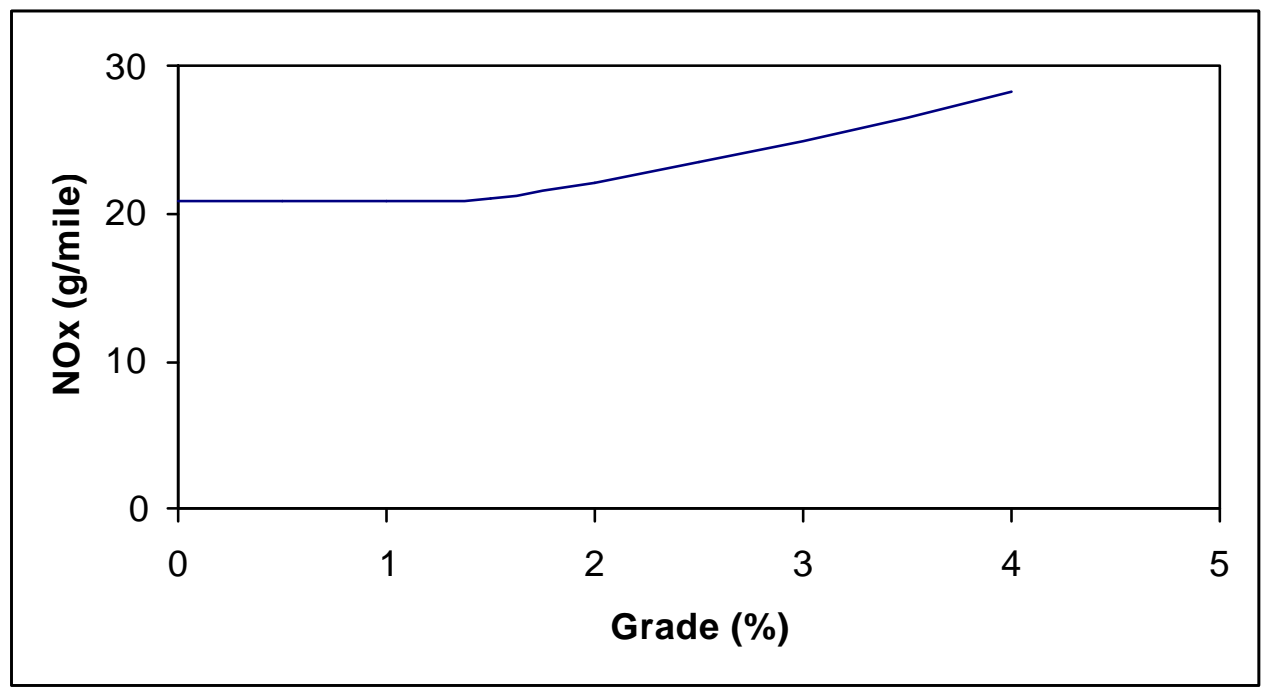

Figure 6.14 Grade Influence on $\mathrm{NO}_{\mathrm{x}}$ Emissions in $\mathrm{g} / \mathrm{mile}$ of the Considered Class 8 Heavy-Duty Tractor Truck. The Model Uses the Emissions Equation Shown in Figure 5.1.

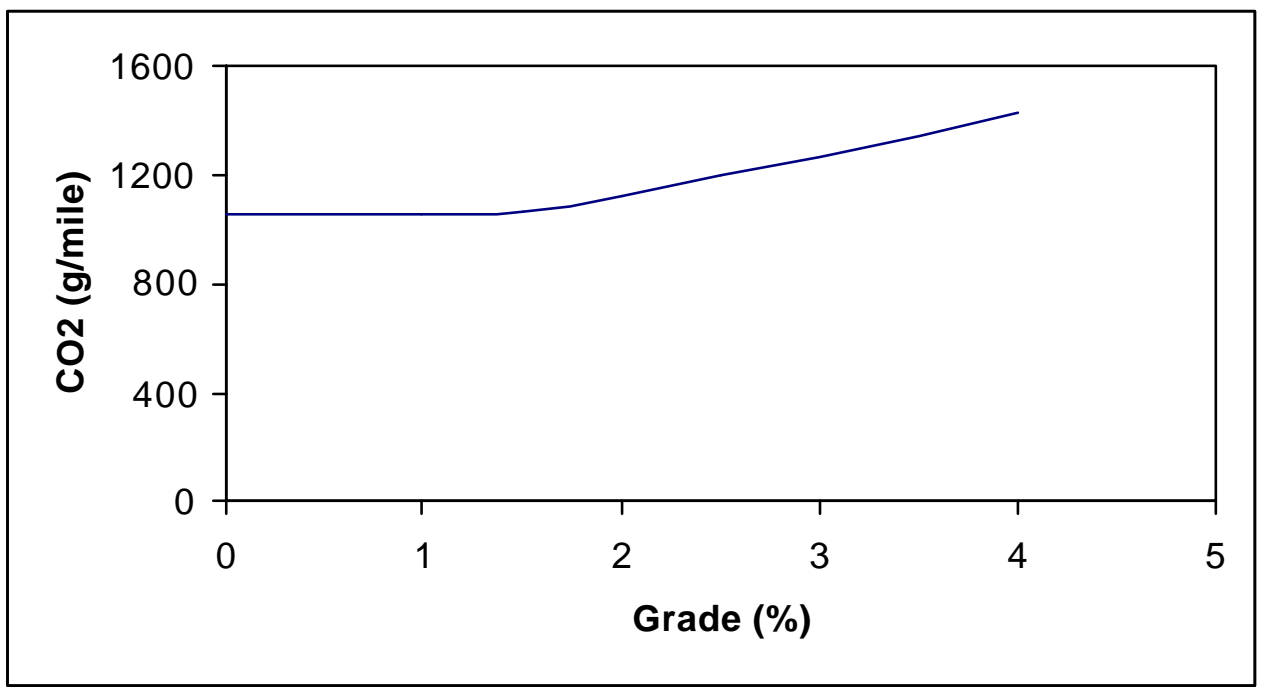

Figure 6.15 Grade Influence on $\mathrm{CO}_{2}$ Emissions in g/mile of the Considered Class 8 Heavy-Duty Tractor Truck. The Model Uses the Emissions Equation Shown in Figure 5.2. 


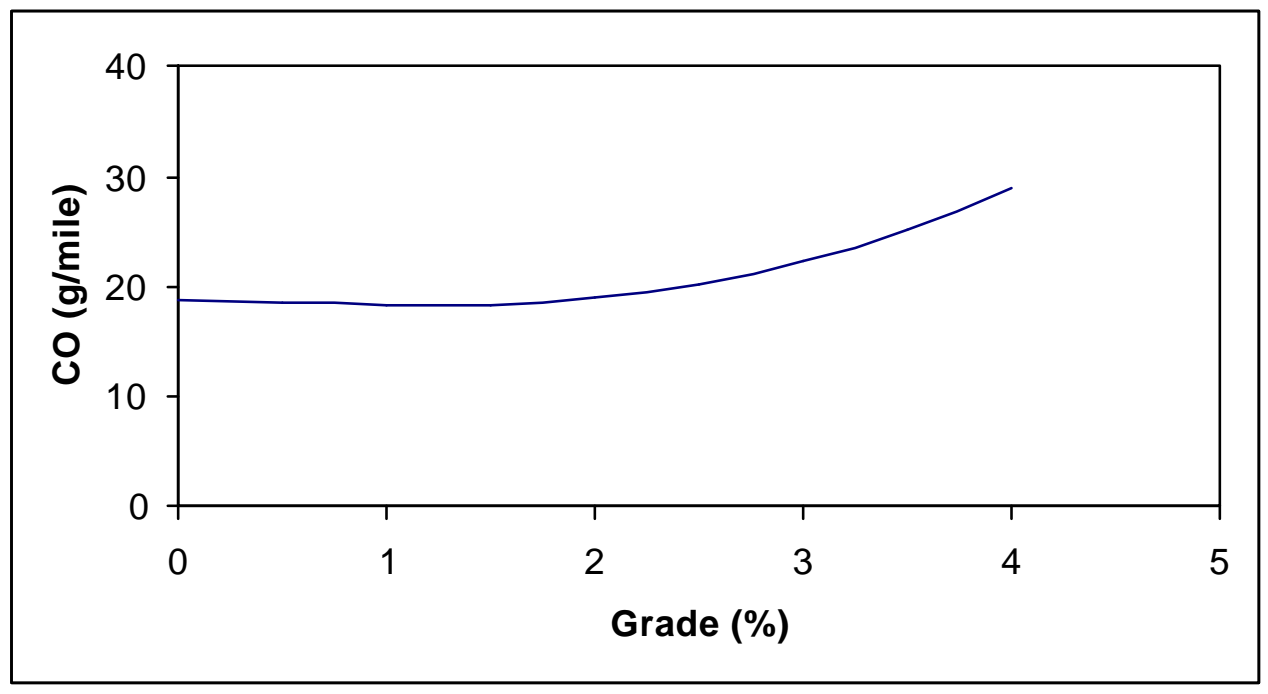

Figure 6.16 Grade Influence on CO Emissions in g/mile of the Considered Class 8 Heavy-Duty Tractor Truck. The Model Uses the Emissions Equation Shown in Figure 5.3.

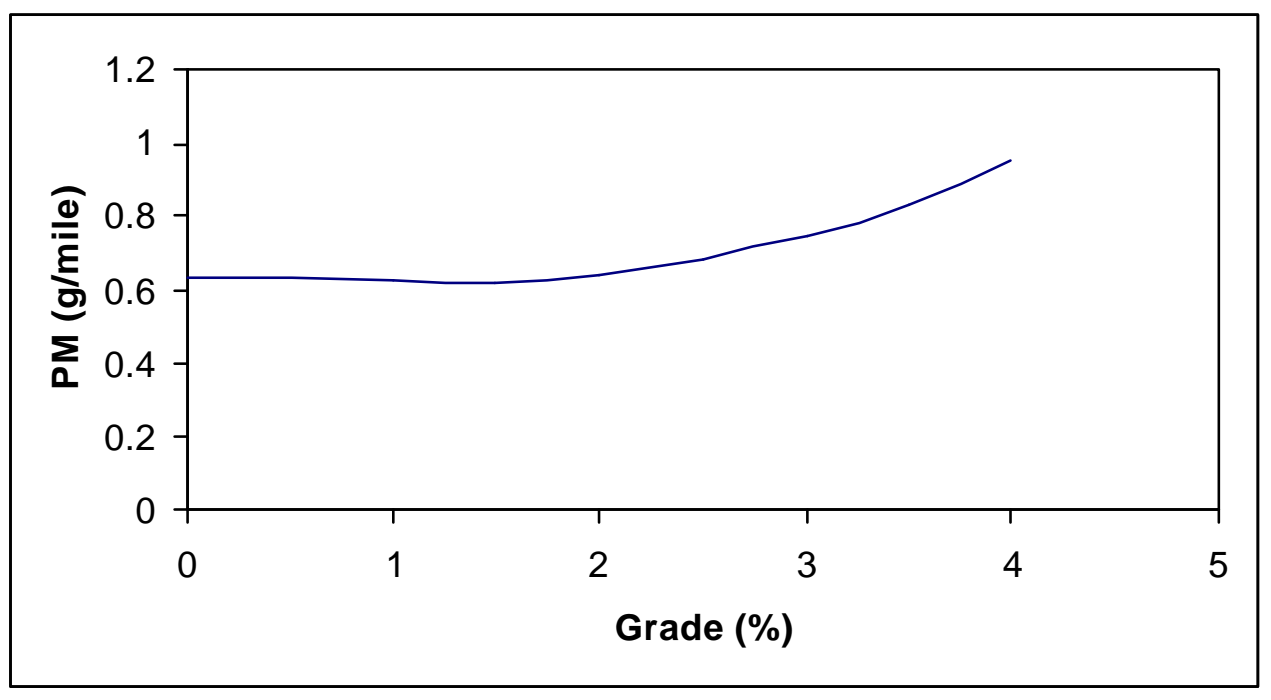

Figure 6.17 Grade Influence on PM Emissions in g/mile of the Considered Class 8 Heavy-Duty Tractor Truck. The Model Uses the Emissions Equation Shown in Figure 5.4. 


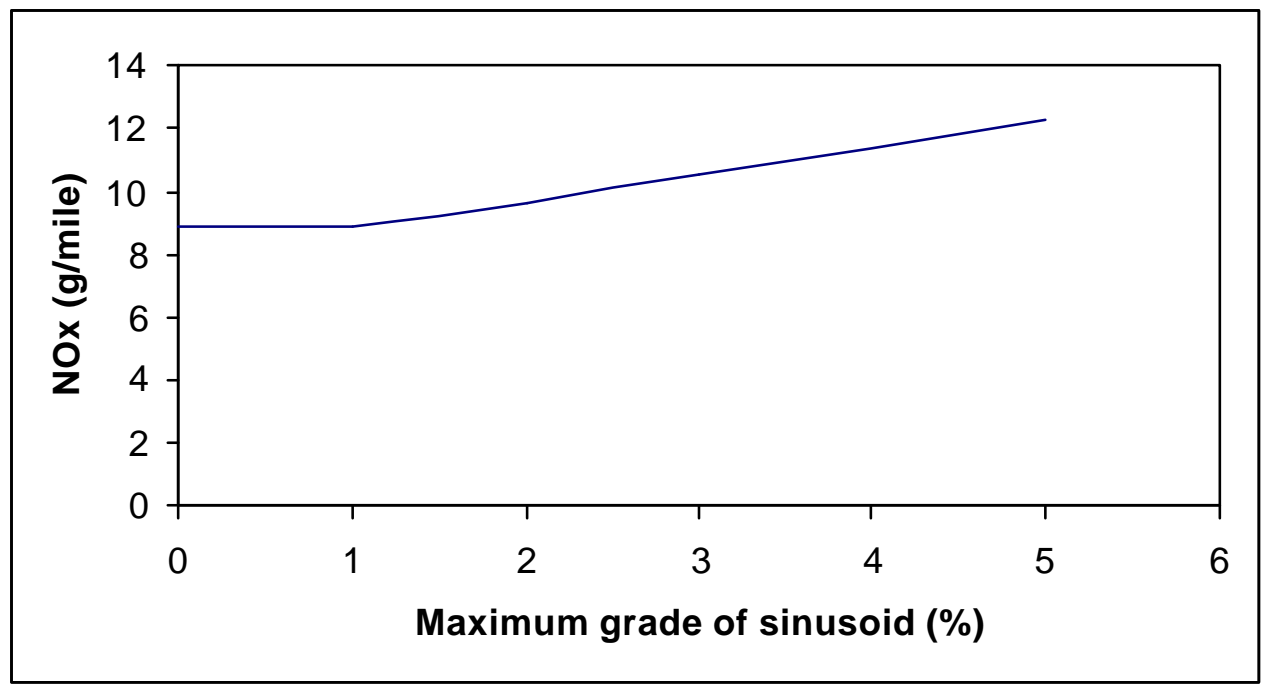

Figure 6.18 Grade Influence on $\mathrm{NO}_{\mathrm{x}}$ Emissions in $\mathrm{g} / \mathrm{mile}$ of the Considered Class 6 Medium-Duty Box Truck. The Model Uses the Emissions Equation Shown in Figure 5.5.

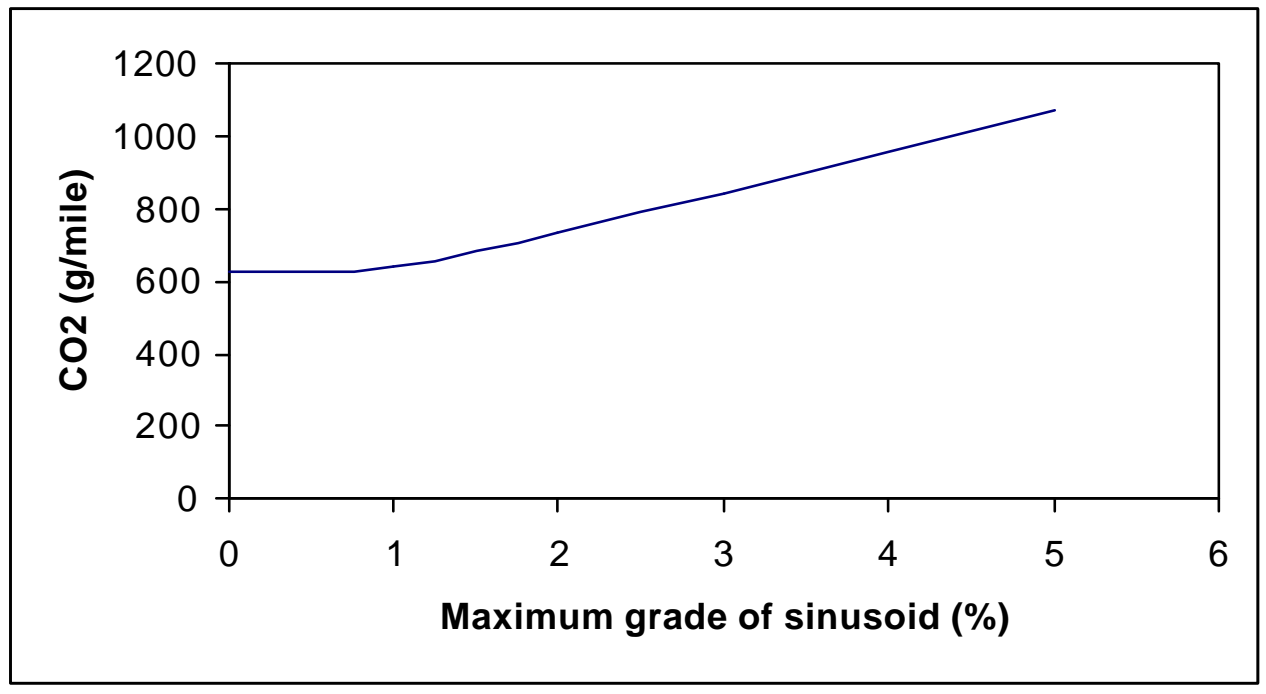

Figure 6.19 Grade Influence on $\mathrm{CO}_{2}$ Emissions in g/mile of the Considered Class 6 Medium-Duty Box Truck. The Model Uses the Emissions Equation Shown in Figure 5.6. 


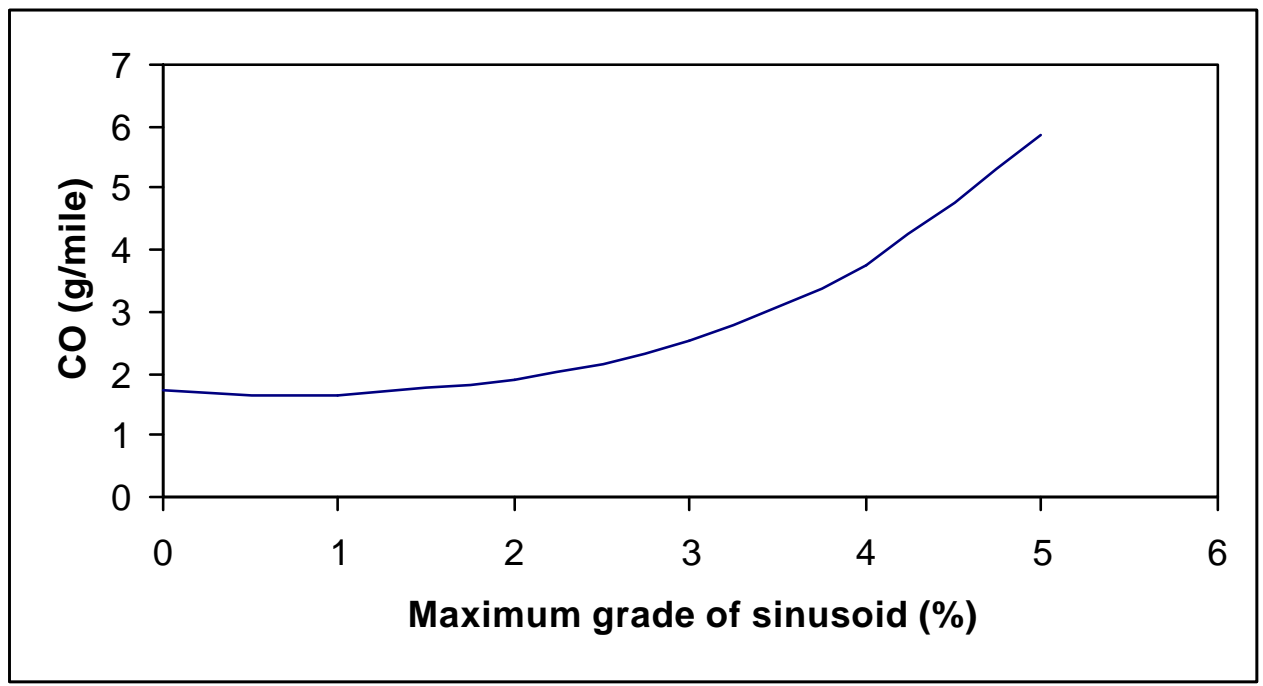

Figure 6.20 Grade Influence on CO Emissions in g/mile of the Considered Class 6 Medium-Duty Box Truck. The Model Uses the Emissions Equation Shown in Figure 5.7.

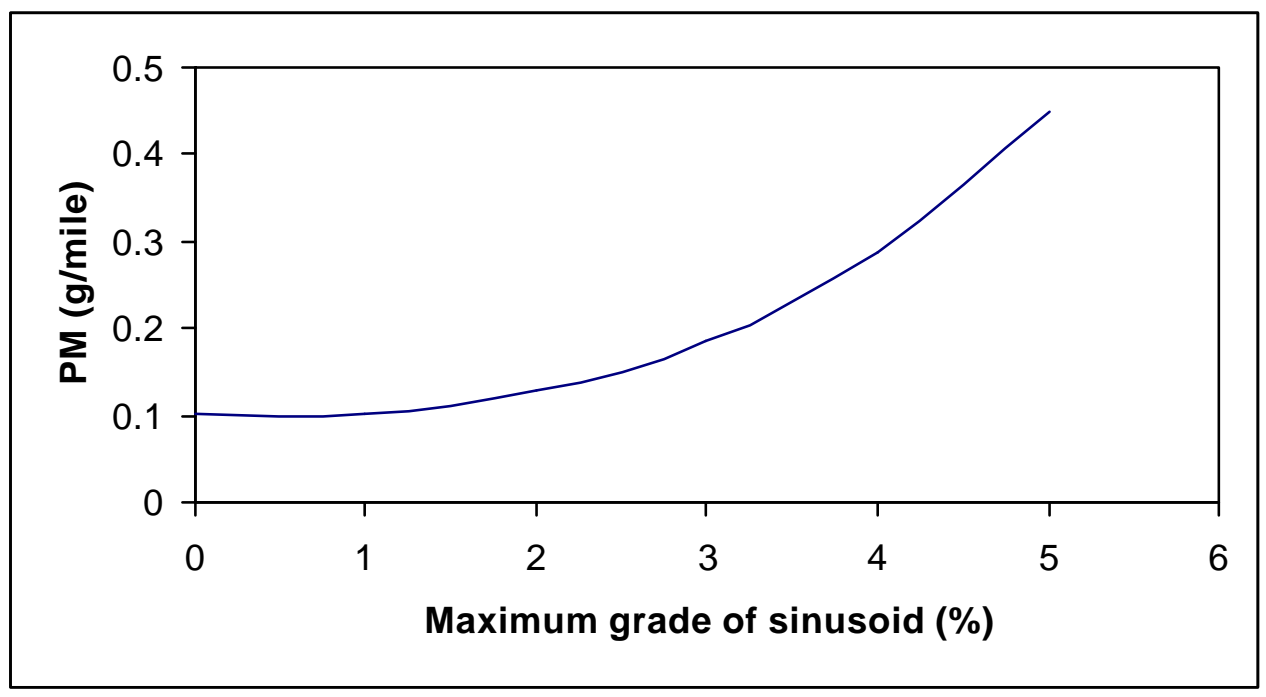

Figure 6.21 Grade Influence on PM Emissions in $\mathrm{g} / \mathrm{mile}$ of the Considered Class 6 Medium-Duty Box Truck. The Model Uses the Emissions Equation Shown in Figure 5.8. 


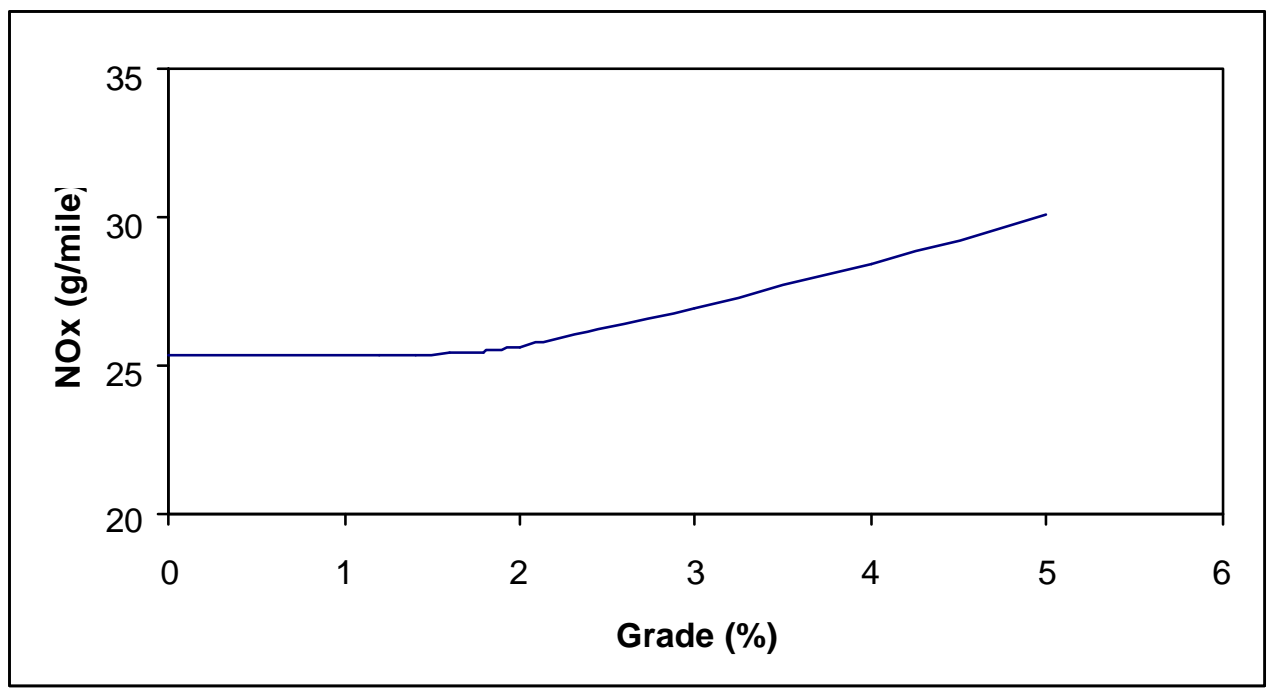

Figure 6.22 Grade Influence on $\mathrm{NO}_{\mathrm{x}}$ Emissions in g/mile of the Considered Class 8 Transit Bus. The Model Uses the Emissions Equation Shown in Figure 5.9.

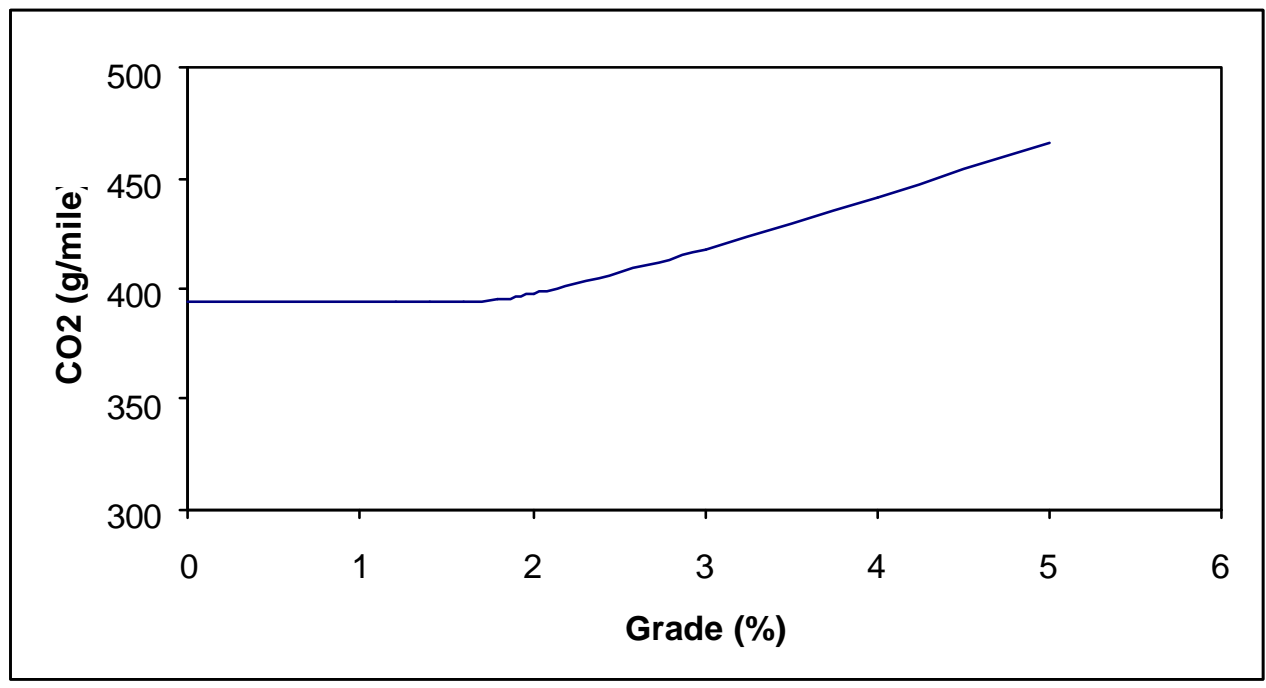

Figure 6.23 Grade Influence on $\mathrm{CO}_{2}$ Emissions in g/mile of the Considered Class 8 Transit Bus. The Model Uses the Emissions Equation Shown in Figure 5.10. 


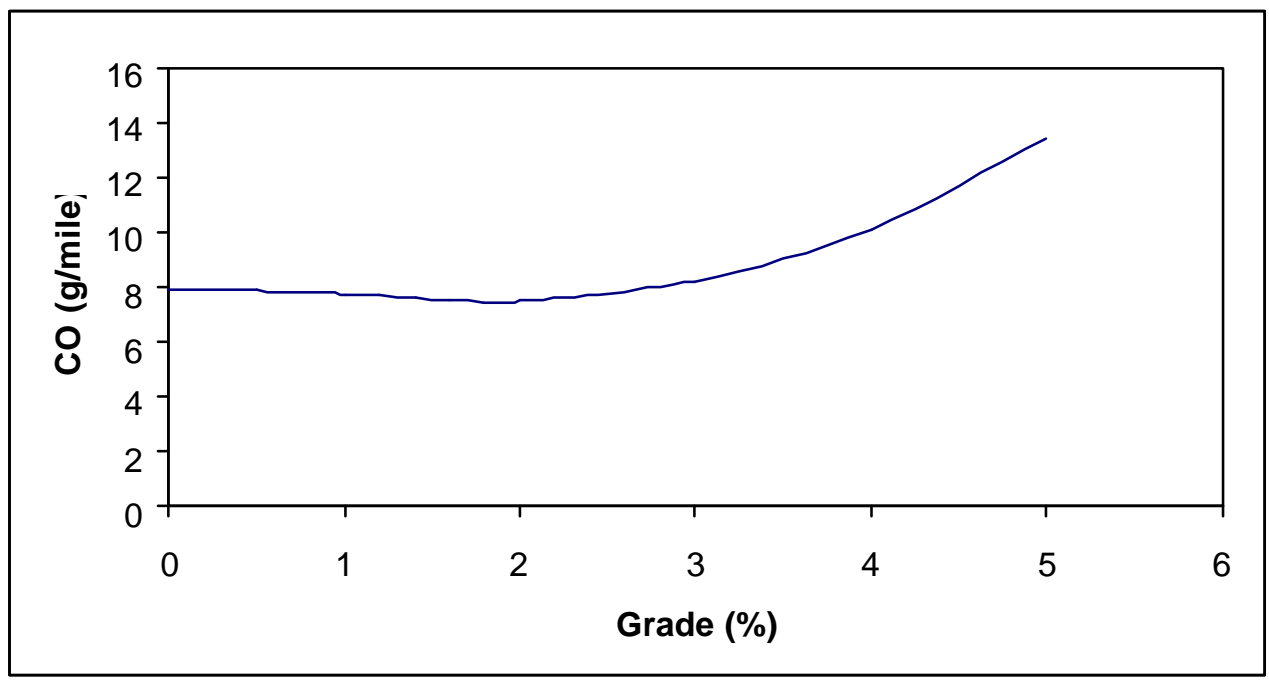

Figure 6.24 Grade Influence on CO Emissions in g/mile of the Considered Class 8 Transit Bus. The Model Uses the Emissions Equation Shown in Figure 5.11.

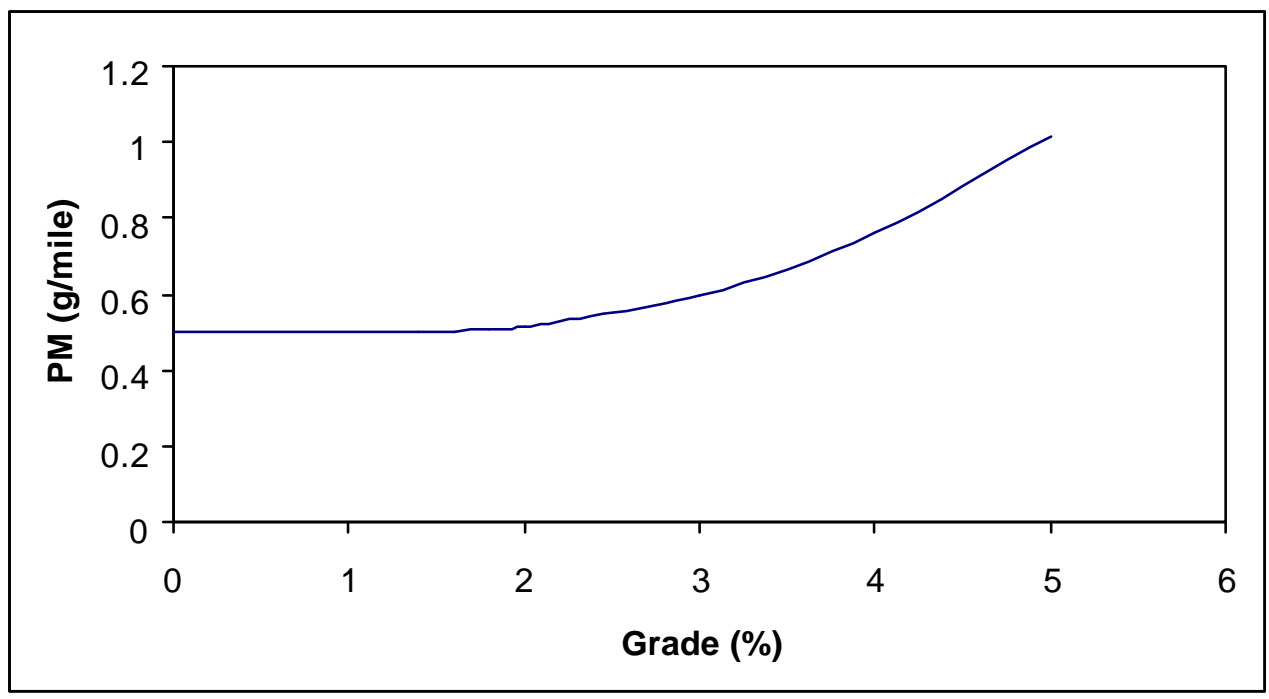

Figure 6.25 Grade Influence on PM Emissions in g/mile of the Considered Class 8 Transit Bus. The Model Uses the Emissions Equation Shown in Figure 5.12. 


\section{Stop and Go Model}

For the stop and go model each vehicle from this analysis was considered to stop applying a constant acceleration of $-0.5 \mathrm{~m} / \mathrm{s}^{2}$ from $65 \mathrm{mph}(29 \mathrm{~m} / \mathrm{s})$ to $0 \mathrm{mph}$ and then reaccelerate to the cruise speed of $65 \mathrm{mph}$ using the full (rated) power of the engine. For the analysis from this chapter there was neglected the influence of gears change on acceleration. There also has been considered the case when the vehicles travel the same considered distance (5 $\mathrm{km}$ or 3.1 miles) without stopping.

The results of this analysis are presented on plots of distance, speed and $\mathrm{NO}_{\mathrm{x}}$, $\mathrm{CO}_{2}, \mathrm{CO}$ and PM emissions versus time for each of the considered vehicle in Figures 7.1 to 7.18 .

For the case when one of the vehicles does not start immediately after it stops, there have been calculated the additional $\mathrm{NO}_{\mathrm{x}}, \mathrm{CO}_{2}, \mathrm{CO}$ and $\mathrm{PM}$ emissions that each vehicle emits for each extra minute of the stop while the engine is running. These results are presented in Table 7.1 for the considered class 8 heavy-duty tractor truck, in Table 7.2 for the considered class 6 medium-duty box truck and in Table 7.3 for the considered class 8 transit bus, in $\mathrm{g} / \mathrm{sec}$. 


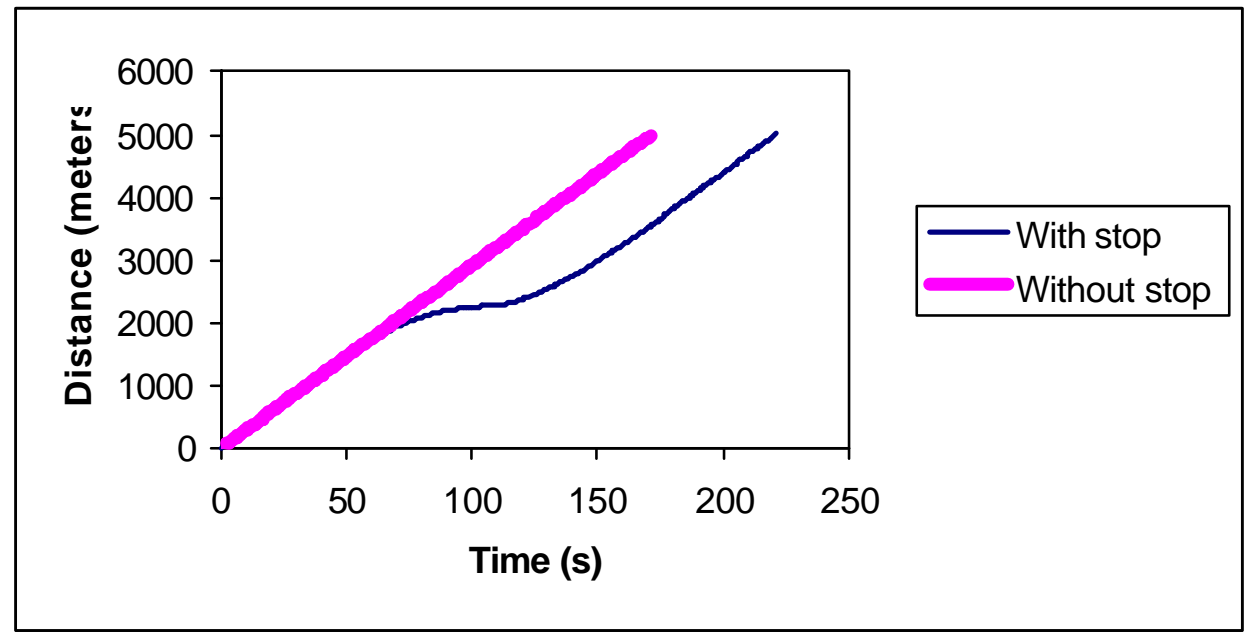

Figure 7.1 Distance Versus Time Plot for the Considered Heavy-Duty Class 8 Tractor Truck Traveling Over a Distance of 5000 meters, With and Without Stop.

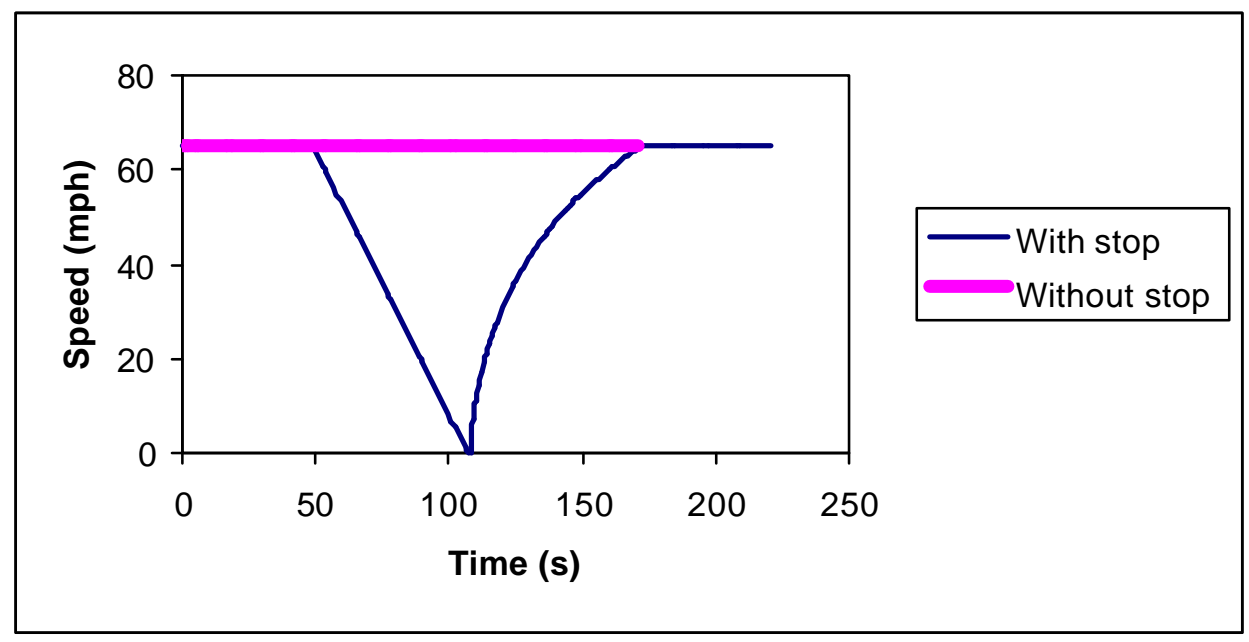

Figure 7.2 Speed Versus Time Plot for the Considered Heavy-Duty Class 8 Tractor Truck Traveling Over a Distance of 5000 meters, With and Without Stop. 


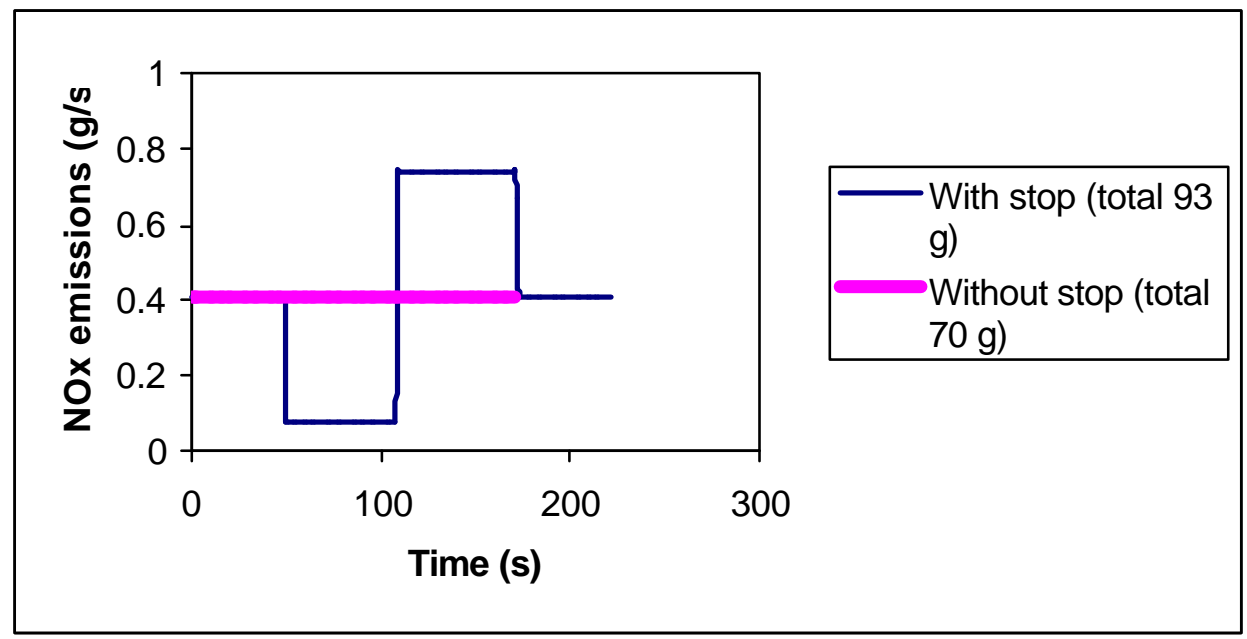

Figure 7.3 $\mathrm{NO}_{\mathrm{x}}$ Emissions Versus Time Plot for the Considered Heavy-Duty Class 8 Tractor Truck Traveling Over a Distance of 5000 meters, With and Without Stop.

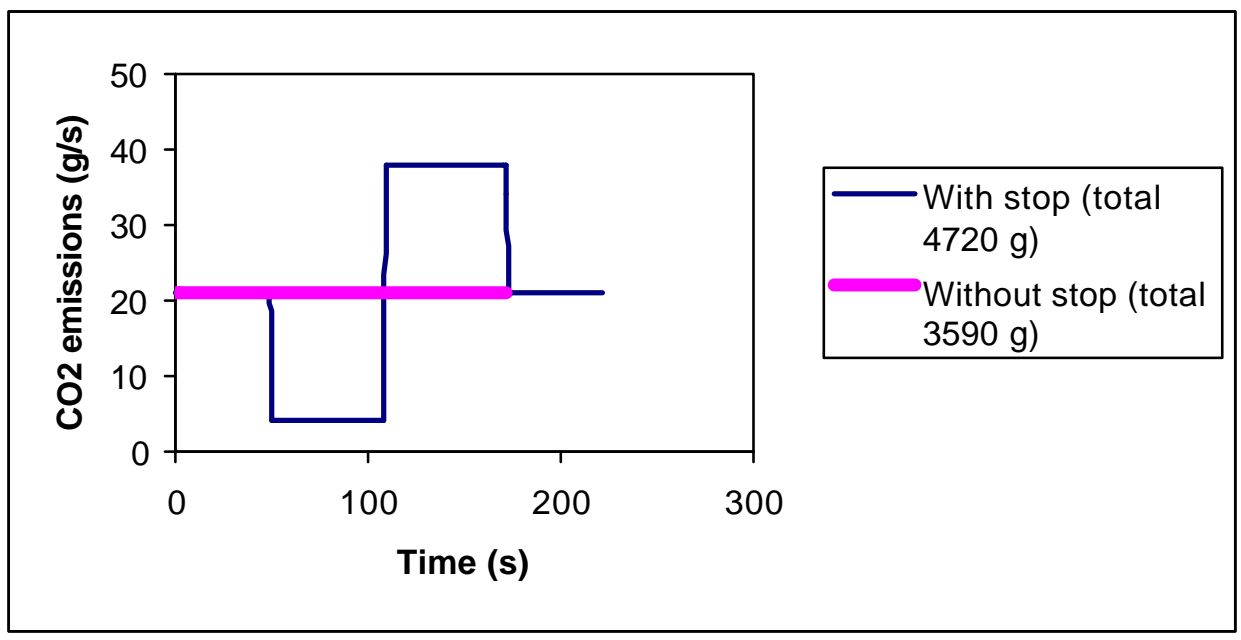

Figure 7.4 $\mathrm{CO}_{2}$ Emissions Versus Time Plot for the Considered Heavy-Duty Class 8 Tractor Truck Traveling Over a Distance of 5000 meters, With and Without Stop. 


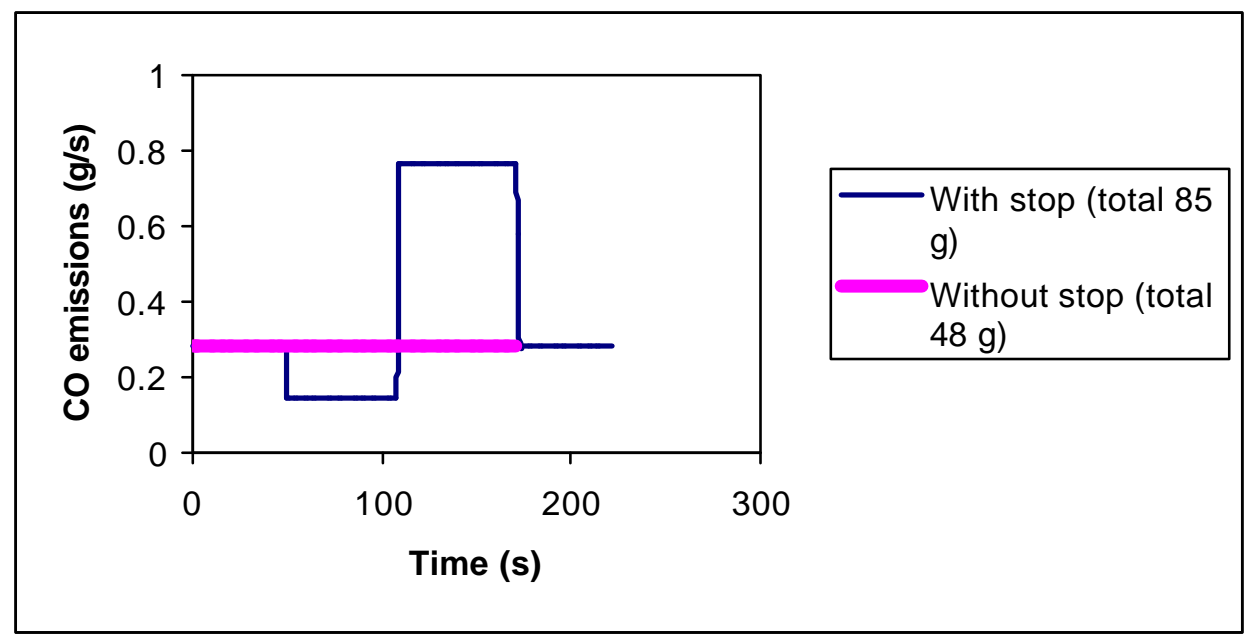

Figure 7.5 CO Emissions Versus Time Plot for the Considered Heavy-Duty Class 8 Tractor Truck Traveling Over a Distance of 5000 meters, With and Without Stop.

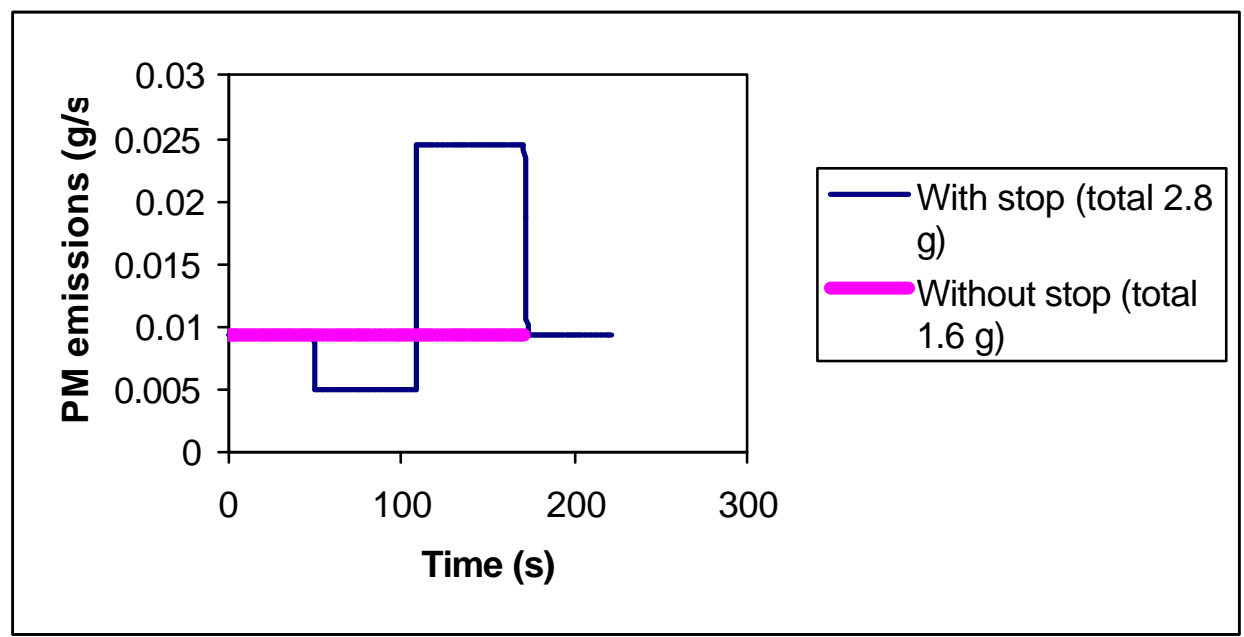

Figure 7.6 PM Emissions Versus Time Plot for the Considered Heavy-Duty Class 8 Tractor Truck Traveling Over a Distance of 5000 meters, With and Without Stop. 


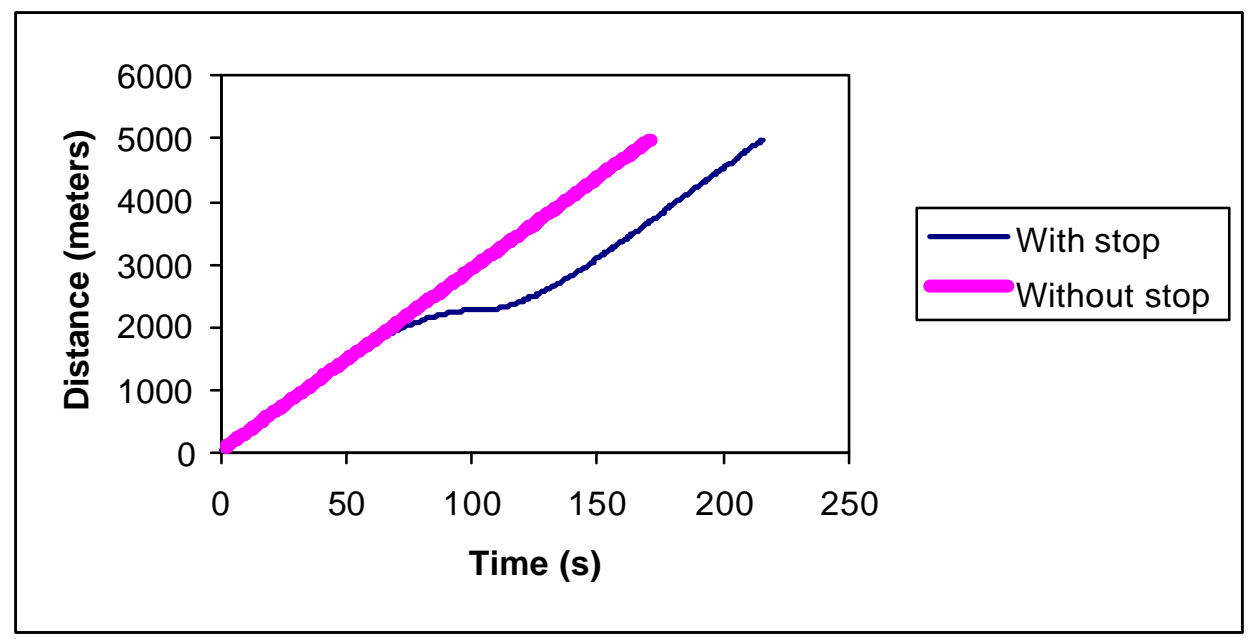

Figure 7.7 Distance Versus Time Plot for the Considered Medium-Duty Class 6 Box Truck Traveling Over a Distance of 5000 meters, With and Without Stop.

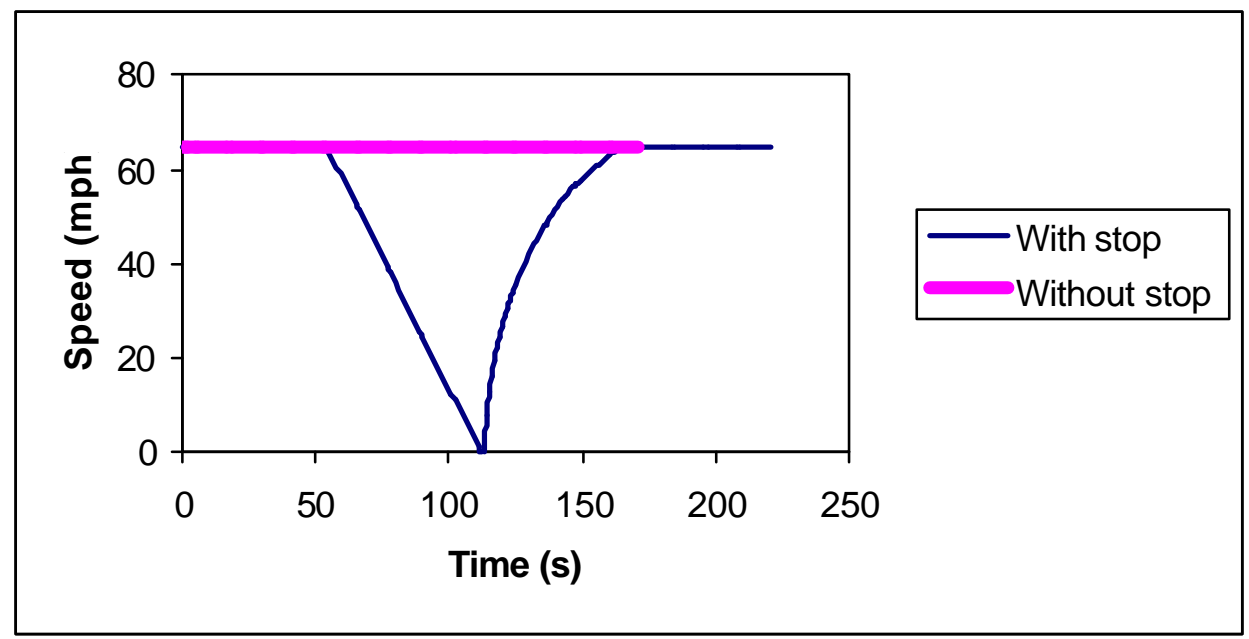

Figure 7.8 Speed Versus Time Plot for the Considered Medium-Duty Class 6 Box Truck Traveling Over a Distance of $\mathbf{5 0 0 0}$ meters, With and Without Stop. 


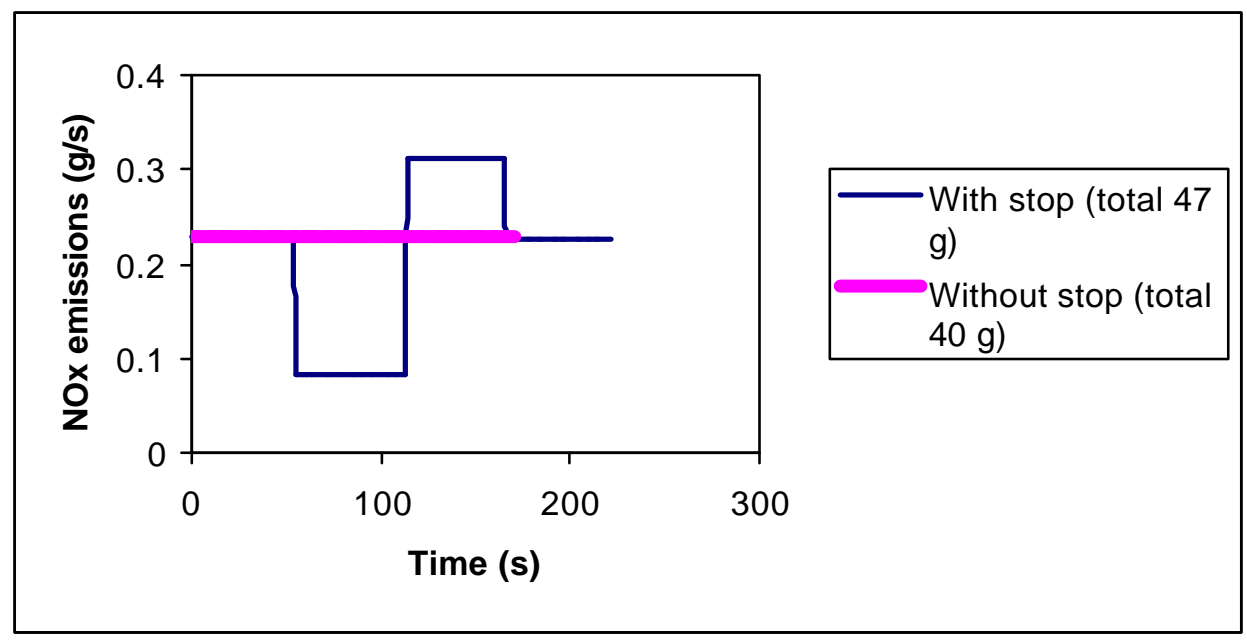

Figure 7.9 NO $_{x}$ Emissions Versus Time Plot for the Considered Medium-Duty Class 6 Box Truck Traveling Over a Distance of 5000 meters, With and Without Stop.

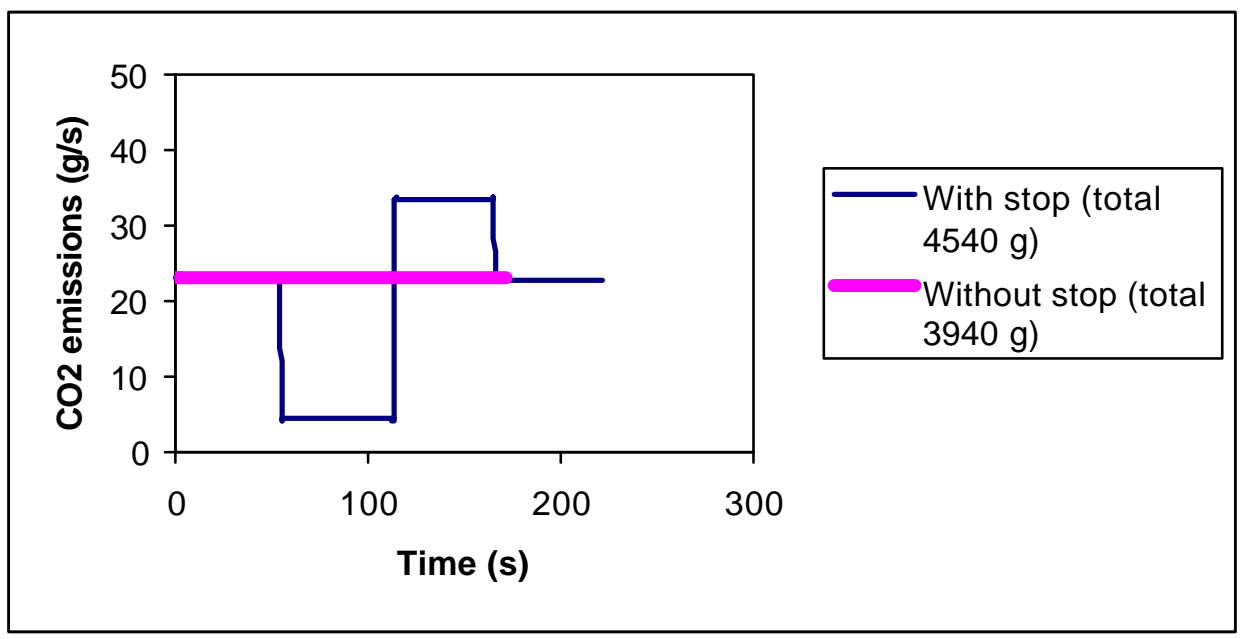

Figure 7.10 $\mathrm{CO}_{2}$ Emissions Versus Time Plot for the Considered Medium-Duty Class 6 Box Truck Traveling Over a Distance of 5000 meters, With and Without Stop. 


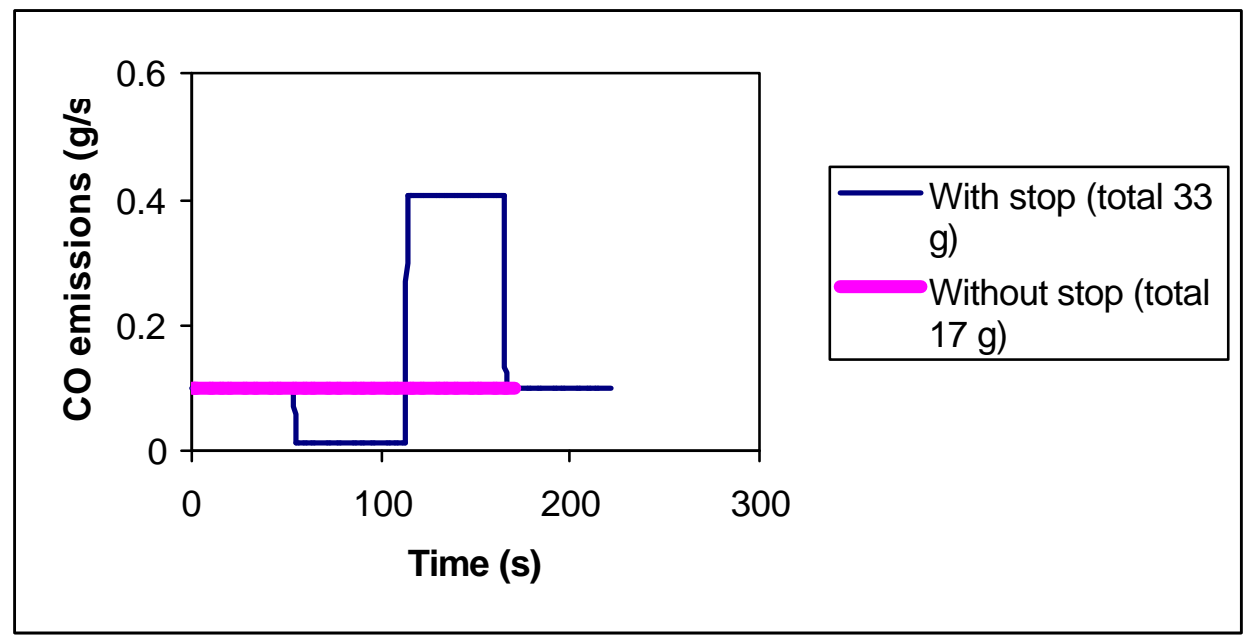

Figure 7.11 CO Emissions Versus Time Plot for the Considered Medium-Duty Class 6 Box Truck Traveling Over a Distance of 5000 meters, With and Without Stop.

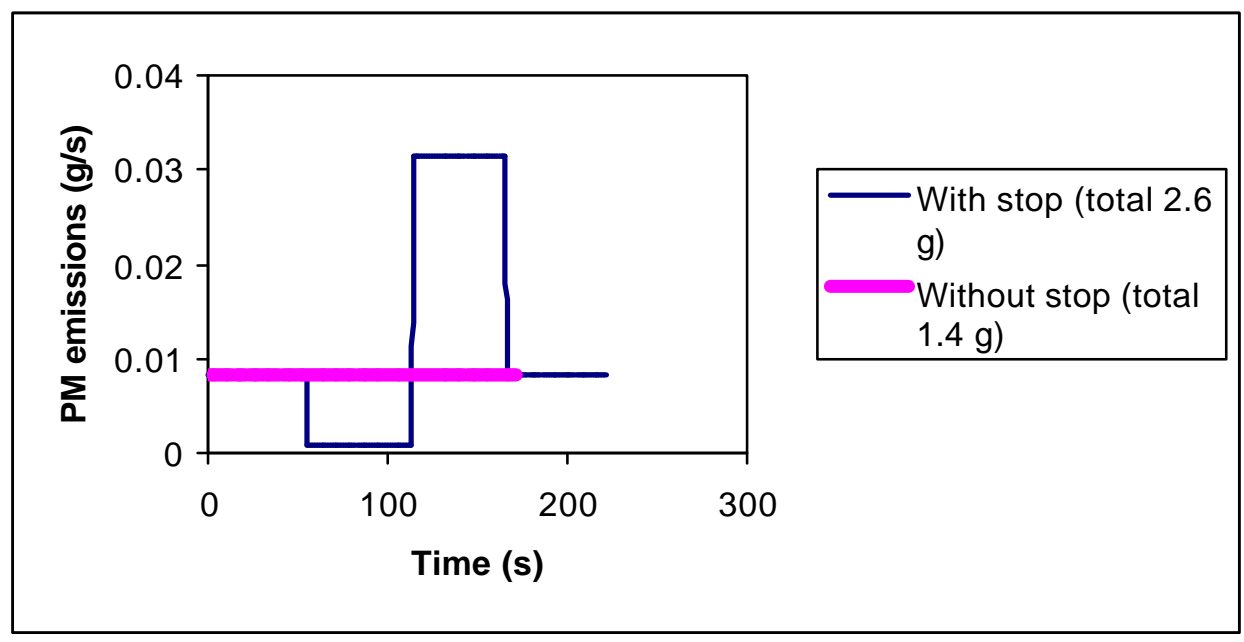

Figure 7.12 PM Emissions Versus Time Plot for the Considered Medium-Duty Class 6 Box Truck Traveling Over a Distance of 5000 meters, With and Without Stop. 


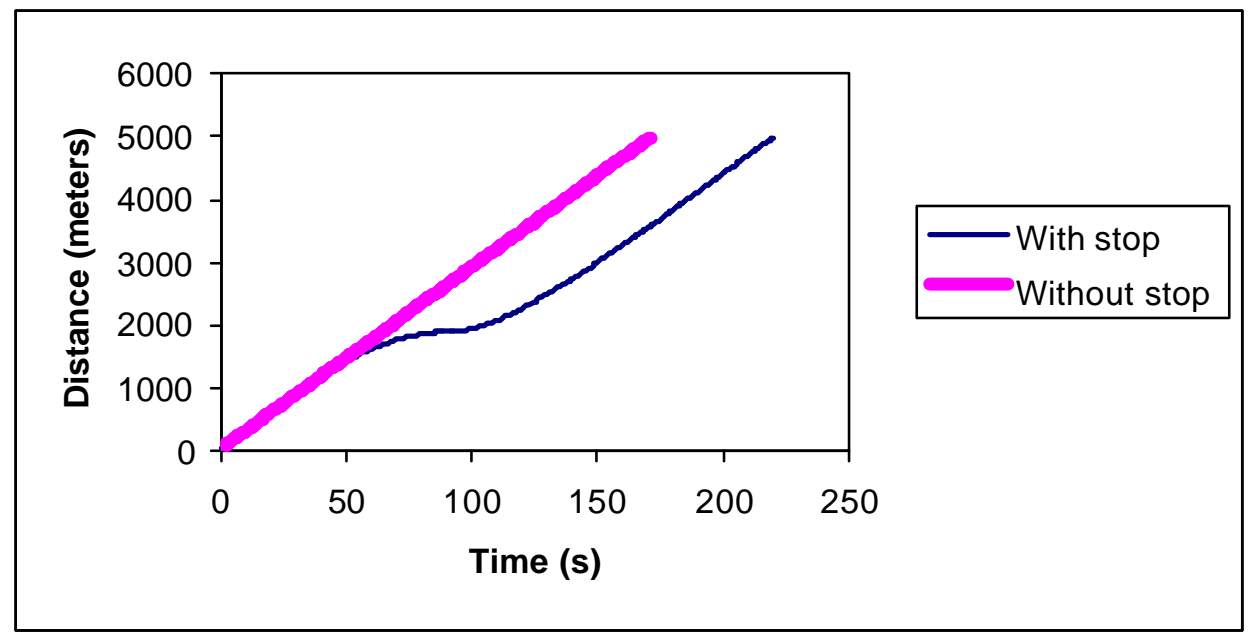

Figure 7.13 Distance Versus Time Plot for the Considered Class 8 Transit Bus Traveling Over a Distance of 5000 meters, With and Without Stop.

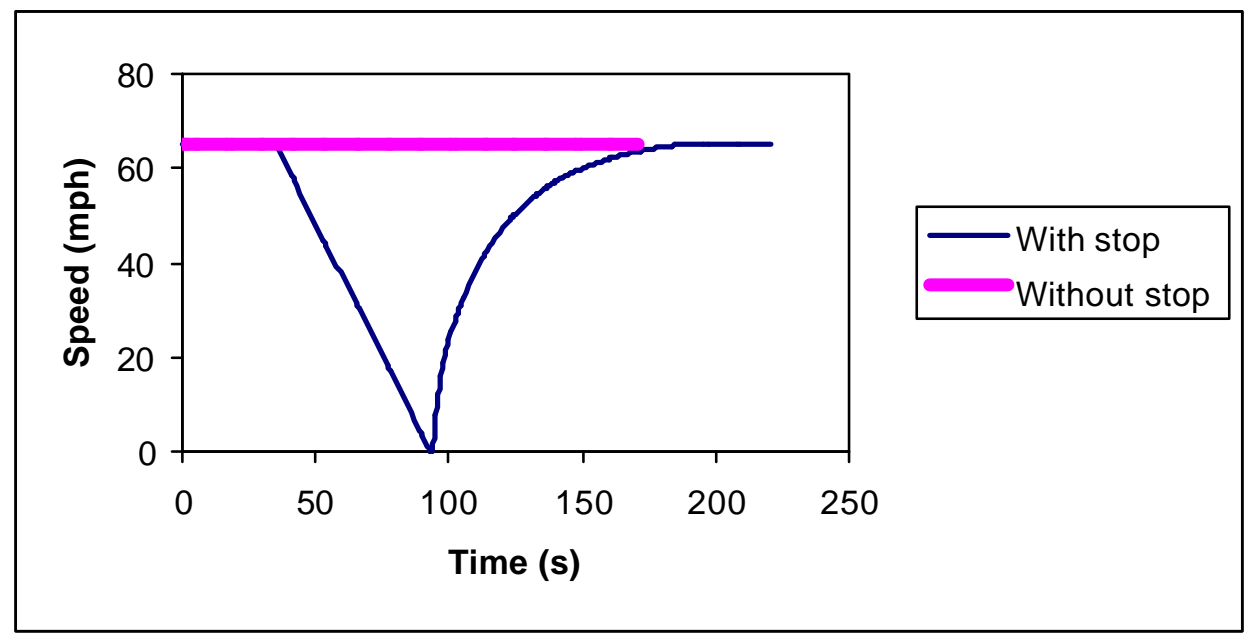

Figure 7.14 Speed Versus Time Plot for the Considered Class 8 Transit Bus Traveling Over a Distance of 5000 meters, With and Without Stop. 


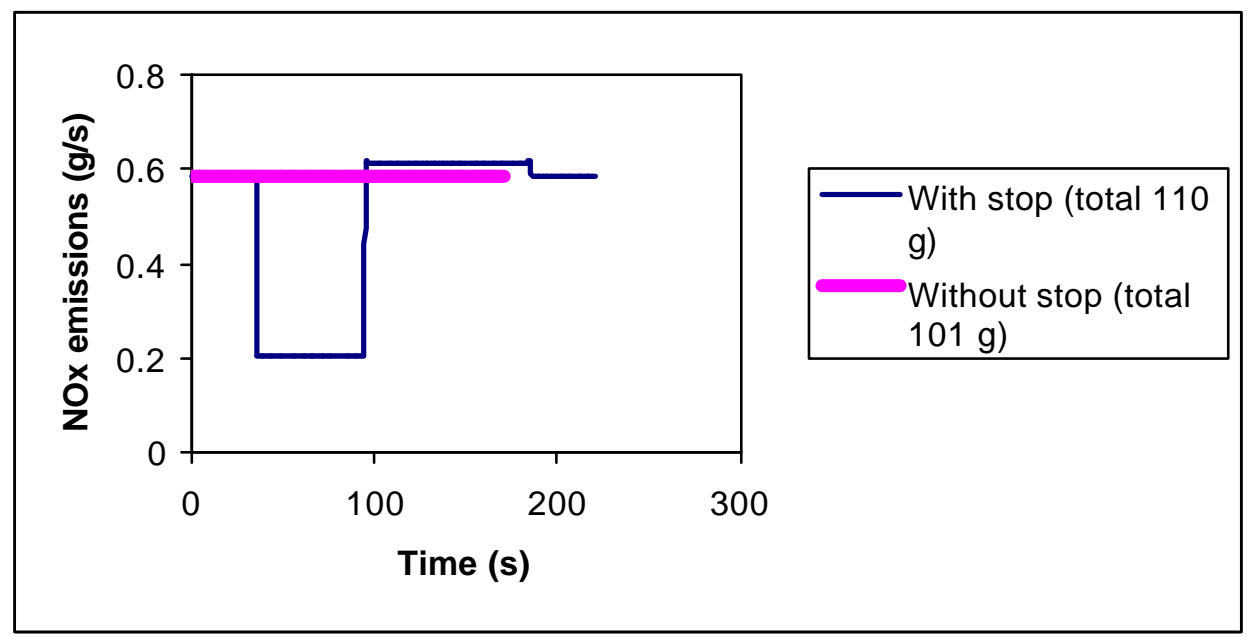

Figure 7.15 NO $_{x}$ Emissions Versus Time Plot for the Considered Class 8 Transit Bus Traveling Over a Distance of 5000 meters, With and Without Stop.

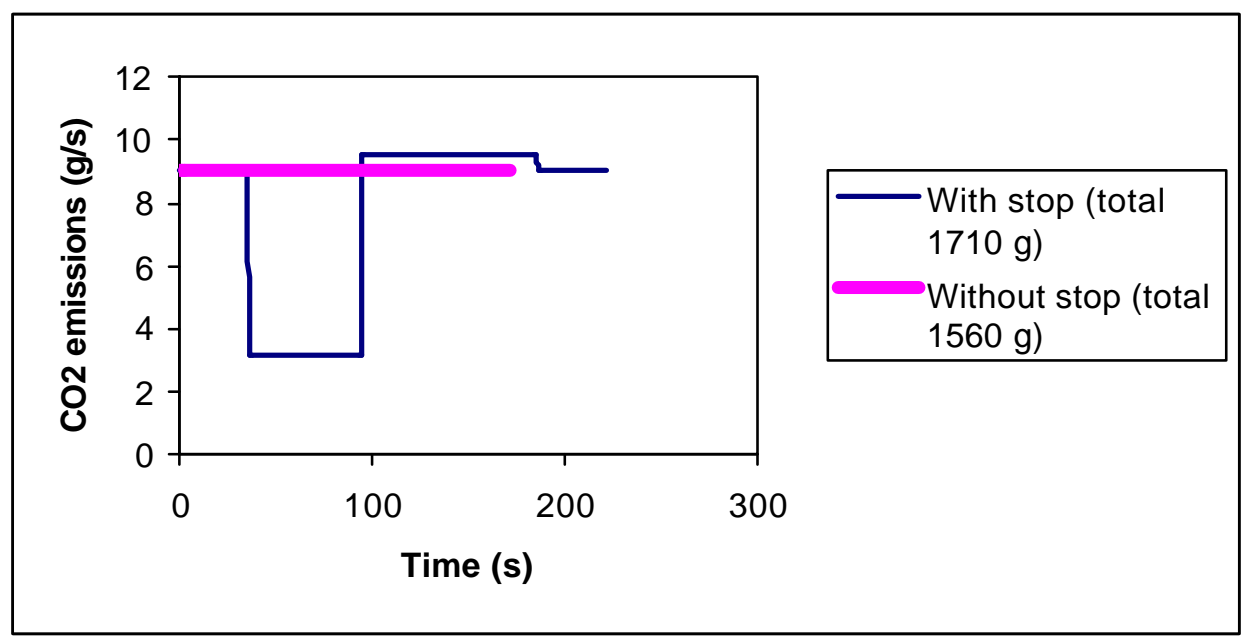

Figure 7.16 $\mathrm{CO}_{2}$ Emissions Versus Time Plot for the Considered Class 8 Transit Bus Traveling Over a Distance of 5000 meters, With and Without Stop. 


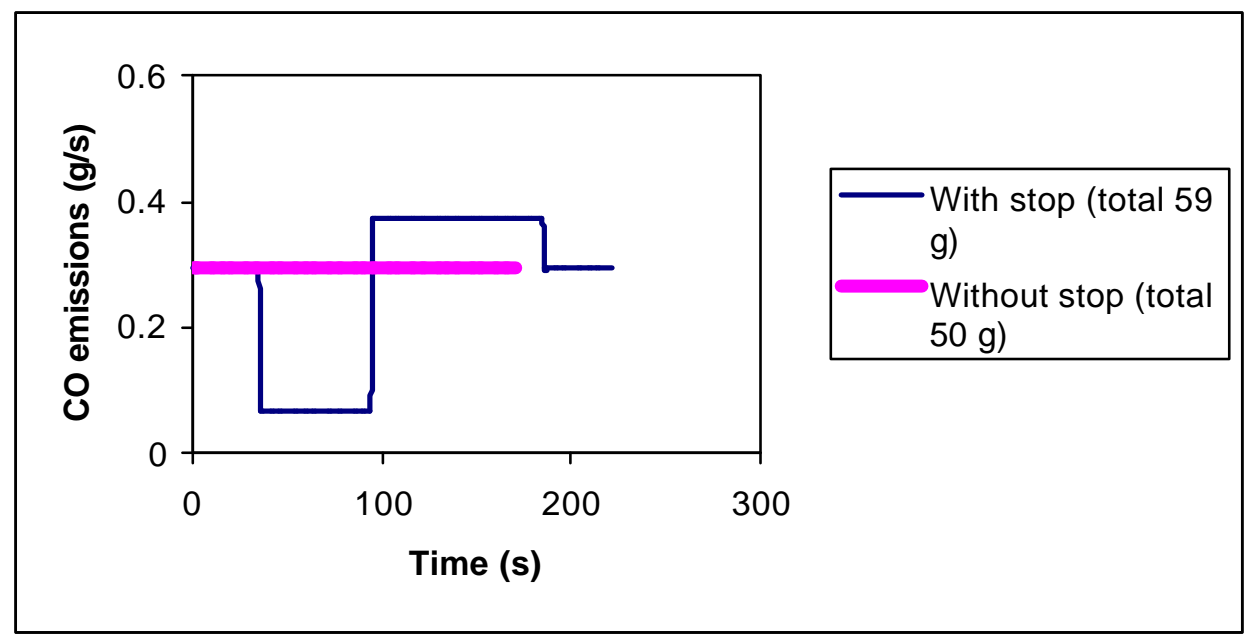

Figure 7.17 CO Emissions Versus Time Plot for the Considered Class 8 Transit Bus Traveling Over a Distance of 5000 meters, With and Without Stop.

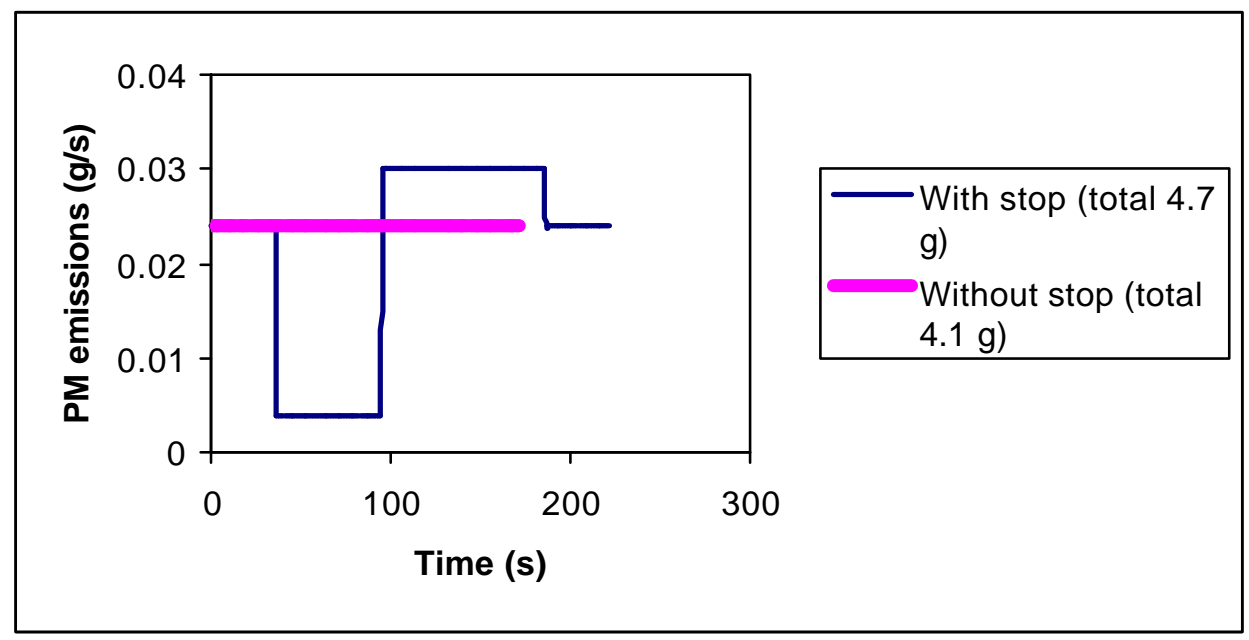

Figure 7.18 PM Emissions Versus Time Plot for the Considered Class 8 Transit Bus Traveling Over a Distance of 5000 meters, With and Without Stop. 
Table 7.1 Additional Emissions for Each Extra Minute of Engine Running at Idle Speed for the Considered Heavy-Duty Class 8 Tractor Truck.

\begin{tabular}{|c|c|}
\hline $\mathbf{N O}_{\mathbf{x}}$ & 4.72 grams \\
\hline $\mathbf{C O}_{\mathbf{2}}$ & 238 grams \\
\hline $\mathbf{C O}$ & 5.87 grams \\
\hline $\mathbf{P M}$ & 0.306 grams \\
\hline
\end{tabular}

Table 7.2 Additional Emissions for Each Extra Minute of Engine Running at Idle Speed for the Considered Medium-Duty Class 6 Box Truck.

\begin{tabular}{|c|c|}
\hline $\mathbf{N O}_{\mathbf{x}}$ & 4.91 grams \\
\hline $\mathbf{C O}$ & 255 grams \\
\hline $\mathbf{C O}$ & 0.88 grams \\
\hline PM & 0.048 grams \\
\hline
\end{tabular}

Table 7.3 Additional Emissions for Each Extra Minute of Engine Running at Idle Speed for the Considered Class 8 Transit Bus.

\begin{tabular}{|c|c|}
\hline $\mathbf{N O}_{\mathbf{x}}$ & 5.12 grams \\
\hline $\mathbf{C O}$ & 191 grams \\
\hline $\mathbf{C O}$ & 3.92 grams \\
\hline $\mathbf{P M}$ & 0.234 grams \\
\hline
\end{tabular}




\section{Speed Correction Factors}

Correction factors are developed to account for the variations in the vehicle condition, class and variations in the testing environment compared to the real road conditions. The correction factors have been widely used in the estimation of light-duty emissions inventory. However, only speed correction factor is used in heavy-duty inventories. The Speed Correction Factor (SCF) used by the USEPA for heavy-duty emission inventory preparation is:

$$
\mathrm{SCF}=\mathrm{EXP}\left(\mathrm{A}+\mathrm{B}^{*} \mathrm{~V}+\mathrm{C}^{*} \mathrm{~V}^{2}\right),
$$

where $\mathrm{V}$ is the vehicle average speed and the empirical constants $\mathrm{A}, \mathrm{B}$, and $\mathrm{C}$ are pollutant dependent and are assumed to be constant for all model years and truck and engine sizes. The origin and rationale behind the development of SCF are undocumented. The problem that is encountered in using aggregated vehicle speed in SCF is that the relation cannot be correlated to real road driving conditions. The SCF does not represent the emissions from a vehicle at an instantaneous speed but the emissions that would occur at an average speed if the vehicle were driven in the same manner as the testing conditions. The SCF is not defined for higher average speeds more than $65 \mathrm{mph}$ and the cycles generally have a low average speed.

As it is well known vehicles emissions in $\mathrm{g} / \mathrm{bhp}-\mathrm{hr}$ are infinite at idle. Also known is that vehicles emissions are often high due to high load $\left(1 / 2 \rho_{\mathrm{a}} \mathrm{C}_{\mathrm{D}} \mathrm{A} \underline{\mathrm{V}}^{3}\right)$ at high speeds. All these show the necessity of the development of speed correction factors to be used in inventory and prediction purposes. 
In order to develop $\mathrm{NO}_{\mathrm{x}}, \mathrm{CO}_{2}, \mathrm{CO}$ and $\mathrm{PM}$ speed correction factors for the vehicles considered in this analysis, first step was to plot $\mathrm{NO}_{\mathrm{x}}, \mathrm{CO}_{2}, \mathrm{CO}$ and $\mathrm{PM}$ emissions data in units of $\mathrm{g} / \mathrm{mile}$ versus vehicle average speed for each available cycle. Through each obtained set of data points there has been fit an exponential trendline defined by an equation. The exponential trendline was choose because it fits best the each set of data points. All exponential trendlines have the form of the equation presented on previous page. The equation of each trendline was then used to develop $\mathrm{NO}_{\mathrm{x}}, \mathrm{CO}_{2}, \mathrm{CO}$ or PM speed correction factors, considering $20 \mathrm{mph}$ as the reference average speed. For this, were selected the values of emissions trendline at $5,7.5,10,12.5,15,17.5,20$ and so on until $30 \mathrm{mph}$ for the class 8 heavy-duty tractor truck and until $40 \mathrm{mph}$ for the class 6 medium-duty box truck. These values were divided by the value of emissions trendline at the considered reference of $20 \mathrm{mph}$, the results being the speed correction factors for each of the $\mathrm{NO}_{\mathrm{x}}, \mathrm{CO}_{2}, \mathrm{CO}$ and $\mathrm{PM}$ emissions.

To obtain more emissions data points and to have a wider area of average speeds covered, each cycle was divided in several microcycles. One microcycle was considered to be a section of a cycle between two zones where the vehicle speed is zero. For example WVU-5 Peak Cycle (shown in Figure 3.3) was divided in 5 microcycles as follows: the first between seconds 0 and 147, the second between seconds 148 and 298, the third between seconds 299 and 460, the fourth between seconds 461 and 634 and the fifth microcycle between seconds 635 and 823. Based on these microcycles another set of $\mathrm{NO}_{\mathrm{x}}, \mathrm{CO}_{2}, \mathrm{CO}$ and PM speed correction factors was developed for each vehicle in the same manner that was presented earlier on the same page. 
Because for the considered transit bus a single cycle (CBD) was available, there was no way to develop $\mathrm{NO}_{\mathrm{x}}, \mathrm{CO}_{2}, \mathrm{CO}$ or $\mathrm{PM}$ speed correction factors based on emissions versus cycles or microcycles average speed data.

The $\mathrm{NO}_{\mathrm{x}}, \mathrm{CO}_{2}, \mathrm{CO}$ and $\mathrm{PM}$ emissions versus cycles and microcycles average speed are presented in Figures 8.1, 8.2, 8.3 and 8.4 for the considered class 8 heavy-duty tractor truck and in Figures 8.9, 8.10, 8.11 and 8.12 for the considered class 6 mediumduty box truck. Likewise, generated $\mathrm{NO}_{\mathrm{x}}, \mathrm{CO}_{2}, \mathrm{CO}$ and $\mathrm{PM}$ speed correction factors versus cycles and microcycles average speed are presented in Figures 8.5, 8.6, 8.7 and 8.8 for the class 8 heavy-duty tractor truck and in Figures $8.13,8.14,8.15$ and 8.16 for the class 6 medium-duty box truck. Because PM emissions are measured only for a whole cycle PM speed correction factors versus microcycles average speed cannot be developed, unless a $\mathrm{CO}$ apportion similar to the one presented in chapter five is done.

The deviations between the whole cycles based speed correction factors and microcycles based speed correction factors appear because whole cycles have more time with engine running at idle speed when emission to vehicle speed or power ratio is nearly infinite. Another factor that conducts to these deviations is the difference between average power to average speed ratios of the whole cycles and the microcycles. 


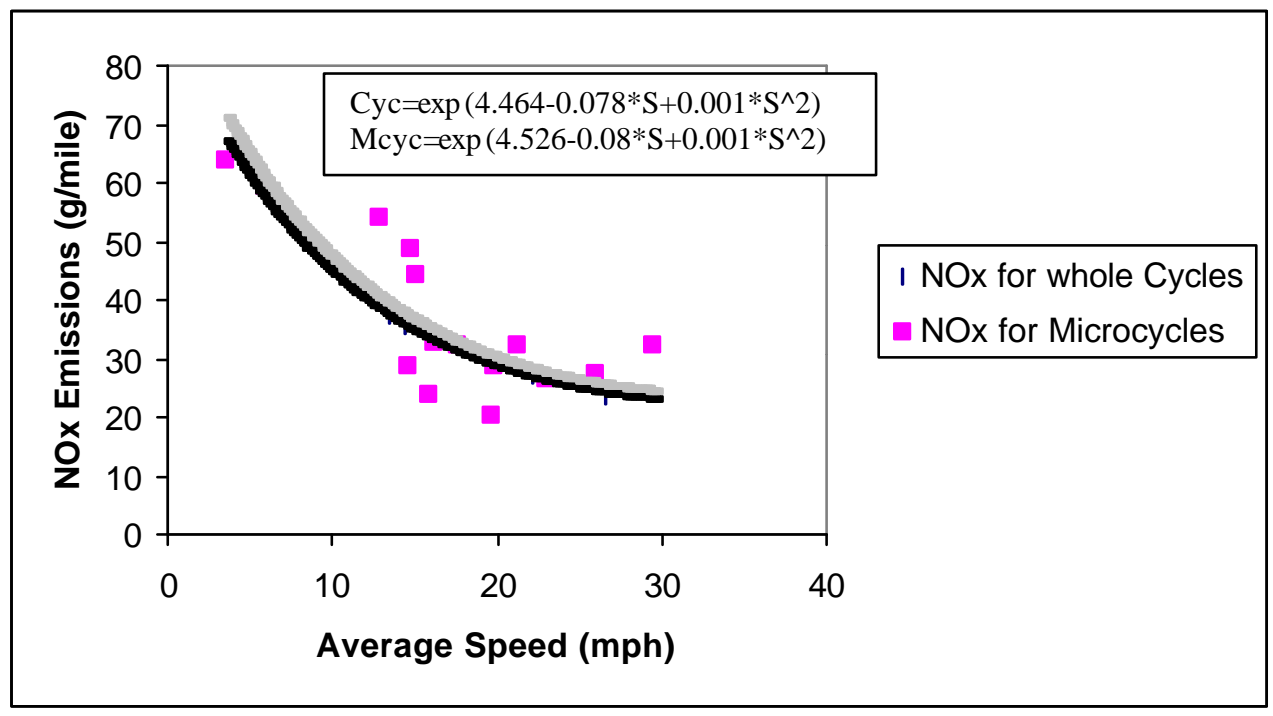

Figure 8.1 NO $_{\mathrm{x}}$ Emissions in g/mile Versus Average Speed for Several Cycles and Microcycles of these Cycles for the Considered Class 8 Heavy-Duty Tractor Truck Described in Table 4.2.

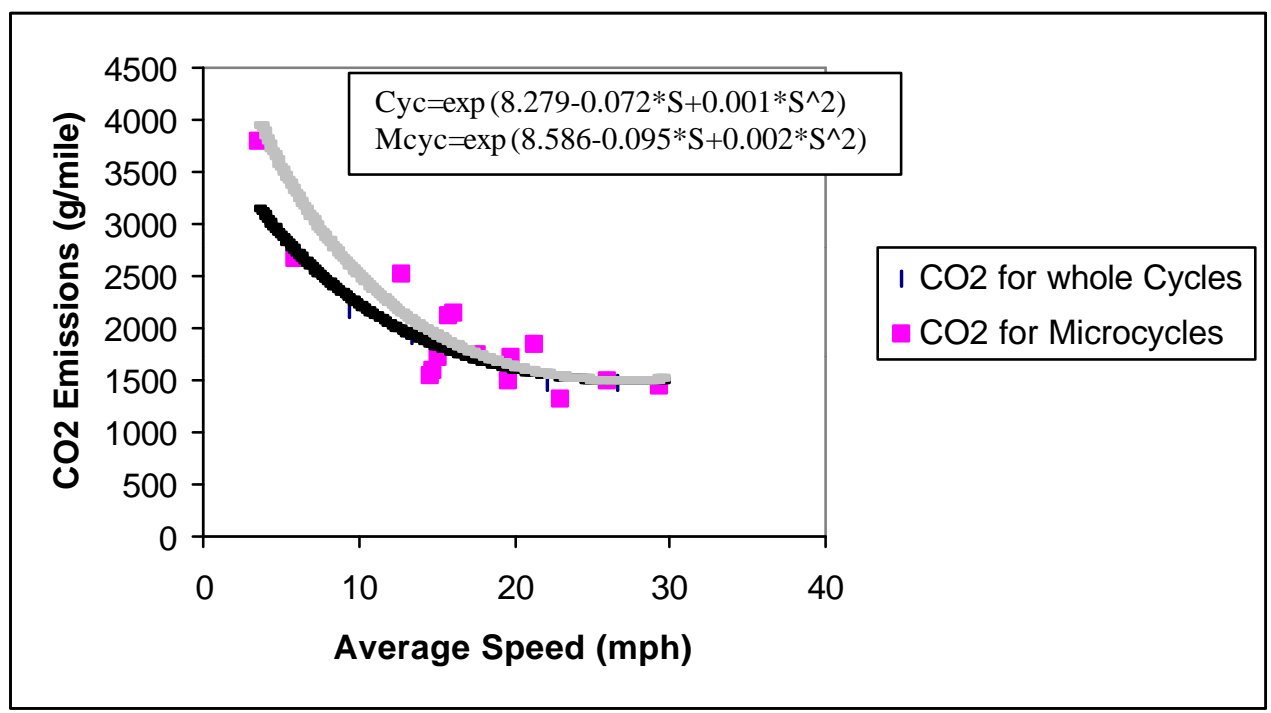

Figure 8.2 $\mathrm{CO}_{2}$ Emissions in g/mile Versus Average Speed for Several Cycles and Microcycles of these Cycles for the Considered Class 8 Heavy-Duty Tractor Truck Described in Table 4.2. 


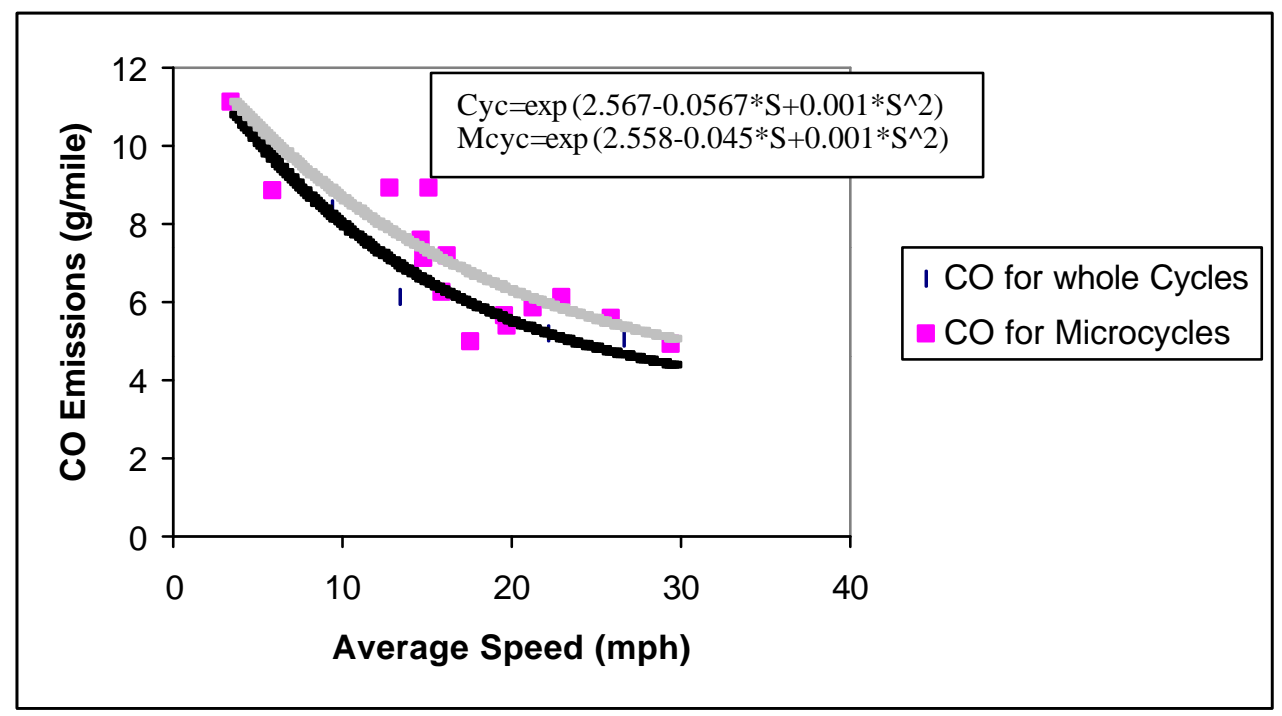

Figure 8.3 CO Emissions in g/mile Versus Average Speed for Several Cycles and Microcycles of these Cycles for the Considered Class 8 Heavy-Duty Tractor Truck Described in Table 4.2.

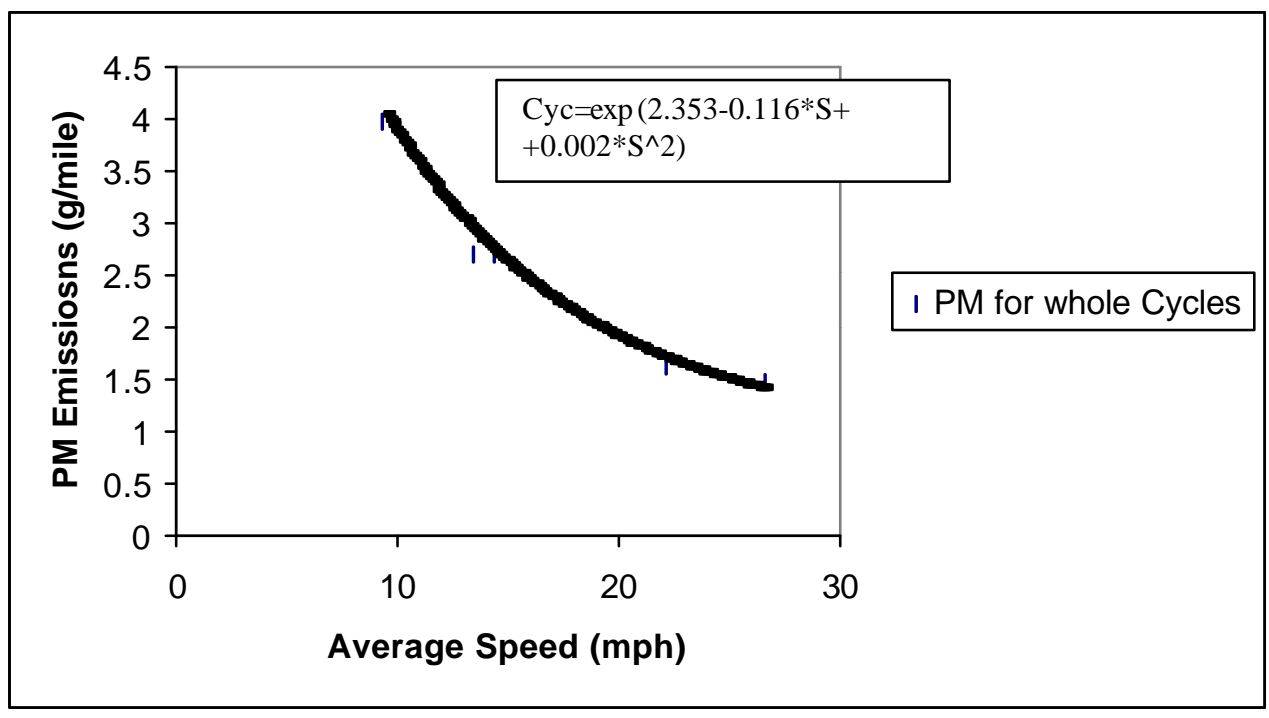

Figure 8.4 PM Emissions in g/mile Versus Average Speed for Several Cycles for the Considered Class 8 Heavy-Duty Tractor Truck Described in Table 4.2. 


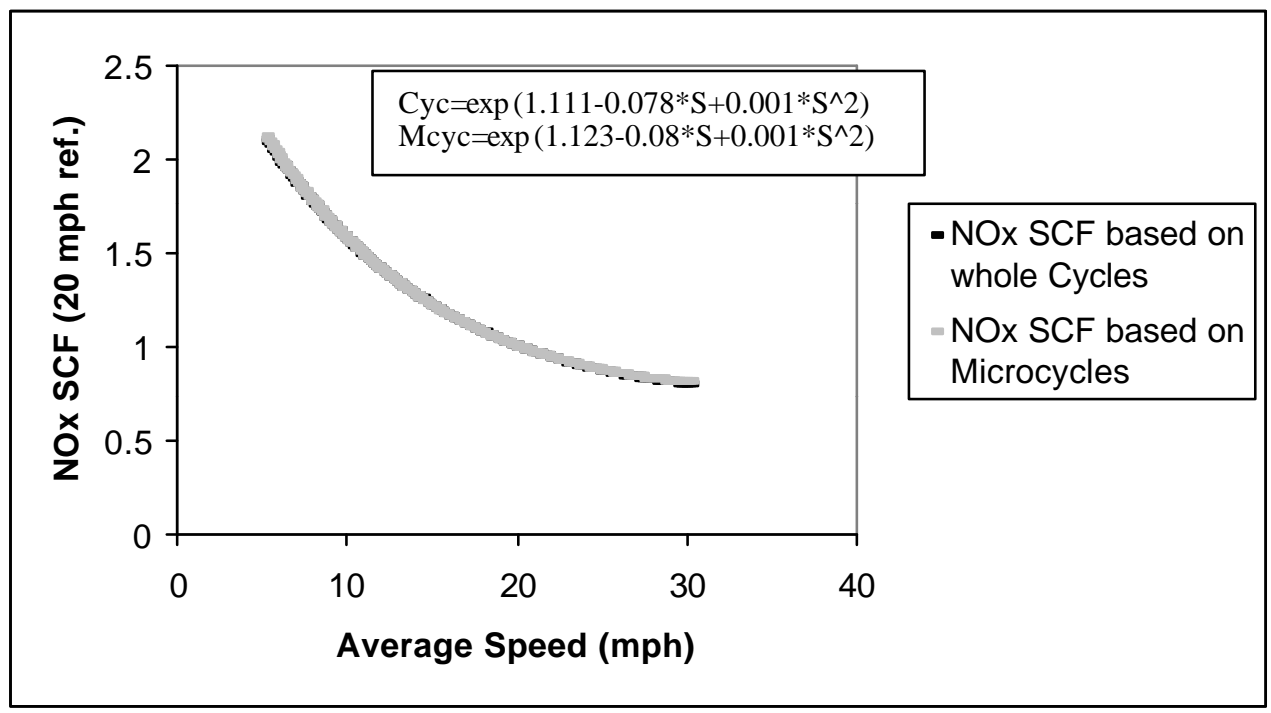

Figure 8.5 $\mathrm{NO}_{\mathrm{x}} \mathrm{SCF}$ Versus Average Speed for Several Cycles and Microcycles of these Cycles for the Class 8 Heavy-Duty Tractor Truck Described in Table 4.2. The SCF Uses Emissions Equations Shown in Figure 8.1.

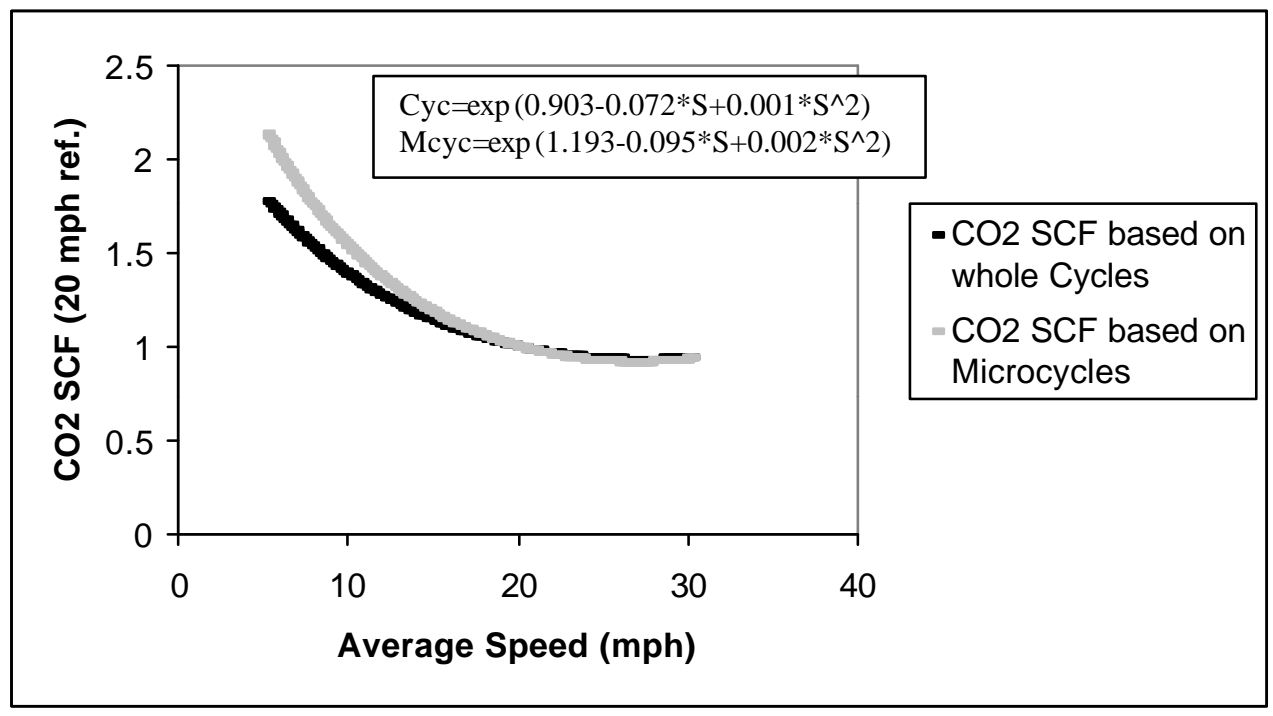

Figure 8.6 $\mathrm{CO}_{2} \mathrm{SCF}$ Versus Average Speed for Several Cycles and Microcycles of these Cycles for the Class 8 Heavy-Duty Tractor Truck Described in Table 4.2. The SCF Uses Emissions Equations Shown in Figure 8.2. 


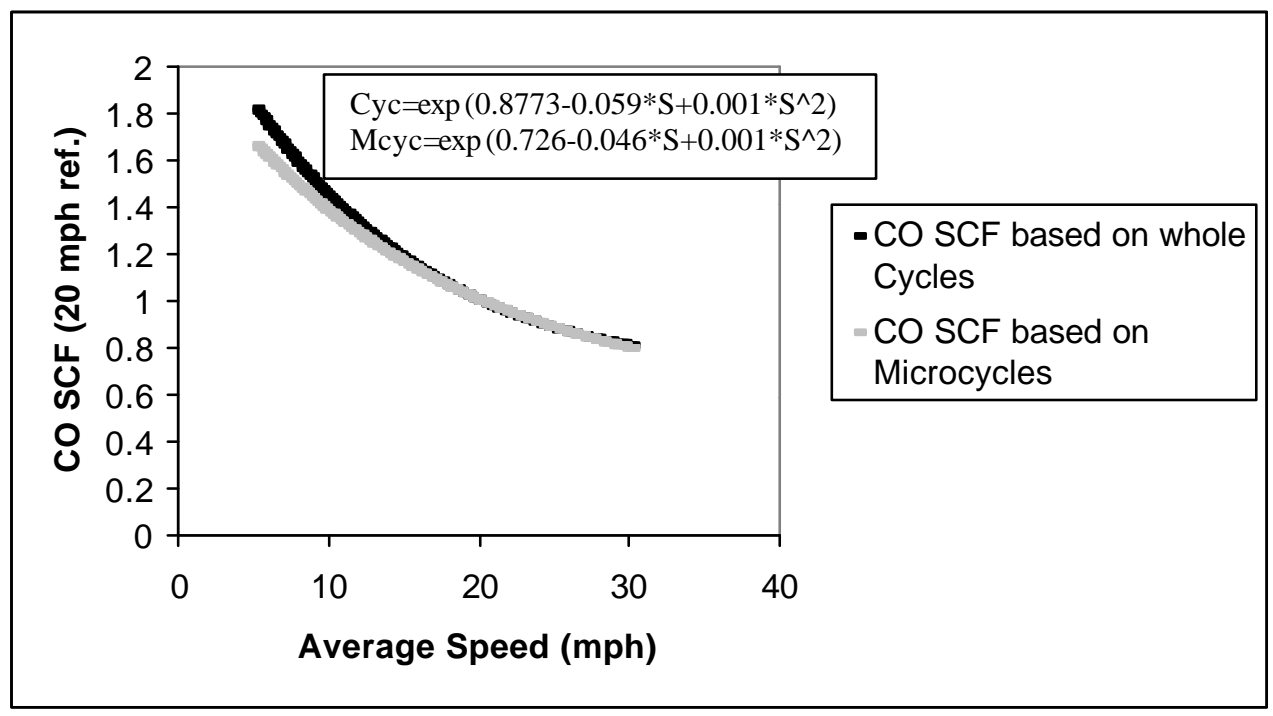

Figure 8.7 CO SCF Versus Average Speed for Several Cycles and Microcycles of these Cycles for the Class 8 Heavy-Duty Tractor Truck Described in Table 4.2. The SCF Uses Emissions Equations Shown in Figure 8.3.

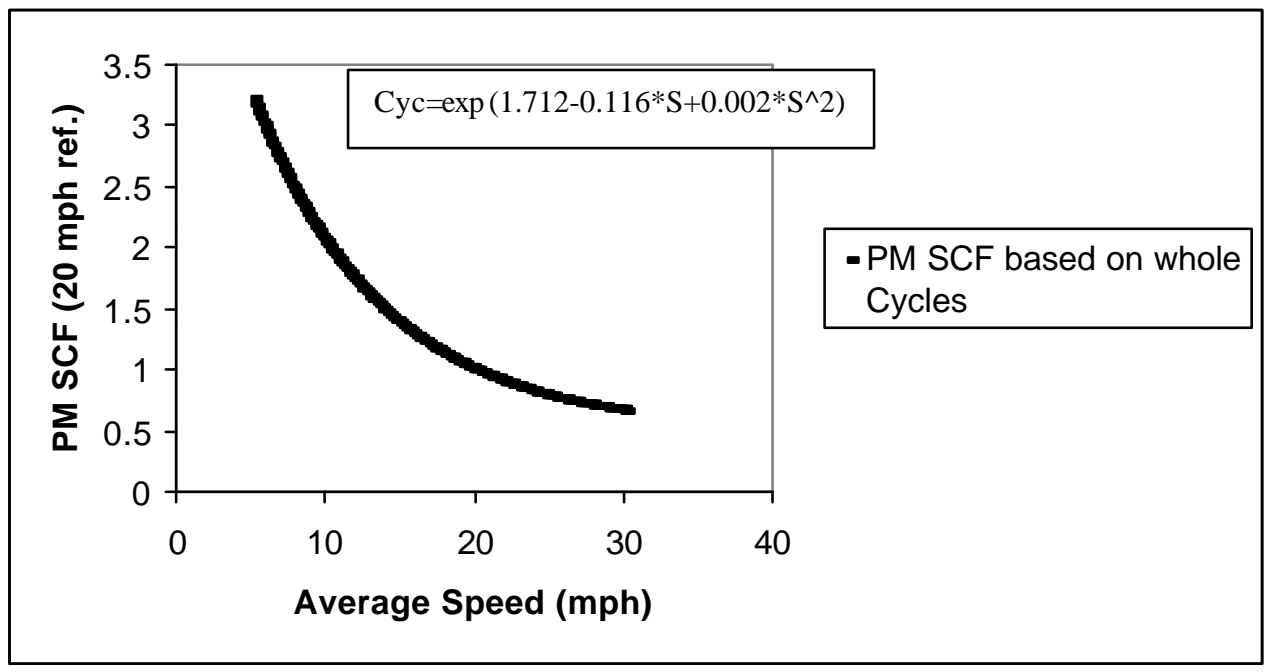

Figure 8.8 PM SCF Versus Average Speed for Several Cycles for the Class 8 HeavyDuty Tractor Truck Described in Table 4.2. The SCF Uses Emissions Equations Shown in Figure 8.4. 


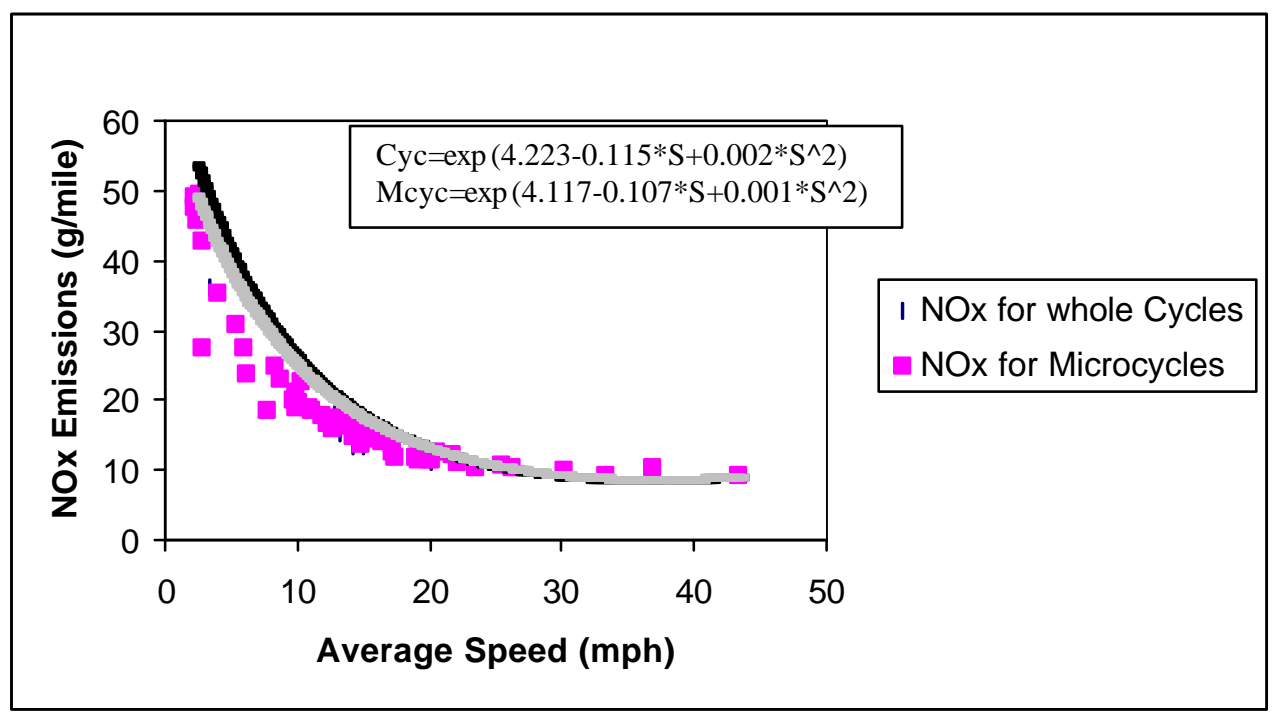

Figure 8.9 NO $_{\mathbf{x}}$ Emissions in g/mile Versus Average Speed for Several Cycles and Microcycles of these Cycles for the Considered Class 6 Medium-Duty Box Truck Described in Table 4.2.

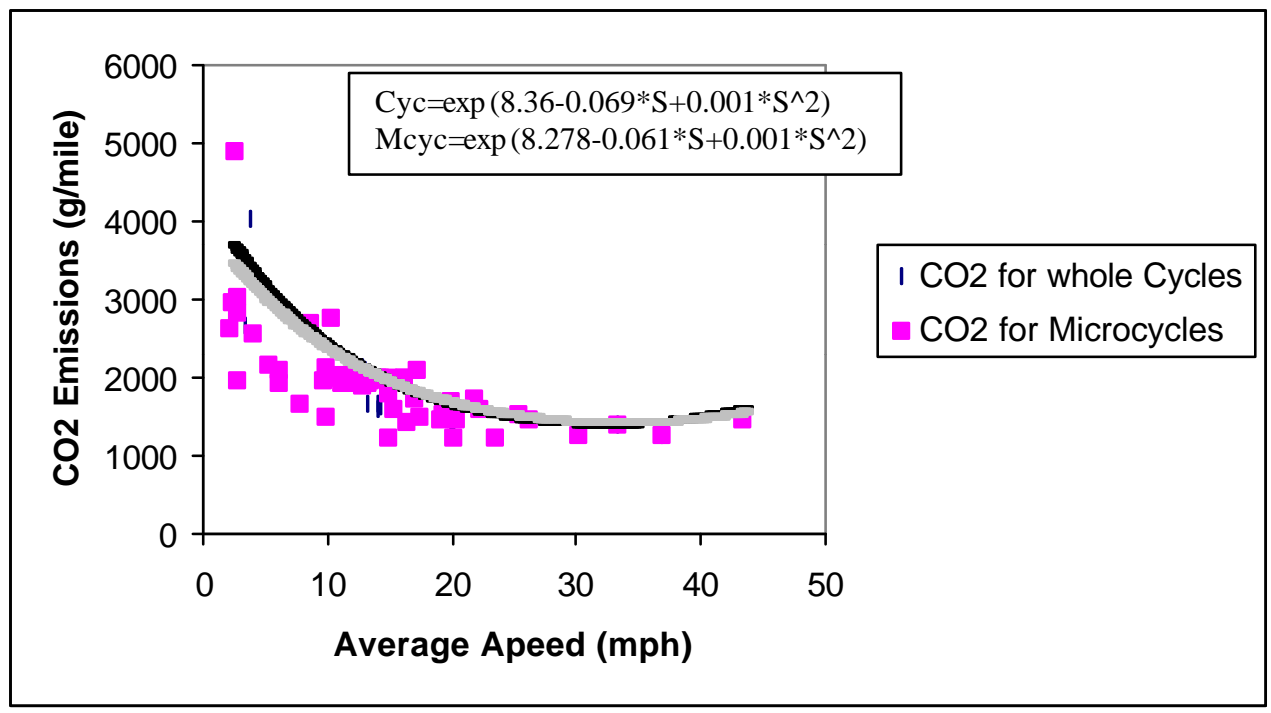

Figure 8.10 $\mathrm{CO}_{2}$ Emissions in g/mile Versus Average Speed for Several Cycles and Microcycles of these Cycles for the Considered Class 6 Medium-Duty Box Truck Described in Table 4.2. 


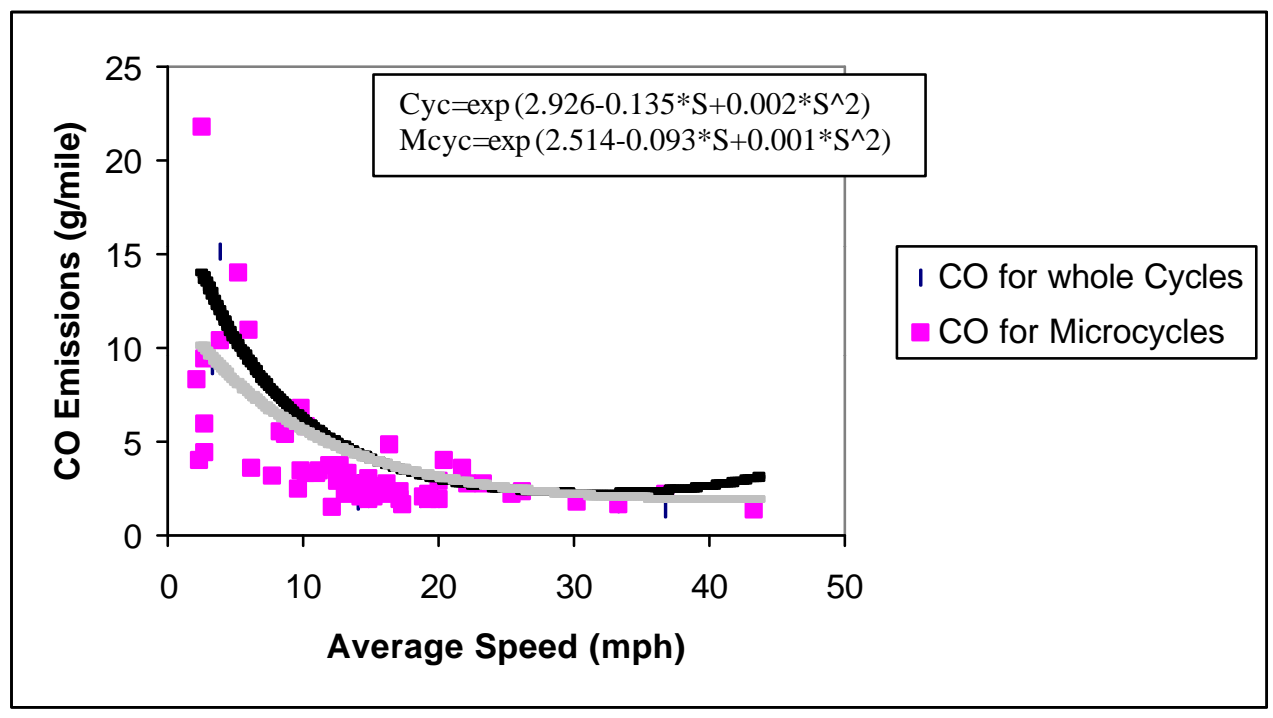

Figure 8.11 CO Emissions in g/mile Versus Average Speed for Several Cycles and Microcycles of these Cycles for the Considered Class 6 Medium-Duty Box Truck Described in Table 4.2.

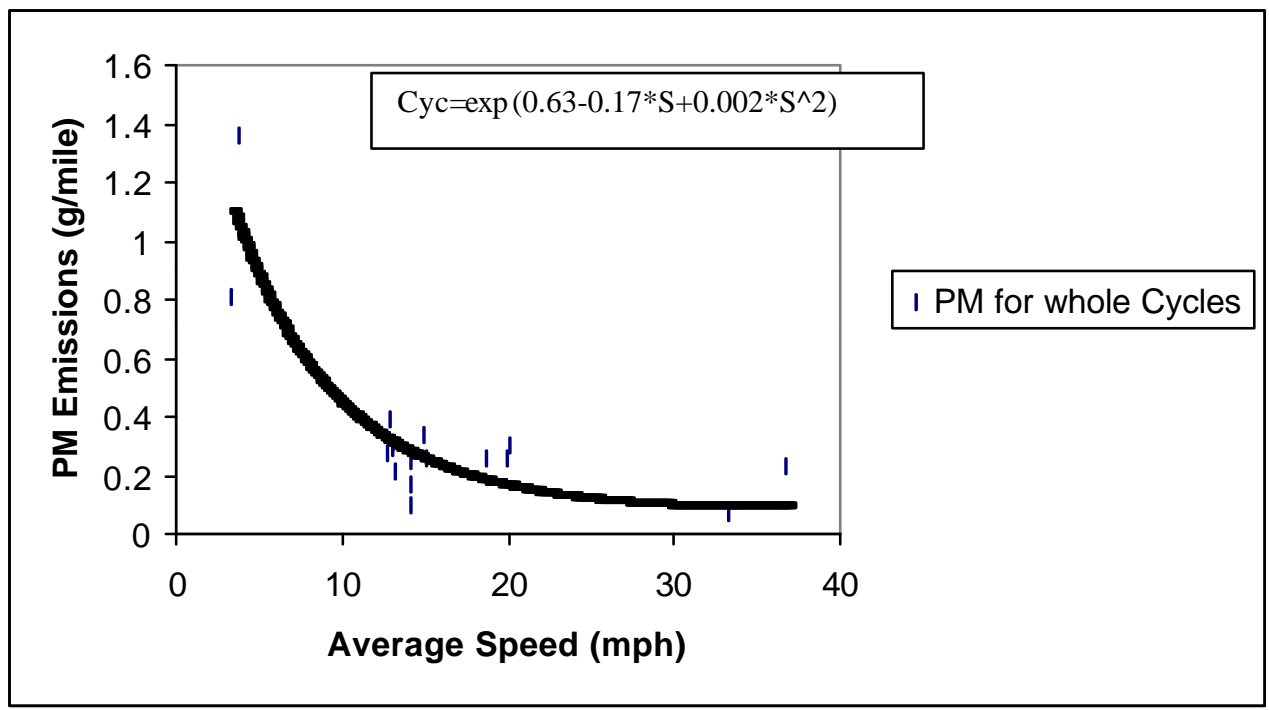

Figure 8.12 PM Emissions in g/mile Versus Average Speed for Several Cycles for the Considered Class 6 Medium-Duty Box Truck Described in Table 4.2. 


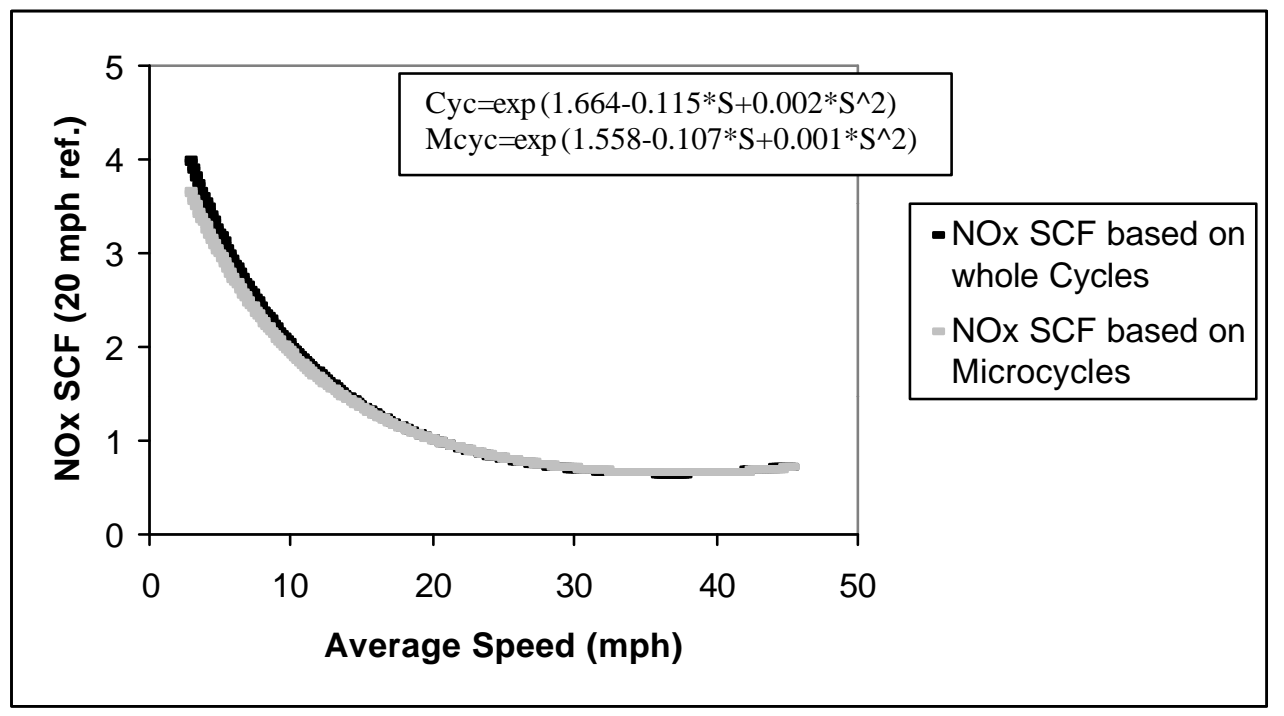

Figure 8.13 $\mathrm{NO}_{\mathrm{x}} \mathrm{SCF}$ Versus Average Speed for Several Cycles and Microcycles of these Cycles for the Class 6 Medium-Duty Box Truck Described in Table 4.2. The SCF Uses Emissions Equations Shown in Figure 8.9.

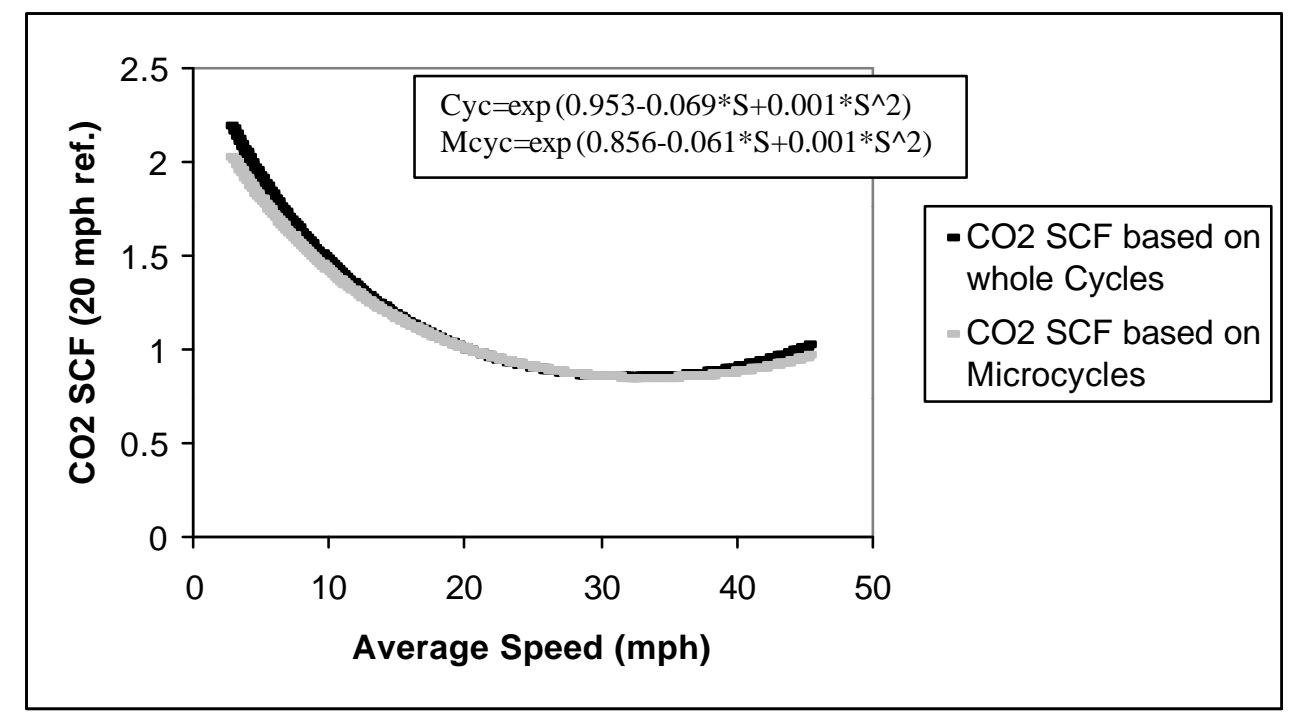

Figure 8.14 $\mathrm{CO}_{2} \mathrm{SCF}$ Versus Average Speed for Several Cycles and Microcycles of these Cycles for the Class 6 Medium-Duty Box Truck Described in Table 4.2. The SCF Uses Emissions Equations Shown in Figure 8.10. 


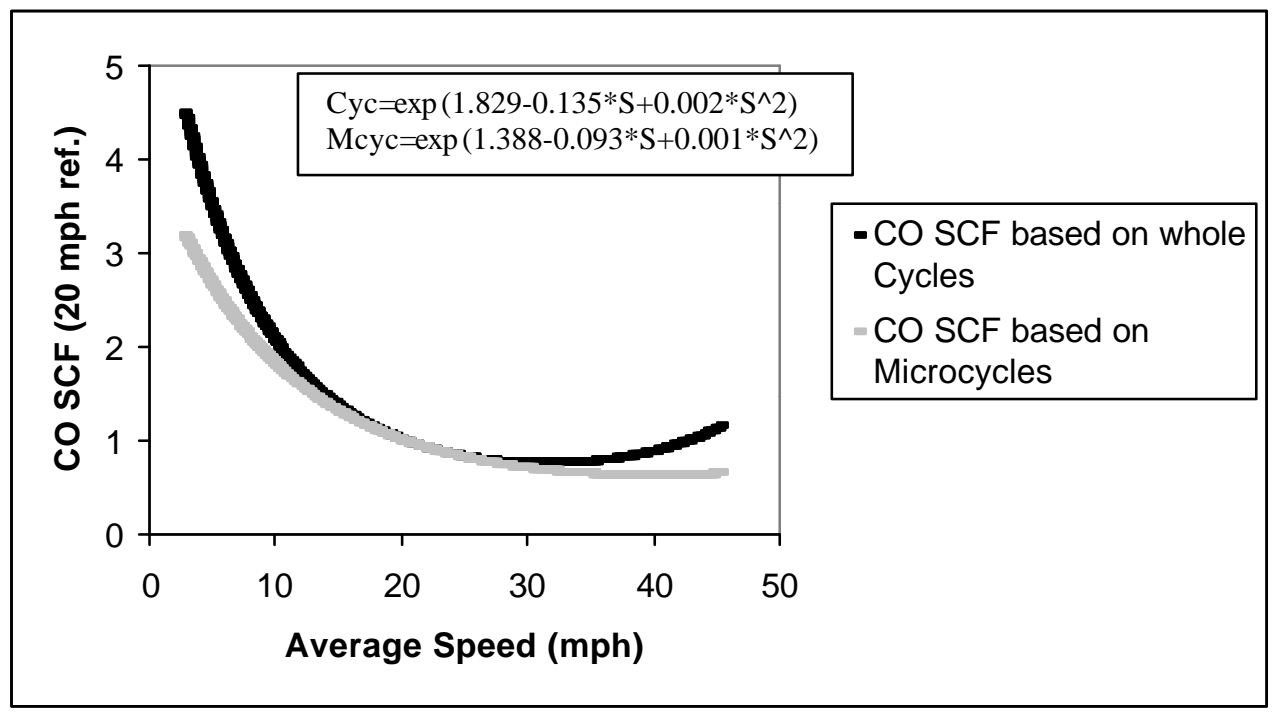

Figure 8.15 CO SCF Versus Average Speed for Several Cycles and Microcycles of these Cycles for the Class 6 Medium-Duty Box Truck Described in Table 4.2. The SCF Uses Emissions Equations Shown in Figure 8.11.

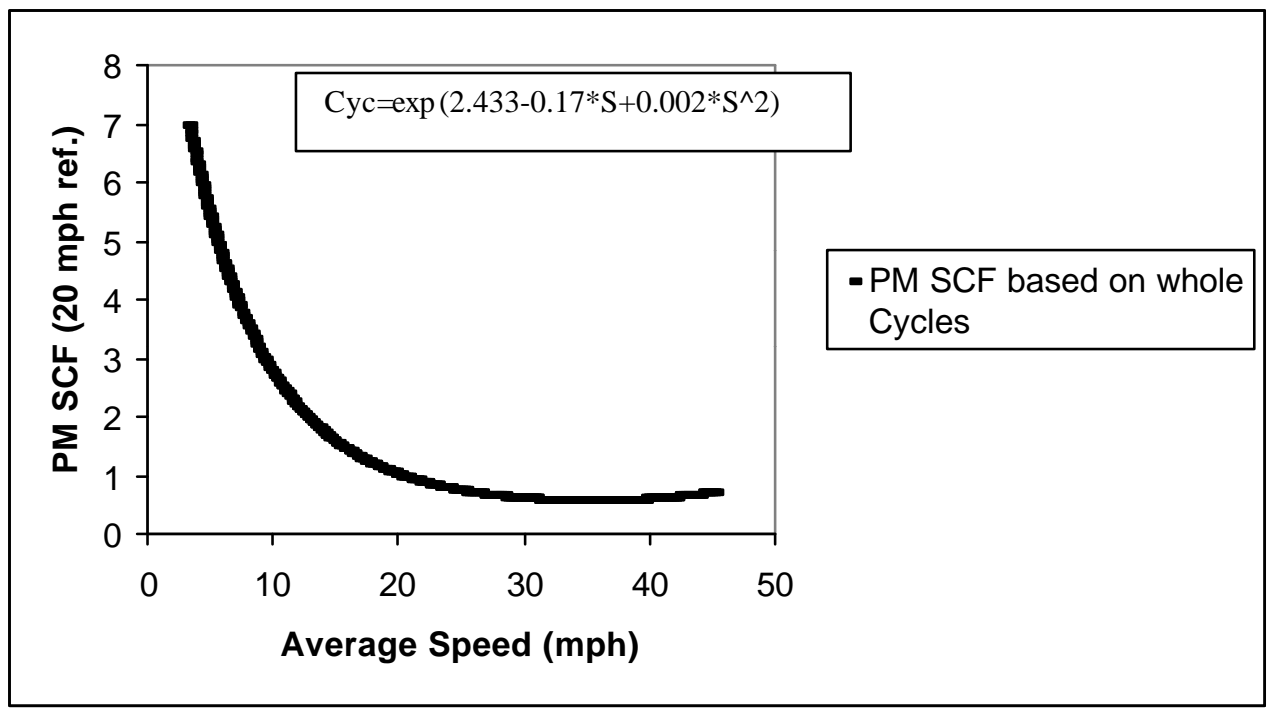

Figure 8.16 PM SCF Versus Average Speed for Several Cycles for the Class 6 Medium-Duty Box Truck Described in Table 4.2. The SCF Uses Emissions Equations Shown in Figure 8.12. 
To extend even more the range of vehicle average speeds, in order to obtain extended speed correction factors, there has been chosen the microcycle that includes the highest vehicle speed for each of the considered vehicles. Each of these microcycles were divided in several strips as shown in the simplified example from Figure 8.17 in order to obtain $\mathrm{NO}_{\mathrm{x}}, \mathrm{CO}_{2}$ and $\mathrm{CO}$ emissions data versus average speeds of 20, 15, 10 and $5 \mathrm{mph}$. For an average speed of $20 \mathrm{mph}$ were selected only data from zone 1; for an average speed of $15 \mathrm{mph}$ were selected all data from zones 1 and 2 , for an average speed of 10 mph were selected data that correspond to zones 1,2 and 3 and for an average speed of 5 mph were selected data from zones $1,2,3$ and as many data as necessary from zone 4 . If necessary, additional data of zero mph and nonzero emissions can be added to extremities of the zone 4.

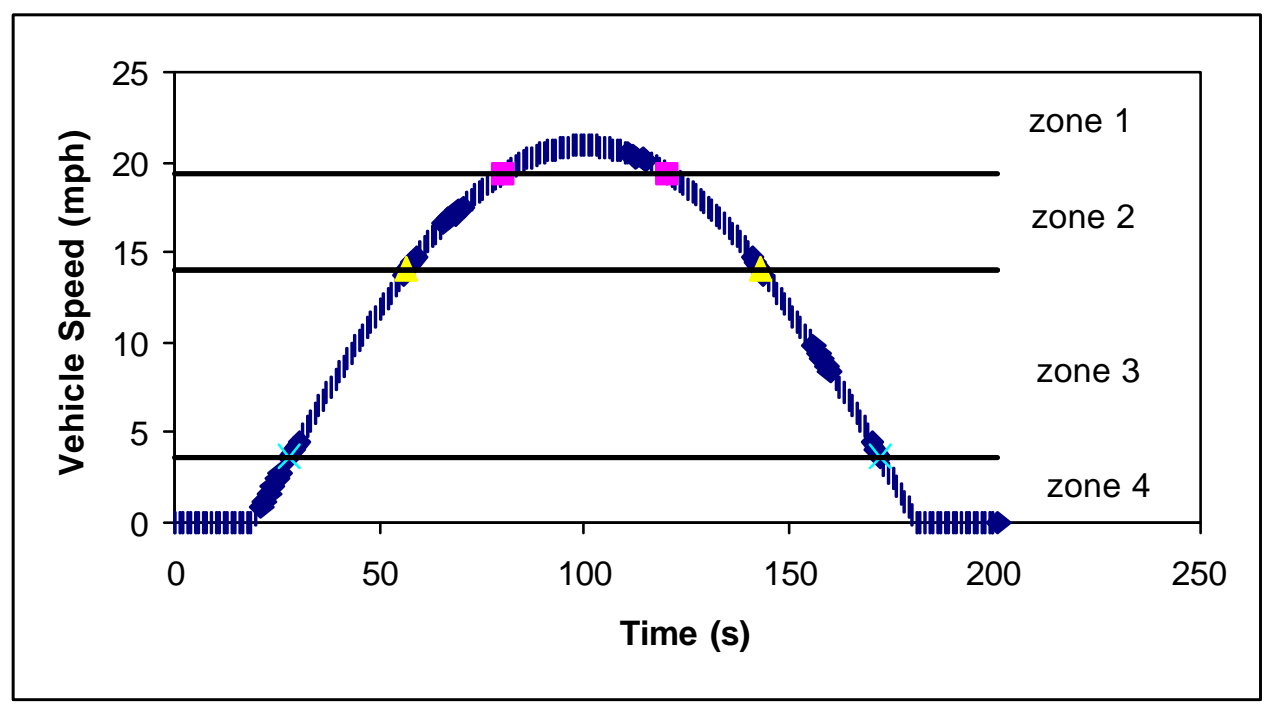

Figure 8.17 Simplified Model of a Divided Microcycle Used to Develop $\mathrm{NO}_{\mathrm{x}}, \mathrm{CO}_{2}$ and CO SCF. 
For the class 8 heavy-duty tractor truck the microcycle with the highest average speed of the CSHVR was divided in 8 zones in order to obtain $\mathrm{NO}_{\mathrm{x}}, \mathrm{CO}_{2}$ and $\mathrm{CO}$ emissions versus averages speeds of 40, 35, 30, 25, 20, 15, 10 and $5 \mathrm{mph}$. For the class 6 medium-duty box truck the microcycle with the highest average speed of a Highway Cycle was divided in 11 zones in order to obtain $\mathrm{NO}_{\mathrm{x}}, \mathrm{CO}_{2}$ and $\mathrm{CO}$ emissions versus averages speeds of 55, 50, 45, 40, 35, 30, 25, 20, 15, 10 and $5 \mathrm{mph}$. For the class 8 transit bus the microcycle with the highest average speed of the CBD Cycle was divided in 4 zones in order to obtain $\mathrm{NO}_{\mathrm{x}}, \mathrm{CO}_{2}$ and $\mathrm{CO}$ emissions versus averages speeds of 20, 15, 10 and $5 \mathrm{mph}$. The emissions and speed correction factors results of this analysis based on microcycles divided in zones are presented in Figures 8.18 to 8.23 for the class 8 heavy-duty tractor truck, in Figures 8.24 to 8.29 for the class 6 medium-duty box truck and in Figures 8.30 to 8.35 for the considered class 8 transit bus.

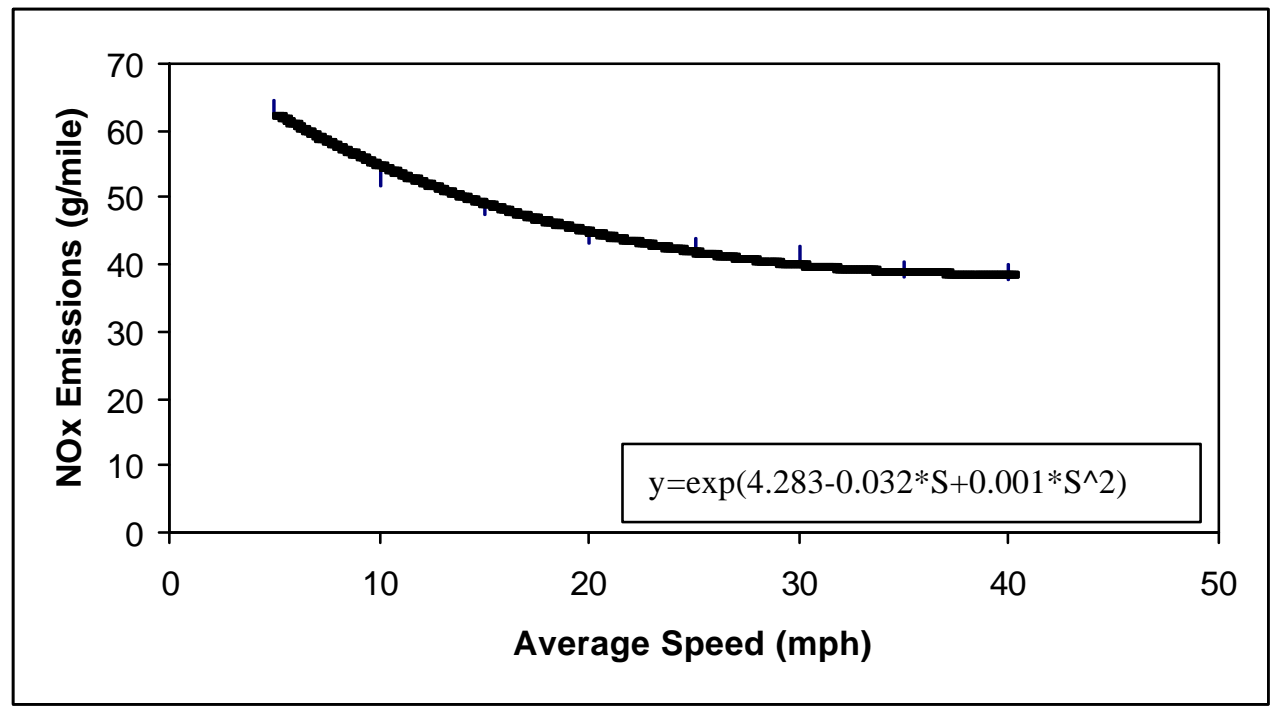

Figure 8.18 NO$_{\mathrm{x}}$ Emissions in g/mile Versus Average Speed for Different Zones of a Microcycle of the CSHVR for the Considered Class 8 Heavy-Duty Tractor Truck Described in Table 4.2. 


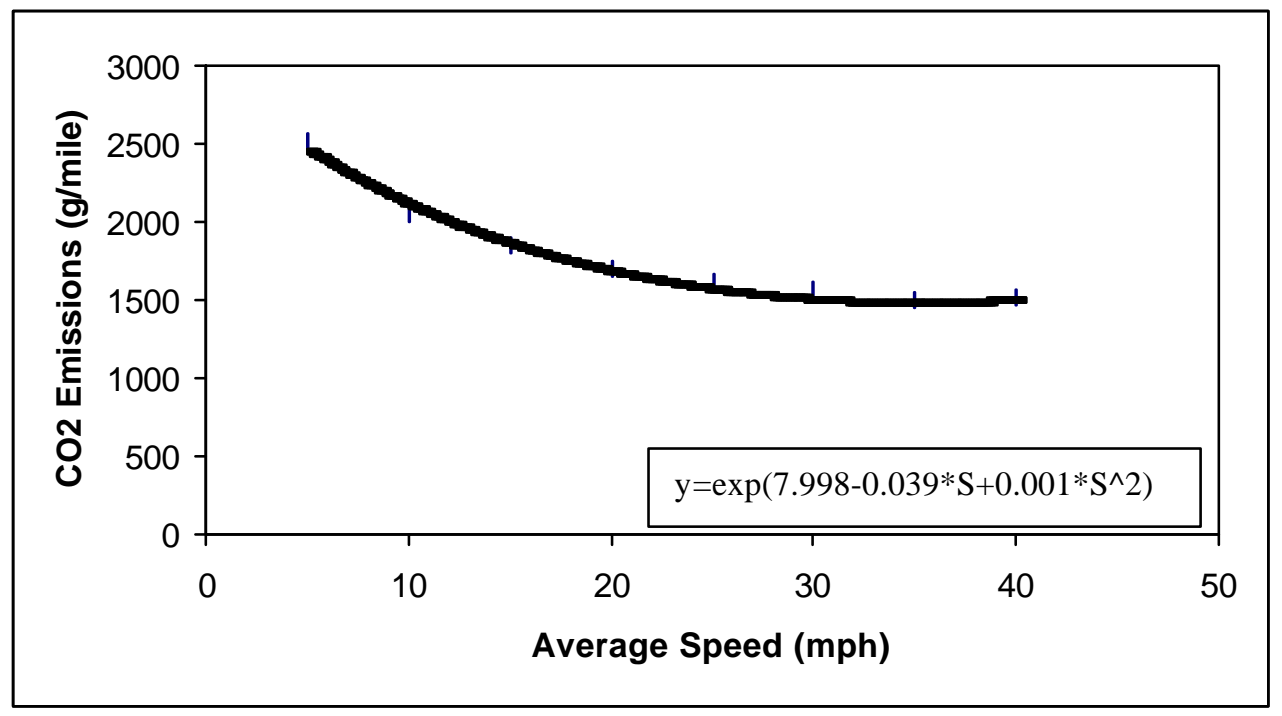

Figure 8.19 $\mathrm{CO}_{2}$ Emissions in g/mile Versus Average Speed for Different Zones of a Microcycle of the CSHVR for the Considered Class 8 Heavy-Duty Tractor Truck Described in Table 4.2.

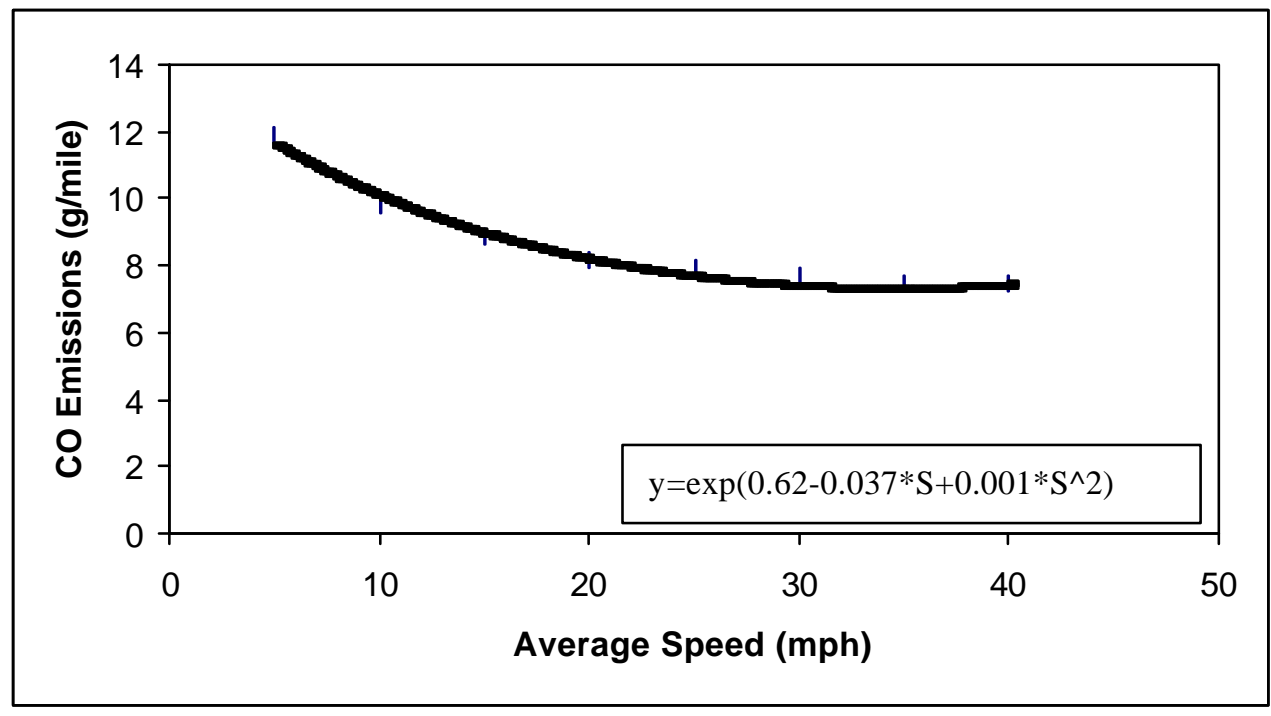

Figure 8.20 CO Emissions in g/mile Versus Average Speed for Different Zones of a Microcycle of the CSHVR for the Considered Class 8 Heavy-Duty Tractor Truck Described in Table 4.2. 


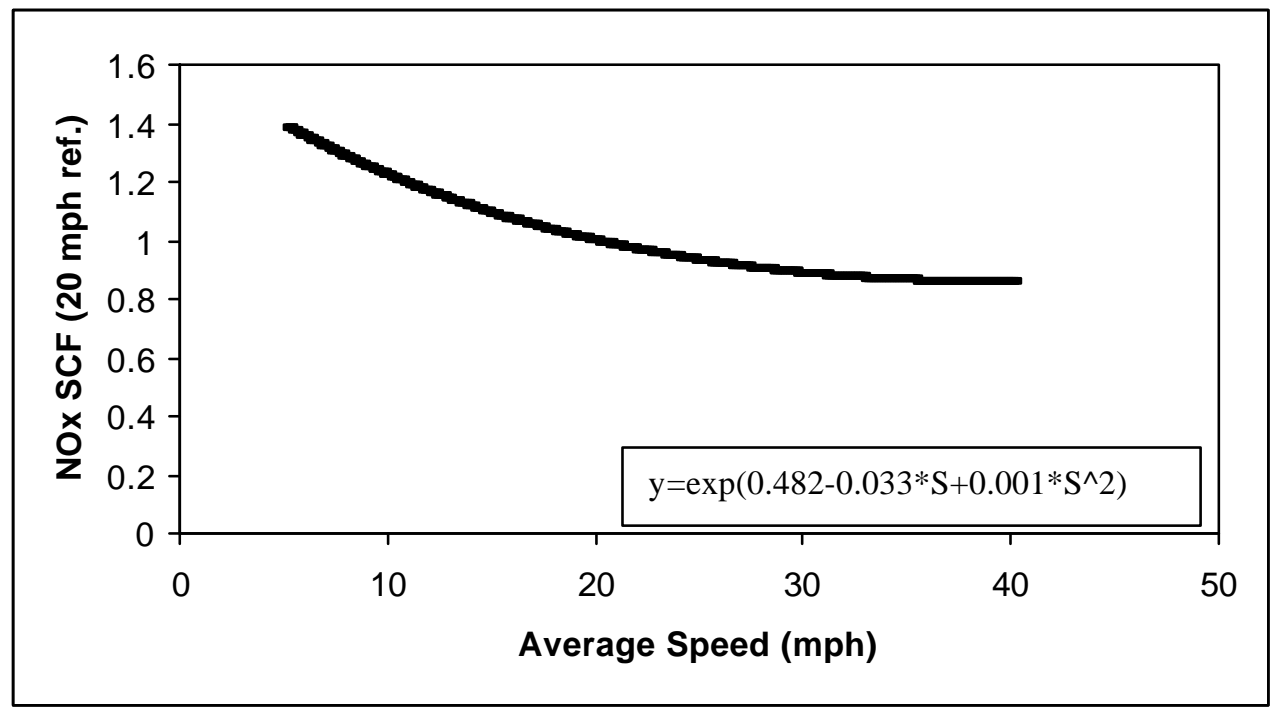

Figure 8.21 NO $_{x}$ SCF Versus Average Speed Based on the Model Presented in Figure 8.18 for the Considered Class 8 Heavy-Duty Tractor Truck Described in Table 4.2.

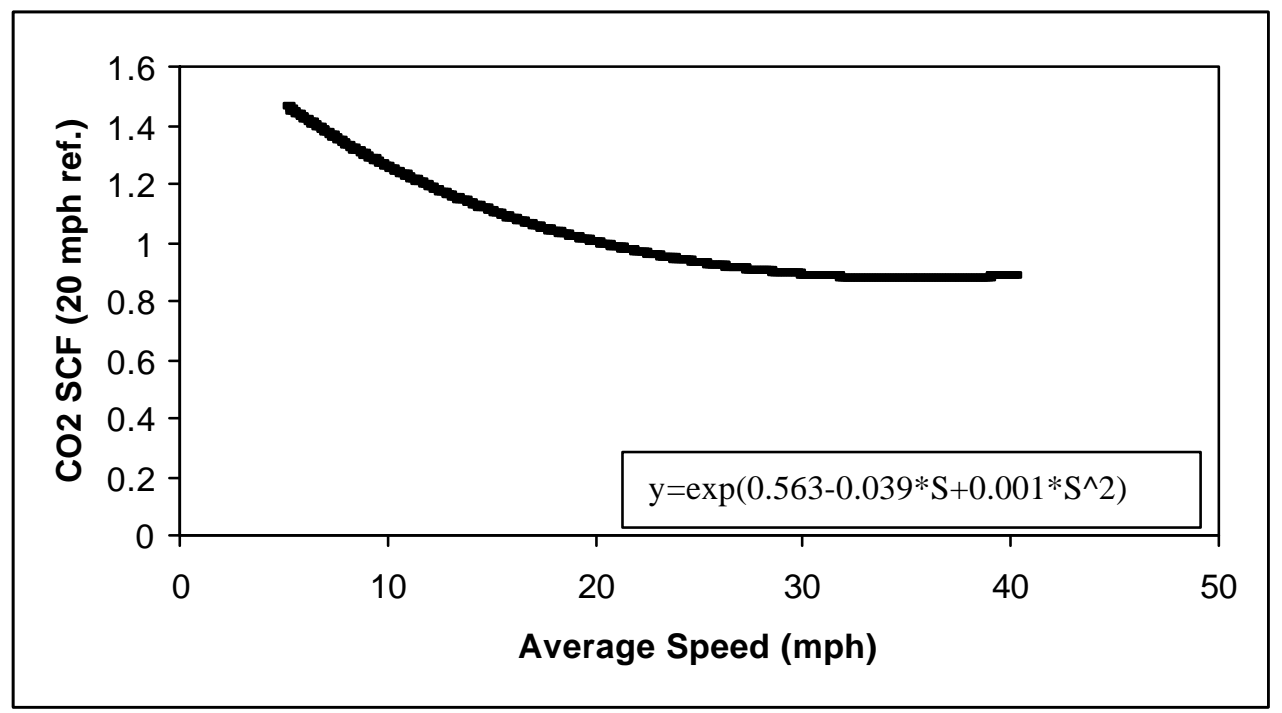

Figure 8.22 $\mathrm{CO}_{2} \mathrm{SCF}$ Versus Average Speed Based on the Model Presented in Figure 8.19 for the Considered Class 8 Heavy-Duty Tractor Truck Described in Table 4.2. 


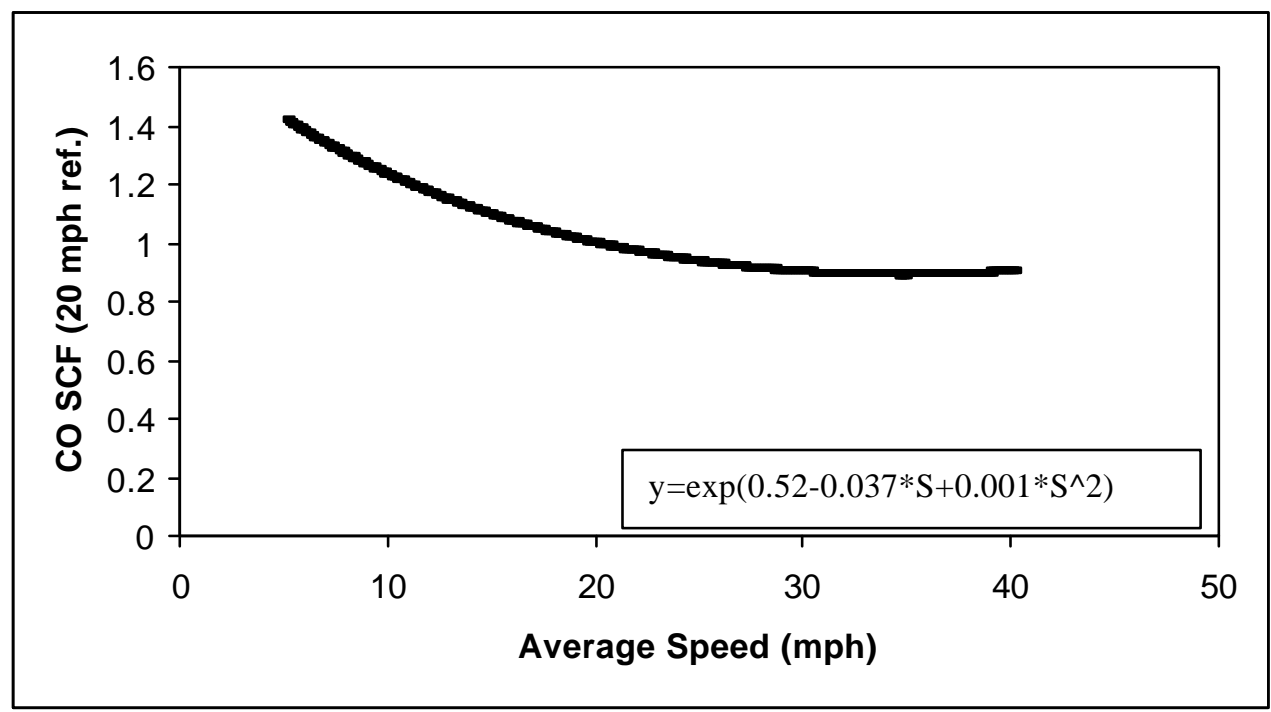

Figure 8.23 CO SCF Versus Average Speed Based on the Model Presented in Figure 8.20 for the Considered Class 8 Heavy-Duty Tractor Truck Described in Table 4.2.

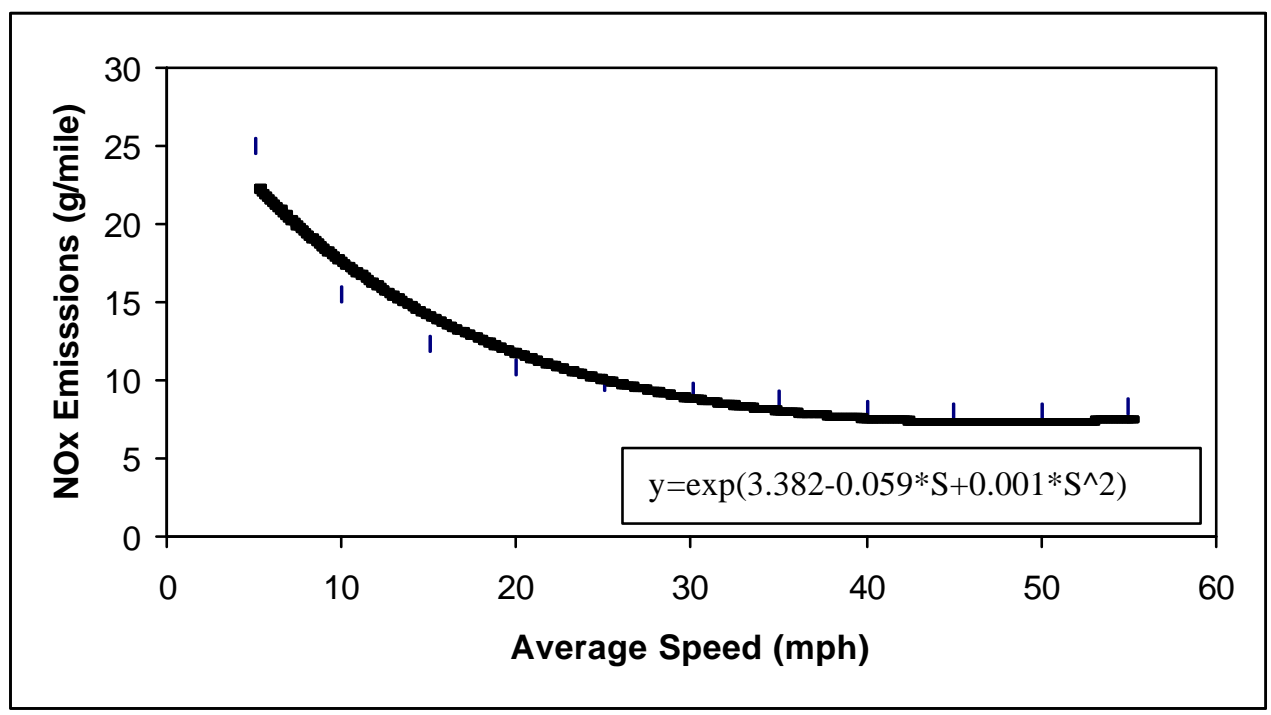

Figure 8.24 $\mathrm{NO}_{\mathrm{x}}$ Emissions in g/mile Versus Average Speed for Different Zones of a Microcycle of a Highway Cycle for the Considered Class 6 Medium-Duty Box Truck Described in Table 4.2. 


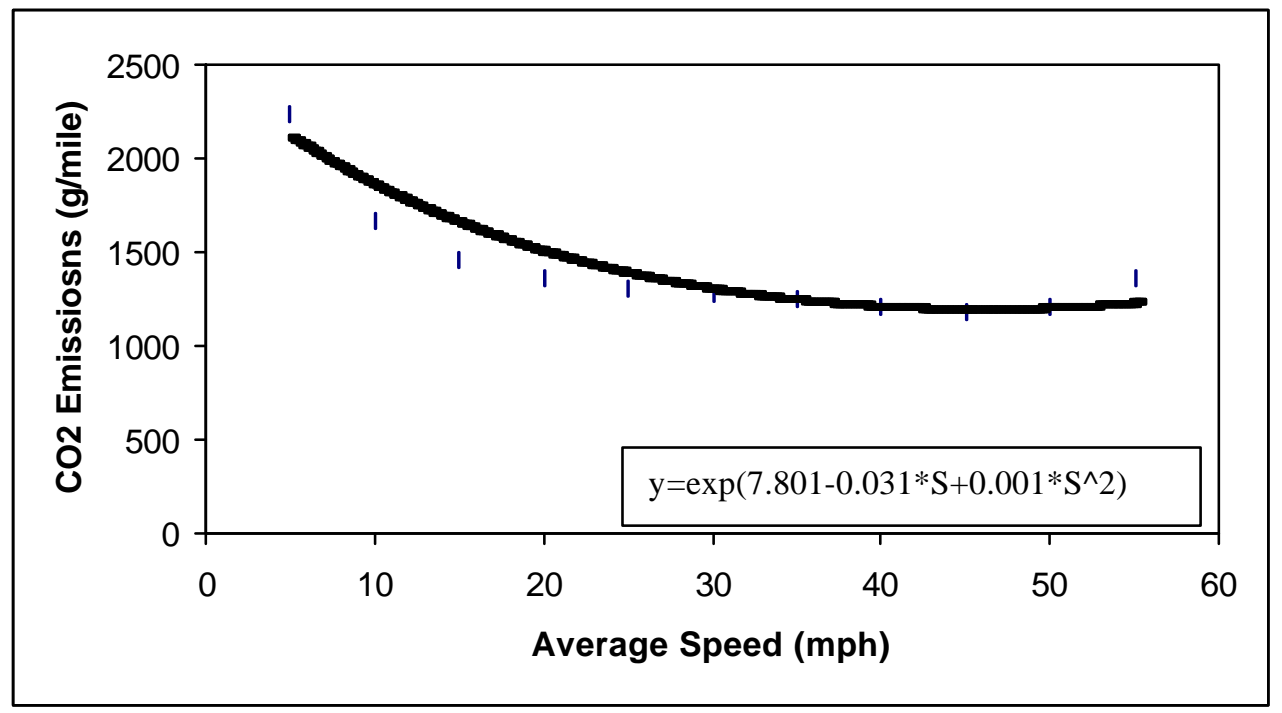

Figure 8.25 $\mathrm{CO}_{2}$ Emissions in g/mile Versus Average Speed for Different Zones of a Microcycle of a Highway Cycle for the Considered Class 6 Medium-Duty Box Truck Described in Table 4.2.

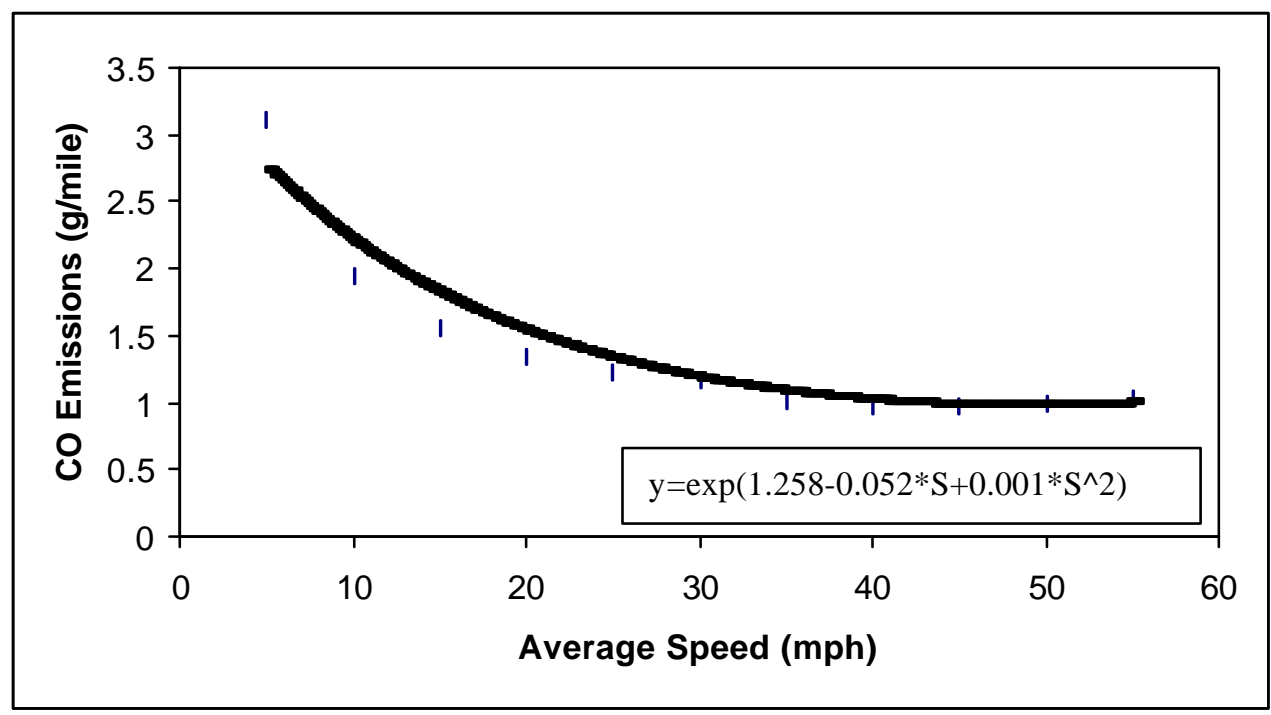

Figure 8.26 CO Emissions in g/mile Versus Average Speed for Different Zones of a Microcycle of a Highway Cycle for the Considered Class 6 Medium-Duty Box Truck Described in Table 4.2. 


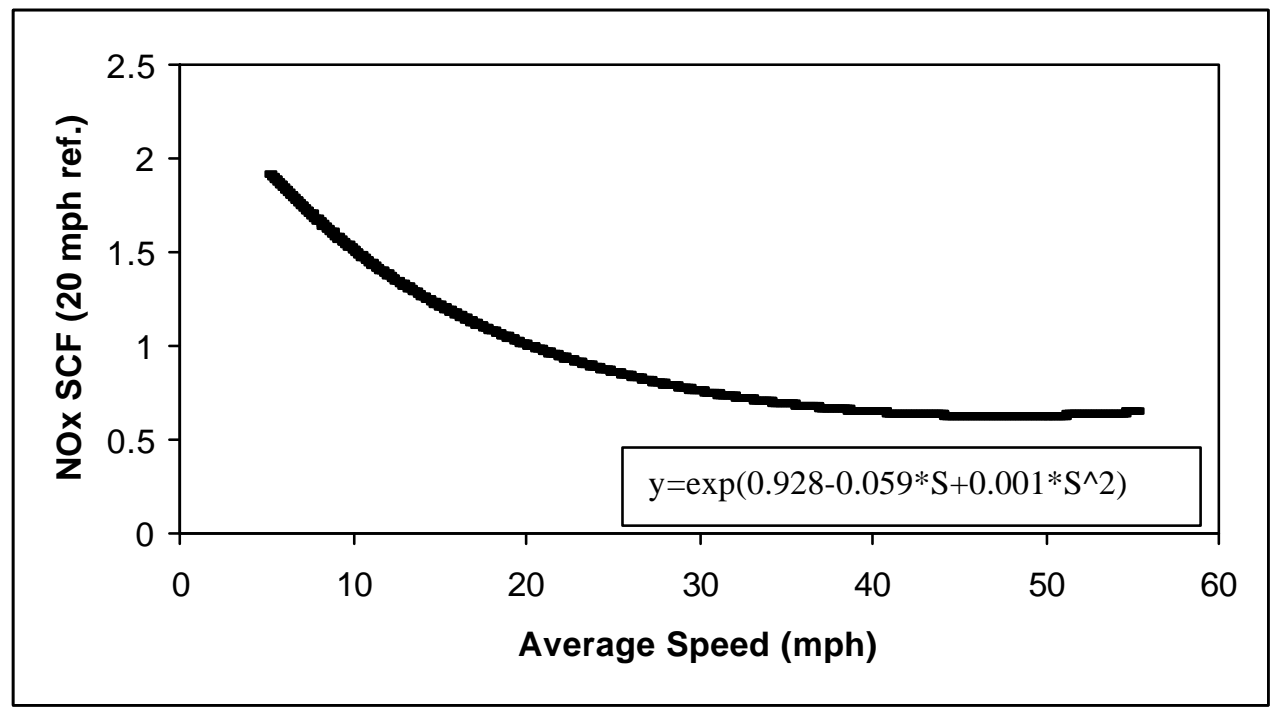

Figure 8.27 $\mathrm{NO}_{\mathrm{x}}$ SCF Versus Average Speed Based on the Model Presented in Figure 8.24 for the Considered Class 6 Medium-Duty Box Truck Described in Table 4.2.

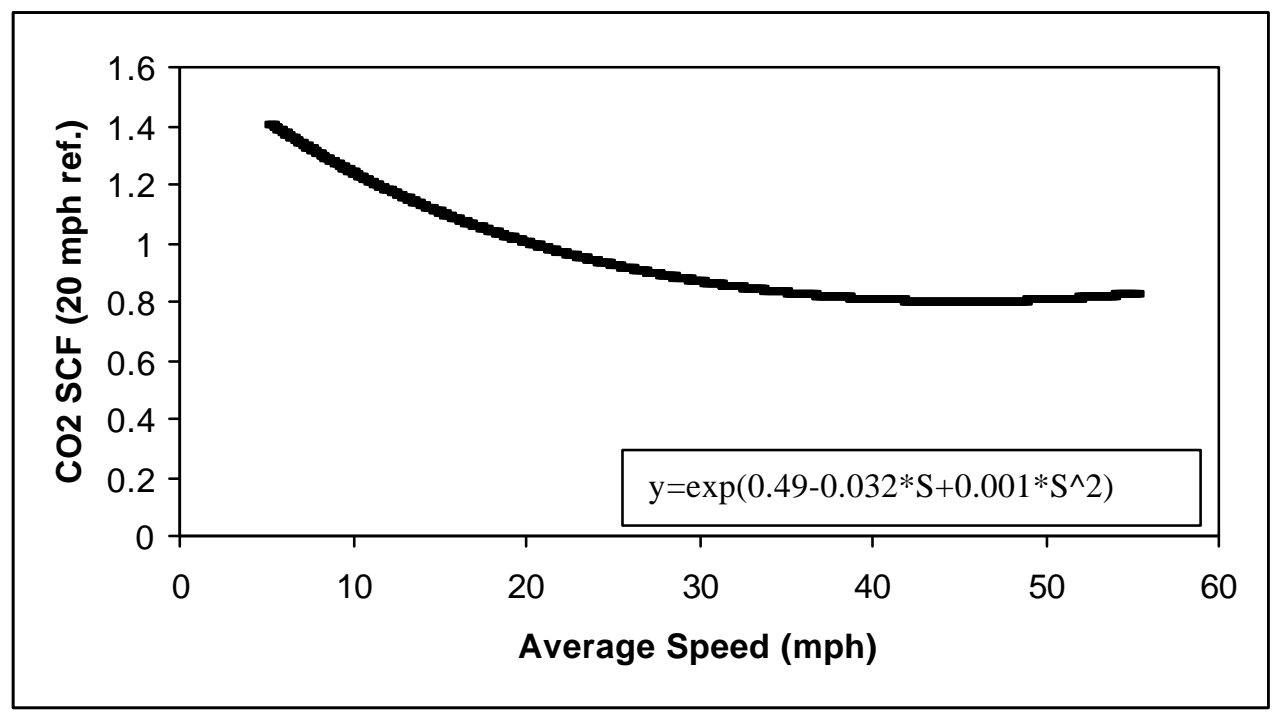

Figure 8.28 $\mathrm{CO}_{2} \mathrm{SCF}$ Versus Average Speed Based on the Model Presented in Figure 8.25 for the Considered Class 6 Medium-Duty Box Truck Described in Table 4.2. 


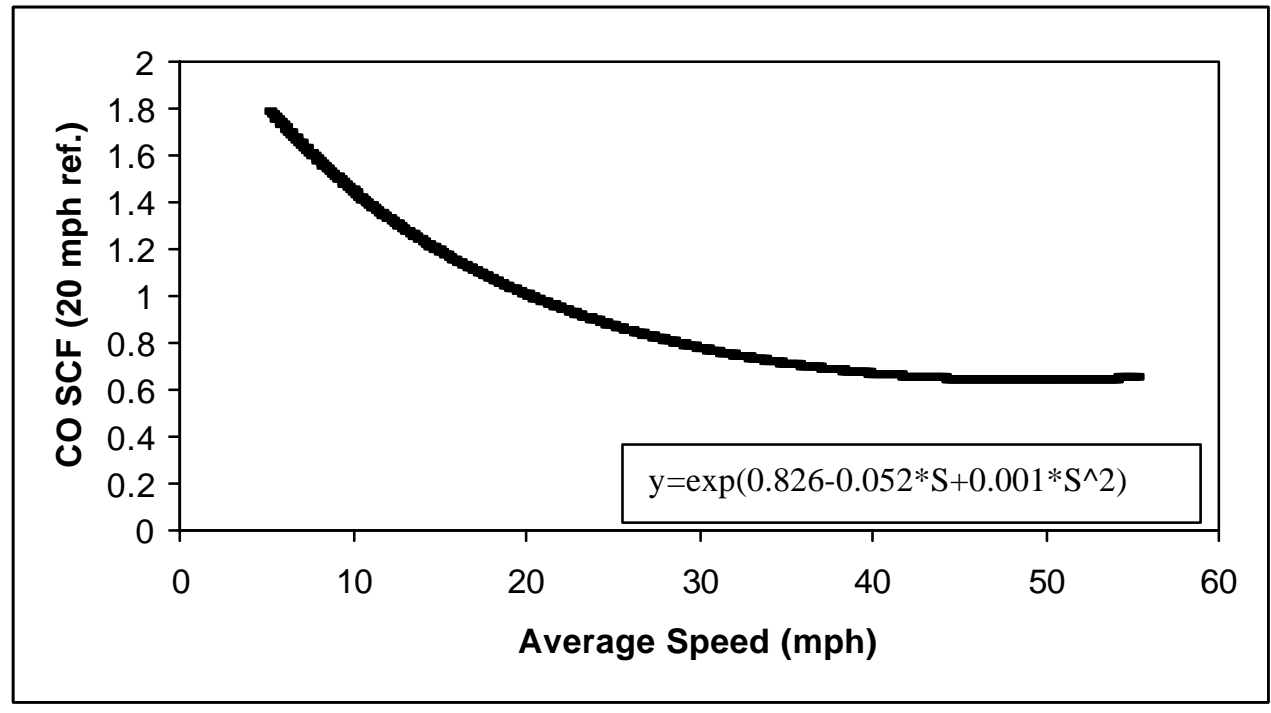

Figure 8.29 CO SCF Versus Average Speed Based on the Model Presented in Figure 8.26 for the Considered Class 6 Medium-Duty Box Truck Described in Table 4.2.

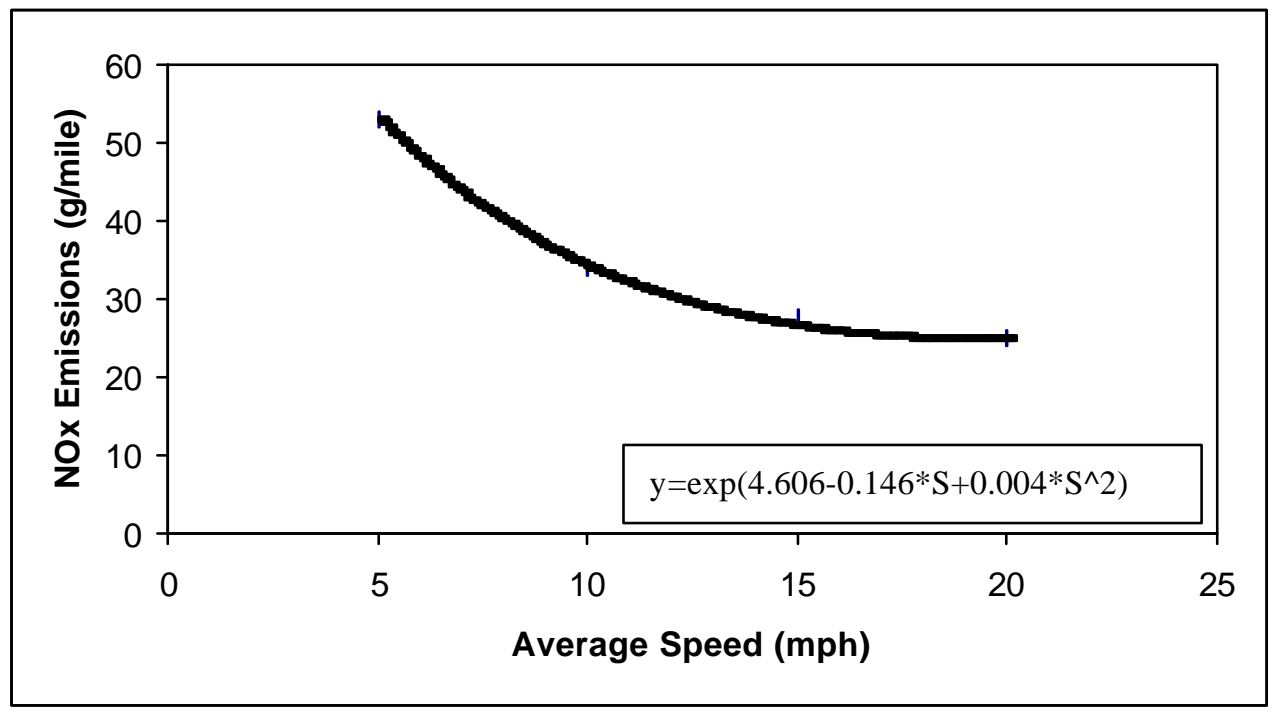

Figure 8.30 $\mathrm{NO}_{\mathrm{x}}$ Emissions in g/mile Versus Average Speed for Different Zones of a Microcycle of the CBD Cycle for the Considered Class 8 Transit Bus Described in Table 4.2. 


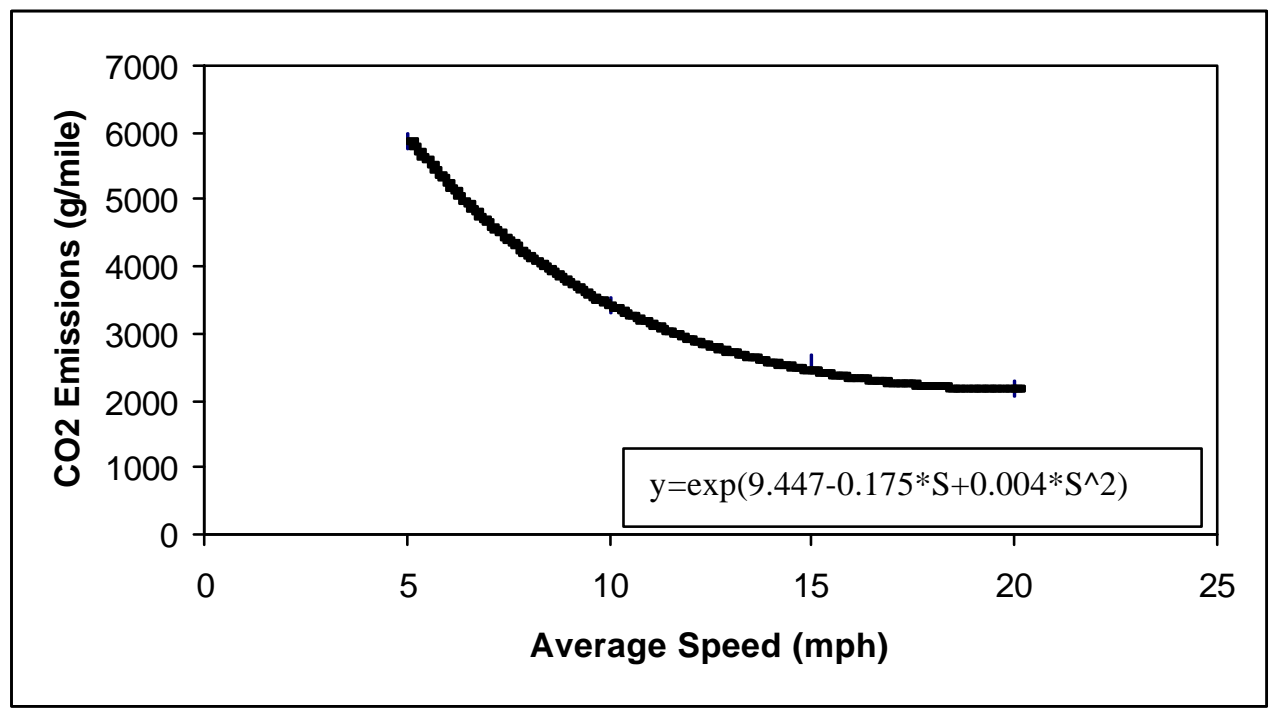

Figure 8.31 $\mathrm{CO}_{2}$ Emissions in g/mile Versus Average Speed for Different Zones of a Microcycle of the CBD Cycle for the Considered Class 8 Transit Bus Described in Table 4.2.

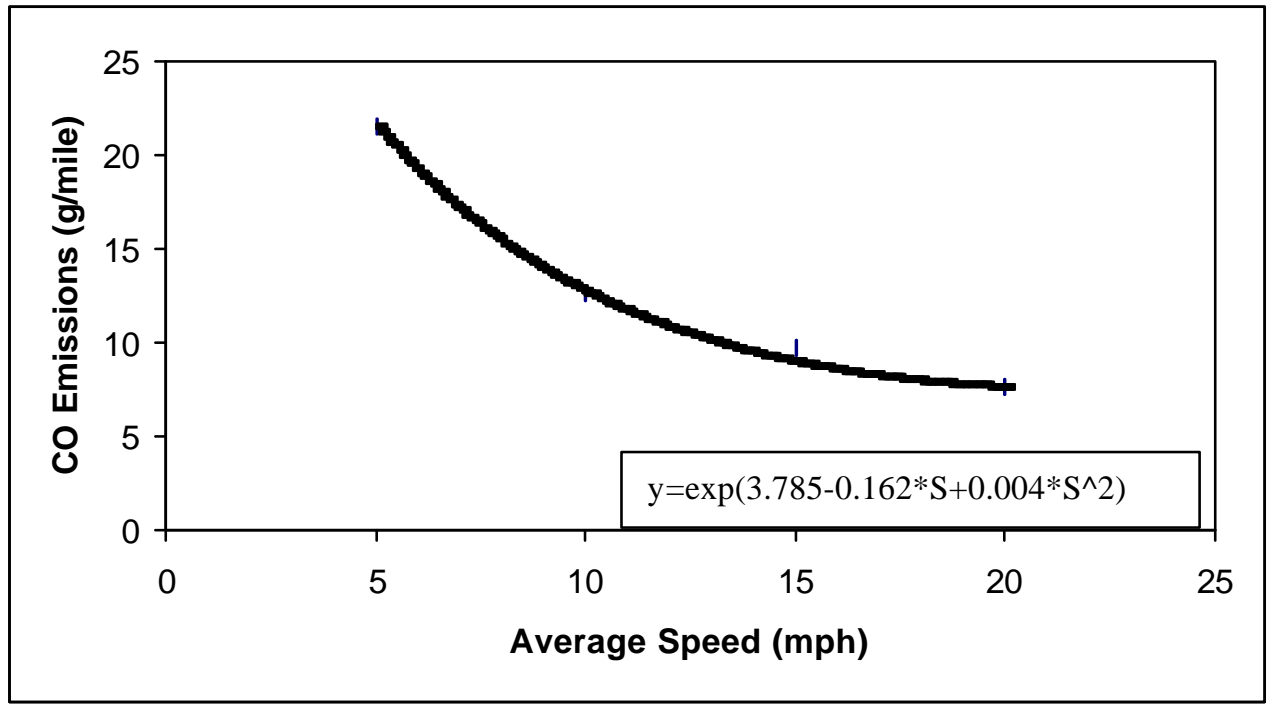

Figure 8.32 CO Emissions in g/mile Versus Average Speed for Different Zones of a Microcycle of the CBD Cycle for the Considered Class 8 Transit Bus Described in Table 4.2. 


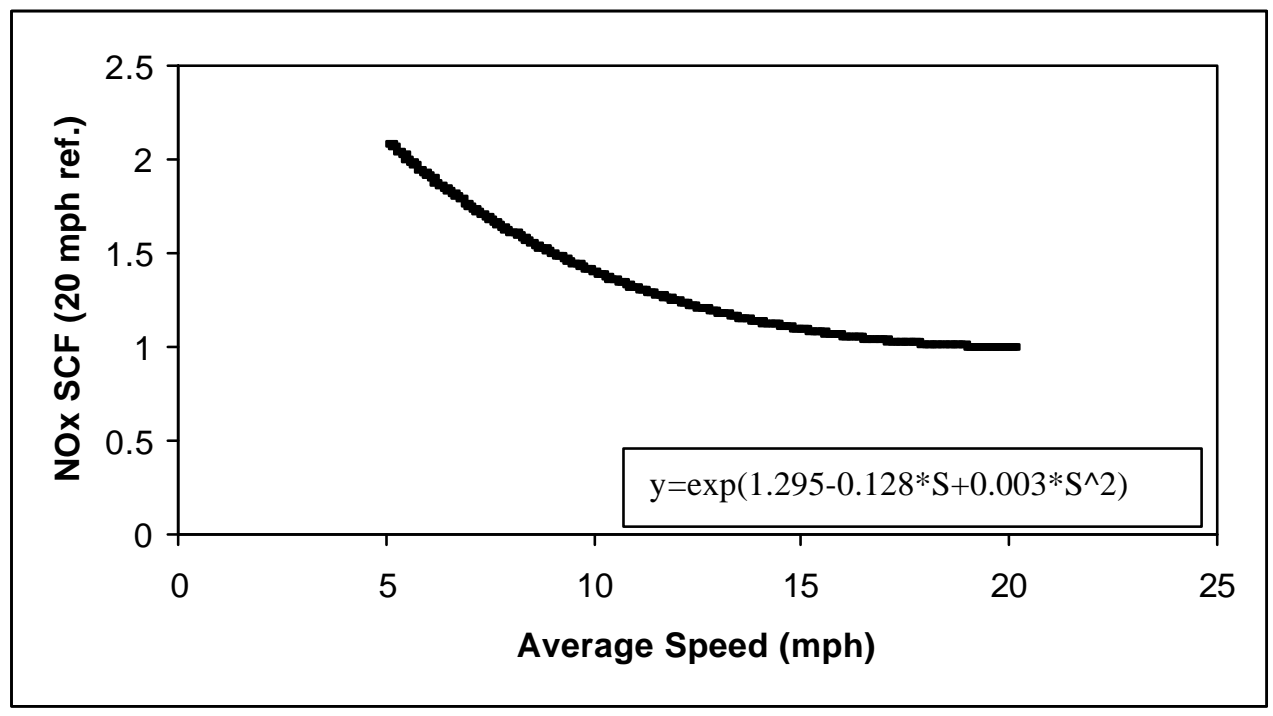

Figure 8.33 NO$_{x}$ SCF Versus Average Speed Based on the Model Presented in Figure 8.30 for the Considered Class 8 Transit Bus Described in Table 4.2.

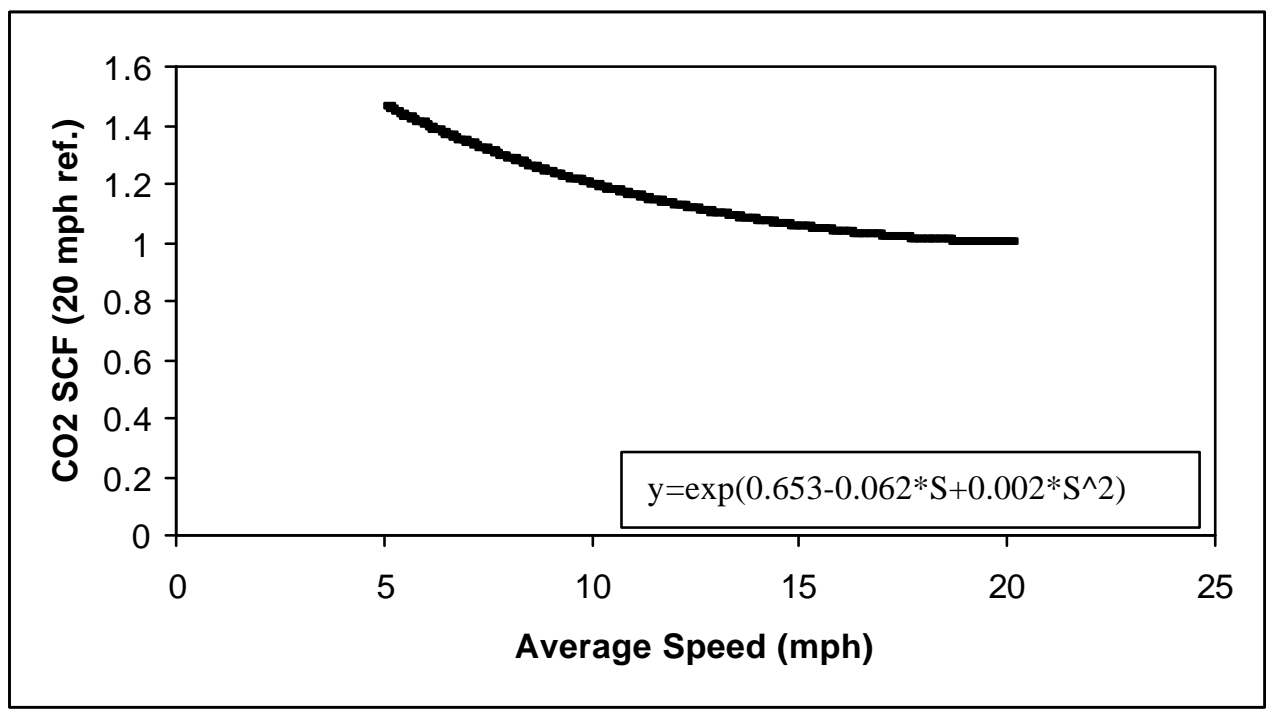

Figure 8.34 $\mathrm{CO}_{2} \mathrm{SCF}$ Versus Average Speed Based on the Model Presented in Figure 8.31 for the Considered Class 8 Transit Bus Described in Table 4.2. 


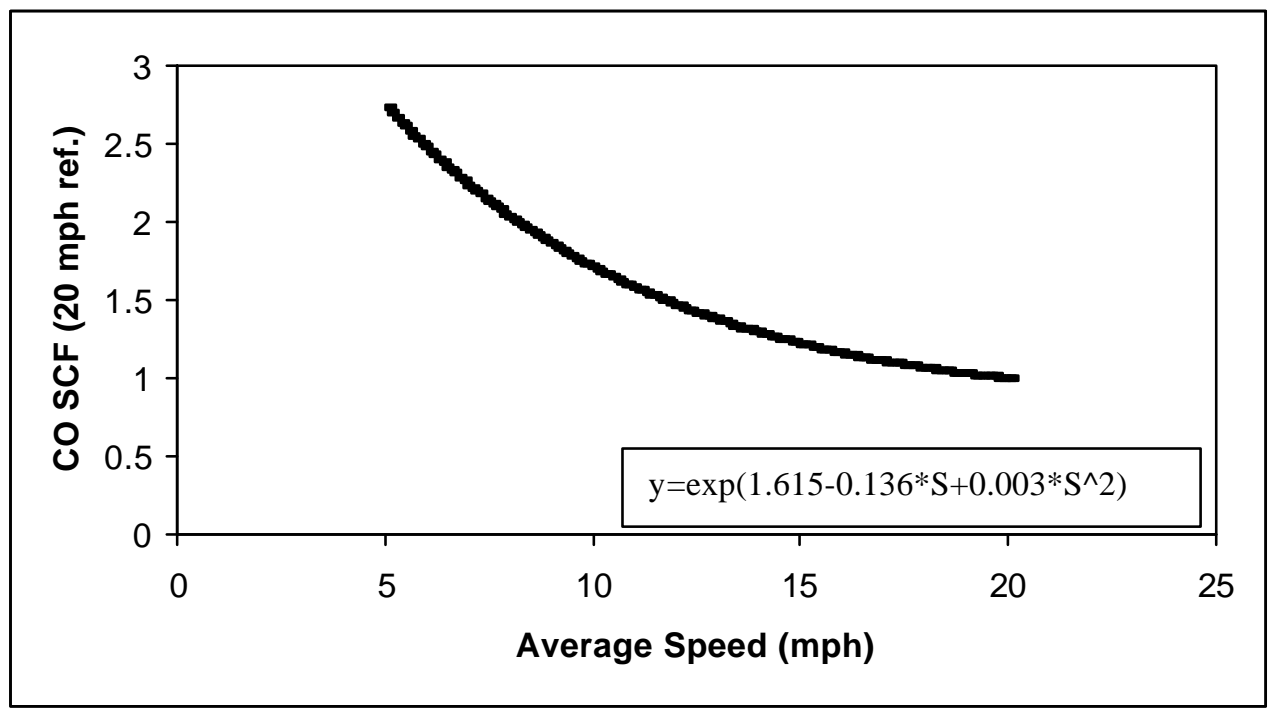

Figure 8.35 CO SCF Versus Average Speed Based on the Model Presented in Figure 8.32 for the Considered Class 8 Transit Bus Described in Table 4.2.

A comparison between heavy-duty vehicles EPA $\mathrm{NO}_{\mathrm{x}}$ and CO SCF and the $\mathrm{NO}_{\mathrm{x}}$ and CO SCF previously developed in the thesis for the considered class 8 heavy-duty tractor truck described in Table 4.2, is presented in Figures 8.36 and 8.37. In these Figures EPA, Cyc, Mcyc and Zones represent the $\mathrm{NO}_{\mathrm{x}}$ or the $\mathrm{CO}$ SCF equation use by the EPA, respectively developed based on whole cycles, microcycles or zones of a microcycle. As it can be seen all SCF are equal to 1 at the reference speed of $20 \mathrm{mph}$. 


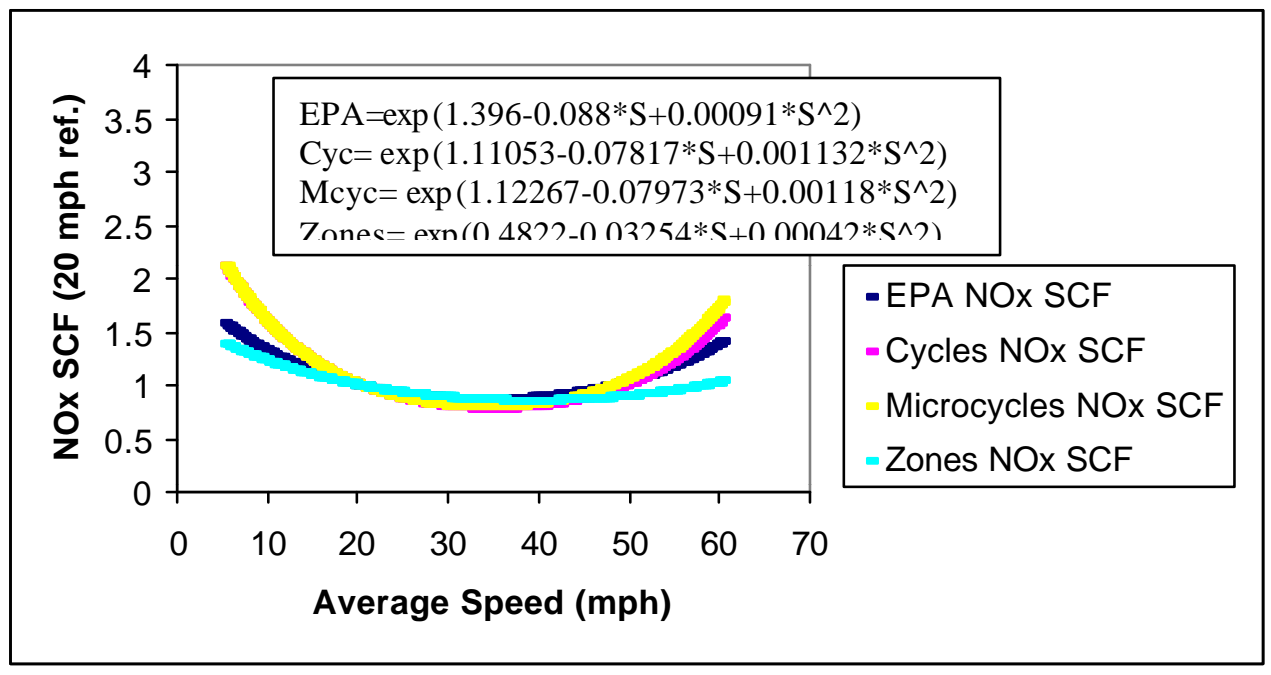

Figure 8.36 Comparison Between EPA NO $\mathrm{SCF}_{\mathrm{x}}$ and the Three NO $\mathrm{NCF}_{\mathrm{x}}$ Developed in This Paper for the Considered Class 8 Heavy-Duty Tractor Truck Described in Table 4.2.

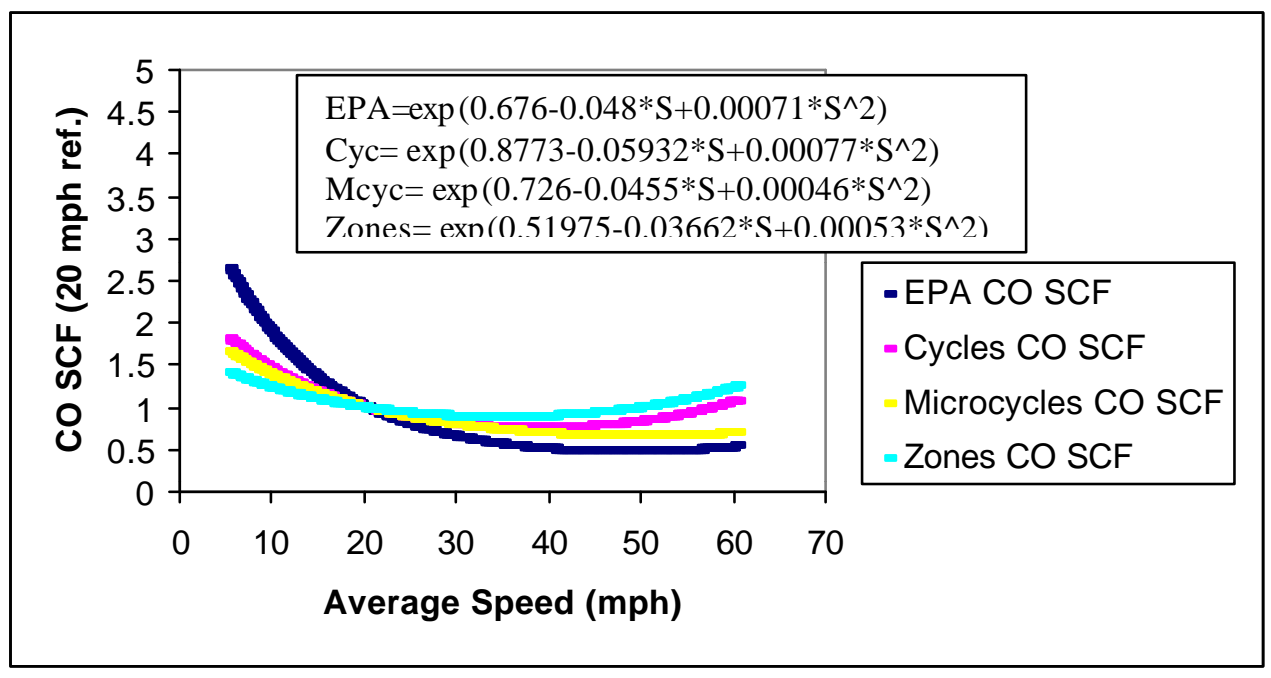

Figure 8.37 Comparison Between EPA CO SCF and the Three CO SCF Developed in This Paper for the Considered Class 8 Heavy-Duty Tractor Truck Described in Table 4.2. 


\section{Conclusions and Recommendations}

The analysis from this thesis was conducted in three major directions. First, there was studied the influence of road grade on diesel vehicles. Then was performed an analysis of the influence of a "stop and go" sequence on the three considered vehicles. In the last part of the thesis several speed correction factors for each of the considered vehicles were developed and then compared with the in use EPA SCF.

The first important conclusion that arose from the analysis of the influence of road grade on emissions is that road grade has a modest but significant effect on $\mathrm{NO}_{\mathrm{x}}$ and $\mathrm{CO}_{2}$ emissions, especially when the road is very steep (road grade greater than $2 \%$ ), but a substantial effect on $\mathrm{CO}$ emissions. Like $\mathrm{CO}$, PM emissions are very much influenced by the road grade especially if the road is very steep because these emissions increase substantially near full engine load. If an accurate emissions prediction is desired for inventory purposes the road grade must be included in the model, especially for prediction of $\mathrm{CO}$ and $\mathrm{PM}$ emissions.

Another important conclusion show that in the "stop and go" analysis $\mathrm{NO}_{\mathrm{x}}$ and $\mathrm{CO}_{2}$ emissions are affected only by the extra time needed to cover a certain distance. This happened because the quantity of $\mathrm{NO}_{\mathrm{x}}$ and $\mathrm{CO}_{2}$ emissions that are "saved" while braking from cruise speed to $0 \mathrm{mph}$, are "lost" almost in the same amount while reaccelerating back to the cruise speed. This is a consequence of the linearity of $\mathrm{NO}_{\mathrm{x}}$ and $\mathrm{CO}_{2}$ emissions with power. When it comes to $\mathrm{CO}$ and PM emissions, it can be observed that these are also influenced by the reacceleration because of the large extra amount of emissions put out while reaccelerating back to the cruise speed. This happened because of the nonlinearity of $\mathrm{CO}$ and PM emissions. 
The speed correction factors developed in the last part of the thesis show that driving speed will influence $\mathrm{NO}_{\mathrm{x}}, \mathrm{CO}_{2}, \mathrm{CO}$ and $\mathrm{PM}$ emissions and should be considered in conjunction with road grade and "stop and go" influence for accurate inventories and predictions. All the developed $\mathrm{NO}_{\mathrm{x}}, \mathrm{CO}_{2}, \mathrm{CO}$ and PM SCF are high at low average speeds and equal one at $20 \mathrm{mph}$ (the chosen reference average speed). For average speeds greater then $30 \mathrm{mph}$, for example when a vehicle is driving on a highway, the SCF start to increase slowly for $\mathrm{NO}_{\mathrm{x}}$ and $\mathrm{CO}_{2}$ and more rapidly for $\mathrm{CO}$ and $\mathrm{PM}$ emissions. These are a result of the relations between $\mathrm{NO}_{\mathrm{x}}, \mathrm{CO}_{2}, \mathrm{CO}$ and $\mathrm{PM}$ emissions and vehicle power.

\section{RECOMMENDATIONS}

Measurements of the influence of an existing road with a grade other than zero on $\mathrm{NO}_{\mathrm{x}}, \mathrm{CO}_{2}, \mathrm{CO}$ and PM emissions can be useful in correlation with the developed model of a constant grade and a sinusoidal road.

Since PM is measured gravimetrically, as a composite for a whole test, the instantaneous PM is not known and a method of measuring continuous PM is evidently more accurate than different methods for apportioning PM.

There is a need for additional correction factors accounting for vehicle class, vehicle vocation, effect of weather and altitude, and power to weight ratio in addition to the existing ones to refine existing heavy-duty emissions inventory and prediction. 


\section{References}

1. U.S. Environmental Protection Agency, National Air Pollutant Emission Trends Update, 1970-1997; EPA 454/E-98-007; U.S. Government Printing Office: Washington DC, 1998.

2. Kern, J. M. Inventory and Prediction of Heavy-Duty Diesel Vehicle Emissions, M. S. Thesis, West Virginia University, 2000.

3. Ramamurthy, R. Heavy Duty Emissions Inventory and Prediction, M. S. Thesis, West Virginia University, 1999.

4. Heywood, J. B.; Internal Combustion Engines Fundamentals; McGraw-Hill: New York, New York, 1988.

5. Yanowitz, J.; McCormick, R. L.; Graboski, M. S. In-Use Emissions from Heavy-Duty Diesel Vehicles; Environmental Science \& Technology, Vol. 34, No. 5, pp. 729-740, 2000.

6. Lyons, D. W.; Bata, R. M.; Wang, W. G.; Clark, N. N.; Palmer, G. N.; Howell, A. D.; Loth, J. L.; Long, T. Jr.; Design and Construction of a Transportable Heavy-Duty Vehicle Emissions Testing Laboratory; 25 ${ }^{\text {th }}$ Int. Symp. on Automotive Technology and Automation, Florence, Italy, 1992. Also, Annual Automotive Technology Development Contractors' Coordination Meeting, Dearbon, MI, October, 1991, SAE Special Pub., P-256, pp. 593-598.

7. Clark, N. N.; McKain, D. L.; Messer, J. T.; Lyons, D. W.; Chassis Test Cycles for Assessing Emissions from Heavy-Duty Trucks; SAE Technical Paper 941946, 1994. 
8. Chasey, T. D.; Design of a Data Acquisition and Control System Hardware and Software for Transportable Emissions Testing Laboratory; M. S. Thesis, West Virginia University, 1992.

9. Merrion, D. F.; Diesel Engine Design for the 1990s; SAE SP-1011 or SAE 940130, 1994.

10. Clark, N. N.; Lyons, D. W.; Bata, R. M.; Gautam, M.; Wang, W. G.; Norton, P.; Chandler, C.; Natural Gas and Diesel Transit Bus Emissions: Review and Recent Data; SAE 973203, 1997.

11. EPA Document; Heavy-Duty Vehicle Cycle Development; EPA-PB-288-805, July, 1978.

12. Diezman, H. E.; Warner-Selph, M. A.; Comparison of Emissions from Heavy-Duty Engines and Vehicles During Transient Operation, ASME Paper 85-DGP-10, Energy Sources and Technology Conference, Dallas, TX, 1985.

13. Clark, N. N.; Nine, R. D.; Daley, J. J.; Atkinson, C. M.; Development of a HeavyDuty Chassis Dynamometer Driving Route, Phase I Report; 1998.

14. Messer, J. T.; Clark, N. N.; Measurement Delays and Modal Analysis for a Transportable Heavy-Duty Vehicle Emissions Testing Laboratory; SAE Congress, Detroit, 1995, SAE Paper 950218.

15. Kern, J. M.; Clark, N. N.; Nine, R. D. Factoring Terrain Effects into Vehicle Emissions Modeling and Inventory, 10th CRC On-Road Vehicle Emissions Workshop, San Diego, CA, March, 2000.

16. Atkinson, C. M.; Clark, N. N.; Traver, M.; Thompson, G. J.; Vertin, K.; Myburgh, I.; Schaberg, P.; Schnell, M. NO $O_{x}$ and PM Emissions Reduction as a Function of Cetane 
Rating and Sulfur Content in Fischer-Tropsch and Conventional Diesel Fuels, 10th CRC On-Road Vehicle Emissions Workshop, San Diego, CA, March 2000.

17. Clark, N. N.; Jarrett, R. P.; Atkinson, C. M. Field Measurements of Particulate Matter Emissions, Carbon Monoxide and Exhaust Opacity from Heavy-Duty Diesel Vehicles, Journal of the Air \& Waste Management Association, Vol. 2, pp. 143-159, September 1999. 